Effect of soil and water conservation measures on hydrological processes and sediment yield in the highlands of North-Western Ethiopia 


\section{Thesis committee}

\section{Promotor}

Prof. Dr C.J. Ritsema

Professor of Soil Physics and Land Management Group

Wageningen University and Research

\section{Co-promotors}

Dr ir. JEM Baartman

Assistant professor, Soil Physics and Land Management Group

Wageningen University and Research

Dr ir. L Fleskens

Associate professor, Soil Physics and Land Management Group

Wageningen University and Research

\section{Other members}

Prof. Dr J. Wallinga, Wageningen University \& Research

Dr K. Woldearegay, Mekelle University, Ethiopia

Dr C.M. van Beek, Soil Cares Foundation, Netherlands

Dr M. VanMaercke, University of Liège, Belgium 


\title{
Effect of soil and water conservation measures on hydrological processes and sediment yield in the highlands of North-Western Ethiopia
}

\author{
Walle Jemberu Lakew
}

Thesis

Submitted in the fulfilment of the requirements for the degree of doctor At Wageningen University

By the authority of the Rector Magnificus

Prof. Dr A.P.J. Mol, In the presence of the

Thesis committee appointed by the Academic Board to be defended in public

On Tuesday 18 September 2018

at 11 a.m. in the Aula 
Walle Jemberu Lakew

Effect of soil and water conservation measures on hydrological processes and sediment yield in the highlands of North-Western Ethiopia, 159 pages.

PhD thesis, Wageningen University, Wageningen, NL (year)

With references, with summaries in English

ISBN:978-94-6343-493-5

DOI:https://doi.org/10.18174/457530 


\section{Table of contents}

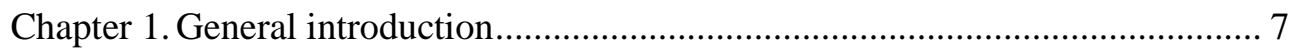

Chapter 2. Participatory assessment of soil erosion severity and performance of mitigation measures using stakeholder workshops in Koga catchment, Ethiopia.

Chapter 3. Assessing the variation in bund structure dimensions and its impact on soil physical properties and hydrology in Koga catchment, Highlands of Ethiopia.

Chapter 4. Magnitudes and dynamics of runoff and sediment yield: an indepth analysis of hydrological responses of three sub-watersheds in the Ethiopian highlands.

Chapter 5. Modelling the effect of soil and water conservation measures on soil erosion and sediment yield in the highlands of North-Western Ethiopia 90

Chapter 6 Synthesis

Literature cited.

English summary..... 151

Acknowledgements 155

About the author 



\section{General introduction}

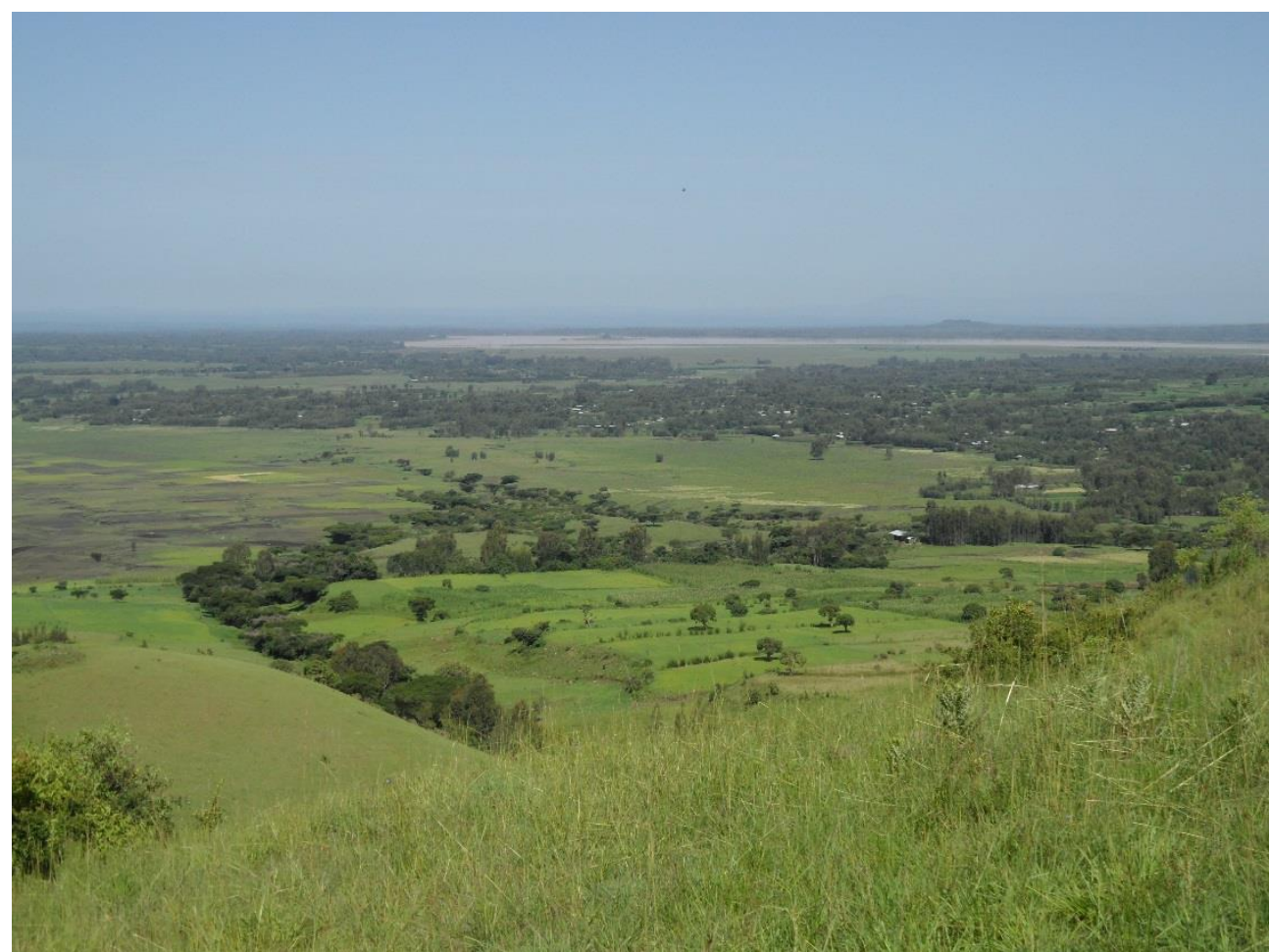




\subsection{Land degradation in the highlands of Ethiopia}

The Ethiopian highlands have a long history of sedentary agriculture due to fertile soil, rich biodiversity and a favourable climate (Hurni, 1988; Taddese, 2001; Mitiku et al., 2006; Adimassu et al., 2012). As a result of this, the highlands of Ethiopia, which account for $45 \%$ of the country's land area, support $85 \%$ of Ethiopia's human population and $75 \%$ of its livestock population (Grepperud, 1996; Berry, 2003; Nyssen et al., 2007; Adimassu et al., 2012). Increasing population pressure has lead people to use marginal lands for cultivation and grazing and severely overexploit the natural resource base of the region (Hurni, 1993; Shiferaw and Holden, 1998; Berry, 2003). The exploitation of these natural resources is inextricably linked to securing food and livelihoods (Dubale, 2001; Adimassu et al., 2012). This has resulted in accelerated soil erosion, deforestation, water resource depletion and environmental degradation (Desta, 2000; Berry, 2003; Mitiku et al., 2006; Nyssen et al., 2008; Change, 2014). The severity of land degradation depends on the intensity of the degrading factors and the land's resilience to degrading conditions (Bewket, 2007). These degradation factors are mostly interwoven and the effect of one could initiate another degradation process.

The Ethiopian sub-humid/humid highlands are one of the most degraded regions in the world (Shiferaw and Holden, 1998; Dubale, 2001). Land, water, forest and biodiversity are being degraded and destroyed at an alarming rate and land degradation is becoming a major constraint to future growth and development in the highlands of Ethiopia (Hurni, 1993; Hurni, 1988; Holden and Shiferaw, 2004; Haileslassie et al., 2005; Mitiku et al., 2006; Amsalu and De Graaff, 2007). In North-Western Ethiopia, almost all cultivated lands are prone to accelerated soil erosion (Hurni, 1988; Scherr, 1999; Symeonakis and Drake, 2004) and annual soil loss in individual cultivated fields has been reported to reach up to $300 \mathrm{tha}$ ${ }^{1} \mathrm{y}^{-1}$ (Hurni, 1993; Mitiku et al., 2006).

Agriculture using inappropriate techniques is associated with accelerated erosion, increased surface runoff and evaporation, reduced infiltration, drying up of rivers, increased flooding frequency and rapid silting up of reservoirs (Shiferaw and Holden, 1998; Bewket, 2002; Nyssen et al., 2008; Tilahun et al., 2013; Tamene et al., 2017). Accelerated soil erosion by water is the primary cause of land degradation in the region (Herweg and Ludi, 1999; Berry, 2003; Hurni et al., 2010) and this is the consequence of a changed relationship between environmental biophysical factors which occur as a result of human interventions (Hurni, 1988; Dubale, 2001; Holden and Shiferaw, 2004; Gebrernichael et al., 2005; Jemberu et al., 2017). Consequently, a diverse set of changes in physical, chemical or biological characteristics of the soil resulted in reduced fertility and severe erosion (Herweg and Ludi, 1999; Grum et al., 2017; Tamene et al., 2017; Jemberu et al., 2018). These changes include 
for example loss of biological diversity and vegetation cover, nutrient imbalance, decline in soil organic matter, and decrease in infiltration and water retention capacity (Awulachew et al., 2010b; Betrie et al., 2011; Grum et al., 2017). The direct (proximate) causes of land degradation are: farming on steep slopes, limited fallow and vegetation cover, deforestation, overgrazing, limited or poorly constructed soil and water conservation (SWC) measures, limited application of organic matter, and burning of dung and crop residues (Hurni, 1988; Grepperud, 1996; Desta, 2000; Taddese, 2001; Holden and Shiferaw, 2004). The indirect or underlying causes include: population pressure, poverty, landlessness and smallholding, limited human, physical and financial capital, limited access to markets, infrastructure and credit, land tenure insecurity, lack of awareness of technological options and poor policy enforcement, which underpin the direct causes of land degradation (Hurni, 1993; Taddese, 2001; Holden and Shiferaw, 2004; Mitiku et al., 2006; Amsalu and De Graaff, 2007). The direct and indirect causes are linked by a chain of cause and effect or causal nexus (Shiferaw and Holden, 1998; Bewket, 2002).

In the Ethiopian highlands water scarcity arises due to uneven seasonal rainfall distribution and the lack of adequate water storage capacity in watersheds on the one hand, and increasing water demand on the other (Herweg and Ludi, 1999; Hurni, 1999; Molle et al., 2010). In contrast to water shortage during the dry season, the rainy season is characterised by rainfall excess and corresponding high runoff events (Zeleke and Hurni, 2001; Nyssen et al., 2004; Vancampenhout et al., 2006; Tilahun et al., 2013). The negative effect of marked seasonality on water availability is reinforced by the fact that water storage capacity of catchment areas declines owing to a self-enforcing process in which continued erosion causes degradation of the absorptive function of the topsoil, which reduces water infiltration rate and thus enhances the generation of surface runoff which causes even more soil erosion (Nyssen et al., 2008; Tilahun et al., 2013; Tamene et al., 2017; Jemberu et al., 2018).

The land degradation problem has serious impacts such as environmental hazards, persistent food insecurity, economic losses, poverty and migration ( Hurni, 1993; Shiferaw and Holden, 1998; Scherr, 1999; Zeleke and Hurni, 2001; Bewket, 2002; Hurni et al., 2010). Land degradation results in significant costs, particularly in developing country like Ethiopia (Stoorvogel and Smaling, 1990; Hurni, 1999; Shiferaw and Holden, 1999; Taddese, 2001; Bewket, 2002; Berry, 2003). Land degradation not only reduces farm productivity affecting livelihood and regional economies, it also reduces the biodiversity and increases reservoir sedimentation affecting the storage and quality of water resources (Stoorvogel and Smaling, 1990; Shiferaw and Holden, 1999; Taddese, 2001). Moreover, land degradation decreases the potential of land and water resources to provide sustainable ecosystem services (Adimassu et al., 2012; Baptista et al., 2015b). 


\subsection{On-site and off-site impacts of soil erosion}

Soil erosion, sometimes called the "creeping death" of the soil, is a worldwide problem with serious negative impacts (Segarra et al., 1991; Mati et al., 2000; Hurni et al., 2010). It affects the land from which the soil is washed, damages the area downstream by floods and sediments and is detrimental to the economy (Mitiku et al., 2006). Soil erosion entails the processes of detachment, transportation and deposition, resulting in relocation of the top soil which is rich in organic matter, nutrients, soil microorganisms (Grepperud, 1996; Shiferaw and Holden, 1998; Hengsdijk et al., 2005) . As the top soil contains organic matter, humus and nutrients, its removal by erosion means a loss of soil fertility or productivity leading to a deterioration in the quality of cropping and grazing land (Grepperud, 1996; Mekuria et al., 2007; Teklewold et al., 2013). In extreme conditions yield may become so poor that the land has to be taken out of cultivation (Shiferaw and Holden, 1999; Taddese, 2001; Tilahun et al., 2013). According to Eswaran et al. (2001) yield reduction in Africa due to past soil erosion may range from 2 to $40 \%$, with a mean loss of $8.2 \%$ for the continent. Erosion also leads to decreasing soil depth, and therefore decreasing rooting depth and water storage capacity (Nyssen et al., 2010; Meshesha et al., 2012).

The eroded soil may be transported from a few centimetres to hundreds of kilometres. Usually the coarser sand fraction of the eroded soil is deposited in depressions fields, while the finer particles are carried further away to the lower end of reservoirs, dams, waterways and roads (Shiferaw and Holden, 1998; WoldeGabriel et al., 2000; Holden and Shiferaw, 2004; Easton et al., 2010; Nyssen et al., 2010). Notable off-site effects of soil erosion include flooding, sedimentation, water salinization and pollution (Tefera and Sterk, 2010; Uhlenbrook et al., 2012). Nutrient pollutants, heavy metals and chemicals are transported with soil particles causing water eutrophication and disturbance of delicate aquatic ecosystems (Stoorvogel and Smaling, 1990; Nyssen et al., 2010; Uhlenbrook et al., 2012; Taye et al., 2013). The problem of soil erosion, flooding and sedimentation is severe in the Ethiopian highlands because of its adverse impact on agronomic productivity, the environment, and its effect on food security and the quality of life (Zeleke and Hurni, 2001; Bayabil et al., 2010).

\subsection{The effects of SWC measures on hydrological processes and sediment yield}

Previous studies demonstrate that physical, agronomic and vegetative SWC measures directly affect the overall on- and off-site impacts of runoff and soil erosion (Shiferaw and Holden, 1999; Nyssen et al., 2007). Hence, in an effort to reduce runoff, soil loss and 
sediment yield, SWC measures could have a vital role for sustainable land management (SLM) in the Ethiopian highlands (Vancampenhout et al., 2006; Nyssen et al., 2007; Tilahun et al., 2013). The government of Ethiopia launched and implemented a massive soil and water management (SWM) program over the past three decades (Shiferaw and Holden, 1998; Herweg and Ludi, 1999; Mitiku et al., 2006) to reduce the damages caused by erosion, flooding and sedimentation. The interventions were focused on physical SWC measures with the goal to reduce accelerated erosion and downstream sedimentation (Desta, 2000; Zeleke and Hurni, 2001; Jemberu et al., 2017). The major physical SWC measures include bund structures, check dams, hillside terraces and diversion channels (Herweg and Ludi, 1999; Adimassu et al., 2014). The empirical analyses in the following chapters of the thesis provide tangible evidence of the positive impacts of SWC on runoff, soil erosion and sediment yield.

Damage to the soil caused by splash erosion can be controlled by providing sufficient surface cover, while transportation of soil by surface runoff can be reduced by regulating its velocity using physical and vegetative measures (Nyssen et al., 2008). Hence, the fundamental principle of combating or reducing soil erosion by water is to reduce the amount of runoff as much as possible (Mitiku et al., 2006; Nyssen et al., 2010). Physical SWC measures such as bund structures, trenches, micro-basins, and hillside terraces modify the terrain through changing the length and degree of the slope, which reduces runoff velocity, enhances water infiltration and traps sediment at the downstream section of the structures (Gebrernichael et al., 2005; Mitiku et al., 2006; Vancampenhout et al., 2006; Nyssen et al., 2007). Sediment accumulated behind bunds provides suitable growing conditions for crops through conservation of soil moisture and nutrients (Gebrernichael et al., 2005; Mitiku et al., 2006; Vancampenhout et al., 2006; Dagnew et al., 2015). Agronomic and biological conservation measures play a vital role to reduce soil erosion, conserve soil moisture, restore vegetation, and maintain biodiversity (Haileslassie et al., 2005; Vancampenhout et al., 2006; Mekuria et al., 2007). Vegetation cover on the soil reduces erosion by intercepting rainfall, decreasing the velocity and erosional power of runoff, increasing granulation and porosity, and reducing soil drying. Studies indicate that physical, biological and agronomic SWC measures can help not only to reduce runoff and soil erosion but also to improve the physical and biochemical fertility status of the soil (Medeiros et al., 2010; Mekuria et al., 2007; Meshesha et al., 2012; Jemberu et al., 2018). When agronomic measures or changing tillage practices and vegetative measures are not enough to control erosion on the field, a combination of approaches or various conservation measures might be necessary. For example, contour ploughing, strip-cropping or bund structures may be considered jointly, and in more serious cases where concentrated runoff is expected to occur with damaging intensity, it is necessary to include further structural controls as part of an overall solution 
such as water ways, cut-off drains, check dams and water and sediment control basins (Tefera and Sterk, 2010).

Few studies have reported about the impacts of SWC measures on hydrological processes and sediment yield in the Ethiopian highlands (Herweg and Ludi, 1999; Shiferaw and Holden, 1998; Mitiku et al., 2006). Besides the inadequacy of the studies about effects of SWC measures on runoff, soil loss and sedimentation, in some cases the conclusions are inconsistent (Bewket, 2007; Adimassu et al., 2014). According to Bewket (2007) and RuizJaen and Mitchell Aide (2005) SWC measures were insufficiently effective in reducing runoff, soil erosion and restoring soil fertility in studies conducted in the Ethiopian highlands, while studies in similar areas elsewhere in the Ethiopian highlands reported vital impacts of SWC measures on controlling runoff and soil erosion, enhancing soil fertility and reducing sediment yield (Herweg and Ludi, 1999; Hurni, 1999; Gebrernichael et al., 2005; Hengsdijk et al., 2005; Mitiku et al., 2006; Nyssen et al., 2010).

The majority of studies that aimed at understanding the effects of SWC measures on soil erosion, infiltration, runoff and sedimentation processes in the Ethiopian highlands focus on small-scale, on-field effects of SWC measures (Hengsdijk et al., 2005; Adimassu et al., 2014; Lemann et al., 2016). Some modelling studies were carried out to understand the effects of SWC practices on hydrological processes and sediment yield; they confirm the potential of SWC measures to enhance infiltration and water productivity by simultaneously reducing surface runoff and soil erosion (Tilahun et al., 2013; Tamene et al., 2017). Nevertheless, a holistic approach and scenario based analysis is essential in the Ethiopian highlands where most of the annual rain is lost as runoff and the upstream interventions directly affect water availability and sedimentation downstream (Steenhuis et al., 1995; Ritsema et al., 1996). Such integrated approach is particularly important in regions where more water is used than there is available during some portions of the year (Molle et al., 2010; Krois et al., 2013). Decisions on the implementation of SWC measures have been based on very few studies (Tefera and Sterk, 2010; Tamene et al., 2017). In addition, most studies are focused on assessing the severity of soil erosion in physical terms and do not address the impacts of SWC measures on runoff, infiltration, and sediment delivery. Moreover, the implementation of SWC measures demands huge resources (financial, labour, material and equipment), and adoption and recommendation of SWC interventions should be justified by empirically proven evidence (Asefa et al., 2003; Bewket and Stroosnijder, 2003; Amsalu and De Graaff, 2007). In order to fill this information gap and support the country's effort in combating land degradation, a study that assesses the effectiveness of SWC measures on hydrological processes and sediment yield is of paramount importance. 


\subsection{The performances of SWC measures and farmers' perceptions in the Ethiopian highlands}

Since long, farmers are aware of the negative consequences of soil erosion in the Ethiopian highlands on agricultural production. As a result, SWC measures such as stone bunds, hillside terraces, and different types of crop and soil management activities exist as an indigenous knowledge for centuries (Hurni, 1985; Bewket, 2002; Nyssen et al., 2007; Awulachew, 2010). However, farmers view some of the physical SWC measures as showing limitations as they were not getting immediate returns (Bewket and Stroosnijder, 2003; Amsalu et al. 2007). Some of the limitations of physical SWC measures are: the structures take land out of production, harbour pests and rodents, and their construction is labour intensive (Herweg, 1998; Amsalu and de Graaff, 2007; Jemberu et al., 2017). However those limitations can be reduced by proper design and implementation specific to the needs of the local conditions (Herweg and Ludi, 1999; Mimiku et al., 2006; Jemberu et al., 2017).

SWC measures constitute an important component of farming activity in the Ethiopian highlands and farmers apply various traditional and introduced SWC measures (Hurni, 1985; Adimassu et al., 2014; Jemberu et al., 2018). Biological SWC such as hedge rows, grass strips, reforestation, bund stabilization with vegetation, and homestead plantations help to enrich soil organic matter content and restore vegetation cover and biodiversity (Asefa et al., 2003; Boix-Fayos et al., 2008; Amare et al, 2014). Restoration of vegetation cover also helps to control the detachability of soil by raindrop impact and transportability by surface runoff (Haileslassie et al., 2005). Besides controlling soil erosion and maintaining soil fertility, SWC measures play a considerable role in improving the water supply through a better recharge. The vegetation cover enhances the infiltration capacity and reduces loss of water through surface runoff (Haileslassie et al., 2005; Jemberu et al., 2017). Considerably increased discharge, and reduction of flood risk and sedimentation in downstream areas are witnessed by the local people in some treated catchments areas of North-Western highlands. Thus, the on-site and off-site impacts of SWC measures can lead to efficient use of soil and water resources and ultimately to sustainable land management (SLM) (Hengsdijk, 2005; Mekuria, 2007; Awulachew, 2010; Betrie, 2011; Baptista, 2016).

A system in which the land users continuously increase land productivity using measures that are ecologically sound, economically viable and culturally acceptable is key for sustainable development (Dubale, 2001; Mimiko et al., 2006; Adimassu et al., 2012; Baptista et al., 2015b; Van Beek et al., 2017). Such SLM involves the management and conservation of land resources such as soil, water and vegetation in such a manner as to ensure the attainment and continued satisfaction of human needs for present and future generations (FAO, 1991; Okigbo, 1991; Swift et al, 1991; Greenland, 1994; Hurni, 1996). SLM is the 
foundation of sustainable agriculture and development and poverty reduction (Herweg, 1998; Hurni and Meyer, 2002). Thus, practicing SLM for enables land users to generate income without destroying the quality of land as a basis for production (Herweg and Ludi, 1999; Mimiko et al., 2006). According to Herweg (1998) and Hurni and Meyer (2002), there are certain factors which affect SLM in the Ethiopian highlands such as climate, soils, land use, topography, economic and socio-cultural settings and government policies. The limitation of these factors in SLM can be reduced by genuine participation of local community in planning and implementation of SLM activities (Rose et al., 2007; Baptista et al., 2015b; Jemberu et al., 2018).

Although it has been reported that bunds increase the physical fertility status of the soil by controlling soil erosion (Gebrermichael et al., 2005; Geissen et al, 2006; Nyssen et al., 2007; Tadele et al., 2014), the performances of these measures on controlling the losses of soil and water are generally site-specific and highly variable (Anderson et al., 1990; Shiferew and Holden, 2001; Sonneveld and Keyzer, 2003; Roes et al., 2007). Many SWC measures are implemented with design flaws, without proper design and maintenance, and do not match conservation requirements (Roes et al., 2007). As a consequence, widespread failure of SWC measures occurred (Herweg and Ludi, 1999; Gebrernichael et al., 2005; Tefera and Sterk, 2010). Due to this, the desired impacts of SWC measures are limited and the process of soil erosion and land degradation is not reversed as expected (Herweg and Ludi, 1999; Bakker et al., 2008; Steenhuis et al, 2008).

Despite the constraints and problems farmers have, they are willing to adopt SLM practices if they provide higher net returns and lower risk (Herweg and Ludi, 1999; Zeleke and Hurni et al., 2001; Nyssen et al., 2007; Admassu et al., 2012). Thus, cost efficiency, including short and long term benefits, is the key issue for adoption of SLM in the Ethiopian highlands (Herweg and Ludi, 1999; Desta, 2000; Meshesha et al., 2012). Farmers are more willing to adopt SWC measures that provide rapid and sustainable returns in terms of income and food (Bewket and Sterk, 2003; Mimiko et al., 2006; Vancamphout et al., 2006). Thus for SLM, farmers' participation and decision making in implementation of SWC measures is crucial (Betru, 2002; Tesemma et al., 2010; Adimassu et al., 2012; Jemberu et al., 2018).

\subsection{Aim and research questions}

The main objective of this thesis is to investigate the effects of SWC measures on hydrological processes and sediment yield and to select technically feasible SWC strategies for sustainable use of the soil and water resources in the Ethiopian highlands. The research combines local traditional experiences and perceptions, field sampling and measurements, 
and spatially distributed modelling in three sub-watersheds of Koga catchment, located in the North-Western highlands of Ethiopia.

This research addresses the following research questions:

1. What are the local peoples' perceptions about the severity of soil erosion and impacts of mitigation measures in the North-Western highlands of Ethiopia?

2. How do bund structures' dimensions influence soil physical properties and hydrology in North-Western highlands of Ethiopia?

3. How do the three sub-watersheds, varying in slope and degree of SWC coverage, respond in terms of hydrology and sediment yield?

4. What is the effect of alternative SWC scenarios on soil erosion and sediment yield in the Ethiopian highlands?

This thesis presents options to support enhanced decisions towards SLM in the sub-humid Ethiopian highlands through the implementation of efficient SWC measures and approaches that reduce runoff and soil erosion and increase water infiltration, soil fertility and crop productivity.

\subsection{Methodological approach}

\subsubsection{Study area}

The study area is Koga catchment, located in the North-Western Ethiopian highlands, which extends from $37^{\circ} 02^{\prime}-37^{\circ} 17^{\prime} \mathrm{E}$ longitude, and from $11^{\circ} 10^{\prime}-11^{\circ} 25^{\prime} \mathrm{N}$ latitude (Figure 1.1). The region is affected by severe erosion-driven land degradation (Zeleke and Hurni, 2001; Adimassu et al., 2012; Yeshaneh et al., 2013). Koga catchment has a total area of $230 \mathrm{~km}^{2}$ and is one of the major watersheds at the source of the Blue Nile in Amhara Regional State. The Koga irrigation reservoir at the outlet of Koga river, which supplies water to 7000 ha of irrigation land, has been severely affected by sedimentation. The mean annual rainfall ranges between 1460 and $1850 \mathrm{~mm}$ and shows high inter-annual variations. The area is subjected to excess rainfall during the short rainy season and prolonged moisture shortage and soil drying during the dry season. The soil types in Koga have been classified as Leptosols, Nitisols, Vertisols, Cambisols, Alisols, Gleysols and Fluvisols. These soils have clay to clay loam texture with exception of Gleysols that have clay to sandy clay loam texture. Approximately $86 \%$ of Koga catchment is cultivated land, while around $12 \%$ is forest and the remaining part fallow and grazing land.

Soil erosion and on-site and off-site effects of various SWC strategies were investigated at three major sub-watersheds of Koga catchment. The most upstream sub-watershed, Asanat (756 ha), has rugged topography: more than $55 \%$ of the area has slopes of $15 \%-30 \%$ and 
$\sim 11 \%$ of the area has slopes greater than 30\%. In Debreyakob (303 ha) 32\% of the area has slopes of $15 \%-30 \%$ and about $33 \%$ of the area has slopes of less than $10 \%$. Rim subwatershed (1010 ha) is relatively flat with $85 \%$ of the area having slopes of less than $10 \%$. Although the Amhara National Regional State, local projects and NGOs such as the Koga Irrigation and Watershed Development project and Water and Land Resource Centre (WALRIC) have been promoting massive implementation of SWC measures, soil erosion remains severe and at low-lying bottom slopes, sedimentation and flooding are common.

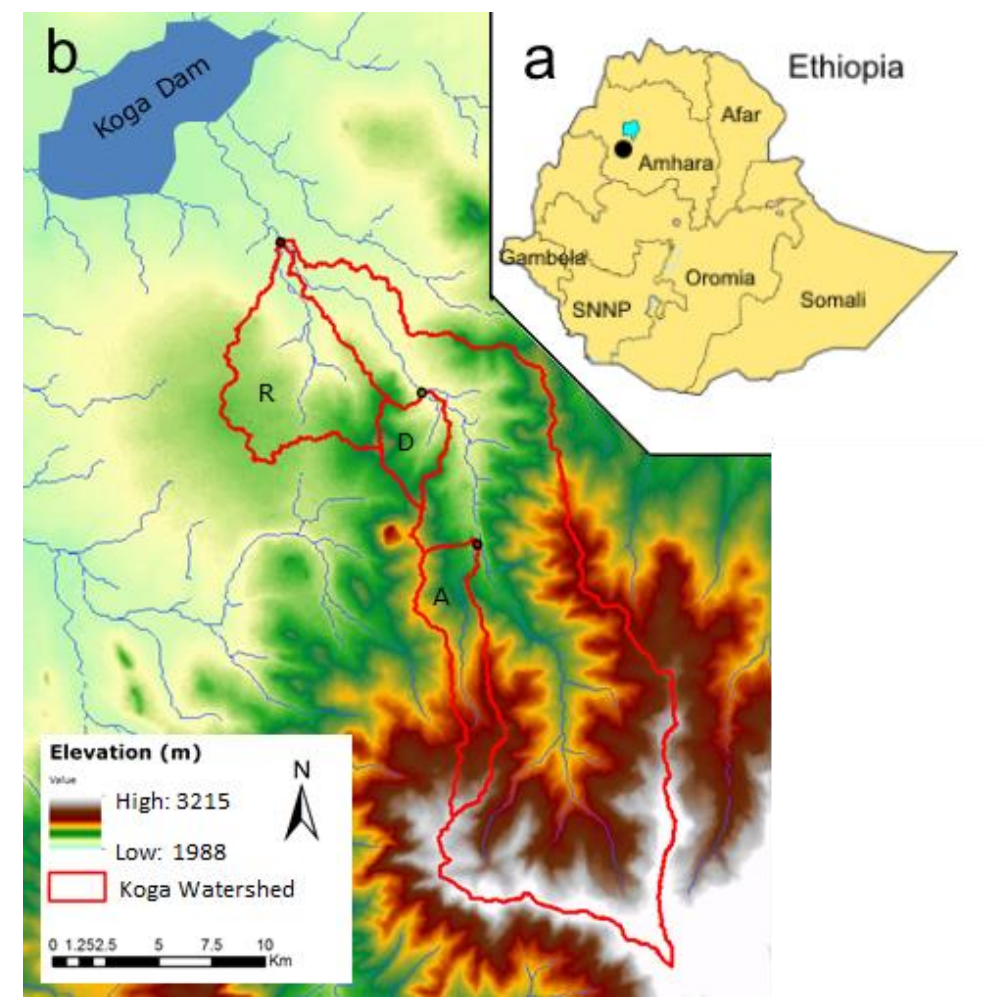

Figure 1.1 Location of Koga catchment in (a) Ethiopia - Amhara Regional State (black dot indicates location of study area) and (b) Elevation of Koga catchment with the three study sub-watersheds Asanat (A), Debreyakob (D) and Rim (R). Dots at the outlet of the catchments indicate the location of the runoff and sediment measurements.

\subsubsection{Methods}

The methods in this study comprised of field investigation, participatory stakeholder workshops, statistical analysis and spatially distributed modelling. This wide range of methods was used to assess hydrological processes and soil erosion, and to evaluate the 
effect of SWC measures on soil properties, runoff, soil-water storage, soil erosion and sedimentary processes. The methodological framework of the research is presented in Figure 1.2.

The severity of soil erosion and performances of mitigation measures were assessed based on a participatory approach organized at the local level as a co-learning process aimed at integrating local and traditional knowledge with scientific knowledge regarding soil erosion and SWC. This approach is inspired by mixed methods (Daba, 2003; Schwilch et al., 2012) and seeks to empower communities, strengthening their capacity for research by actively engaging them in field observation, measurements, evaluation, and continuous group discussions and dialogues (Stringer et al., 2017). Three workshop rounds were organised. The first round workshop was organised to discuss, identify and estimate the causes, types and rates of soil erosion based on local peoples' knowledge and field observation of sheet erosion indicators. The second round workshop was undertaken to measure, with local communities, rill erosion and to assess the quality and stability of SWC measures in the field. Rills were measured using the Assessment of Current Erosion Damage (ACED) methodology (Herweg, 1996). The third round workshop was conducted to evaluate the impacts of SWC measures. The desirable and undesirable impacts of bund structures on three factors: (i) soil erosion and runoff, (ii) soil fertility and (iii) yield were identified from the experience of farmers.

Field observations and measurements of the dimensions of the main type of SWC measure that is implemented in Koga catchment, bund structures, were carried out in the three major sub-watersheds to investigate the influence of dimensions of bunds on stability and quality of implementation. The variation vis-à-vis standard dimensions and need of ties, aprons and outlets, alignment to the watershed (orientation), and current position and stability of bund structures were used to evaluate the design qualities of bunds. Field sampling and monitoring and laboratory analysis were carried out to evaluate the impacts of variations in bund structure dimensions on soil-water retention, texture, bulk density, porosity, erodibility and soil depth.

Analysis of the relationships between rain intensity, runoff and SSC is useful in understanding factors and processes determining sediment responses of the catchment areas for conservation planning (Bekele and Knapp, 2010; Li and Gao, 2015; Miao et al., 2010). To get insight in the hydrological and sedimentological functioning of the three subwatersheds, an in-depth analysis was done using rainfall, discharge and sediment data as measured at the outlet of the three sub watersheds during the 2014-2015 rainy seasons. Multiple regression models were formulated to predict sediment discharge using daily data on: rainfall, 10-minute maximum rain intensity, rain intensity, suspended sediment 
concentration (SSC) and runoff discharge. Hydrographs, flow duration curve (FDC), sedigraphs and statistical analysis were used to study hydrological processes and the responses of treated sub-watersheds to extreme events of rainfall and runoff.

Finally, the spatially distributed WATEM/SEDEM model was used to simulated the impacts of bund structures on soil erosion and sediment yield (Van Rompaey et al., 2001; Verstraeten et al., 2007). After calibration and validation, WATEM/SEDEM was applied to alternative SWC scenarios at sub-watershed level to identify critical sediment source areas or erosion hotspots and to evaluate the impacts of SWC strategies on soil erosion and sediment delivery.

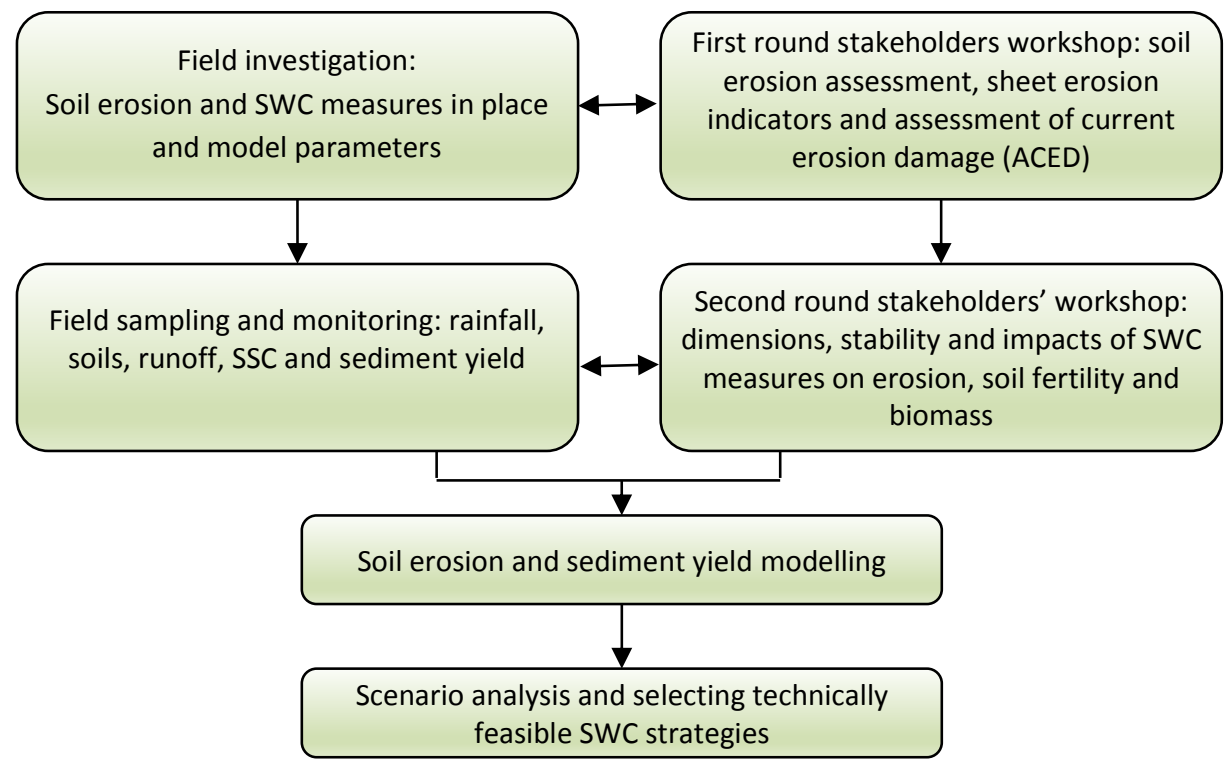

Figure 1.2 Systematic representation of methodological approach.

\subsection{Thesis outline}

The research questions are addressed in the following four chapters (Chapters 2 to 5 ) and then linked by the synthesis in Chapter 6. Figure 1.2 summarises the outline of this thesis, showing the research topics addressed in each chapter. After this general introduction Chapter 2 deals with participatory approaches used to assess soil erosion severity and performances of mitigation measures in the three sub-watersheds. This chapter discusses participatory soil erosion assessment techniques based on monitoring of sheet erosion 
indicators and the ACED method, and quantifying the quality of SWC measures and their effects on runoff, erosion, soil fertility and biomass production.

Chapter 3 addresses the impact of dimensions of bund structures on soil hydrology and soil physical characteristics for different slope classes. This chapter analyses the effect of height and width of bund structures on soil structure, bulk density, erodibility, depth, infiltration, porosity and soil-water retention. To study these effects field sampling and laboratory analysis were conducted.

Chapter 4 focuses on patterns and variations of runoff and sediment yield and the responses of treated sub-watershed areas to extreme events of rainfall and runoff. This chapter studies interrelationships of rainfall characteristics, runoff and SSC in controlling the magnitudes and dynamics of discharge and sediment yield. The contribution of extreme rainfall and runoff events on annual discharge and sediment yield are presented. The effect of rainfall characteristics, runoff, SSC and discharge on sediment yield is studied by stepwise multiple regression analysis taking sediment yield as dependent variable and rainfall characteristics, runoff and SSC as independent or explanatory variables.

Chapter 5 deals with the effects of various SWC strategies on soil erosion and sediment yield at sub-watershed level. For this, the effect of different SWC scenarios including the presentday situation were simulated with the spatially distributed WATEM/SEDEM model for the three sub-watersheds. The effects of various (combinations of) SWC measures such as bund structures, contour cultivation, and strip cropping and vegetative measures (grass strips) were analysed in this chapter.

Finally, Chapter 6 presents a syntheses of the research findings outlining the new contributions they make to the research fields of hydrology, soil erosion and SLM. Furthermore, this chapter gives recommendations for SLM and concludes with directions for future research. 


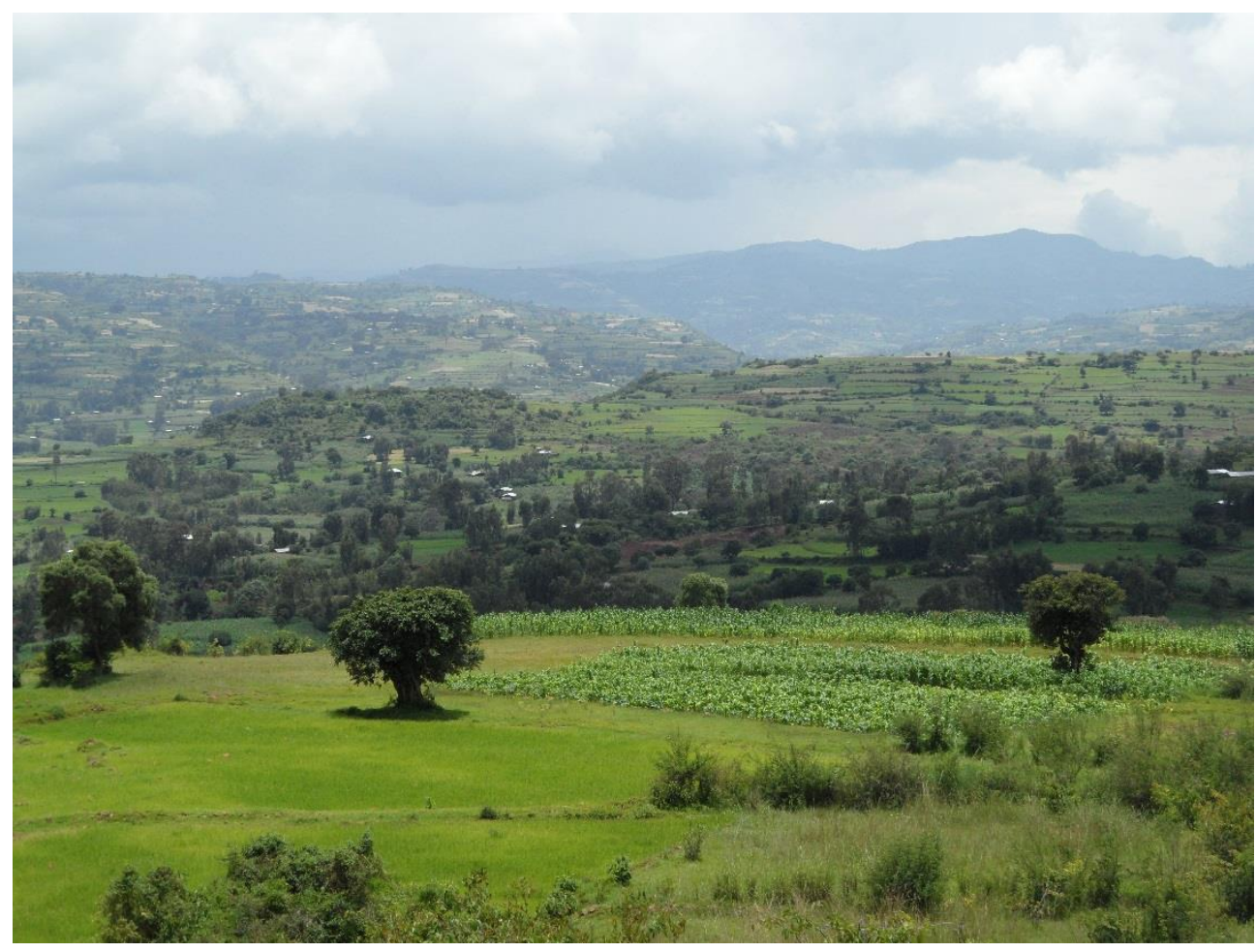




\section{Participatory assessment of soil erosion severity and performance of mitigation measures using stakeholder workshops in Koga catchment, Ethiopia}

Farmers possess a wealth of knowledge regarding soil erosion and soil and water conservation (SWC), and there is a great demand to access it. However, there has been little effort to systematically document farmers' experiences and perceptions of SWC measures. Sustainable Land Management (SLM) has largely evolved through local traditional practices rather than adoption based on scientific evidence. This research aimed to assess soil erosion and performance of different SWC measures from the farmers' perspective by documenting their perceptions and experiences in Koga catchment, Ethiopia. To this aim, workshops were organised in three sub-catchments differing in slopes and SWC measures. Workshops included group discussions and field monitoring of erosion indicators and systematically describing the status of soil erosion, soil fertility and yield to assess the performance of SWC measures. Results show that farmers are aware of the harmful effects of ongoing soil erosion and of the impacts of mitigation measures on their farms. Sheet erosion was found to be the most widespread form of erosion while rill damage was critical on plots cultivated to cereals on steep slopes. The average rill erosion rates were 24.2 and $47.3 \mathrm{t} / \mathrm{ha} / \mathrm{y}$ in treated and untreated farmlands, respectively. SWC reduced rill erosion on average by more than 48\%. However, the impacts of SWC measures varied significantly between sub-watersheds, and farmers believed that SWC measures did not prevent erosion completely. Comparatively, graded stone-faced soil bunds revealed maximum desired impacts and were most appreciated by farmers, whereas level bunds caused water logging. Most traditional ditches were highly graded and begun incising and affected production of cereals. Despite the semi-quantitative nature of the methodology, using farmers' perceptions and experiences to document land degradation and the impacts of SWC measures is crucial as they are the daily users of the land and therefore directly affecting the success or failure of SWC measures.

This chapter is based on:

Jemberu, W., Baartman, J., Fleskens, L., Ritsema, C.J. 2017. Participatory assessment of soil erosion severity and performance of mitigation measures using stakeholder workshops in Koga catchment, Ethiopia. Journal of Environmental Management. 207: 230-242. 


\subsection{Introduction}

Soil erosion is the most pressing environmental problem in the Ethiopian highlands where the topography is rugged, steep lands are cultivated and the erosivity of rainfall is high (Hurni, 1993; Herweg \& Ludi, 1999; Holden \& Shiferaw, 2004; Ludi, 2004). Both sheet and rill erosion exist. Sheet erosion is the spatially uniform removal of soil by the action of surface runoff and it is the initial stage of erosion by rainfall and running water (Danano, 2002; Nyssen et al., 2007; Zegeye et al., 2010). Rill erosion is the formation of shallow channels that can be smoothened out by normal cultivation (Vancamphout et al., 2006; Yitaferu et al., 2007; Tadele et al., 2014). Rill erosion occurs when the runoff flow increases in depth and starts to concentrate. Both forms of soil erosion have been traditionally associated with poor agricultural practices as well as with long dry periods followed by intensive rain falling on steep slopes with vulnerable soil and low vegetation cover (Amsalu \& de Graaff, 2006; Odendo et al., 2010). To reverse land degradation, the government of Ethiopia launched a massive soil and water conservation (SWC) program for the last three decades (Ludi, 2004). Although it is widely claimed that SWC strategies can contribute to reverting soil erosion, the performance of past SWC programs in most cases was below expectation (Ludi, 1997; Ludi, 2004; Brevik, 2010).

To protect the land from soil erosion and make mitigation measures more effective, it is essential to know the areas susceptible to soil erosion, assess hazard severity and the impacts of SWC technologies. However, the assessment of soil erosion and SWC measures in field experiments is costly, must cover a wide range of biophysical parameters, is not standardised and is season-dependent (Bie, 2004; Novora et al., 2011). Models and empirical formulae have been used as tools to evaluate soil erosion and impacts of SWC measures (Vente \& Poesen, 2005; Brunner et al., 2008; Fleskens et al., 2014). The applicability of models in Ethiopian conditions is limited due to lack of primary data (Yitaferu, 2007; Steenhuis et al., 2008). Tapping into farmers' knowledge could overcome some of the limitations of field experiments and modelling. Thus researchers and experts have to rely on local knowledge for quick and reliable assessment methods under local conditions (Herweg \& Ludi, 1999; Carvalho et al., 2002; Stringer \& Reed, 2007; Masto et al., 2015).

In the past decades, the focus has been on assessing implementation of conservation measures, while little attention has been paid to systematically documenting stakeholders' perceptions of, and experiences with SWC practices. In fact, a wealth of SWC knowledge and information exists, and there is a great demand to access it (Shiferaw and Holden, 2001; Yitaferu, 2007; Zhou et al., 2008). Sustainable land management (SLM) exists throughout the world and has in many cases largely evolved through local traditional practices rather 
than being adopted on basis of scientific evidence (Shiferaw and Holden, 2001; Stringer \& Reed, 2007; Schwilch et al., 2012). Active inclusion of local stakeholders and valuing of local knowledge in SWC is absolutely essential to increase the uptake of conservation measures and promote understanding of their functioning (Baartman et al., 2007; Steenhuis et al, 2008). Moreover, stakeholder involvement in investigation of erosion and conservation allows for semi-quantitative statements about soil erosion patterns and impacts of SWC technologies (Daba, 2003; Schwilch et al., 2012; Fleskens et al., 2014).

The degree of public awareness of soil erosion and conservation, which is directly related to knowledge and experience of farmers, is of critical importance in order to integrate local experiences with scientific evidences and to reverse the trend of increasing environmental damage and degradation (Belay, 1992; Ólafsdóttir and Juluisson, 2000; Yitaferu, 2007; Tefera and Sterk, 2010; Pío-León et al., 2017; Stringer et al., 2017). However, available guidelines exhibit a lack of integration of the local knowledge of land users with the technical descriptions of potential solutions for better transfer, adaptation and improvement of SWC technologies (Herweg and Ludi, 1999; Bewket and Sterk, 2002; Moges and Holden, 2007; Tefera and Sterk, 2010). There is a need for understanding of farmers' decision-making in order to evaluate the impacts of SWC measures at the local level (Jabbar et al., 2000; Daba, 2003; Yitaferu, 2007; Jemberu et al., 2014; Tadele et al., 2014; Nyssen et al., 2015; Yazdanpanah et al, 2016; Capler et al., 2017). Farmers generate know-how related to the impacts of SWC measures on runoff, soil erosion, soil fertility, yield and biomass production on a daily basis. However, most of this valuable knowledge remains a local individual resource, unavailable to others working in similar areas and seeking to accomplish similar tasks (Stringer \& Reed, 2007; Schwilch et al., 2012). This may be one of the reasons why land degradation persists despite many years of effort and high investment in SWC measures in Ethiopia (Herweg \& Ludi, 1999; Bewket \& Sterk, 2002; Ludi, 2004).

To increase the effectiveness of SWC practices and their adoption rate, promising conservation measures have to be identified by involving farmers in erosion assessment and implementation and evaluation of the impacts of SWC practices (Hurni et al., 2005; Moges \& Holden, 2007; Wei et al., 2009; Schwilch et al., 2012; Nabahungu \& Visser, 2013; Nyssen et al., 2015; Sileman et al., 2015). Participatory workshops empower communities by recognising the value of their knowledge and strengthening their capacity to produce knowledge that is useful to others such as governments (Stringer \& Reed, 2007). Knowledge-based participatory research thus combines modern approaches with indigenous traditional knowledge and instils cultural identity (and hence social cohesion) through the process of participation (Stringer \& Reed, 2007; Schwilch et al., 2012). This approach seeks to maximise the use of local and traditional knowledge and strengthen local knowledge systems, while also enabling communities to conduct conventional research to 
generate qualitative and quantitative knowledge that is scientifically credible (Yitaferu, 2007; Tefera and Sterk, 2010; Zegeye et al., 2010).

SWC measures can have an entirely different impact and consequently a different degree of adoption if they are transferred to other biophysical and/or socio-economic conditions (Ritsema et al., 1996; Herweg and Ludi, 1999; Baartman et al., 2007; Schwilch et al., 2012). Therefore, farmers' statements and observations can place the results from on-farm measurements and experiments in a wider context. In line with this, this study focused on farmers' perception and knowledge of soil erosion and SWC measures. The main objective of this study was to assess soil erosion and overall performances of different erosion mitigation measures by systematically documenting the perceptions and experiences of local farmers. Specific objectives were (i) to identify soil erosion types, severity and the causes of erosion as perceived by the local farmers, using participatory field assessment and group discussions, (ii) to evaluate the stability of SWC practices and their impacts on soil erosion, soil fertility and yield, and (iii) to identify promising conservation measures for SLM using local community knowledge. This study was carried out in three catchments with different topography, cultivation and SWC practices, so that possible differences between these catchments could be revealed.

\subsection{Material and methods}

\subsubsection{Study area}

This study is performed in three sub-catchments of Koga catchment, North-western Ethiopia $\left(37^{0} 02^{\prime}-37^{0} 17^{\prime} \mathrm{E}\right.$ longitude, $11^{0} 10^{\prime}-11^{0} 25^{\prime} \mathrm{N}$ latitude; Figure 2.1). Koga catchment has a total area of $230 \mathrm{~km}^{2}$ and is one of the major watersheds at the source of the Blue Nile in Amhara Regional state. Koga catchment represents a typical Ethiopian highland environment where SWC measures have been implemented on a massive scale to reduce the impacts of soil erosion and sedimentation of downstream reservoirs used for irrigation. The Koga River flows north-west with a total length of $69 \mathrm{~km}$. The topography of Koga catchment is rugged with elevation ranging between $1860-3120 \mathrm{~m}$. The climate of Koga catchment is characterised by dry (October to April) and wet (May to September) seasons. Mean annual rainfall is about $1400 \mathrm{~mm}$ of which more than $90 \%$ falls in the wet season. The mean maximum monthly temperature ranges from $30.0^{\circ} \mathrm{C}$ in March to $23.1{ }^{\circ} \mathrm{C}$ in August (ANRS, 1999; ADSE, 2013). Soils are classified as Leptosols, Luvisols, Nitosols, Vertisols and Fluvisols (ADSE, 2013). The three study sub-catchments, Asanat ( 750 ha), Debreyakob ( $300 \mathrm{ha})$ and Rim ( $1000 \mathrm{ha})$, have different slope steepness (Rim being relatively flat and Asanat located in the steeper upstream part of the catchment), cultivation 
patterns and land uses (Figure 2.2, Table 2.1). Approximately $86 \%$ of Koga catchment is cultivated land, while around $12 \%$ is forest and the remaining part fallow and grazing land. Most of the cultivated fields are usually planted with barley, teff, wheat, linseed, peas and beans. Different types of conservation measures have been practiced by the local farmers for a long time to increase soil fertility, control soil erosion and increase land value (Figure2. 3). Different types of bunds are the main conservation measure that is used (stone bunds, soil bunds, stone-faced soil bunds, fanyajuu bunds, Table 2.1). A bund is an embankment or ridge made of soil, stone or a combination of both, with or without a collection channel on its upper side (Danano, 2002; Yitaferu et al., 2007; Tadele et al., 2014). If the collection channel or basin is on its lower side the bund is known as Fanyajuu (Danano, 2002). Other conservation measures in the area include cut-off drains, water ways, grass strips, check dams and agronomic and soil /farm management activities.

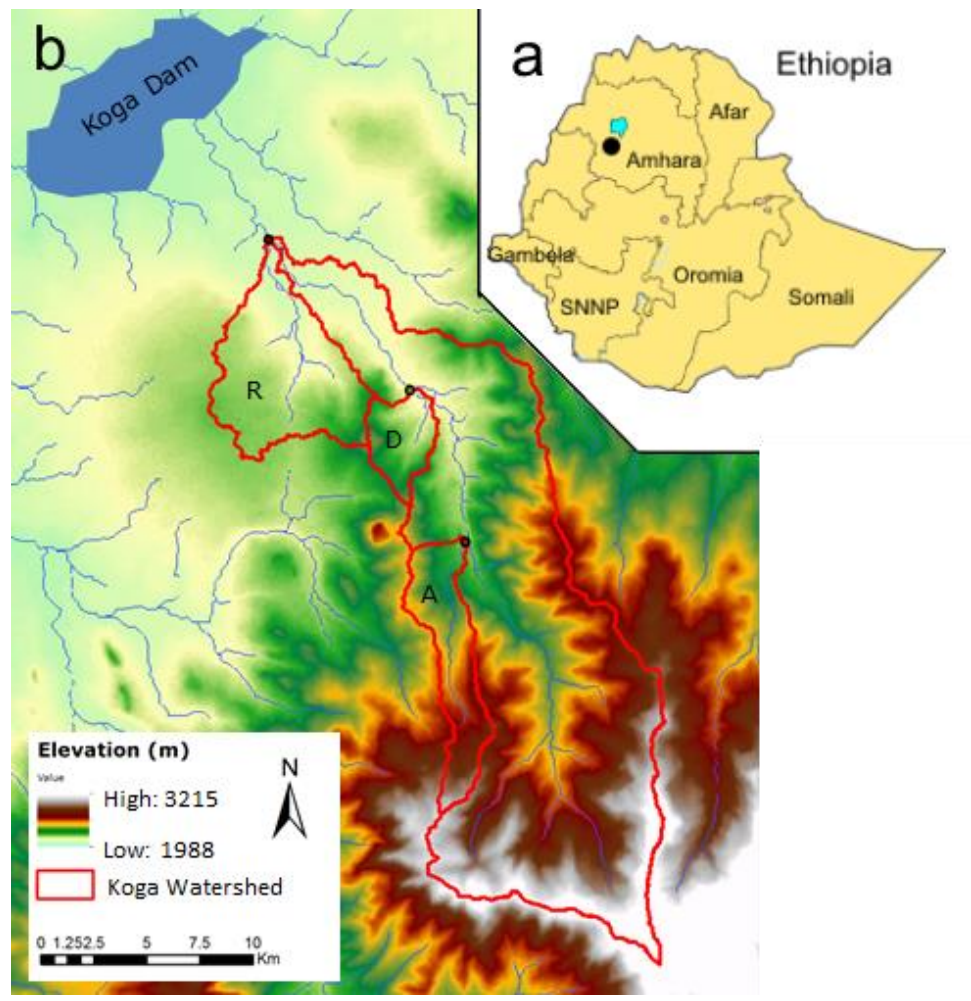

Figure 2.1 Location of Koga catchment in (a) Ethiopia - Amhara Regional State - black dot indicates location of study area and (b) Koga catchment with the three study sub-watersheds - Asanat (A), Debreyakob (D) and $\operatorname{Rim}(R)$. 
Table 2.1 Biophysical characteristics of the three study sub-watersheds

\begin{tabular}{llll}
\hline Land use (ha) & Asanat & Debreyakob & Rim \\
\hline Crop cultivation & 542.0 & 195.4 & 726.7 \\
Grazing & 88.4 & 54.2 & 48.2 \\
Bush & 52.3 & 36.5 & 52.8 \\
Plantation & 73.2 & 16.5 & 181.5 \\
Total & 755.9 & 302.6 & 1009.6 \\
\hline Slope class (\%) & & & \\
\hline $0-5$ & 27.1 & 25.1 & 497.7 \\
$5-15$ & 205.6 & 173.6 & 477.2 \\
15-30 & 451.8 & 98.7 & 34.1 \\
30-45 & 70.2 & 5.2 & 0.6 \\
$>45$ & 0.89 & 0 & 0 \\
Total & 755.9 & 302.6 & 1009.6
\end{tabular}
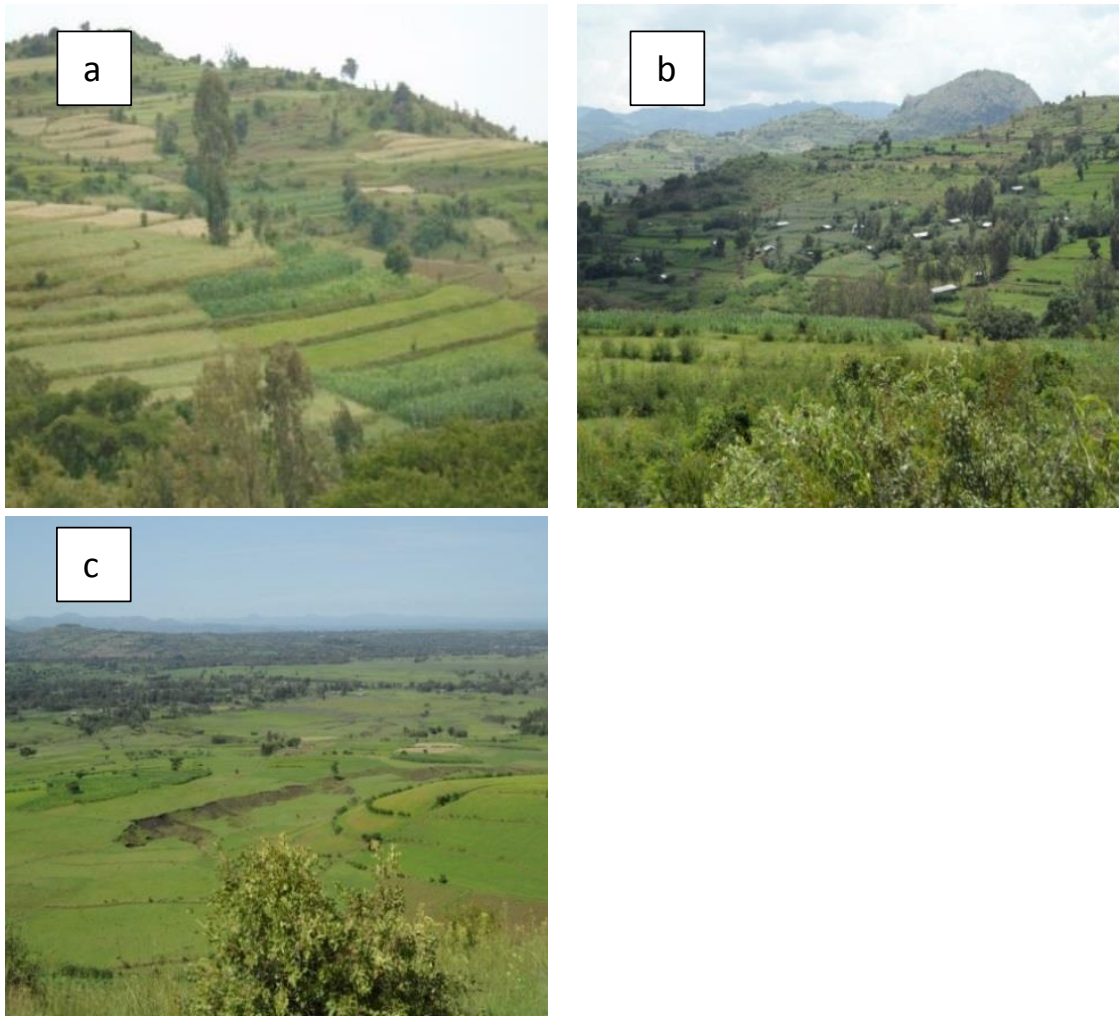

Figure 2.2 Partial view of study sub-watersheds (a. Asanat, b. Debreyakob, and c. Rim). 

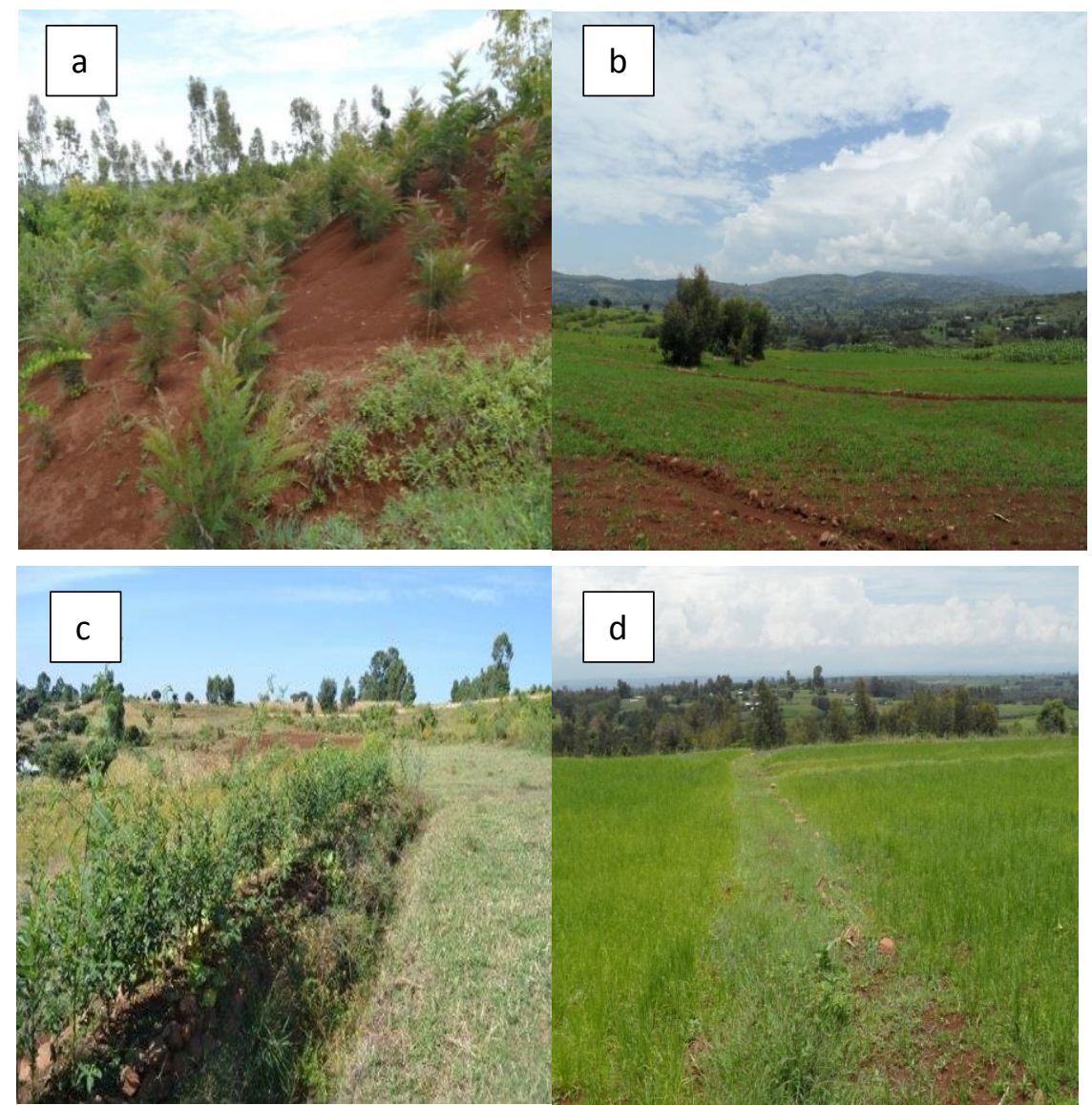

Figure 2.3 Examples of SWC measures in the study area; a) Hillside plantation, b) Traditional ditches, c) Stone-faced soil bund stabilised with sesbania sesban plantation, d) Soil bund.

\subsubsection{Stakeholder workshops}

Participatory stakeholder workshops were organized at the local level as a co-learning process aimed at generating local and traditional qualitative and quantitative knowledge that is scientifically credible regarding soil erosion and SWC. The workshops aimed to offer information on how to assess erosion and SWC measures through field surveys and to maintain a continuous dialogue for exchange of knowledge and experiences. This approach is inspired by mixed methods (Daba, 2003; Schwilch et al., 2012) and seeks to empower communities, strengthening their capacity for research by actively engaging them in field observation, measurements, evaluation, and continuous group, discussions and dialogues (Stringer et al., 2017). This enhances their awareness and skill, and generates strong local ownership. In line with this, the three workshops included group discussions and field 
assessment of sheet erosion indicators, measurement of rill dimensions and analysis of perceived impacts of SWC strategies. An overview of each workshop's objectives, activities and methods is given in Table 2.2 and briefly described below.

Table 2.2 Overview of activities in the three workshops

\begin{tabular}{llll}
\hline Workshop & Objective & Activity & Methods \\
\hline $1^{\text {st }}$ round & $\begin{array}{l}\text { Identify soil erosion types, } \\
\text { rates and causes } \\
\text { Understand soil erosion } \\
\text { variation and its impacts }\end{array}$ & $\begin{array}{l}\text { Assessment of soil erosion: } \\
\text { observation and monitoring of soil } \\
\text { erosion indicators }\end{array}$ & $\begin{array}{l}\text { Observation and } \\
\text { measurement of soil } \\
\text { erosion indicators } \\
\text { Plenary discussions }\end{array}$ \\
\hline $2^{\text {nd }}$ round & Identify the types and & Rill measurements & \\
& integration of already applied & Investigation of SWC measures: & ACED (Assessment of \\
& SWC measures & observation and monitoring the & Measurement of SWC \\
& Understand specifications of & design and stability of SWC & measures dimensions \\
& SWC measures & measures & Group work, and plenary \\
& & & discussion \\
\hline $3^{\text {rd }}$ round & Understand the stability of & Assessment of impacts of SWC & Field observation and group \\
& SWC measures & measures on soil erosion, soil & discussions \\
& Find impacts of SWC & fertility, yield and farming system & Evaluation of group work \\
& measures & Summary and documentation of & and exercises
\end{tabular}

Nine persons with different age, gender and social status participated in the workshops in each sub-catchment (i.e. 27 participants in total). One of the participants was a watershed committee coordinator. In addition, in each sub-watershed, a Development Agent (DA) and a SWC specialist were involved for technical advice during field measurements. The researcher (Mr. Walle Jemberu) and the watershed committee coordinator acted as workshop moderators by effective organisation of discussions, field activities, and facilitating the dialogues and interpersonal relations. Prior to the workshops, informal meetings and a reconnaissance survey were undertaken in the three study sub-watersheds with groups of farmers. Based on the obtained information, the outline and activities of the workshops were prepared.

The first round workshop was organised in December 2014 and lasted three days in each sub-catchment. The aim of the workshop was to identify and estimate soil erosion types, rates and causes (Table 2.2). On the first day the types, causes and effects of soil erosion were discussed and sheet erosion indicators were outlined and discussed. Subsequently, a field survey of sheet erosion was carried out on the second and third day.

In the first part of the workshop, the participants listed all indicators of sheet erosion they knew. These were categorised into current (observable immediately after a rainfall event) 
and past (resulting from long-term erosion) indicators. This resulted in a census list of indicators (Table 2.3). During the group discussions and later during the field survey, the causes and the severity of soil erosion were observed and ranked as low, low to medium, medium, high and very high using scores between $0-5$.

Table 2.3 Sheet erosion indicators selected on the basis of farmers' experiences and group discussions

\begin{tabular}{lll}
\hline Indicator & Brief description & Class \\
\hline $\begin{array}{l}\text { Splash pedestals } \\
\text { Eroding clods }\end{array}$ & $\begin{array}{l}\text { Describes the created feature by rainfall impact } \\
\text { Identified by areas with smoothed micro-relief, caused by deposition } \\
\text { of eroded material } \\
\text { Exposure of aerial roots after top soil is stripped off by runoff and } \\
\text { splash effect of rain drop }\end{array}$ & $\begin{array}{l}\text { Current } \\
\text { Current }\end{array}$ \\
Laminar wash & $\begin{array}{l}\text { Current/past } \\
\text { direction of flow } \\
\text { Identified by the burying of grass/crop or deposition of new soil }\end{array}$ & Current \\
Sedimentation & Small loose stones lying on the soil surface; signifies that overlaying \\
toniness & Partly exposed rocks, indicates that soils are shallow and have been & Past \\
Rock outcrops & washed off by runoff flow & Past \\
\hline
\end{tabular}

Next, sheet erosion was assessed semi-quantitatively by monitoring sheet erosion indicators on sample plots in both treated (with SWC measures) and untreated (without SWC measures) fields. Cultivated fields not treated with SWC measures located adjacent to the treated fields were used to compare the impacts of SWC measures on sheet erosion in each slope class. As slope steepness was thought to be the main factor determining differences in soil erosion, nine sample plots (each $0.50 \mathrm{ha}$ ) composed of both treated and un-treated fields were selected in the lower $(<10 \%)$, middle $(10-20 \%)$ and upper $(>20 \%)$ slope classes of each sub-watershed, leading to a total of 81 sample plots. Land use (arable land under wheat, barley and teff) was similar in these sampling plots. The occurrence of each indicator (Table 2.3) was counted on each sample plot. The area of actual damage was estimated based on the sum of the rates of area coverage of each indicator to the sample area and extrapolated to the whole study area.

The aim of the second round workshop, held in July 2015, was to measure rill erosion and to assess the quality and stability of SWC measures in the field (Table 2.2) and to discuss the results. Rills were measured on fields treated with SWC measures as well as on adjacent untreated fields (i.e. fields not treated with SWC measures) using the Assessment of Current Erosion Damage (ACED) methodology (Herweg, 1996). All rills of current origin were measured on 3 sample plots (covering both treated and untreated fields) on 3 slope classes in each sub-watershed forming a total of 27 sample plots and the total damage was extrapolated to the total area of cultivated land. The dimensions of rills highly varied in depth, width and length. Therefore, widths were measured at two or three depths at a point depending on the dimensions of depths and lengths. Similarly, depth measurements were 
taken at two or three sites along the rill length. These measurements allow for the determination of the volume of rills. This in turn allows obtaining average magnitudes and rates of rill erosion. Equations used in ACED are given as follows (Herrweg, 1996):

The cross sectional area $\operatorname{Ar}\left(\mathrm{m}^{2}\right)$ of the rill is the product of the average width and depth (Eq. 1):

$\mathrm{Ar}=\mathrm{D} \cdot \mathrm{W} \cdot 10^{-4}$

Where, $D$ and $W$ represent the depth and width of the rill $(\mathrm{cm})$

The volume soil from each rill section $\operatorname{Vr}\left(\mathrm{m}^{3}\right)$ was measured from the cross sectional area and rill length (Eq. 2):

$\mathrm{Vr}=\mathrm{Ar} \cdot \mathrm{L}$

Where $L$ is the length of rills, $m$

The soil mass lost from each rill surface $\mathrm{Mr}(\mathrm{kg})$ was computed as (Eq 3):

$\mathrm{Mr}=\mathrm{Vr} \cdot \rho_{\mathrm{b}}$

Where $\rho_{b}$ is the bulk density derived from literature $\left(\mathrm{kg} / \mathrm{m}^{3}\right)$

The total soil loss (ton) per sample plot was determined using (Eq. 4):

$\mathrm{Mt}=\frac{\mathrm{Mr} \cdot \mathrm{n}}{1000}$

Where $\mathrm{n}$ is the number of rills

The average annual soil loss $\mathrm{Ma}$ (t/ha) at sub-watershed level was computed as follows (Eq. 5):

$M a=\frac{1}{N} \sum_{N=1}^{N}(M t / F a)$

Where, $\mathrm{N}$ is number of sample plots and Fa represent sample field area (ha).

The dimensions and stability of different types of bunds were assessed at three slope classes (upper $(>20 \%)$, middle $(10-20 \%)$ and lower $(<10 \%)$ ) in each sub-watershed. Representative fields treated with different types of bunds were selected in each of these locations. In these fields, measurements of dimensions including width, depth, height, vertical interval (VI), and gradient and stability assessments were undertaken randomly at 
three points on a total of 10 bunds for each of the four bund types, leading to a total of 360 sampling points. Details can be found in Jemberu et al. (2017). The dimensions of SWC measures were compared with standard values from 'EthioCAT' design guidelines (ANRS, 1999; Danano, 2002) in upper, middle and lower slope positions. The quality of SWC measures, i.e. the capacity of the SWC measure to resist excess runoff, accumulate sediment and its stability and suitability to the farming system, were observed and rated by each member of the group as low, medium or high. Then the percentage of low, medium or high categories for each type of bund was calculated by dividing the number of responses in each category by the total number of samples.

The third round workshop was held in December 2015 with the aim to evaluate the impacts of (structural) SWC measures (Table 2.2). The desirable and undesirable impacts of bund structures on three factors, i.e. (i) soil erosion and runoff, (ii) soil fertility and (iii) yield, were identified from the experience of farmers. Table 2.4 shows for each of these factors the possible impact that was discussed. Traditional ditches have been used widely on both treated and untreated fields for both diversion of excess runoff and for drainage purposes. The impact of these ditches was assessed based on how well they performed without causing scouring and rills. Four transects were arranged across each sub-watershed with an average distance of $50 \mathrm{~m}$ between two transects based on the occurrence of diverse SWC measures. Depending on the responsibilities assigned, all the participants recorded information during the transect walk, which was subsequently used as a basis for group discussions. Both spatial and temporal impacts were assessed by comparing runoff, soil erosion, soil fertility and yield with/without SWC measures (spatial impact) and before/after SWC measures were installed (the temporal impact). Based on exchange of arguments and open discussions within stakeholder groups, the overall impacts of SWC measures were ranked as very low (negative impact), low, low to medium, medium and high impact for each of the purposes, with corresponding rates of 1, 2, 3, 4 and 5 respectively.

Finally, the effectiveness of agronomic and biological SWC practices and other soil and farm management activities such as mixed cropping, manuring and grass strips were discussed in general terms and experiences shared among participants of the workshop. 
Table 2.4 Possible impact of bund structures on three factors

\begin{tabular}{ll}
\hline Factor & Possible impact as discussed with farmers \\
\hline Runoff and erosion & $\begin{array}{l}\text { Effective in reducing storm runoff } \\
\text { Efficient excess water drainage } \\
\text { Reduce downstream floods } \\
\text { Soil loss reduction } \\
\text { Reduce downstream siltation }\end{array}$ \\
\hline Soil fertility & Increase in soil fertility \\
& Increase in soil moisture \\
\hline Yield & Regular crop growth and development \\
& Change in crop yield, farm income \\
& Biodiversity enhancement \\
& Flexibility of farming system
\end{tabular}

\subsection{Result}

\subsubsection{Soil erosion}

The occurrence of sheet erosion indicators is given in Figure 2.4 for the three sub catchments and slope classes. In general, the occurrences of sheet erosion indicators were higher in non-treated fields as compared to treated fields, with an average of $72 \%$ (Asanat), 76\% (Debreyakob) and 69\% (Rim) of the occurrences found on non-treated fields. Sheet erosion indicators were reduced by more than 61,68 and $54 \%$ in treated farmlands in Asanat, Debreyakob and Rim respectively. The total number of occurrences was highest in Asanat (1107) and lowest in Debreyakob (746), possibly due to effective SWC measures, which have been used in Debreyakob. Furthermore, the occurrence of stoniness and rock outcrops were generally very low in Rim (the lowest and flattest sub-watershed) and highest in the steeper parts of Asanat, as would be expected. In Asanat, sheet wash and eroding clods were the most common indicators in untreated and treated farm plots, respectively whereas sheet wash was the highest in both treated and untreated farm plots in Debreyakob and Rim. However, sedimentation was the lowest in Asanat as compared to other indicators. The occurrence of all indicators were higher on upper slope classes than middle and lower slope classes. 

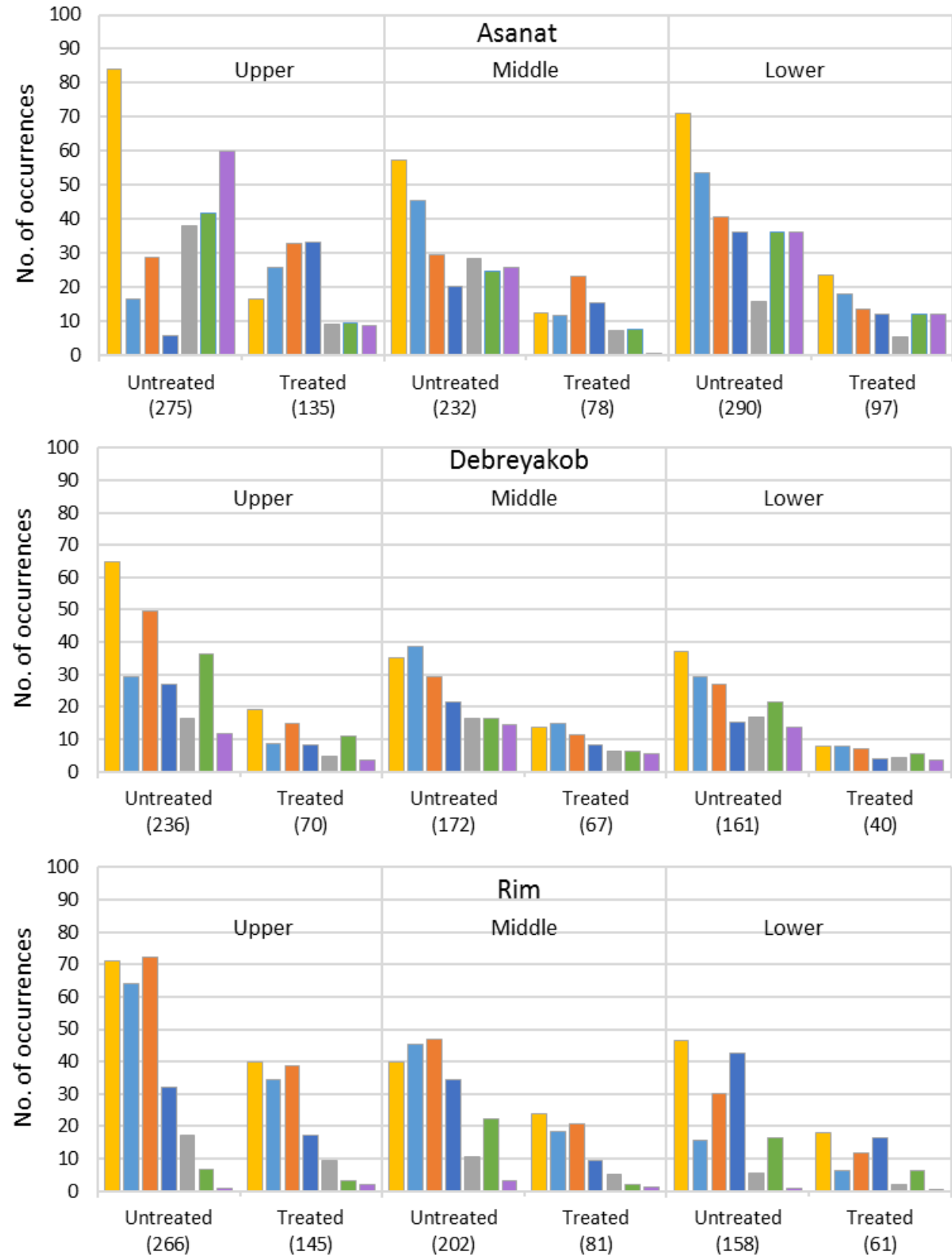
$\square$ Sheet wash
W Splash pedestals
Eroding clods
nedimentation
Root exposure
a Stoniness
Rock out crops

Figure 2.4 Occurrence of sheet erosion indicators for three slope classes (upper, middle and lower) in the three watersheds (Asanat, Debreyakob and Rim). T = treated with SWC measures, NT is not treated with SWC measures; number between brackets is the total number of observations. 
The extent of sheet erosion in treated and untreated fields as calculated from the sheet erosion indicators observed by the farmers, was comparatively low at Debreyakob (middle part of Koga) and high at Rim in the lower part of Koga catchment. For most sheet erosion indicators, a higher percentage of occurrences corresponded to a larger area of damage except for root exposures and splash pedestals. Sheet erosion indicators were assumed to represent runoff effects during the year of investigation except for rock outcrops and stoniness. The indicators were found to be interrelated in their occurrence; for instance the presence of laminar or sheet wash was linked with root exposure; the existence of rock outcrops was associated with stoniness; and splash pedestals and eroding clods were found to be spatially related in various areas. Rock outcrops and stoniness were identified as being the ultimate effect of sheet wash or laminar soil loss by runoff.

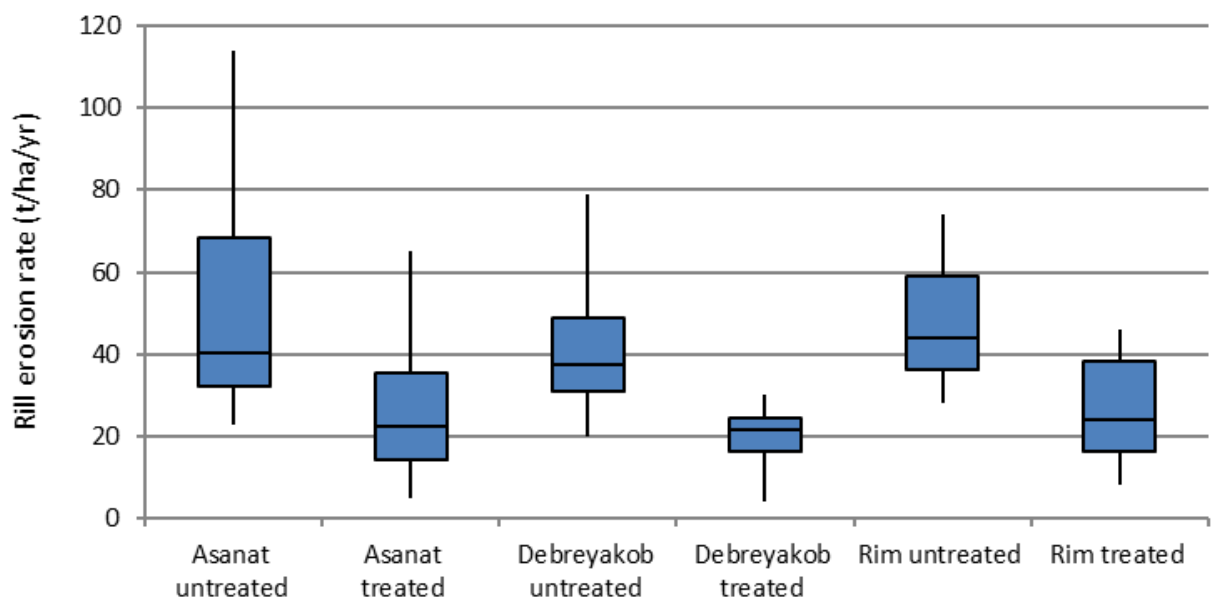

Figure 2.5 Boxplots of estimated rill erosion rates for treated (SWC measures) and untreated (no SWC measures) fields in the three watersheds. Black line indicates median; bars indicate maximum and minimum values.

Figure 2.5 shows estimated rill erosion rates in treated and untreated farm fields in the three sub-watersheds. As can be seen, the rill erosion rates were found to be always lower on fields treated with SWC measures compared to those on untreated fields. The highest erosion rates were observed in Asanat (in the upper part of Koga) whereas relatively low rill erosion rates were measured in Debreyakob (at the middle part of Koga catchment). The average annual estimated rill erosion rates were 27.3 and $51.5 \mathrm{t} / \mathrm{ha}$ for treated versus untreated fields in Asanat, 19.7 and 42.6 t/ha in Debreyakob and 25.7 and 47.0 t/ha in Rim sub-watershed, respectively. The percentage reduction in rill erosion between non-treated and treated field was significantly higher $(p<0.05)$ for Debreyakob $(53.8 \%)$ than $\operatorname{Rim}(45.3 \%)$ 
and Asanat (46.9\%). This is due to widely applied effective SWC measures in Debreyakob than Rim and Asanat. Generally, the development of rills in the study area was observed to be a dynamic process. Some of the rills formed at the beginning of the wet season and grew in size throughout the wet season, while others disappears soon after their formation. In almost every field, maximum development of rills, both in number and dimension, was attained towards the end of the rainy season. Farmers also stated that rill erosion has been increasing in Koga catchment due to intense rainfall, slope steepness and poor land cover. Poor cultivation, poor conservation measures and overgrazing might play a significant role for the increment of rills in Koga.

Figure 2.6a shows the farmers' perception on the severity of the different forms of erosion (sheet, inter-rill, rill and gully) for different slope classes for the three sub-watersheds. Overall, erosion was perceived most severe in Asanat and lowest in Debreyakob. However, gully erosion was relatively more severe in the lowest catchment (Rim) and less important in Asanat.

The overall causal factors of soil erosion as perceived by the workshop participants were grouped into deforestation, overgrazing, poor farming and poor soil and water conservation (Figure 2.6b). Similar to the severity of the different erosion types, the causes of erosion were perceived to be more severe in Asanat and less so in Debreyakob and Rim subwatersheds. The causes contributing to erosion show different spatial trends. For example, overgrazing is perceived as most pressing in Asanat, while it is the least severe in Debreyakob, where free grazing is controlled. Poor farming such as: graded lines of ploughing, land fragmentation and loss of farm boundaries, limited soil management, burning of cow dung and crop residue on the other hand, are seen to be an important cause for erosion throughout the three watersheds. In Debreyakob and Rim, deforestation was not perceived as a cause for erosion, as opposed to Asanat. The stakeholders of the workshop stated that "good farming is good conservation". Poor SWC measures and limited farm or soil management have caused relatively high soil erosion rates in the upper parts of Koga catchment despite similar rainfall intensities as compared to the lower parts of the catchment. 

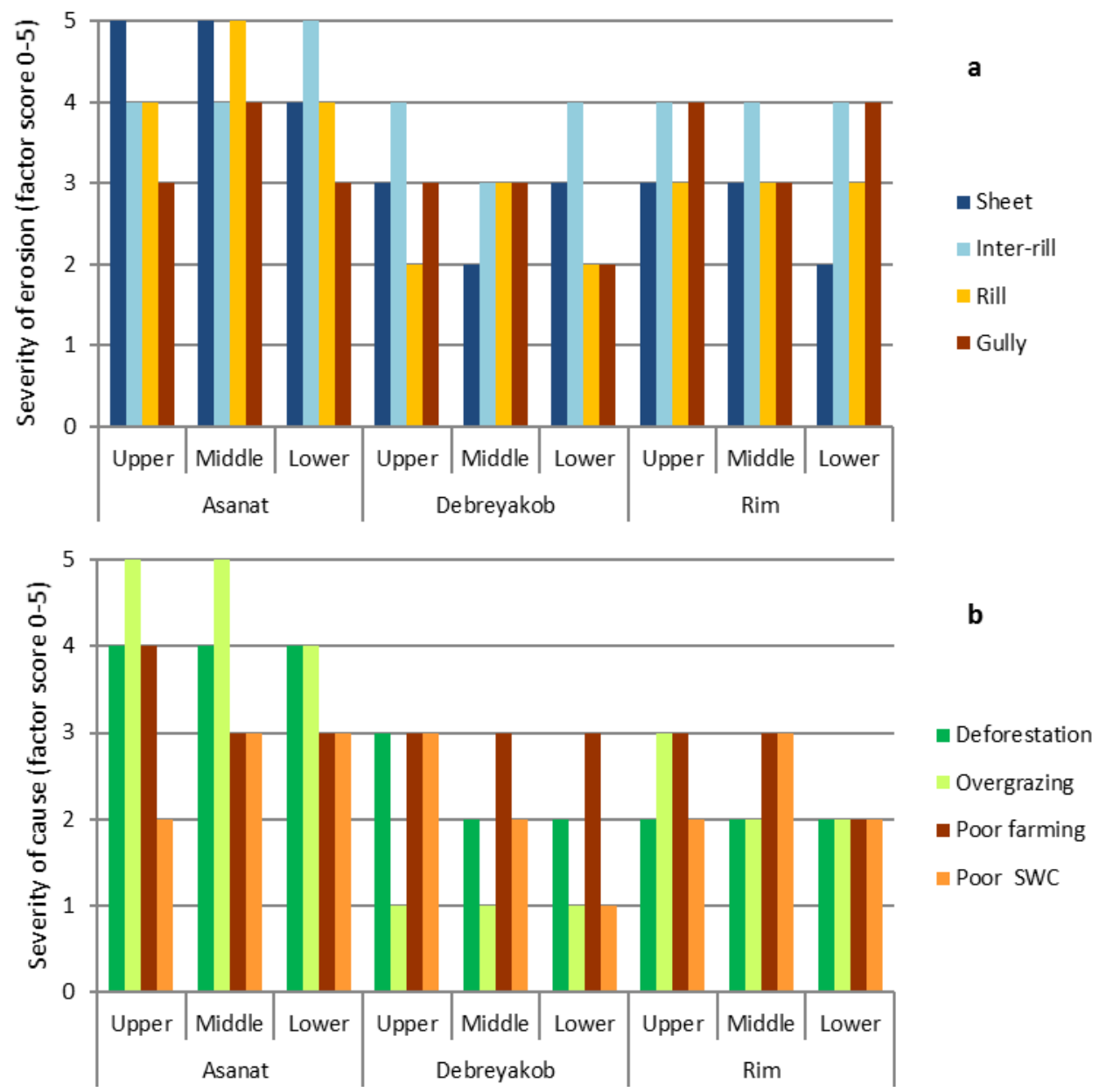

Figure 2.6 Farmers' perception and ranking of the severity of (a) different forms of erosion and (b) causes for erosion.

\subsubsection{Performance of SWC strategies}

Figure 2.7 shows the quality of different bund structures as perceived by the farmers. The quality of bund structures was rated low in general. An opposite trend is visible when comparing Asanat and Debreyakob: in Asanat, the majority of bund structures was rated to be of low quality, while in Debreyakob, most structures were rated as medium or high quality. Difference between the different types of bunds also became apparent: for example in Asanat $68 \%, 22 \%$ and $8 \%$ of the stone-faced soil bunds were rated to be of low, medium 
and high quality, respectively. However, in Debreyakob this was $10 \%$ (low), 33\% (medium) and $56 \%$ (high), respectively. In both Rim and Asanat, soil bunds were perceived to be of lowest quality compared to other types of bunds, while stone-faced soil bunds were rated best in Rim and Debreyakob. In the higher Asanat catchment, stone bunds were perceived to be of best quality as compared to other types of bunds.

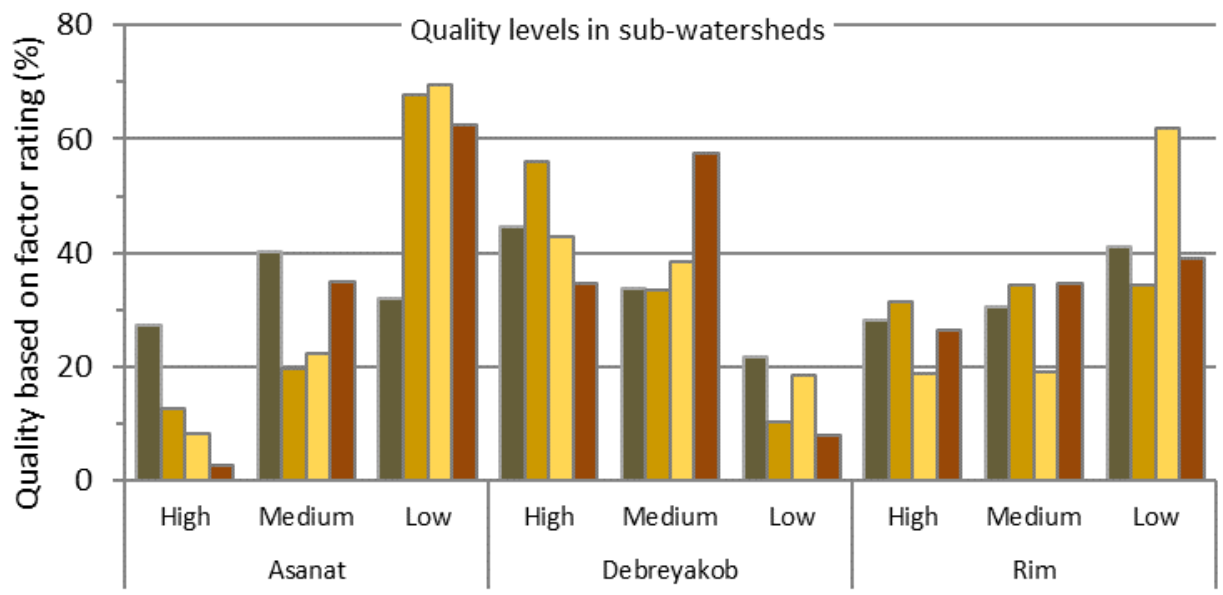

a Stone bund $\square$ Stone-faced soil bund $\square$ Soil bund $\square$ Fanyajuu bund

Figure 2.7 Perceived quality of different types of bunds in the three sub-watersheds.

\subsubsection{Impact of SWC strategies}

The desired impacts of SWC strategies include control of soil erosion and surface runoff, increase infiltration rate, maintain water stored in the soil, increase soil organic matter, improve soil fertility and increase yield. However, some measures are implemented for a specific desired purpose, such as to increase topsoil depth, or to divert surface runoff and after this purpose is fulfilled, the fertile soil or the runoff water would be distributed to the farm. Figure 2.8 shows a radar diagram of the ratings of farmers on the impact of different SWC measures for different purposes (i.e. controlling erosion and runoff, improving soil fertility and increasing yield) for the three sub-watersheds. As can be seen, traditional ditches were not rated very positively. This is due to high gradiency of traditional diches which caused scouring and rill erosion. A high variation in dimensions and spacing of traditional diches was observed in the field. The workshop participants pointed out that SWC measures reduced the effects of rill erosion, specifically in the middle part of Koga (at Debreyakob; Figure 2.8). In Asanat and Debreyakob, stone-faced soil bunds were attributed 
higher impact than other types of bunds, while in Rim, soil bunds were favoured. Especially in Asanat, soil bunds were perceived to have low impact. Soil bunds were unstable and easily overtopped by storm runoff because of the steep slopes and shallow soils in Asanat catchment. The impacts of stone bunds on soil fertility and on yield were perceived to be low in both Asanat and Rim, but relatively high in Debreyakob. In Debreyakob, stones are abundant, and effective and integrated stone bunds have been used more widely than in Asanat and Rim.

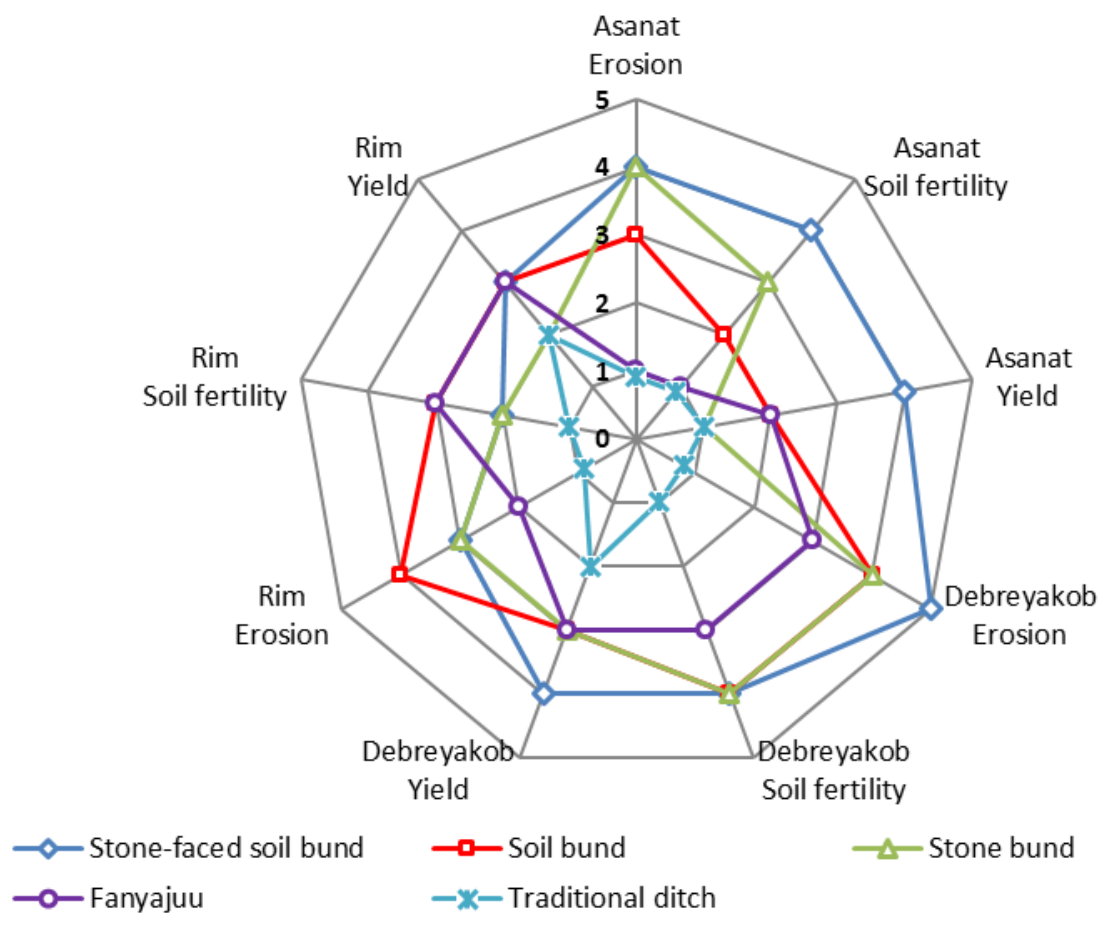

Figure 2.8 Radar diagram showing the relative rated impacts of conservation structures on soil fertility, erosion and yield in the three sub watersheds. Low - high impact measured on $0-5$ scale.

Farmers' experiences revealed that on steep slopes (such as in Asanat), stone bunds were effective in controlling runoff and soil loss because of their superior stability. Stone-faced soil bunds, which are comparatively easy to implement and maintain, were favoured by farmers in all sub-watersheds. Stone-faced soil bunds were argued to have both the advantages of soil bunds (plantation over the bund) and stone bunds (high stability) in Koga catchment. Vegetated soil bunds were more appreciated by farmers on gentle and moderately sloping fields but during maintenance scraping the stabilised soil from the upper side of the embankment was found not advisable. So to obtain effective and sustainable bunds, regular maintenance is needed that should be done only by the fanyajuu technique. 
This system of maintenance was found useful to increase the desired impacts of bunds because the upper stabilised soil and vegetation material is not destroyed during maintenance; instead, the lower side of the embankment is used to increase the height of bund structures. Farmers had serious complaints about all types of bunds which are improperly large and undesirably level. Even though many farms have been treated with level bunds, they were not accepted at all. Water logging and runoff overtopping hazards were the undesirable impacts of level bunds and this was more severe for fanyajuu type of bunds. Due to this, fanyajuu bunds were not effective and the technique was only accepted for management or maintenance of other types of bunds to increase their performances. Besides structural measures like bunds, agronomic SWC practices and soil or farm management activities such as: mixed cropping, strip cropping, relay cropping, manuring and alley cropping were identified as very effective conservation strategies which have been adopted by the local community and need to be fostered. Biological conservation measures like grass strips and hedge rows conserved soil and water, increased crop diversity and conserved local genetic variety, enhanced biodiversity and maintained the balance of agroecology. These benefits were acknowledged by farmers but their establishment was judged to be impeded due to free grazing, lack of plant material (seed and seedlings) and long dry periods. According to the findings from farmers view and in line with technical and scientific theories, graded stone-faced soil bunds established with plantation and integrated with cutoff drains, were the prominent conservation strategies in Koga catchment (Hurni et al., 2016). However, all graded bunds and traditional ditches were not effective. Agronomic SWC practices and soil or farm management activities are regarded as indispensable for SWC, while physical measures alone were perceived to not be sufficient for SWC.

\subsection{Discussion}

\subsubsection{Soil erosion}

The large variation in estimated soil erosion rates (Figure 2.5) reflects high spatial variation of factors potentially influencing soil erosion. According to Nyssen et al. (2007) and Meshesha et al. (2012), variation in soil loss rates by rill and sheet erosion at plot and catchment scale confirm the strong spatial variability of soil erosion processes. Nyssen et al. (2007) found mean soil loss rates of $58 \mathrm{t} / \mathrm{ha} / \mathrm{y}$ in Tigray region of northern Ethiopia and Meshesha et al. (2012) found mean annual soil loss of $36.2 \mathrm{t} / \mathrm{ha} / \mathrm{y}$ in the Rift valley of Ethiopia. However, Taye et al. (2013) and Tilahun et al. (2013) reported high soil erosion rates in Chemoga (110 t/ha/y) and Angeni (102 t/ha/y) in the upper Blue Nile Basin due to high rainfall intensity and steep slopes. These values are in the same range as the estimates presented in Figure 2.5 for Koga catchment. Farmers were aware that intensive cultivation 
on steep slopes as a result of land shortage and poverty caused accelerated soil erosion and they argued that sheet erosion effects were influenced by slope, land use and SWC practices, as is indeed well known from research (e.g. Ritsema et al., 1996, Stoof et al., 2011). Land cover and farming practices are the most important factors controlling soil erosion in Ethiopian highlands, while rainfall characteristics and slope steepness are also important (Yitaferu et al., 2007; Tilahun et al., 2013; Jemberu et al., 2017). Even though this study did not focus on gully erosion, it was perceived as an important form of erosion (Figure 2.6a), especially in the lower Koga catchment (Rim sub-watershed). Farmers mentioned that gully development had been severe in recent years. Deep and wide gullying, at alarming rates, is a known phenomenon for many Ethiopian catchments (e.g. Daba et al., 2001; Steenhuis et al., 2008; Tebebu et al., 2010).

Poor farming practices, like burning of cow dung and crop residues (instead of leaving them on the field), ploughing up and down the slope, poor soil management or use of no farm inputs, were identified as a major cause of soil erosion. Other causes such as overgrazing, lack of conservation, and deforestation were interrelated with poor farming practices. This is in line with Vancampenhout et al. (2006) and Pulido (2016) who found that resource overexploitation and inappropriate land use such as overgrazing, deforestation, expansion of cultivation and grazing of marginal lands, and backward agricultural practices were the major causes of land degradation in Ethiopia. Design flaws in SWC measures, and poor or no integration with subsidiary measures were observed to accelerate soil erosion in various farms and farmers pointed out the various negative impacts of poor SWC strategies. This is in line with results reported by Danano (2002); Nyssen et al. (2007) and Jemberu et al. (2017) that collapsed bunds, mainly due to poor design, lack of maintenance and open grazing created concentrated runoff through breaks that caused severe rill and gully damage.

\subsubsection{Performance of SWC measures}

The principle of implementation of bunds across the slope of the land is to reduce the rate of surface runoff and erosion, to decrease the losses of soil and water and increase the fertility status of soil in cultivated lands which is mainly dependent upon performance of bunds (Danano, 2002; Nedasa, 2002). Well-functioning bunds gradually evolve into bench terraces due to sediment trapping. In the Koga study area, sedimentation did not yet result in the development of bench terraces, possibly due to poor design and maintenance (Jemberu et al., 2017). As a consequence, the desired impacts of SWC measures are limited and the process of soil erosion and land degradation is not reversed as expected (Figure 2.6, 2.8). In line with this, studies by Vancampenhout et al. (2006), Nyssen et al. (2007) and 
Yazdanpanah et al. (2016) have documented that even though bunds increase the physical fertility status of the soil and improve the balance of agro-ecosystems by controlling runoff and soil loss, the performances of these measures on controlling the losses of soil and water are generally site-specific and highly variable and in most cases below the levels of expectation.

Diversion channels were perceived by farmers to be of better quality compared to bunds. However, waterways and traditional ditches were subject to incision on various farmlands because of poor design (random application) and were unfavourable to farmers (Figure 2.8). Farmers stated that "we are forced to use farm diches (feses) in both treated and untreated farms during extreme flooding and unexpected water logging events" despite their contribution to rill and gully erosion. Even though the technical specification of SWC structures are described in the EthioCAT manual and communicated through trainings, in various watersheds of Ethiopian highlands the DAs did not adhere to specifications of conservation strategies, maybe due to technical, political, social and economic constraints. These observations are in line with findings by Mitiku et al. (2006), Vancampenhout et al. (2006), Roes (2007) and Jemberu et al. (2017) who found that attention is rarely given to site-specific characteristics when entire catchments are being considered through SWC campaigns and the uniform layout of SWC structures and the inflexibility of untrained extension staff, often paired with unwillingness to maintain SWC measures, literally invite technical problems.

The stability and suitability of bunds was found to be affected by farm management activities such as ploughing and weeding, and by maintenance of the bunds. This corroborates previous results reported by Nedasa (2002); Gebremkael et al. (2005) and Mitiku et al. (2006) who found that when the embankment riser of stone faced soil bunds was not stabilised with stones, particularly the lower parts can be undercut through erosion and stones fall off, or they are removed to increase the arable surface area. To maintain the quality and stability of physical structures, it is essential to modify the dimensions and spacing between the structures to the local conditions. The purpose of combined stone and soil bunds within a field is to increase the production of arable land through levelling of steep land, reduction of runoff and soil erosion (Sonneveld and Keyzer, 2003; Gebremikael et al., 2005). For example, Vancampenhout et al. (2006) and Herweg and Ludi (1999) state that the maintenance, stability and performance of terraces depends on several factors, the most important ones being integration into the management system, availability of stones, accessibility of the field and removal of stones for cultivation. This is in line with our findings for Debreyakob watershed, where all types of SWC measures were found to be relatively effective. A reason for this may be that due to the awareness and incentives generated by NGOs, most of the SWC practices were integrated and maintained well unlike in the other 
two sub-watersheds. Thus in general, the local biophysical conditions as well as the farmers' perspectives must be taken into account in order to ensure both protective and productive functions of conservation structures which are a prerequisite to ensure sustainability.

\subsubsection{Impacts of SWC measures}

Except for runoff, the desired impacts were obvious in the study area: as perceived by the farmers, soil loss decreased, soil fertility improved and yield increased (Figure 2.8). Similarly Herweg and Ludi (1999); Gebiremikael et al. (2005) and Jemberu et al. (2017) found that despite considerable soil loss reduction, erosion rates remain considerably high, even under SWC in Ethiopian highlands. Bewket and Sterk (2003), using a field survey methodology and Bayabil et al. (2010); Tesemma et al. (2010) and Seifu et al. (2013), using hydrological modelling, found that locations with relatively sound conservation practices in place show rather low soil loss despite high erosion potential due to e.g. steep terrain. However, the widespread conservation efforts undertaken in the region are not always properly maintained and there are several cases where terraces are broken, largely due to livestock trampling or severe runoff (Harweg and Ludi 1999; Gebiremikael et al. 2005; Mitiku et al., 2006). This negates the effectiveness of conservation measures and even may allow concentrated flow which could enhance erosion and downstream gully development.

The undesired impacts of level bunds, as experienced by the farmers in Koga catchment are confirmed by Herweg \& Ludi (1999) stating that level bunds reduced runoff but caused water logging hazard on farmlands throughout the Ethiopian highlands. Koga catchment is subjected to high and intense rainfall during a short period in summer and no or little rainfall for long dry spells. Due to this, SWC strategies in Koga catchment must aim to achieve under both these extreme conditions. Therefore bunds need to be graded to dispose excess runoff during the rainy season and should be combined with appropriate ties, waterways, aprons and cut-off drains as required to reduce risks of damage and also to retain moisture during dry spells (Hurni, 1993; Bakker et al., 2008). But the main difficulties of graded bunds, according to local experiences, were the disposal structures required to remove safely the excess runoff concentrated from graded bunds.

Bund stabilization with planting and controlled grazing were recognized as requirements for effectiveness and sustainability of bunds. Most farmers use the ditches as traditional drainage and diversion channels throughout the study area. However, it was found that traditional ditches were associated with severe rill formations (Figure 2.8). It can thus be deduced that integration with other conservation measures and appropriate design 
(specifically spacing and gradient) are the critical factors for improving the effectiveness of farm ditches or they should be replaced by graded bunds.

\subsubsection{Limitations and advantages of using farmers' perceptions}

This research emphasizes the importance of incorporating the experiences of the local community in order to build trust and common knowledge for action based on self-learning. Participatory workshops, similar to those in this study have been carried out in Ethiopia for soil erosion assessment (Assefa et al., 2010; Desta and Hurni, 2011) and/or SWC measures (Woldeamlak and Sterk, 2002; Tesfaye et al., 2013; Zenebe et al., 2013). All of the participatory techniques rely upon group discussions and /or interviews and questionnaires. However, this study constitutes an important contribution as, to our knowledge, no previous study has been undertaken that combines farmers' perceptions and knowledge with technical assessments of soil erosion and performance of SWC measures, such as the ACED method and factor ratings that were used in this study. In this way a semi-quantitative assessment was made about soil erosion and performances of SWC measures.

Stakeholder participation is regarded as a critical component which promotes the chance of development initiatives being sustainable through community capacity building and empowerment (Ludi et al., 1997; Stringer et al., 2007). Community participation and community based management are the most important issues in current policy and discussion revolving around decision making processes especially in natural resource management (Mitiku et al., 2006; Schwilch et al., 2012). Participatory research is used to maximise local and traditional knowledge and strengthen local knowledge systems. It also enables communities to generate qualitative and quantitative knowledge that is scientifically credible (Alcorn, 1993; Gadgil, 1993). Despite the semi-quantitative nature of the methodology, using farmers' perceptions and experiences to document land degradation and the impacts of SWC measures is crucial as they are the daily users of the land and therefore directly affecting the success or failure of SWC measures. However, participatory research is not easy as farmers within the community were not always willing to participate and invest their time in research activities as they are busy trying to secure the basic necessities of life, especially in developing countries.

\subsection{Conclusion and recommendations}

Farmers were aware of the effects of ongoing soil erosion and impacts of several mitigation strategies in their farm. Soil erosion, mainly caused by poor cultivation, is recognized by 
farmers as a major threat to the productivity of their land. Soil loss is highly influenced by slope steepness and erosivity of the rainfall, and considered very variable between farm plots due to great differences in slope, land use, soils, crop management and SWC strategies. Higher incidence and extent of stoniness, rock outcrops and root exposure was observed on steep slopes whereas sheet wash marks such as runoff paths and smoothened surfaces were more evident on lower and medium slope classes. The desired impacts of SWC strategies are attained in general: runoff rates decreased, soil loss decreased and soil fertility and production increased. The impacts of SWC practices are highly affected by the design quality and maintenance or management of conservation strategies. Farmers had serious complaints about all types of bunds which were improperly large or undesirably level. Level bunds were not accepted in the study areas, due to waterlogging and overflow of runoff problems. The fanyajuu technique was accepted only for management or maintenance of other types of bunds. Comparatively, graded stone-faced soil bunds showed higher desired impacts and were favoured by farmers, and recommended by farmers to be adopted more widely in the subsistence farming system in the highlands of Amhara.

Agronomic SWC practices and soil or farm management activities are regarded as indispensable for SWC, while physical measures alone were perceived to not be sufficient for SWC. Biological SWC measures conserve soil and water effectively, but their establishment is rather difficult due to free grazing, lack of plant material (seeds and seedlings) and long dry periods in Koga catchment.

Some technical recommendations that became apparent in this study, based on farmers' knowledge, are that (i) Physical SWC practices should be integrated with biological conservation strategies and free grazing must be controlled for SLM, (ii) All bunds should be graded and farm ditches must be replaced by graded bunds and diversion channels, and (iii) Regular maintenance of all bunds in Koga catchment should be done by fanyajuu technique. In more general terms, it became clear from this study that farmers have a detailed knowledge of, and opinion about, what works best where. Farmers' involvement therefore can tailor practices to local conditions and safeguard major design errors, and should be taken into account when new SWC plans are being developed and implemented in an area. This farmers' involvement should become a standard part of the planning procedure and should be implemented in the appropriate guidelines (e.g. soil and water conservation in Ethiopia: guidelines for development agents) (Hurni et al., 2016). 


\section{Assessing the variation in bund structure dimensions and its impact on soil physical properties and hydrology in Koga catchment, Highlands of Ethiopia}

Prolonged soil drying and severe moisture stress during the dry season, and soil saturation and erosion during the short rainy season are critical problems in the Ethiopian highlands. Large-scale implementation of bund structures has been used as soil and water conservation (SWC) measures to fight these problems and establish a sustainable land management (SLM) system. However, many SWC measures are implemented with design flaws or without proper design and maintenance, and do not match conservation requirements. The quality of implementation and effects of these bund structures on soil physical properties is not yet documented. Therefore, in this study, field investigations and laboratory analysis were carried out to evaluate the variation in bund structure design and its impact on soil-water retention, bulk density, porosity and soil depth. Results show that the dimensions and stability of bund structures, and consequently, the impacts of bunds varied widely. The widths and heights of bunds, and slope gradients were significantly correlated with infiltration rate and soil water content. Soil water content was 24\% higher compared to that on untreated farms. Bunds with larger dimensions of top width (>85 cm) and height (>75 cm) showed 17 and 18\% higher soil water content compared to fields with bunds having lower dimensions. In addition, results exhibited that the porosity and soil depth were significantly affected by the dimensions of bund structures and increased with increasing widths and heights of bunds. A 14\% increase in porosity; a 41\% increase in infiltration rate; and a 18\% decrease in bulk density was found in soils of treated farms compared to those of untreated farm plots. Differences in particle size distribution and soil erodibility among widths of the bunds were low. It can be concluded that bund structure design varied substantially throughout the study area, which impacted soil water storage and soil physical properties. Bund structure design should be adapted to local biophysical settings at catchment level to enhance on-and offsite impacts.

This chapter is based on:

Jemberu, W., Baartman, J., Fleskens, L., G. Selassie, Y., Ritsema, C.J. 2017. Assessing the variation in bund structure dimensions and its impact on soil physical properties and hydrology in Koga catchment, Highlands of Ethiopia. Catena 157: 195-204. 


\subsection{Introduction}

Soil erosion by water is the main soil degradation process in agricultural lands globally (Ekwue, 1992; Bewket and Sterk, 2002; Agima et al., 2003; FAO, 2014). It generates strong environmental impacts and major economic losses (Dagnew et al., 2015; Tamene et al., 2017) due to decreased agricultural production (Zinabu et al., 2002; Haregeweyn et al., 2005), decreased water quality by sedimentation processes and off-site effects on infrastructures (Amsalu et al., 2007; Jemberu et al., 2014; Ayele et al., 2015, 2016; Tebebu et al., 2016). Large-scale implementation of bund structures has been used as soil and water conservation (SWC) strategy to fight these problems and establish a sustainable land management (SLM) system in the Ethiopian highlands (Shiferew and Holden, 2001; Bewket and Sterk, 2002). The sustainability of land management practices is affected by the effectiveness of SWC measures on runoff, soil and nutrient losses and yield (Roes et al., 2007; Tebebu et al., 2010) but quantitative information on the ecological impacts of conservation measures is often lacking for Ethiopian conditions (Herweg and Ludi, 1999; Bewket and Sterk, 2002; Taye et al., 2013, 2015; Tebebu et al., 2015). A variety of already applied SWC measures exists in the Ethiopian highlands at the local level, but they are not adequately recognised, evaluated and shared, either by land users, technicians, researchers, or policy makers (Shiferew and Holden, 2001; Roes et al., 2007; Jemberu et al., 2014). Likewise, collaboration between research and implementation is often insufficient (Vancampenhout et al., 2006; Steenhuis et al., 2013). Most research on SWC focuses on soil erosion assessment without putting sufficient emphasis on prevention and mitigation strategies, although the concept of SLM is increasingly being acknowledged (Bie, 2004; Brevik, 2010; Tilahun et al., 2016).

Many SWC measures are implemented with design flaws, without proper design and maintenance, and do not match conservation requirements (Roes et al., 2007). As a consequence, the desired impacts of SWC measures are limited and the process of soil erosion and land degradation is not reversed as expected (Herweg and Ludi, 1999; Bakker et al., 2008; Steenhuis et al, 2008; Jemberu et al., 2014). Models and empirical formulae have been used as a tool to measure the impacts of different SWC strategies (Ritsema et al., 1996; Fleskens et al., 2014). Despite their widespread use, the application of models lacks a theoretical background and fitness to different areas and practitioners have to rely on reliable field assessment methods at local conditions to assess the impacts of SWC measures (Herweg and Ludi, 1999; Ritsema et al., 2002; Keesstra et al., 2014).

Bunds are embankments constructed across the slope, made of soil, stone or a combination of both, with or without a basin (collection channel) (Volli, 2002). Soil which is eroded between two bunds is deposited behind the lower bund and the bund will be raised until 
forming a bench terrace in the course of several years ( 3 to 7 depending on slope and soil type) (Herweg and Ludi, 1999; Volli, 2002). The principle of implementation of bunds across the slope of the land is to reduce the rate of surface runoff and erosion, to decrease the losses of soil and water and increase the fertility status of the soil in cultivated lands (Jemberu et al., subm). Although it has been reported that bunds increase the physical fertility status of the soil by controlling runoff and soil loss (Gebrernichael et al., 2005; Geissen et al, 2006; Vancampenhout et al., 2006; Nyssen et al., 2007; Tadele et al., 2014), the performances of these measures on controlling the losses of soil and water are generally site-specific and highly variable (Anderson et al., 1990; Shiferew and Holden, 2001; Sonneveld and Keyzer, 2003; Roes et al., 2007). In addition most studies focus on the impacts of conservation strategies on soil characteristics without paying attention to the effects of specifications of SWC measures on soil hydrology and other physical soil properties at different slope categories.

Improvements of soil physical characteristics and enhancement of soil water storage are the most important indicators of the success of bund structures (Herweg and Ludi, 1999; Brady and Weil, 2002; Walle et al., 2006; García-Ruiz, 2010). Soil physical properties and hydrology directly affect biomass production (Sharma and Bhushan, 2001; Arshad and Martin, 2002; Hessel et al., 2008), e.g. by controlling infiltration and runoff processes or the movement and storage of rainfall at various spatial scales (Chen et al., 1997; Cerda, 1998; Moutier and Shainberg, 2000; Ritsema et al., 2008; Wesseling et al., 2009). Many aspects of the functioning of soil have been shown to be critically dependent on soil physical characteristics and/or soil water storage (Ritsema et al., 2009; Brevik, 2010). In agricultural environments soil water conditions and physical soil characteristics are often subjected to abrupt changes because of tillage, rainfall and temperature changes (Kaihura et al., 1999; Zhang et al., 2004; Lesschen et al., 2008). Soil quality indicators can be related to soil physical properties and water availability to plants (Murthy, 2007; Bojko and Kabala, 2016). Soil quality can be evaluated by using simple soil parameters in a regular soil survey such as: soil depth, soil texture, erodibility, stoniness, infiltration and soil water content (Holman et al., 2000; Ochoa et al., 2006; Cao et al, 2007; Catherine and Ouiment, 2007; Olarieta et al., 2008; Jemberu et al., 2014).

Generally there is insufficient empirical evidence related to the impacts of bund structure design on soil water conditions and other soil physical properties across different slope classes. The design dimensions of bund structures are irregular for given sets of biophysical and socioeconomic parameters and site-specific conservation strategies are not well developed in Ethiopian highlands. Thus, understanding the actual dimensions of bund structures and how bunds affect soil physical properties and soil hydrology is important to advise SWC specialists and farmers on the design of SWC strategies and persuade farmers 
to effectuate appropriate management of bunds. Therefore, in this study we (i) evaluated the dimensions of newly built bund structures in the field and compared them with advised design dimensions; (ii) measured soil physical properties and soil water capacity for $\sim 5$ year old bunds on different slope classes and (iii) related those to bund width and height classes.

\subsection{Materials and Methods}

\subsubsection{Study area}

Koga catchment, located at $37^{\circ} 02^{\prime}$ to $37^{\circ} 17^{\prime}$ E longitude and $11^{\circ} 10^{\prime}$ to $11^{\circ} 25^{\prime} \mathrm{N}$ latitude, has a total area of $260 \mathrm{~km}^{2}$ and is one of the major watersheds in the Blue Nile basin, Amhara National Regional state (Figure 3.1). Slopes range from nearly level at the lower part of the watershed to up to $50 \%$ in the upper parts of the catchment. The climate of Koga catchment falls within the cool semi-humid (1885-2400 masl) and cool (2400-3135 masl) Ethiopian agro-climatic zones, characterised by distinct dry (November to April) and wet (May to October) seasons. The mean maximum monthly temperature is $30.0^{\circ} \mathrm{C}$ in March to $23.1{ }^{\circ} \mathrm{C}$ in August. The monthly minimum temperature varies from $5.4^{\circ} \mathrm{C}$ in December to $13.1^{\circ} \mathrm{C}$ in May and June.

Fieldwork was carried out in three sub-catchments: $\operatorname{Rim}\left(10.09 \mathrm{~km}^{2}\right)$ in the lower part of Koga catchment, Debreyakob $\left(3.02 \mathrm{~km}^{2}\right)$, located in the middle; and Asanat $\left(7.55 \mathrm{~km}^{2}\right)$, representing the upper part of the catchment (Figure 3.1).

\subsubsection{Soils and hydrology}

The study area drains Koga River to Gilgel/little Abay River, which becomes Blue Nile River when leaving Lake Tana. The Koga catchment is narrow and elongated, with a dense drainage network and highly variable and rugged topography. The area receives high rainfall but about 60 to $76 \%$ of the rain is lost as surface runoff (Jemberu et al., subm). The annual rainfall during the study year (2015) was relatively low $(973.2 \mathrm{~mm}$; compared to $1400 \mathrm{~mm}$ on average between 2010-2014); and was distributed as follows: $64.8 \mathrm{~mm}$ (June), $311.9 \mathrm{~mm}$ (July), $503.1 \mathrm{~mm}$ (August) and $93.4 \mathrm{~mm}$ (September). This distribution shows that the area is subjected to excess rainfall during the short rainy season and prolonged moisture shortage and soil drying during the dry season. Soil erosion is severe and at low-lying bottom slopes sedimentation and flooding are common. The soil types in Koga have been classified as Leptosols, Nitisols, Vertisols, Cambisols, Alisols, Gleysols and Fluvisols. These soils have clay to clay loam texture with exception of Gleysols that has clay to sandy clay loam texture 
(Yeshaneh et al., 2014). Cambisols and Leptosol are poor in fertility and less suitable for crop production and are predominant at the middle and upper parts of the catchment. Yields in the upper part of Koga catchment (in Asanat sub-watershed) are declining due to the decrease in fertility of the soil, increased erosion and ultimately total degradation.

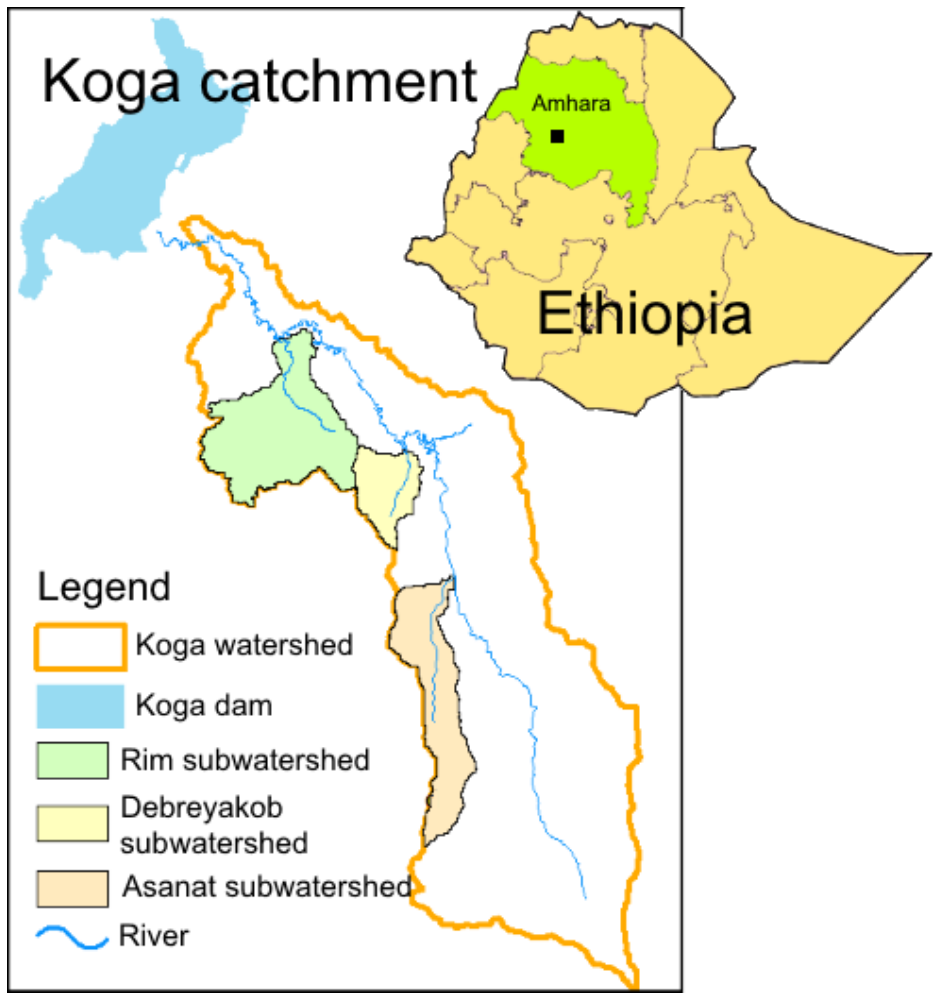

Figure 3.1 Location of study sub-watersheds in Koga catchment

The in situ soil water content was measured indirectly by the automated technique of TDR sensor and directly by thermogravimetric methods in the laboratory. The Pearson correlation coefficient revealed a positive significant $(p=0.01)$ and relatively strong $\left(r^{2}>0.88\right)$ relationship between the two types of soil moisture measurement for all slope classes. Higher variability of soil moisture values measured with the TDR sensor were found, compared to direct measurements of soil moisture, during both dry and wet seasons. The gravimetric measurements were reliable with higher accuracy but costly and tedious as compared to TDR measurements. 


\subsubsection{Soil and water conservation measures}

Bund structures including stone-faced soil bunds, soil bunds, stone bunds and Fanyajuu bunds are widespread conservation strategies in Koga catchment. Stone bunds are implemented mainly on steep slopes where stones are abundant and soil bunds are common on middle and low slope positions where there is limited availability of stones. Stone-faced soil bunds are the most widely applied conservation structures throughout the study area (Figure 3.2). These bund structures have been implemented at variable dimensions of height and width over large areas through community mass mobilizations. Traditional ditches have different sizes, spacing and gradients and are constructed every season by ox plough to dispose excess runoff in farm plots between successive bunds. Recently, integration of biological conservation strategies for stabilization of bund structures and gully treatment with plantation of trees like Sesbania sesban and grass species has become more popular (Jemberu et al., 2018).

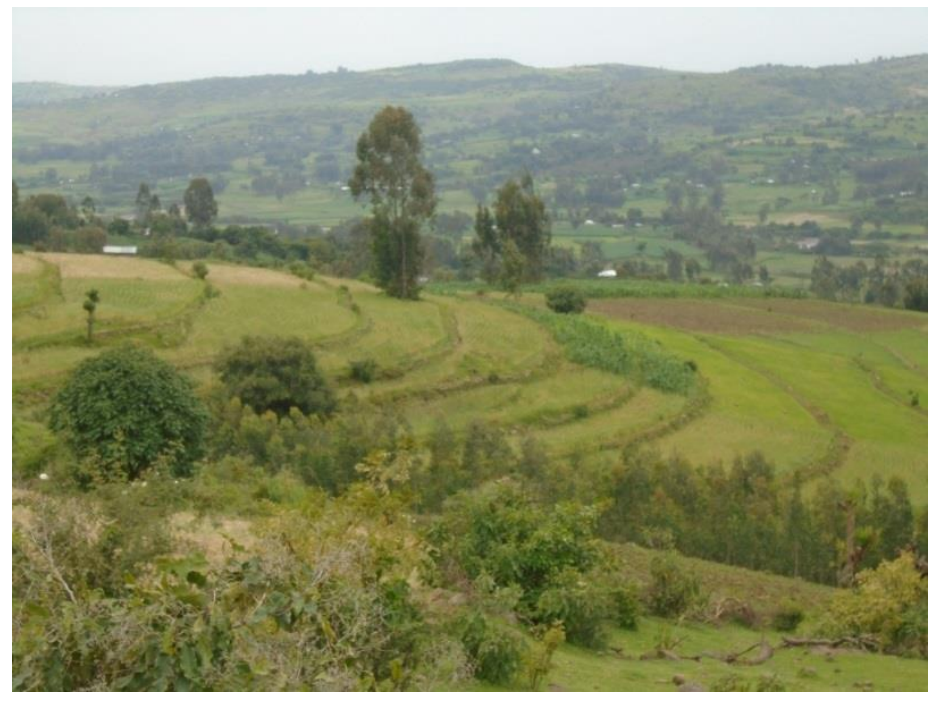

Figure 3.2 Farmland treated with stone-faced soil bunds at Asanat subwatershed (photo taken: 21 September, 2015)

\subsubsection{Field measurements and data collection}

For the first objective, field observation and measurements of the dimensions of newly built stone-faced soil bunds were carried out in the three sub-watersheds to investigate the influence of dimensions of bunds on stability and quality of implementation. Bund dimensions including width, depth, height, vertical interval (VI) and gradient were measured 
for 4 types of bunds at 90 sampling points (Figure 3.3). 120 measurement samples were taken at each of the three slope classes (i.e. 5-10\%, 10-20\% and 20-30\%) leading to a total of 360 sampling points. The measured dimensions were compared to the standard specifications as described in EthioCAT, based on slope steepness, aspect of the land (curvature), soil depth, soil type, land utilisation type and intensity of rainfall. The difference between the observed dimensions of bunds in the field and the recommended standard specifications (SDD) was calculated as:

$\Delta \mathrm{SDD}=\mathrm{Mean} / \mathrm{SDD}$

In which $\triangle S D D$ (dimensionless) is the relative difference between the observed and recommended dimension, Mean is the mean of the observed dimension and SDD is the recommended standard specification (EthioCAT) for a given biophysical condition.

The variation vis-à-vis potential standard measurements, alignment to the watershed (orientation), need of ties, aprons and outlets and current position and stability of bund structures were used to evaluate the design qualities of bunds (Figure 3.3).

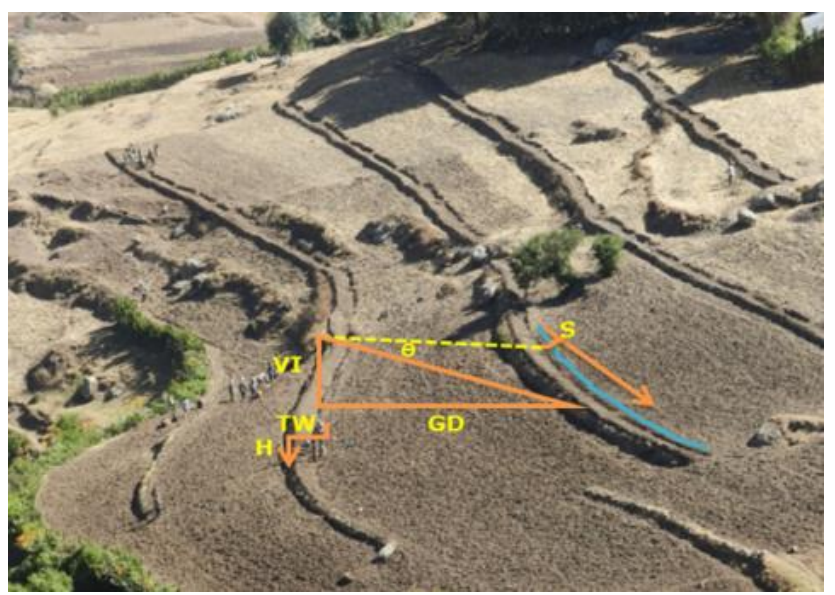

Figure 3.3 Design specifications of newly built stone-faced soil bund at Asanat sub-watershed (photo taken: 12 April, 2015): spacing in terms of vertical interval (VI), front height (H), top width (TW) slope gradient ( $\theta)$, lateral ditch gradient (S) and ground distance (GD).

For the second and third objective, three representative study sites treated with stonefaced soil bunds were selected in each of the three sub-watersheds, each of them located on different slope classes: i.e. steep (20-30\%), moderate (10-20\%) and gentle (5-10\%). Within each study site, stone-faced soil bunds with different widths and heights but on locations with similar land use (cereal cultivation), soils, and vertical interval were selected for comparative analysis. A total of twenty-seven sampling plots were selected (of which 14 
in Asanat, 9 in Debreyakob and 4 in Rim sub-watersheds). Throughout the study area, cultivated plots not treated with SWC measures located adjacent to the treated plots were used as control ('untreated') plots. In all sample sites untreated plots were more stony, degraded and with less vegetation cover as compared with treated farm plots. In all plots, sampling was replicated three times.

A handheld Time Domain Reflectometry (TDR) probe with steel pins was used to measure soil moisture content in the top $20 \mathrm{~cm}$. Soil moisture was measured at $2 \mathrm{~m}$ behind the upper sides of lower bund, at the middle and $2 \mathrm{~m}$ below lower side of the upper bund on the areas between two successive bunds. The soil moisture content was monitored every ten days during the rainy season (June to October, 2014) and occasional measurements were carried out during the dry season (February and March, 2015). Soil depth was measured these sampling points by pitting and auguring. Disturbed and undisturbed core soil samples were collected at $2 \mathrm{~m}$ behind the lower bund on the area between two successive bunds (i.e. at the lower TDR measurement point 0-20 cm depth). A total of 153 disturbed and 153 undisturbed core samples were collected for the determination of soil physical properties (see below).

\subsubsection{Laboratory analysis}

The disturbed samples were thoroughly mixed, air-dried and passed through a $2 \mathrm{~mm}$ sieve for analysis of particle size distribution and organic carbon. The undisturbed core samples were oven-dried for 24 hours at $105^{\circ} \mathrm{C}$ for the determination of bulk density, porosity and soil water capacity using standard procedures as follows.

The soil water content (\% vol) was determined using:

$\theta=M_{w} / V_{t}=\rho b *\left(M_{w} / M_{s}\right)$

Where:

$\theta=\quad$ Volumetric water content $(\%$ vol)

$\mathrm{M}_{\mathrm{w}}=$ Mass of water $(\mathrm{g})$

$\mathrm{M}_{\mathrm{s}}=\quad$ Mass of dried soil sample $(\mathrm{g})$

$V_{t}=$ Volume of wet soil sample $\left(\mathrm{cm}^{3}\right)$

$\rho b=$ Bulk density $\left(\mathrm{g} / \mathrm{cm}^{3}\right)$

Soil water storage (SWS; $\mathrm{mm} / \mathrm{m}$ ) reflects the water stored in the soil and was calculated as: 
SWS $=\theta^{*} \mathrm{D}$

Where:

$\theta=\quad$ Volumetric water content $(\%$ vol)

$D=$ soil depth $(m)$

The porosity was calculated by:

$\mathrm{e}=1-\rho \mathrm{b} / 2.65$

Where: e is porosity (\%vol) and 2.65 is the default density of particles of soil with no pore space (particle density $\left.\left(\mathrm{g} / \mathrm{cm}^{3}\right)\right)$.

Infiltration rate was estimated based on particle size distribution (silt and clay content), bulk density, organic matter (OM) and moisture content of the soil following Rashidi et al. (2014). A five-variable linear regression model was used to predict soil infiltration rate (Eq. 5). The soil infiltration rate values were compared to infiltration rate values measured by field tests and the infiltration prediction model has provided an easy, economic and brief method to predict soil infiltration rate (Rashidi et al., 2014). In this study, the particle size distributions were determined using the hydrometer (Van Reeuwijk, 2002) and the organic matter (OM) was determined by the Walkley and Black (1994) method.

$\mathrm{I}=28.13-0.22(\mathrm{SI})-0.518(\mathrm{CL})+4.592(\rho \mathrm{b})-1.44(\mathrm{OM})+0.022(\theta)$

Where:

$I=\quad$ Infiltration rate $(\mathrm{mm} /$ hour $)$

$\mathrm{SI}=\quad$ Silt content $(\%)$

$\mathrm{CL}=$ Clay content $(\%)$

$\rho \mathrm{b}=$ Bulk density $\left(\mathrm{g} / \mathrm{cm}^{3}\right)$

$\mathrm{OM}=$ Organic matter $(\%)$

Erodibility is defined as the amount of soil that is detached relative to the detaching agent and was derived from the RUSLE model (Hudson, 1993):

$\mathrm{K}=2.77 \times 10^{-6} \mathrm{M}^{1.14}(12-\% \mathrm{OM})+0.043(\mathrm{~S}-2)+0.033(4-\mathrm{P})$

Where:

$\mathrm{K}=$ erodibility

$M=(\%$ silt $+\%$ fine sand $)(\%$ silt $x \%$ sand $)$ 
$\mathrm{OM}=\%$ organic matter

$\mathrm{S}$ and $\mathrm{P}$ are field determined average values of aggregate/structure and permeability classes with,

$S=$ Aggregate/structural class (1-4); 1 for very fine, 2 for fine, 3 for medium coarse, 4 for massive structure respectively; and

$P=\quad$ Permeable class [1-6] ; 1 for fast, 2 for fast to moderate, 3 for moderate, 4 for low to moderate, 5 for low, and 6 for very low permeability respectively.

\subsubsection{Data Analysis}

For the first objective, the coefficient of variation (CV) and standard error of means were used as statistical tools of analysis to compare the dimensions of actual bunds to the EthioCAT standard and derived specifications.

For the second and third objective, the soil laboratory data were statistically analysed by analysis of variance (ANOVA) and Tukey's HSD (honest significant differences) was applied as a single-step multiple comparison procedure. A generalized linear model was used taking soil data as dependent variables and spacing, heights and widths of bunds, and slope of the land as fixed factors to evaluate the impacts of bund dimensions on soil physical properties. The model was evaluated by a likelihood ratio test to decide whether to retain or reject interaction of fixed factors in the model. In order to test the correlation of the different soil properties a bivariate correlation analysis or the Pearson's correlation coefficient (PCC) was computed in SPSS version 23. For the analysis of the design specifications and stability of bund structures, descriptive statistics were used.

\subsection{Results and Discussion}

\subsubsection{Dimensions of bund structures}

Field measurements showed widely variable dimensions of bund heights, widths, basin width and depth, and spacing across the landscape. Improperly large and undesirably small bund structures were observed on various farms; e.g. bunds $<25 \mathrm{~cm}$ and $>2.5 \mathrm{~m}$ in top widths, and $<20 \mathrm{~cm}$ and $>1.27 \mathrm{~m}$ in heights were measured on different slope categories. The observed dimensions were inconsistent with design specifications for given biophysical conditions like slope, soils, land utilisation types and rainfall (Table 3.1). On some locations, the spacing between two graded bunds was found to be too wide to dispose the excess 
runoff volume at non-erosive velocity and hence the bunds were exposed to overtopping and initiation of gully development, while on other locations the spacing between two bunds was too narrow leading to wastage of land and labour.

Table 3.1 Characteristics of sampled bund structures $(n=360)$, recommended dimensions (SDD, EthioCAT) and deviations from the recommended dimensions (in meters unless otherwise stated)

\begin{tabular}{|c|c|c|c|c|c|c|c|c|}
\hline Slope (\%) & Dimensions* & Minimum & Maximum & Mean & $\mathrm{SD}^{* *}$ & $\mathrm{CV}^{* *}$ & SDD** & $\triangle \mathrm{SDD}^{* *}$ \\
\hline \multirow{6}{*}{$5-10$} & TW & 0.24 & 2.85 & 1.31 & 0.68 & 0.52 & 0.45 & 2.91 \\
\hline & $\mathrm{H}$ & 0.26 & 1.26 & 0.83 & 0.23 & 0.28 & 0.45 & 1.84 \\
\hline & VI & 0.48 & 4.70 & 1.72 & 1.14 & 0.66 & 1.50 & 1.15 \\
\hline & BW & 0.34 & 2.30 & 1.19 & 0.56 & 0.47 & 0.45 & 2.64 \\
\hline & $\mathrm{D}$ & 0.27 & 1.20 & 0.72 & 0.29 & 0.40 & 0.55 & 1.31 \\
\hline & $S$ & 0.00 & 4.50 & 2.74 & 1.04 & 0.38 & 0.75 & 3.65 \\
\hline \multirow{6}{*}{$10-20$} & TW & 0.50 & 2.54 & 1.53 & 0.58 & 0.38 & 0.68 & 2.25 \\
\hline & $\mathrm{H}$ & 0.18 & 1.28 & 0.70 & 0.33 & 0.47 & 0.46 & 1.52 \\
\hline & VI & 0.40 & 4.50 & 2.04 & 1.02 & 0.50 & 1.75 & 1.17 \\
\hline & BW & 0.32 & 2.8 & 1.18 & 0.63 & 0.54 & 0.45 & 2.62 \\
\hline & $\mathrm{D}$ & 0.20 & 0.95 & 0.67 & 0.16 & 0.24 & 0.55 & 1.22 \\
\hline & $S$ & 0.00 & 5.60 & 2.10 & 1.71 & 0.81 & 0.75 & 2.80 \\
\hline \multirow{6}{*}{$20-30$} & TW & 0.62 & 2.75 & 1.55 & 0.53 & 0.34 & 0.75 & 2.07 \\
\hline & $\mathrm{H}$ & 0.53 & 1.22 & 1.01 & 0.28 & 0.28 & 0.55 & 1.84 \\
\hline & VI & 0.72 & 5.1 & 2.25 & 1.33 & 0.59 & 2.5 & 0.90 \\
\hline & BW & 0.54 & 2.8 & 1.33 & 0.55 & 0.42 & 0.5 & 2.66 \\
\hline & D & 0.48 & 0.95 & 0.82 & 0.13 & 0.16 & 0.5 & 1.64 \\
\hline & $S$ & 0.00 & 5.40 & 1.94 & 1.14 & 0.59 & 0.75 & 2.59 \\
\hline
\end{tabular}

* TW- top width, $\mathrm{H}$ - front height, VI- vertical interval, BW- bottom width, D- average basin depth, S- lateral bund gradient

** SD- standard deviations; CV-coefficient of variation, SDD-required standard dimension (EthioCAT and derivations), $\triangle \mathrm{SDD}=$ ratio between observed and recommended SDD

The closer the $\triangle S D D$ to 1 , the closer the observed dimensions are to the recommended dimensions. As can be seen, all dimensions, in each slope category, are larger than recommended ( $\triangle S D D s>1$ ) except for the vertical interval in the steepest slope category. The vertical interval $(\mathrm{VI})$ is closest to the recommended values for all slope classes, while the bund gradient deviated most. Comparing between slope classes, the lateral ditch gradient is slightly closer to the recommended value for steeper slope classes, but still more than 2.5 times larger. The observed high CV (often $>0.5$ ) indicates high levels of variability in dimensions of bund structures. Especially for vertical interval (VI) and lateral ditch gradient $(S)$, variation in the observed dimensions is high on all slope classes. 
Stone-faced soil bunds with top widths $>50 \mathrm{~cm}$ and heights of $60-75 \mathrm{~cm}$ were observed to be comparatively well stabilised and good in resisting runoff and controlling soil loss, and were accepted by farmers on medium and higher slope classes (Jemberu et al., subm). According to Yeshaneh et al. (2014) the average specific sediment yield of Koga at the outlet of Koga river is about $25 \mathrm{t} / \mathrm{h} / \mathrm{yr}$. However, annual soil erosion rates by rill and gully erosion were estimated at 38.3, 29.5 and $33.7 \mathrm{t} / \mathrm{ha}$ at Asanat, Debreyakob and Rim sub-watersheds respectively (Jemberu et al., 2017).

Even though the technical specifications and design of physical conservation structures are well described in the manual and communicated through trainings, it has been observed in various watersheds that extension agents did not comply with the advised sizes of bunds, gradient of the ditches of graded bunds and the VI between two bunds (Herweg et al., 2006). Note that, even though we compare the observed dimensions with the standards advised by EthioCAT, we do not assume these standards to be necessarily the correct ones, but they were developed as good guidelines for Ethiopia and do provide a baseline reference. SWC structures were designed and implemented on various farms based on only land use and slope which may not serve the intended purpose. Attention is rarely given to site-specific characteristics when entire catchments are being treated through SWC campaigns and uniform layout of SWC structures and inflexibility of untrained extension staff, often combined with unwillingness to maintain SWC measures, literally invite technical problems (Danano, 2002; Herweg et al., 2006). According to Volli (2002), too narrowly spaced physical SWC structures lead to a reduction in cropland by occupying 8$12 \%$ of the potential cropping area in Ethiopian highlands. According to Development Agents and SWC specialists, design quality is not a criterion for evaluation of their achievement, but the quantity of work ( $\mathrm{km}$ or ha of bunds) is. Due to the short time of implementation and high labour demand nature of physical conservation measures, most of the time they focused on achievement of plans.

Closely spaced and relatively high structures were observed on steep slopes and the bund height differences resulted in soil depth gradients across the landscape. However, most of the bund structures in Koga catchment were in the process of benching and not stabilised accurately. The slope gradient measurements between the edges of lower and upper embankments of five year old stone-faced soil bunds indicated $10.7 \%$ to $28.4 \%$ slope, while slopes were expected to be virtually level within 5-7 years. The goal of bunds as mechanical conservation strategy is to change the natural length and steepness of the slope to benches and thereby to control runoff and soil loss (Danano, 2002; Gebrernichael et al., 2005; Nyssen et al., 2007; Tilahun et al., 2013). However, due to poor design and maintenance, sedimentation did not yet result in the development of bench terraces. According to 
Dagnew et al. (2016), sedimentation in bench terraces is usually low in Ethiopian highlands because of high infiltration rates.

Field observations revealed that bund structures have been widely implemented in Koga catchment but that most of the structures were not well stabilised. Water logging and runoff-overtopping hazards were the undesirable impacts of unstable level bunds. The stability of bund structures depends on various factors such as slope, design quality, construction material and support of physical structures by biological measures and appropriateness of the structures to the site conditions (Zhang et al., 2004; Olarieta et al., 2008; Dagnew et al., 2016). The stability of bunds was also influenced by other design requirements on the farm like the need for ties, drainage outlets and aprons. In general, for appropriate design of the SWC structures, both the local biophysical conditions as well as the farmers' perspectives must be taken into account during planning processes. If the technical specification and farmers' interest confront, the best compromise should be to then consult the local community and modify the dimensions and spacing between the structures as requested by the local conditions. For example for wider spacing, broader and higher structures would be applicable as the VI between two successive bunds should not be greater than two times the average soil depth between bunds in order to attain both protective and productive functions which are prerequisites to ensure sustainability (Betru, 2002; Nyssen et al., 2007; Jemberu et al., subm). However, as can be deducted from Table 3.1, bunds in Koga catchment were relatively well spaced (i.e. $\triangle$ SDD relatively close to 1 ), while their widths and heights deviated much more from the recommended values. It seems, therefore, that unnecessarily high and wide bunds have been constructed for the spacing that they were given.

\subsubsection{Soil physical properties between bunds on different slope classes}

The implementation of stone-faced soil bunds modifies the terrain condition by changing the natural length and degree of slope. Consequently, bund structures influence the soil physical properties and hydrology by changing the soil erosion and deposition processes. Accordingly, soil physical characteristics and hydrology were significantly different across the slope of the terrain (Table 3.2).

The analysis of infiltration rate and soil moisture content showed significantly higher values for treated farm lands than untreated cultivated farm plots. The statistical analysis also revealed that porosity, soil moisture contents, depths and infiltration rates showed significant differences between the bunds on lower, middle and upper slope classes. Soils 
in all fields with bunds on gentle and moderately steep slopes have a significantly higher soil moisture content than those on steep slopes (Table 3.2).

Table 3.2 Soil physical properties in inter-bunds space having different slopes

\begin{tabular}{lllllll}
\hline $\begin{array}{l}\text { Slope } \\
(\%)\end{array}$ & $\begin{array}{l}\text { Bulk density } \\
\left(\mathrm{gm} / \mathrm{cm}^{3}\right)\end{array}$ & Erodibility & Porosity & $\begin{array}{l}\text { AWC } \\
(\% \mathrm{VO})\end{array}$ & $\begin{array}{l}\text { Depth }(\mathrm{m}) \\
\text { (mm/hour) }\end{array}$ \\
\hline $5-10$ & $1.34^{\mathrm{a}}$ & 0.37 & $0.41^{\mathrm{a}}$ & $26.09^{\mathrm{a}}$ & $1.11^{\mathrm{a}}$ & $26.85^{\mathrm{a}}$ \\
$10-20$ & $1.42^{\mathrm{b}}$ & 0.41 & $0.37^{\mathrm{b}}$ & $23.05^{\mathrm{b}}$ & $0.88^{\mathrm{b}}$ & $25.40^{\mathrm{b}}$ \\
$20-30$ & $1.42^{\mathrm{b}}$ & 0.40 & $0.33^{\mathrm{c}}$ & $20.11^{\mathrm{c}}$ & $0.68^{\mathrm{c}}$ & $20.78^{\mathrm{c}}$ \\
\hline \multicolumn{7}{l}{ Different letters indicate statistically significant differences at $95 \%$ confidence level (Tukey HSD). }
\end{tabular}

The higher silt content was measured in soils on lower and medium sloping terrain. This may be due to erosion and sedimentation processes as coarser material may be expected to remain on uplands, while fine-textured material would be preferably deposited in the downslope positions (Wu et al., 2012; Dagnew et al., 2015; Tebebu et al., 2015). According to Olarieta et al. (2008), the use of physical conservation measures modifies terrain conditions by changing slope angle and length, and thereby slows down the soil texture change caused by erosion.

The impacts of bund height on infiltration rate and soil moisture content decreased toward the upslope terrain position in treated farmlands. This is to be expected; e.g. according to Flanagan and Johnson (2005), due to topographic influences, soil water could be drained down the soil profile easily by gravity or high sub-surface flow water, which may cause lower soil water content in relatively moderately steep and steep slopes. Hamza and Anderson (2002) stated that at the beginning of bund implementation the basins excavated at the upper side of the embankments not only reduce the energy of incoming runoff but also serve as storage tank for sediment-loaded runoff. Consequently, the water retained behind the embankment would have adequate time to deliver the sediment and infiltrate into the soil. It was observed that the design dimensions affected soil management activities, biological integration and maintenance strategies leading to differences in stability of bunds. This affected soil-water storage and overall soil quality differences in cultivated farm plots between successive bunds (Dagnew et al., 2016). 


\subsubsection{The effect of bund width}

The results of the analysis of the soil physical properties measured between the stone-faced soil bunds with variable widths are presented in Table 3.3. The statistical analysis revealed that soil depth was significantly different between all width classes and also compared to the control situation without bunds. Soil bulk density was highest in the control plots and significantly lower in fields with both small bund widths $(25-55 \mathrm{~cm})$ and larger bund widths $(>85 \mathrm{~cm})$. Erodibility was not very different between different bund width classes. Soil porosity was found to be significantly higher in fields with larger bund widths as compared to fields with narrow bund widths or without bunds (Table 3.3). Soil water content and infiltration rate were both significantly lower in untreated plots and plots with small bund widths than in fields with wider bunds.

Table 3.3 Soil physical properties in inter-bunds space having different widths of bunds

\begin{tabular}{|c|c|c|c|c|c|c|}
\hline $\begin{array}{l}\text { Bund Width } \\
(\mathrm{cm})\end{array}$ & $\begin{array}{l}\text { Bulk density } \\
\left(\mathrm{gm} / \mathrm{cm}^{3}\right)\end{array}$ & Erodibility & Porosity & $\begin{array}{l}\text { AWC } \\
\text { (\%VOL) }\end{array}$ & Depth (m) & $\begin{array}{l}\text { Infiltration rate } \\
\text { (mm/hour) }\end{array}$ \\
\hline $25-55$ & $1.38^{b}$ & $0.42^{a}$ & $0.37^{a}$ & $20.2^{a}$ & $0.73^{b}$ & $21.6^{a}$ \\
\hline $55-85$ & $1.44^{c}$ & $0.40^{\mathrm{ab}}$ & $0.33^{a}$ & $21.4^{\mathrm{b}}$ & $0.89^{c}$ & $24.2^{\mathrm{b}}$ \\
\hline $85-120$ & $1.34^{\mathrm{b}}$ & $0.42^{a}$ & $0.42^{\mathrm{b}}$ & $26.3^{c}$ & $1.08^{d}$ & $26.3^{c}$ \\
\hline $120-175$ & $1.28^{\mathrm{a}}$ & $0.36^{b}$ & $0.44^{b}$ & $26.8^{c}$ & $1.22^{\mathrm{e}}$ & $27.2^{\mathrm{c}}$ \\
\hline Control* & $1.50^{c}$ & $0.36^{b}$ & $0.31^{a}$ & $19.0^{\mathrm{a}}$ & $0.52^{a}$ & $19.2^{\mathrm{a}}$ \\
\hline
\end{tabular}

* 'Control' refers to the soil properties measured on farms not treated with any SWC measures. Different letters indicate statistically significant differences at 95\% confidence level (Tukey HSD).

Many aspects of the structural functions of soils are shown to be critically dependent on soil porosity which also provides an environment in which soil microorganisms live who contribute to the turnover of carbon and some of the major nutrients in the soil (Chambers and Garwood, 2000). A study by Rasool et al. (2007) indicated that bund implementation resulted in particle size distribution, porosity, bulk density and land use (cover) changes across the slope of the terrain. According to Chen et al. (1997), soil erosion and deposition processes modify soil physical characteristics across a landscape. The difference in effectiveness of bunds to control runoff and soil loss and modification of the landscape is attributed to variations in bund dimensions; in turn, affecting soil physical properties and hydrology.

Hamza and Anderson (2002) and Rasool et al. (2007) showed that soil-water movement influences the soil physical properties, root penetration and nutrient uptake by plants. For stabilization of bunds, agronomic and/or biological management strategies have been used as an integral part of conservation- based interventions (Betru, 2002). These management strategies were found to be related to and affected by the design specifications of bund structures and influenced the physical qualities of soils (Jemberu et al., subm). Therefore, the changes in bulk density and porosity for different widths of bunds may be attributed to 
the subsequent processes of erosion and deposition as well as the management or treatment activities on the soils during and after the application of bunds. Effects tend to vary with the dimensions of bunds which are also directly or indirectly related to their spacing. The differences in erodibility between bunds with different top widths were relatively small (Table 3.3).

The laboratory and field TDR soil moisture measurements showed significantly higher soil moisture content for soils in between bunds with larger widths. The statistical analysis revealed significantly different infiltration rate and soil moisture content of soils with different widths of bund structures (Table 3.3). Soils in between bunds with top widths $>55$ $\mathrm{cm}$ were found to have significantly higher infiltration rates and soil moisture contents than soils in between bunds with smaller top widths or untreated farm plots. Soil moisture content was higher on treated cultivated farm lands than on untreated plots. As a result, the use of bund structures played an important role in enhancing water conservation in the watershed.

The variations in soil water conditions between widths of bund structures could be attributed to variations in runoff and erosion processes in the catchment as a result of changes in stability and effectiveness of bund structures. Wider bund structures are more impermeable and stable to resist runoff and sediment transport than smaller structures. The difference in soil water storage is also attributed to the differences in soil physical characteristics between the widths of bunds. The TDR field soil moisture monitoring during the 2015 rainy season and derived soil water storage indicated that bunds enhance soil water storage significantly (Figure 3.4) and this was observed to be affected by the stability of bunds and their effectiveness in controlling runoff and soil erosion.

According to Wang et al. (2014) physical SWC measures change the natural length of the slope profile, the biophysical characteristics of the catchment and altered the hydrological cycle and quantity of water that is available to runoff water and stream flow. A study by Moutier and Shainberg (2000) suggested that the lower infiltration was attributed to higher loss of rainfall in the form of surface flow. Thus the differences in infiltration rate of soils between bunds could be related to differences in dimensions of bunds that affect the effectiveness of bunds in controlling rainfall loss in the form of runoff. The variation in soil water storage between widths of bunds may be attributed to the differences in soil depth and bulk density between bund structures which were highly influenced by the design qualities during bund implementation. Soil depth increased sharply with different bund widths, and all classes were significantly different from each other. Stone bunds enhance soil water storage on both sides of the bund, especially on loamy and sandy soils. The effect 
is important at greater depth of soil (1-1.5 m), where soil moisture persists for a few months after the end of the rainy season (Vancampenhout, et al., 2006; Jemberu et al., 2014).

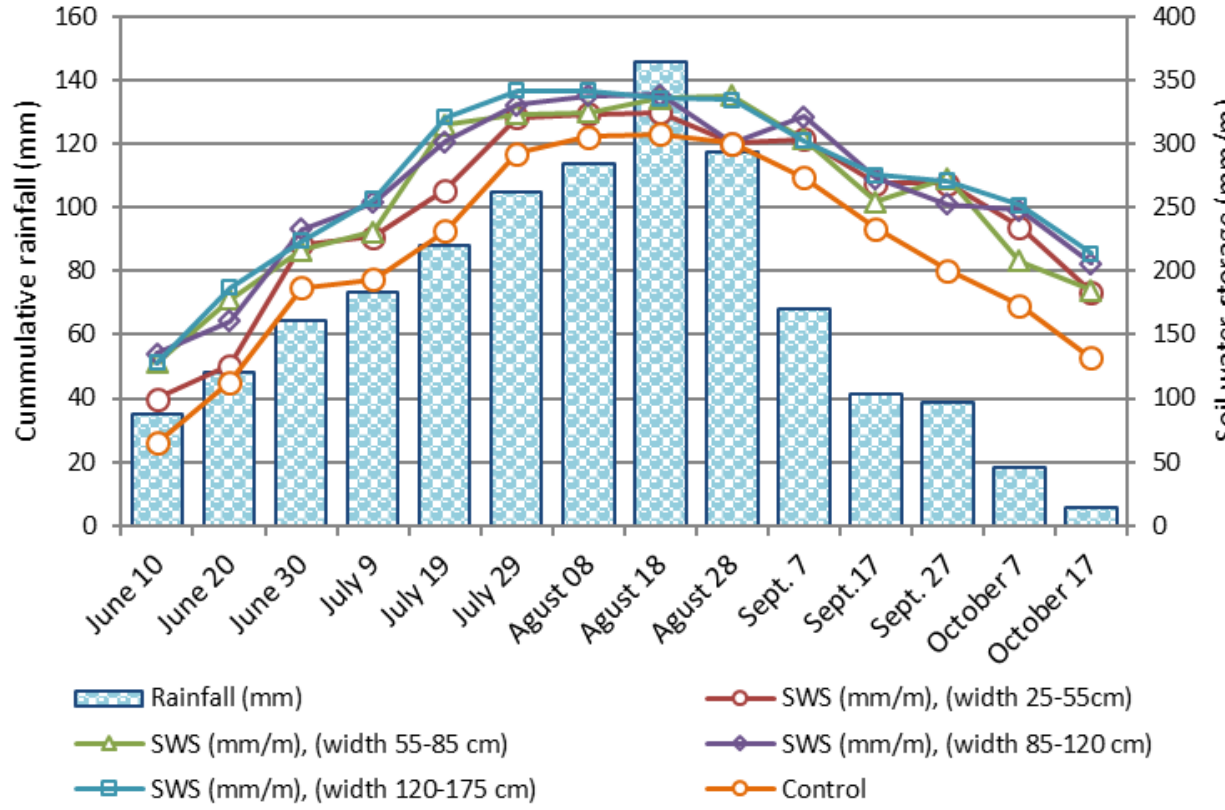

Figure 3.4 The variation of soil water storage in relation to rainfall and widths of bunds for the rainy season of 2015.

\subsubsection{The effect of bund height}

Table 3.4 shows the differences in soil properties in relation to bund height. Similar to the results for bund width classes, also here bulk density decreased with increasing bund height and soils in fields with bund heights $>55 \mathrm{~cm}$ are significantly different from soils in fields with lower bunds or without bunds. Erodibility showed an irregular trend and limited significant difference between the heights of bunds was found. Soil porosity was generally higher in fields with higher bunds, but not statistically significant. Similar to results for bund width classes, also here the soil water content and infiltration rate were significantly higher on fields with higher bunds (> $55 \mathrm{~cm}$ ) as compared to fields with low bunds or untreated fields. Finally, soil depth was found to increase with bund height, with soils in fields with bunds higher than $75 \mathrm{~cm}$ even reaching twice the soil depth as compared to fields with low bunds or without bunds. 
Table 3.4 Soil properties in inter-bund soils with different bund height classes

\begin{tabular}{|c|c|c|c|c|c|c|}
\hline $\begin{array}{l}\text { Bund Height } \\
\text { (cm) }\end{array}$ & $\begin{array}{l}\text { Bulk density } \\
\left(\mathrm{gm} / \mathrm{cm}^{3}\right)\end{array}$ & Erodibility & Porosity & $\begin{array}{l}\text { AWC } \\
\text { (\%VOL) }\end{array}$ & Depth (m) & $\begin{array}{l}\text { Infiltration rate } \\
\text { (mm/hour) }\end{array}$ \\
\hline $30-55$ & $1.50^{\mathrm{a}}$ & $0.45^{a}$ & $0.37^{b}$ & $22.0^{\mathrm{ab}}$ & $0.76^{\mathrm{ab}}$ & $23.2^{\mathrm{ab}}$ \\
\hline $55-75$ & $1.44^{b}$ & $0.44^{\mathrm{ab}}$ & $0.32^{\mathrm{a}}$ & $23.3^{b}$ & $0.78^{b c}$ & $25.1^{\mathrm{bc}}$ \\
\hline $75-110$ & $1.35^{\mathrm{c}}$ & $0.42^{\mathrm{ab}}$ & $0.41^{c}$ & $23.8^{b}$ & $0.93^{c}$ & $26.6^{c}$ \\
\hline $110-140$ & $1.34^{c}$ & $0.42^{b}$ & $0.42^{c}$ & $26.2^{c}$ & $1.29^{d}$ & $30.9^{d}$ \\
\hline Control & $1.49^{a}$ & $0.43^{a b}$ & $0.38^{b c}$ & $18.5^{a}$ & $0.53^{a}$ & $19.2^{\mathrm{a}}$ \\
\hline
\end{tabular}

In the study site, it was observed that bunds implemented 5-7 years ago were spaced relatively wider and were relatively smaller in size as compared to newly implemented bunds. Farmers did not maintain the bunds as required and the benching process is very slow. The slope gradients measured across the bund structures in the study site for seven years old bunds were very high (average 16.2 to $27.5 \%$ ) and the natural length of the slope was not transformed as expected. The high variation in soil depth and limited benching processes between bunds indicated lower design quality and impacts of bund structures on soil water storage and soil physical characteristics in the studied sub-watersheds. The moisture contents of soils in between higher bunds were found to be statistically significantly $(p<0.05)$ higher than those between lower bunds. The statistical analysis showed significantly higher infiltration rates for soils in between higher bunds on treated farmlands (Table 3.4). The results indicate that the impacts of heights of bunds on infiltration and soil water content were relatively higher as compared to the impacts of widths of bunds (Table 3.3 and 3.4) in the study sites.

When rainfall exceeds the infiltration rate, a large part of the rainfall will become run off and any factor that reduces the runoff rate increases the likelihood of water to infiltrate (Rasool et al., 2007; Bojko and Kabala, 2016). Being a dynamic property, the infiltration rate of soils is mostly affected by soil surface conditions, which vary with crop management, tillage practices and soil and water conservation measures (Zeleke, 2000; Rasool et al., 2007; Tilahun et al., 2013; Bojko and Kabala, 2016; Tilahun et al., 2016). Hence, the most successful method to maintain the soil moisture content under most circumstances is increasing the infiltration rate of the soil by reducing the loss of rainfall in the form of runoff. Therefore, effective bund structures with appropriate design dimensions are an important strategy to maintain soil moisture especially during dry spells. 


\subsection{Conclusions}

Despite widespread implementation of bunds in the field, the effect of bund structure design on soil physical properties and hydrology is not well documented. The principle of implementation of bunds, across the slope of the land, is to reduce the rate of surface runoff and to decrease the losses of soil and water and increase the fertility status of soils in cultivated lands. The stability of bund structures depends on various factors such as slope, design quality, construction material and support of physical structures by biological measures and appropriateness of the structures to the site conditions. Field investigation in Ethiopia of newly built bund structure dimensions showed that the dimensions of bunds varied widely and that they were often not according to the local guidelines as described in EthioCAT. In general, a trend of wider and higher bunds with wider spacing than recommended by EthioCAT was observed. Wider bund structures were more impermeable and stable to resist runoff and sediment transport than smaller structures. Soil sample analysis of samples taken between older bunds across different slope categories showed that soils in fields with wider bunds had higher soil porosity, infiltration rate and soil moisture content compared to soils in fields with narrow bunds. Infiltration rate and soil moisture content increased with increasing height of bund structures. The bulk density showed lower values for medium and higher heights of bunds. The impacts of bund height on infiltration rate and soil water content decreased towards the upslope terrain positions in treated farmlands. Soil hydrology and physical soil properties were further influenced by the maintenance and integration strategies, soil management, and treatment activities. The significant differences in soil-water storage and other soil physical properties, as found in this study, in croplands treated with bunds are beneficial for long-term sustainability of crop production. Bund structure design should be adapted to local biophysical settings at catchment level to enhance on- and offsite impacts. 


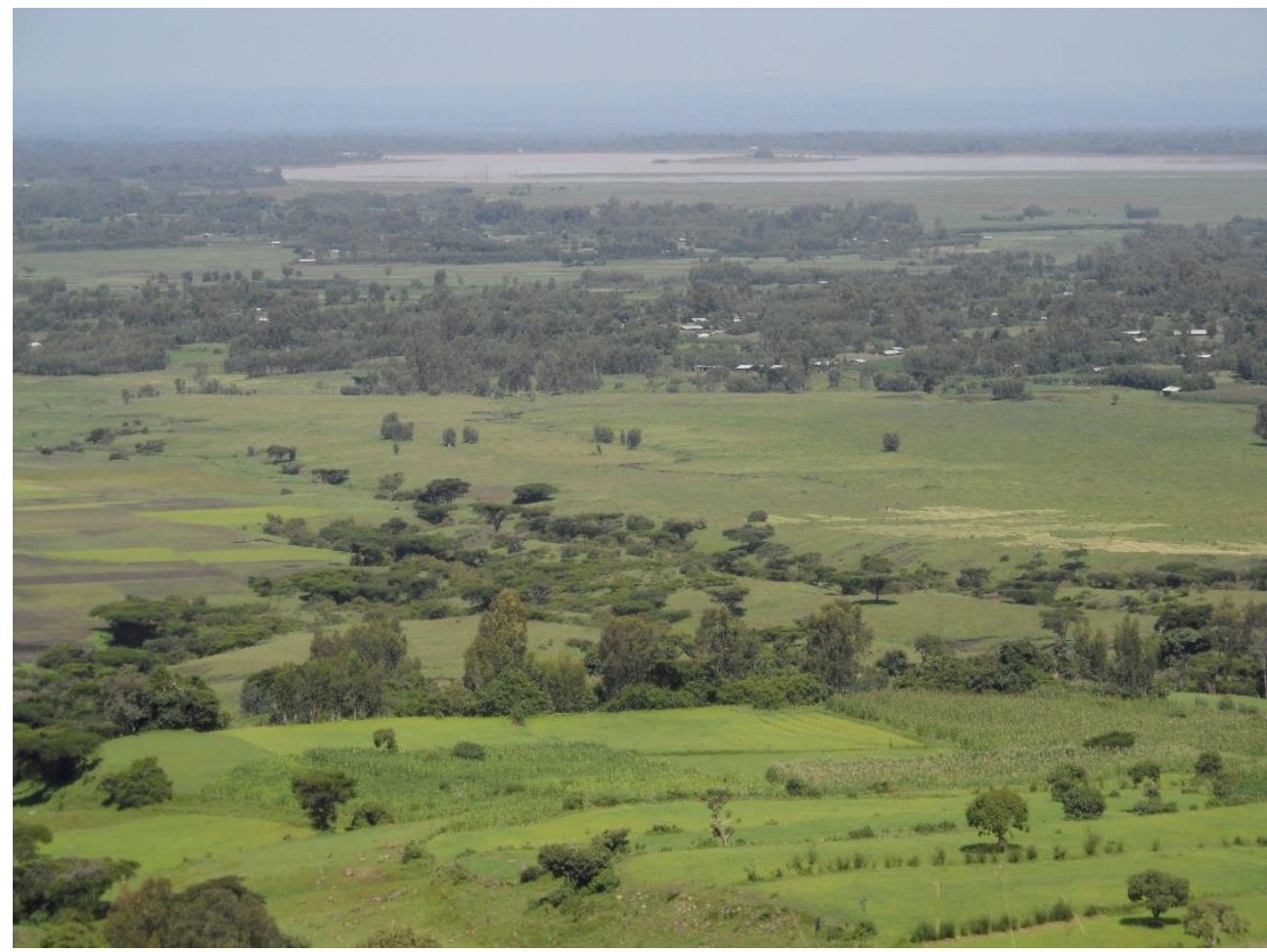




\section{Magnitudes and dynamics of runoff and sediment yield: an in-depth analysis of hydrological responses of three sub- watersheds in the Ethiopian highlands}

Regardless of the fact that soil loss, flooding and sedimentation are critical problems in the sub-humid Ethiopian highlands, lack of adequate datasets has inhibited the understanding and effective management of runoff and sediment detachment and transport. In this study, quantitative relationships were established among rainfall features, runoff characteristics and sediment yield patterns measured during 2014-2015 in Asanat, Debreyakob and Rim sub-watersheds of Koga catchment, North-Western Ethiopia. Multiple regression models were developed to predict sediment discharge using daily data on: rainfall, 10-minute maximum rain intensity, average rain intensity, suspended sediment concentration (SSC) and runoff discharge. Very strong seasonal and event variability in rain intensity, runoff and sediment yield was observed in all subwatersheds. The rain intensity was found to be the strongest predictor of sediment discharge. Area specific sediment yield was 35.6, 24.4, and $31.7 t h^{-1} y^{-1}$ for Asanat, Debreyakob and Rim sub-watersheds and did not show scale dependency. The importance of individual events was very high and more than 53\% of the total annual sediment load was produced by the five largest events. Runoff and SSC event analysis during different seasons showed four different types of hysteresis: clockwise and linear (mainly for early rain season), complex and negative for middle and late rainy season. This indicates the complex and heterogeneous nature of runoff and sediment source area and yield response of the study sub-watersheds. Also, a striking trend of decreasing SSC with time was observed, unrelated to the increasing runoff and rainfall. Thus, hydrological and sediment response to rainfall is highly variable and dynamic in these Ethiopian catchments.

Based on:

Jemberu, W., Baartman, J., Fleskens, L., G.Selassie, Y., Ritsema, C.J. Magnitudes and dynamics of runoff and sediment yield: an in-depth analysis of hydrological responses of three sub-watersheds in the Ethiopian highlands. Hydrological Processes (to be resubmitted). 


\subsection{Introduction}

Despite many years of effort to reduce their effects, soil erosion and sedimentation remain critical problems in the Ethiopian highlands (Girmay et al., 2009; Setegn et al., 2009). In addition, water storage is declining and droughts are becoming more frequent and intense (Zeleke and Hurni, 2001; Hurni et al., 2005; Tessema, 2006; Setegn et al., 2009; Tilahun et al., 2015). Soil erosion causes not only on-site degradation of land resources but also offsite problems such as downstream sedimentation and deposition in fields, flood plains and water bodies (Zeleke and Hurni, 2001; Hurni et al., 2005; Yeshaneh et al., 2014). Soil erosion, besides having significant impact on the productivity of cultivated land, also adversely affects chemical, physical and biological functions of soil leading to eutrophication of surface water resources and environmental pollution (Hurni et al., 2005; Wudneh, 2012; Tilahun et al., 2013; Van Beek et al., 2017). Loss of top soil and subsequent silting up of reservoirs degrades the environmental resources necessary for subsistence (Steenhuis et al., 1995; Hudson, 2003; Nyssen et al., 2009; Dagnew et al., 2015). This problem extends to downstream countries of Sudan and Egypt because the Blue Nile drains the Ethiopian highlands and contributes to sedimentation of downstream resources (Tessema, 2006; Nyssen et al., 2008; Bayabil et al., 2010; Setegn et al., 2010; Tilahun, 2012; Lakew et al., 2014).

Soil erosion and sedimentation rates are highly variable in response to climate and human influence in the highlands of Ethiopia (Tessema, 2006; Nyssen et al., 2008; Tebebu, 2009; Bayabil et al., 2010; Nyssen et al., 2010; De Vente et al., 2013; Gessesse, 2014). For example, Vanmaercke et al. (2010) indicated high variability and uncertainty in runoff and sediment yield in Northern Ethiopian highlands. Haregeweyn et al. (2008); Bayabil et al. (2010) and Guzman et al. (2013) reported the variability in effectiveness of SWC measures in controlling runoff, erosion and sedimentation in the highlands of North-West Ethiopia. Understanding the basic relationships between rainfall, runoff, erosion and sediment yield is vital for effective management and use of soil and water resources (Herweg and Ludi, 1999; Easton et al., 2010; Grum et al., 2017; Jemberu et al., 2017).

Although soil loss, flooding and sedimentation are critical problems in the sub-humid highlands of Ethiopia, lack of adequate datasets has greatly inhibited our understanding of runoff and sedimentary processes in these settings (Steenhuis et al., 1995; Ritsema and Dekker, 2000; Setegn et al., 2010; Wudneh et al., 2014; Yeshaneh et al., 2014; Tilahun et al., 2015; Jemberu et al., 2017). However, understanding runoff and sediment transport processes is essential to understand catchment areas' hydrological responses and geomorphology of streams which is required for effective soil and water management (Asselman, 1999; Nyssen et al., 2008; Bayabil et al., 2010; Guzman et al., 2013; Tilahun et 
al., 2015). Therefore, there is a need to assemble quantitative data on the extent, magnitude and actual rates of runoff, soil loss and sedimentation as well as their variations within the landscape (Nyssen et al., 2008; Bayabil et al., 2010; Nu-Fang et al., 2011; Baptista et al., 2015). Identifying and prioritizing areas for soil and water management interventions should consider water erosion risk in conjunction with processes of runoff and sedimentation (Ritsema et al., 1993; Baartman et al., 2012; Tilahun, 2012; Ali et al., 2013; Wudneh et al., 2014).

Data on variation of runoff and sediment yield in relation to rainfall features could be used for calibration and validation of spatial distributed soil erosion and sediment yield models (Brasington and Richards, 2000; Rovira and Batalla, 2006; Ali et al., 2013; Baartman et al., 2013). Understanding runoff and sediment transport processes on different slope classes is also important for planning of SWC measures in the Ethiopian highlands. However, in most cases, very little data exist for different slope classes in the Ethiopian highlands where hydrographs are complex and sediment delivery depends on surface runoff, rainfall and land use/cover which are spatially and temporally highly variable (Walling and Webb, 1982; Setegn et al., 2010; Wudneh et al., 2014; Mekonnen et al., 2015; Tilahun et al., 2015).

Analyzing the (relative) contribution of single (extreme) runoff and sediment yield events to annual totals is important for catchments that drain into water bodies (such as reservoirs) and for the design of diversion channels and runoff management structures (Asselman, 2000; Brasington and Richards, 2000; Bracken and Croke, 2007; Baartman et al., 2012). Gonzalez-Hidalgo et al. (2010) reported that the three largest events contribute an average of 38 percent of the sediment transport and the ten largest events represent more than 61 percent of the total annual sediment transport. One of the most important problem in the analysis of hydrological and sedimentary data is the uncertainty in the mean value that may be biased by the presence of extreme events (Hudson, 2003; de Vente et al., 2008; Guy et al., 2009; Setegn et al., 2009). Likewise, erosion processes are greatly compressed in time and soil erosion depends on a limited number of events (Hudson, 2003; Wei et al., 2015). A few daily events, representing short time intervals and not being necessarily extreme events, could be responsible for high amounts of sediment load (Wolman and Miller, 1960; Nadeu et al., 2014; Wei et al., 2015). Thus, analysis of extreme events establishes the magnitude-frequency ratio and its effects on geomorphological evolution in the present context (Wolman and Miller, 1960; Yair and Raz-Yassif, 2004; Awulachew et al., 2010; Vanmaercke et al., 2010).

The event sequences and sediment exhaustion, and the hysteresis at single event scale have been used for identifying runoff and soil erosion types, sediment delivery and source area (Piest et al., 1975; Seeger et al., 2004; Kirkby et al., 2005; Nadeu et al., 2014). The rising and 
receding limbs of peaks of runoff and SSC are used to characterize the hysteresis with a linear relationship when peaks of runoff and SSC coincide in time and have approximately equal SSC values on receding limbs of the hydrograph (Hudson, 2003). When the SSC peaks before runoff and SSC values are lower than runoff on the receding limb of the hydrograph, this indicates clockwise (positive) hysteresis. When SSC peaks after runoff and it has high values during the receding limb of the hydrograph, this indicates a counter wise (negative) hysteresis relation between runoff and SSC (Nadal-Romero et al., 2008; Li and Gao, 2015).

Knowledge of the magnitudes, patterns and variation of runoff, soil loss and sediment detachment and transport processes and their control factors is crucial for understanding and modelling of the hydrological functioning and to assess the stream geomorphological characteristics in the sub-humid Ethiopian highlands (de Vente et al., 2006; Bayabil et al., 2010; Gessesse, 2014; Tilahun et al., 2015). However, runoff and sedimentary processes in these areas have been poorly quantified using empirical data. The aim of this study was to analyse how treated sub-watersheds respond to rainfall features and runoff, and to assess the rate and patterns of sediment yield measured during two years (2014-2015) in three sub-watersheds of different size in the Ethiopian Highlands. Using this data, we analysed (a) the contribution of largest events of runoff and sediment discharge to total overland flow and sediment yield, (b) the temporal dynamics of runoff and sediment exhaustion patterns and (c) the hysteresis in the hydrographs and sedigraphs of different typical events in Koga river catchment.

\subsection{Materials and methods}

\subsubsection{Study site}

This study was conducted at three sub-watersheds of Koga catchment, North-western Ethiopia $\left(37^{0} 02^{\prime \prime}-37^{0} 17^{\prime \prime}\right.$ E longitude, $11^{0} 10^{\prime \prime}-11^{0} 25^{\prime \prime} \mathrm{N}$ latitude (Figure 4.1). Koga catchment has a total area of $230 \mathrm{~km}^{2}$ and is one of the major watersheds at the source of the Blue Nile, in Amhara Regional state. The Koga River flows south to north-west with a total length of $69 \mathrm{~km}$. Koga catchment is narrow and elongated, with a dense drainage network. The topography of Koga catchment is rugged and highly variable with an elevation of $1860-3120 \mathrm{~m}$ (Figure 4.1). The climate of Koga catchment is characterized by dry (October to April) and wet (May to September) seasons. Mean annual rainfall is about 1480 $\mathrm{mm}$ of which more than $90 \%$ falls in the wet season. The temporal distribution of rainfall shows that the area is subjected to excess rainfall during the short rainy season and prolonged moisture shortage and soil drying during the dry season. The mean maximum monthly temperature ranges from $30.0^{\circ} \mathrm{C}$ in March to $23.1^{\circ} \mathrm{C}$ in August. Approximately $86 \%$ 
of Koga catchment is cultivated land, while around $12 \%$ is forest and the remaining part fallow and grazing land. Most of the cultivated fields are usually planted with barley, teff, wheat, linseed, peas and beans.

The three sub-watersheds studied, Asanat, Debreyakob and Rim, are the main subwatersheds and the three principal tributaries of Koga River at upper, middle and lower slope positions (Figure 4.1). The three study sub-watersheds have different topographic characteristics, altitude, land use and soil types. Asanat (756 ha) is a hilly area where more than $55 \%$ of the area has slopes of $15 \%-30 \%$ and $11 \%$ of the area has slopes greater than $30 \%$. In Debreyakob (303 ha) $32 \%$ of the area has slopes of $15 \%-30 \%$ and about $33 \%$ of the area has slopes of less than $10 \%$. Rim sub-watershed (1010 ha) is relatively flat with $85 \%$ of the area having slopes of less than $10 \%$. Currently, the Asanat sub-watershed, is composed of scattered indigenous tree species and shrubs and rock outcrops whereas in Rim extensive eucalyptus tree plantations have been expanding due to their short-term economic return. In Debreyakob, plantation of physical SWC measures and forage production, control grazing and areas closures have been practiced. Rainfall and farming systems are similar in all subwatersheds.

Soil erosion is severe and at low-lying bottom slopes, sedimentation and flooding are common. The soil types in Koga have been classified as Leptosols, Nitisols, Vertisols, Cambisols, Alisols, Gleysols and Fluvisols. These soils have clay to clay loam texture with exception of Gleysols that have clay to sandy clay loam texture. Cambisols and Leptosol are poor in fertility and less suitable for crop production and are predominant at the middle and upper parts of the catchment. Yields in the upper part of Koga catchment (in Asanat subwatershed) are declining due to the decrease in fertility of the soil and increased erosion (Jemberu et al., 2017). 


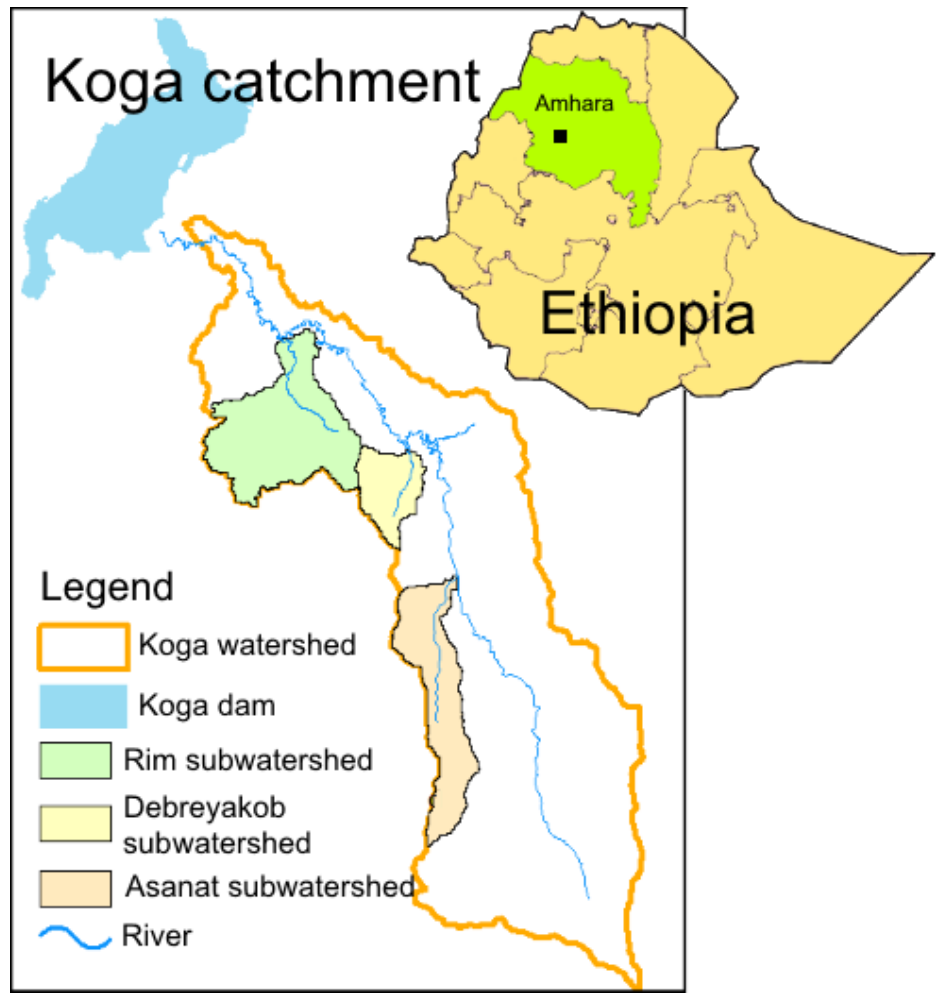

Figure 4.1 Location of Koga catchment in Ethiopia - Amhara Regional State - black dot indicates location of study area and Koga catchment with the three study sub-watersheds Asanat, Debreyakob and Rim.

\subsubsection{Data collection: rainfall, runoff and sediment yield}

Rainfall at the three study sub-watersheds was recorded at 10-minute interval using RG3Hobo data logging rain gauges in two rainy seasons (2014 and 2015). The Hobo data loggers were calibrated in the field for accurate data recording with a controlled rate of flow of water through the tipping bucket mechanism. During installation, the rain gauges were mounted in a level position on a vertical pole, clear of overhead structure and free of vibration. From continuous readings of the automatic rain gauges, rainfall characteristics such as 10-minute maximum rain intensity were determined.

Digital pressure transducers (Divers) were calibrated at the outlet of Asanat, Debreyakob and $\operatorname{Rim}$ (Fig. 4.1) to record automatically the flow depth on a continuous basis at 10-minute interval. Steel pipes with a radius of $8.4 \mathrm{~cm}$ were used to install the divers at the centre of the cross section of the rivers. The steel pipes were placed vertically at the centre of the river to ensure that the divers measure the flow of discharge at both maximum and minimum depths. 
The stream sections at the outlet point were reshaped and temporally stabilised with trapezoidal sections. The surface velocity was determined with a float that was released 8 to $12 \mathrm{~m}$ upstream of the diver position. Manual measurement of velocity was started when the water became turbid and every 10 minutes velocity was recorded until the water became less turbid. The time required for the float to reach the diver point was recorded. The surface velocities were multiplied by $2 / 3$ to compute the mean discharge as indicated in Eq. 4.1. The discharge for specific flow depth $\left(\mathrm{m}^{3} / \mathrm{s}\right)$ was measured from surface velocity and area of the flow as follows (Nyssen et al., 2006; Nyssen et al., 2008; Vanmaercke et al., 2006).

$\mathrm{Q}=\mathrm{A} * \mathrm{~V}$

Where:

$A=$ area of the flow $\left(\mathrm{m}^{2}\right)$

$\mathrm{V}=$ the average velocity of flow $(\mathrm{m} / \mathrm{s})$

For each study sub-watershed, the continuous flow depths series were converted to continuous runoff discharge series using a rating curve. In order to easily compare areaspecific runoff among the sub-watersheds, a runoff coefficient, defined as the quotient of runoff and rainfall, was used.

One-litre sediment samples were collected from river discharge after rainfall events during two rainy seasons (2014 and 2015). Discharge sampling during a rainfall event started when the runoff developed and when the water from the rainfall event at the outlet looked brown. Sampling was carried out in 10-minute intervals. A total of 101 one-litre samples for Asanat, 98 for Debreyakob and 105 for Rim were taken. Each sample was filtered using Whatman filter paper with a pore opening of $2.5 \mu \mathrm{m}$, then oven-dried and weighted to allow determination of dry soil losses. Due to large runoff amounts, it was often impossible to sample sediment from the entire water column. However, since the flow was very turbulent during these events, a good mixing of sediments was expected for the rising and receding limbs of the runoff.

The soil loss for that sampling interval (i.e. runoff event) was then estimated by multiplying the total flow of water per unit time $\left(Q, \mathrm{~m}^{3} / \mathrm{s}\right)$ with the sediment concentration determined from the one-litre samples. Suspended sediment discharge was computed by multiplying the instantaneous SSC by daily stream flow and a conversion factor to convert $\mathrm{g} / \mathrm{l}$ to tons per day (Nyssen et al., 2008). 


\subsubsection{Data analysis}

\subsubsection{Correlation-regression analysis}

The relation between suspended yield, rainfall features, runoff depth, flow rate and SSC for the three sub-watersheds was tested using the Pearson's product movement correlation coefficient. We formulated a stepwise multiple regression analysis for Asanat, Debreyakob and Rim by taking sediment discharge as dependent variable and rainfall, rain intensity, lomax, runoff, runoff coefficient, discharge and SSC (all daily) as estimators using SPSS version 23. Variation in land use, soils and topography at sub-watershed level was not taken into account as the regression analysis is a lumped statistical model. However, the regression model with flow duration cure, hydrographs, sedigraphs can be used indirectly to depict the effect of watershed characteristics on runoff and sediment yield.

\subsubsection{Flow duration curves (FDCS)}

The response of sub-watersheds to the processes and rates of runoff was analysed using stream direct flow characteristics. A flow duration curve (FDC) provides the percentage of time (duration) a daily stream flow is exceeded over a historical period for a particular stream gauge (Vogel and Fennessey, 1994). It is a principal means for summarising the hydrological characteristics of the watershed areas (Vogel and Fennessey, 1994; Banasik and Hejduk, 2013). A FDC characterises the ability of the watershed to provide flows of various magnitudes and the area under the FDC gives the average daily flow (van der Wateren-de Hoog, 1998). A FDC was constructed from the daily stream flow rate of each sub-watershed by sorting the daily discharge from 2014-2015 period from the largest to smallest values, and assigning each discharge value a rank $r$ starting with 1 for the largest value and $\mathrm{N}$ for the lowest value of $\mathrm{N}$ runoff events as follows (Sugiyama et al., 2003):

$P=(r / N+1)$

Where,

$P$ is exceedance probability

$\mathrm{N}$ is the total number of daily flow

$r$ is the rank assigned to each daily steam flow value.

\subsubsection{Relative event contribution}

The analysis of the relative contribution of the largest runoff and sediment events was based on the two years measurement of peak discharge and suspended sediment data (2014-2015). For this purpose, daily values of runoff and sediment yield were ranked to identify the n-largest ones, with those events then expressed as their percentage contribution to the total runoff and sediment load. The percentage of sediment load 
produced by first largest, second largest, third largest, etc. up to the $12^{\text {th }}$-largest daily events were accumulated to be analysed across the three study sub-watersheds (Gonzalez-Hidalgo et al., 2010). The differences between mean values of relative events were analysed for significance using t-test ( $p>0.05)$.

\subsubsection{Hysteresis analysis}

The event sequences and sediment exhaustion, and the hysteresis at single event scale were used for identifying runoff and soil erosion types, sediment delivery and source area (Piest et al., 1975; Seeger et al., 2004; Kirkby et al., 2005; Nadeu et al., 2014). The response time, rising and recession limb of the hydro- and sedigraphs were used to characterise the hysteresis (Hudson, 2003). The response time relates to the soil saturation in the study subwatersheds whereas the shape and size of the rising limb show the correspondence with duration and intensity of storms (Dingman, 1994). Analysis of the recession flow characteristics has been applied to infer upon the behaviour of soil storage-excess runoff which feed stream flow (Tallaksen, 1995). In this study, single representative events in early, middle and late rainy season were selected for hysteresis analysis.

\subsection{Results}

\subsubsection{Observed rainfall, runoff and sediment yield in the three sub- watersheds}

A summary of the daily values of rainfall, rain intensity, runoff and suspended sediment discharge measured at the outlets of three sub-watersheds during the rainy seasons of 2014 and 2015 is given in Table 4.1. Long-term average annual rainfall from the nearby Merawi town weather station is $1450 \mathrm{~mm}$ (2004-2013) which shows that both years received belowaverage rainfall. Most of the rainfall events were small in magnitude and only 19 events (21.3\%) in Asanat, 22 events (25.6\%) in Debreyakob and 26 events (26.3\%) in Rim were above $30 \mathrm{~mm}$ for 2014-2015 (Table 4.1). The maximum daily rainfall was about $100 \mathrm{~mm}$. The maximum 10-minute rainfall intensity was $96.3 \mathrm{~mm} / \mathrm{h}$ for Asanat, $94.1 \mathrm{~mm} / \mathrm{h}$ for Debreyakob and $85.3 \mathrm{~mm} / \mathrm{h}$ for Rim. The variation in rainfall intensity can be explained by the relative difference in altitude of the three catchments with Asanat being the highest and Rim the lowest catchment. 
Table 4.1 Overview of rainfall, runoff and sediment characteristics as measured for the three sub-watersheds for the rainy seasons of 2014-2015.

\begin{tabular}{|c|c|c|c|c|c|c|}
\hline \multirow{2}{*}{ Rainfall features } & \multicolumn{2}{|c|}{ Asanat } & \multicolumn{2}{|c|}{ Debreyakob } & \multicolumn{2}{|l|}{ Rim } \\
\hline & 2014 & 2015 & 2014 & 2015 & 2014 & 2015 \\
\hline Total rainfall (mm) & 990 & 902 & 957 & 916 & 945 & 934 \\
\hline \multirow[t]{2}{*}{ Events (\#) } & 40 & 49 & 39 & 47 & 36 & 47 \\
\hline & \multicolumn{2}{|c|}{$2014-2015$} & \multicolumn{2}{|c|}{$2014-2015$} & \multicolumn{2}{|c|}{$2014-2015$} \\
\hline Events > $30 \mathrm{~mm}(\#)$ & \multicolumn{2}{|l|}{19} & \multicolumn{2}{|l|}{22} & \multicolumn{2}{|l|}{26} \\
\hline Maximum daily rainfall (mm) & \multicolumn{2}{|l|}{103.5} & \multicolumn{2}{|l|}{102.4} & \multicolumn{2}{|l|}{94.3} \\
\hline Max. 10-min rain intensity $(\mathrm{mm} / \mathrm{h})$ & \multicolumn{2}{|l|}{96.3} & \multicolumn{2}{|l|}{94.1} & \multicolumn{2}{|l|}{85.3} \\
\hline Runoff flow depth $(\mathrm{cm})^{*}$ & \multicolumn{2}{|c|}{$1.3-110.7$} & \multicolumn{2}{|c|}{$0.6-82.4$} & \multicolumn{2}{|c|}{$3.7-137.8$} \\
\hline Peak stream discharge $\left(\mathrm{m}^{3} / \mathrm{s}\right)$ & \multicolumn{2}{|l|}{15.6} & \multicolumn{2}{|l|}{6.3} & \multicolumn{2}{|l|}{25.2} \\
\hline Max. daily suspended sediment concentration $(\mathrm{g} / \mathrm{l})$ & \multicolumn{2}{|l|}{33.5} & \multicolumn{2}{|l|}{21.3} & \multicolumn{2}{|l|}{32.2} \\
\hline Daily sediment discharge (t/day)* & \multicolumn{2}{|c|}{$1.14-4148$} & \multicolumn{2}{|c|}{$0.1-1124$} & \multicolumn{2}{|c|}{$0.75-4718$} \\
\hline Runoff coefficient* & \multicolumn{2}{|c|}{$0.02-0.78$} & \multicolumn{2}{|c|}{$0.1-0.69$} & \multicolumn{2}{|c|}{$0.05-0.74$} \\
\hline Area specific sediment yield $\left(\mathrm{t} \mathrm{ha}^{-1} \mathrm{y}^{-1}\right)$ & \multicolumn{2}{|l|}{35.6} & \multicolumn{2}{|l|}{24.4} & \multicolumn{2}{|l|}{31.7} \\
\hline Absolute sediment yield $\left(\mathrm{t}^{-1}\right)$ & \multicolumn{2}{|c|}{26914} & \multicolumn{2}{|l|}{7393} & \multicolumn{2}{|c|}{32017} \\
\hline
\end{tabular}

* Minimum and maximum values (range) given

As can be seen in Table 4.1, the runoff-flow depth ranged from 1.3 to $110.7 \mathrm{~cm}, 0.6$ to 82.4 $\mathrm{cm}$ and 3.7 to $137.8 \mathrm{~cm}$ in Asanat, Debreyakob and Rim respectively. The peak stream discharge as well as the maximum daily sediment discharge were significantly lower in Debreyakob than in the other watersheds. Discharge of streams lasted from a few minutes to many hours after the rainfall events. The maximum daily suspended sediment concentration was slightly lower in Debreyakob compared to Asanat and Rim watersheds. The runoff coefficient calculated over the two years varied between 0.02 to 0.78 in Asanat, 0.1 to 0.69 in Debreyakob and 0.05 to 0.74 in Rim and were relatively low in the beginning of the rainy season for all study areas. The temporal variations of runoff flow depth and SSC in response to the rain intensity (2014) are shown in Fig. 4.2. A high degree of variability in SSC at similar runoff depth was observed, reflecting the differences in rainfall-runoff generation across the study sub-watersheds.

To be able to compare directly, the measured runoff depth and SSC for 2015 are plotted together for all three sub-watershed in Fig. 4.3. There are slight differences between the three watershed, but the overall trend is the same. However, the temporal pattern of runoff depth and SSC for Debreyakob is somewhat smoother and values are lower as compared to Asanat and Rim. This indicates a lower response of Debreyakob sub-watershed to runoff and sediment loss. Striking is the high SSC at the start of the rainy season, which declines over time and which is seemingly unrelated to temporal variation in rainfall intensity and/or runoff depth. This is probably related to the depletion of sediments and the development of vegetation cover through the rainy season. There is a sharp increase in runoff around half of July 2015 and a decline towards the end of the rainy season. However, this decline is not very rapid, which is probably due to the higher contribution of base flow towards the end 
of the rainy season. The temporal pattern of SSC is strikingly different than the runoff pattern, starting with the highest values at the start of the rainy season and continuously decreasing throughout the season. Smaller events that occurred early in the rainy season typically displayed much scatter between discharge (Q) and SSC, but were often associated with the highest SSC, suggesting that much of the sediment was flushed through the system early in the rainy season (July).
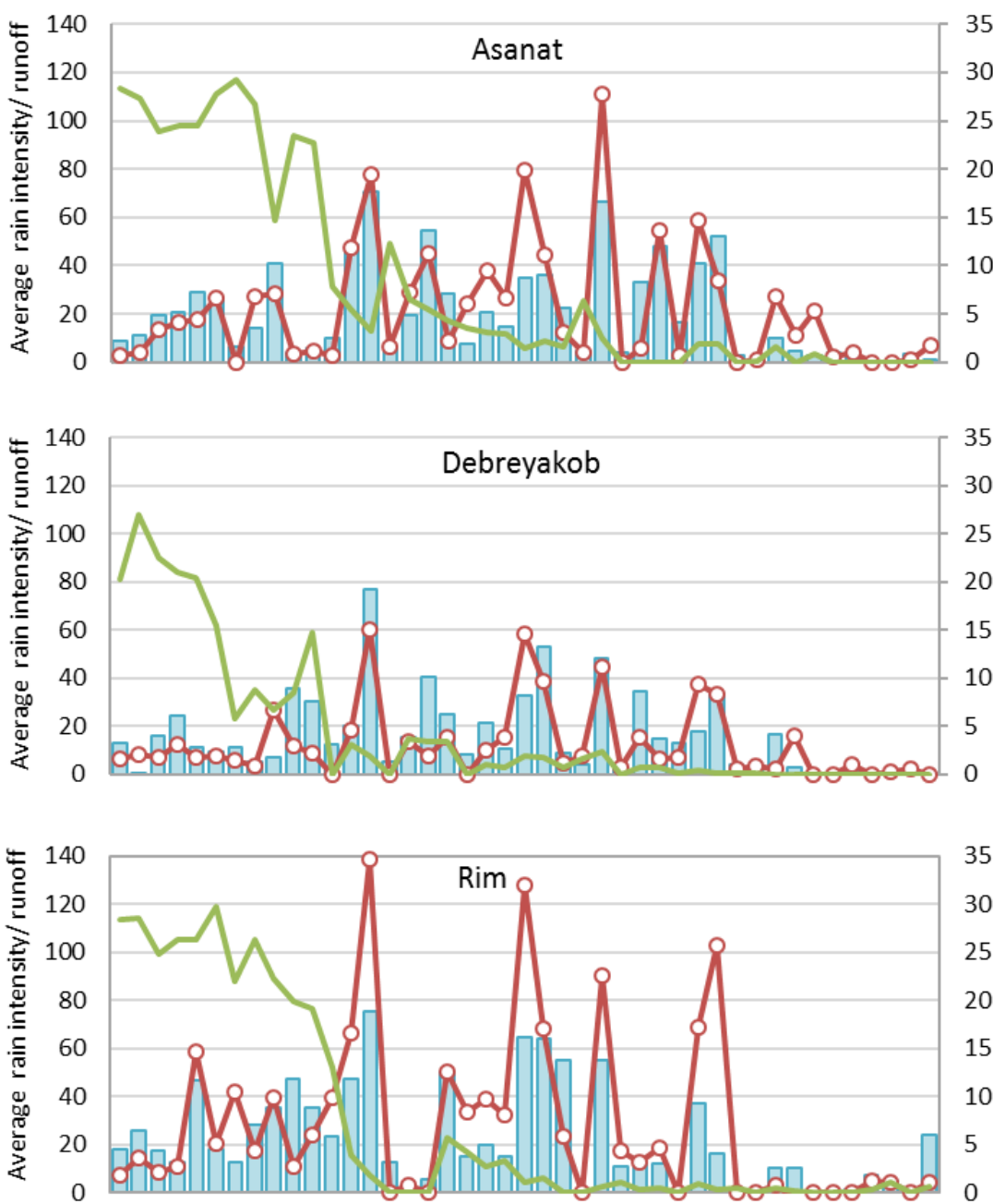
intensity $(\mathrm{mm} / \mathrm{h})$

Figure 4.2 Temporal variation of runoff and SSC in response to rain intensity for the rainy season of 2014 in a) Asanat, b) Debreyakob and c) Rim sub-watersheds. 


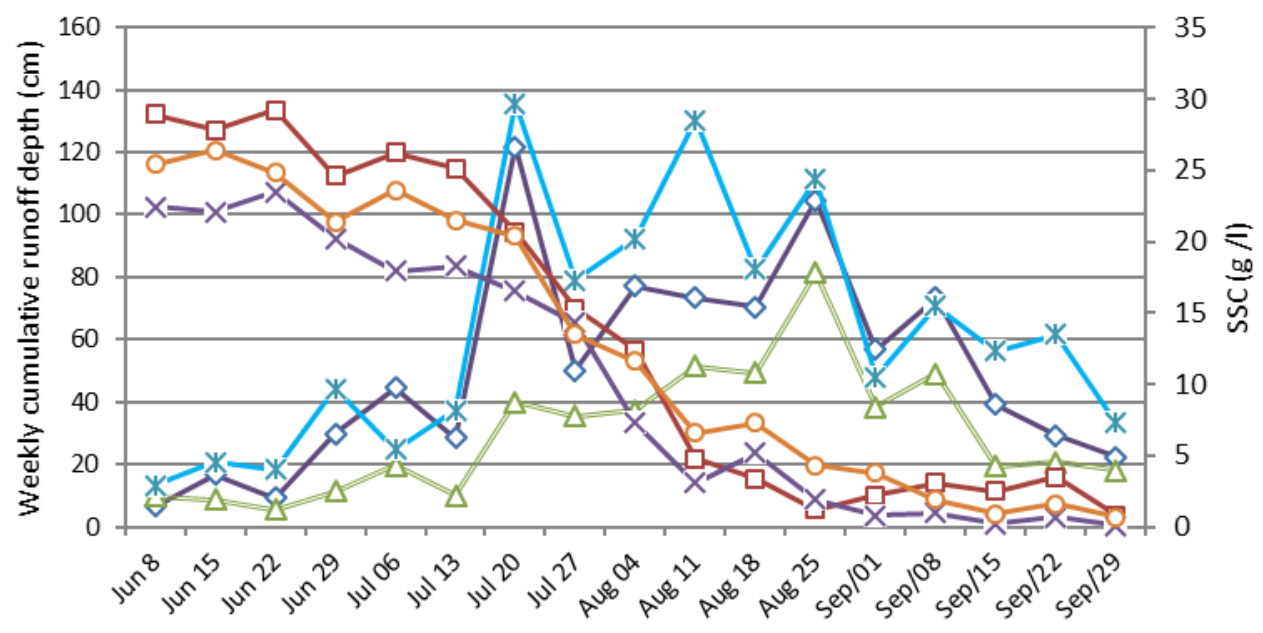
$\prec$ Asanat runoff $(\mathrm{cm})$
$\triangle$ Debreyakob runoff $(\mathrm{cm}) \quad-*-\operatorname{Rim}$ runoff $(\mathrm{cm})$
$-\square-$ Asanat SCC (g/l)
-×-Debreyakob SCC (g/l) $\quad-0-\operatorname{Rim~SCC~}(\mathrm{g} / \mathrm{l})$

Figure 4.3 Temporal pattern of runoff depth and suspended sediment concentration for Asanat, Debreyakob and Rim sub-watersheds in the rainy season of 2015.

\subsubsection{Correlation between rainfall, runoff and soil loss}

Fig. 4.4 shows the frequency-magnitude relationships for rain intensity, runoff depth and SSC. As would be expected, low magnitude daily events occurred more frequently than highmagnitude events. The same applies to the occurrence of runoff depth and SSCs. In all study sub-watersheds, a direct and strong relationship between rain intensity and runoff depth was observed whereas there was no clear relation between SSC and rain intensity or runoff depth, confirming the observation on the temporal trends visible in Fig. 4.2 and 4.3. 


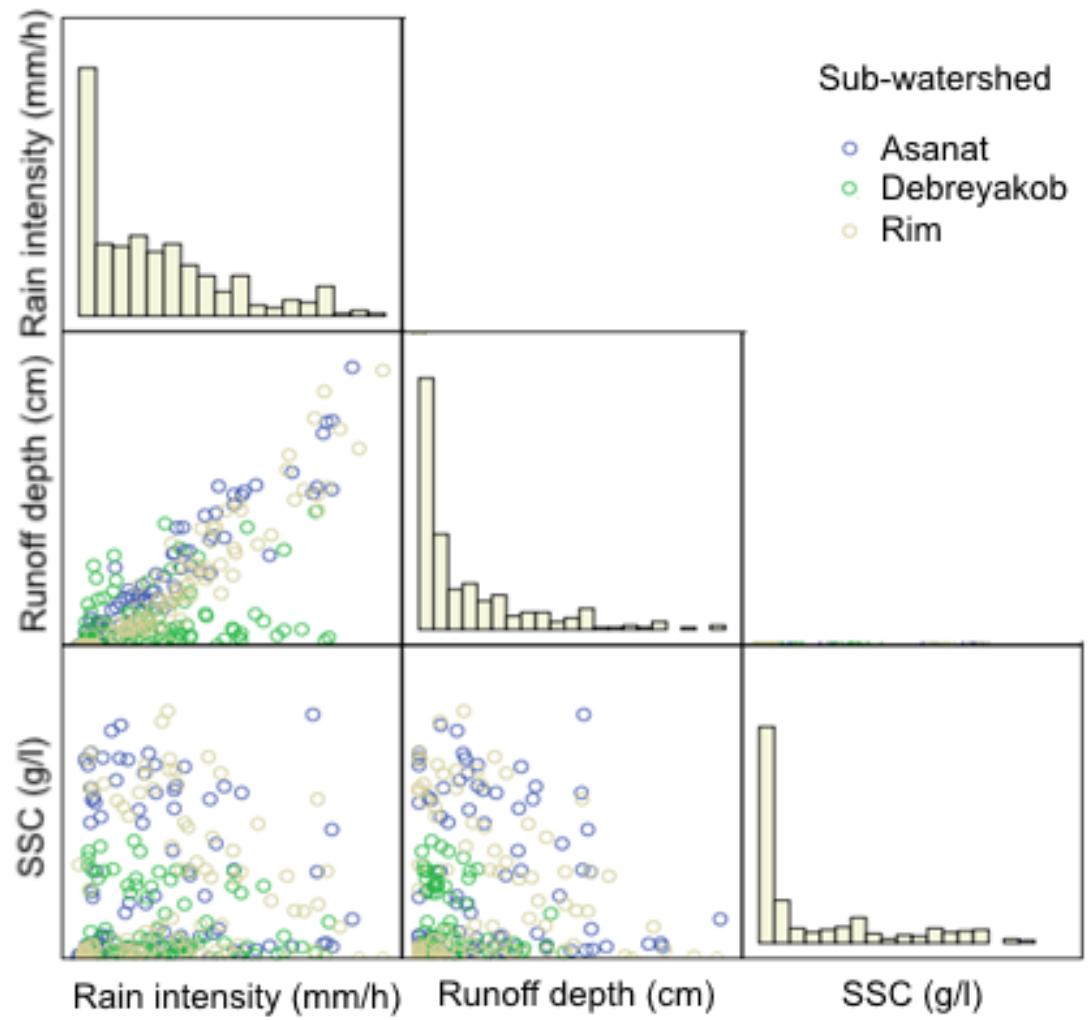

Figure 4.4 Matrix plot showing the frequency-magnitude relations between rain intensity, runoff and SSC in Asanat, Debreyakob and Rim (2014-2015).

Tables 4.2-4.4 show the Pearson Correlation Matrices between daily: rainfall, rain intensity, I 10 max, runoff depth, SSC and sediment discharge for the three study watersheds. The strongest correlation was found between rain intensity and runoff for all study areas, with correlation coefficients of $0.92,0.88$ and 0.90 for Asanat, Debreyakob and Rim subwatersheds respectively. Sediment discharge was significantly correlated with rainfall, rain intensity and runoff in Asanat and Rim. However sediment yield was related to rainfall and runoff less strongly in Debreyakob as compared to Asanat and Rim (Tables 4.2-4.4). SSC was not significantly related to any of the hydrological parameters in Debreyakob and only slightly to RC in Asanat and Rim. Also, the RC was correlated to none of the sediment parameters in Debreyakob, while it was for the other two watersheds. This indicates that the hydrological and sediment response in Debreyakob differs from that of the other two watersheds. 
Table 4.2 Pearson correlation matrix among selected hydrological parameters in Asanat ( $n=68)$

\begin{tabular}{lllllllll}
\hline & Rainfall & Intensity & I 1 max & Runoff depth & RC & SSC & Discharge & SY \\
\hline Rainfall & 1.00 & & & & & & & \\
Intensity & 0.83 & 1.00 & & & & & & \\
I 1 max & 0.52 & 0.72 & 1.00 & & & & & \\
Runoff depth & 0.79 & 0.92 & 0.51 & 1.00 & & & & \\
RC & 0.80 & 0.75 & 0.53 & 0.78 & 1.00 & & & \\
SSC & $0.13^{\text {ns }}$ & $0.11^{\text {ns }}$ & $0.05^{\text {ns }}$ & $0.19^{\text {ns }}$ & 0.26 & 1.00 & & \\
Discharge & 0.68 & 0.61 & 0.42 & 0.74 & 0.64 & $0.09^{\text {ns }}$ & 1.00 & \\
SY & 0.62 & 0.60 & $0.27^{\text {ns }}$ & 0.71 & 0.44 & $0.27^{\text {ns }}$ & 0.45 & 1.00 \\
\hline
\end{tabular}

All correlation coefficients are significant at $p<0.01$ except marked in "ns" which are not significant at $P<0.01$

Table 4.3 Pearson correlation matrix between selected hydrological parameters in Debreyakob $(n=68)$

\begin{tabular}{|c|c|c|c|c|c|c|c|c|}
\hline & Rainfall & Intensity & $I_{10 \max }$ & Runoff depth & $\mathrm{RC}$ & SSC & Discharge & SY \\
\hline Rainfall & 1.00 & & & & & & & \\
\hline Intensity & 0.63 & 1.00 & & & & & & \\
\hline Iomax & 0.57 & 0.94 & 1.00 & & & & & \\
\hline Runoff depth & 0.66 & 0.88 & 0.60 & 1.00 & & & & \\
\hline $\mathrm{RC}$ & 0.30 & $0.29^{\text {ns }}$ & $0.23^{\mathrm{ns}}$ & $0.28^{\text {ns }}$ & 1.00 & & & \\
\hline SSC & $0.07^{n s}$ & $0.04^{\text {ns }}$ & $0.09^{n s}$ & $0.05^{\text {ns }}$ & $0.06^{n s}$ & 1.00 & & \\
\hline Discharge & 0.71 & 0.57 & 0.49 & 0.80 & $0.29^{\text {ns }}$ & $0.08^{\text {ns }}$ & 1.00 & \\
\hline SY & 0.46 & 0.46 & 0.37 & 0.57 & $0.04^{\text {ns }}$ & 0.45 & 0.44 & 1.00 \\
\hline
\end{tabular}

All correlation coefficients are significant at $p<0.01$ except marked in "ns" which are not significant at $P<0.01$

Table 4.4 Pearson correlation matrix between selected hydrological parameters in Rim ( $n=68)$

\begin{tabular}{lllllllll}
\hline & Rainfall & Intensity & lomax & Runoff depth & RC & SSC & Discharge & SY \\
\hline Rainfall & 1.00 & & & & & & & \\
Intensity & 0.59 & 1.00 & & & & & & \\
lomax & 0.55 & 0.93 & 1.00 & & & & & \\
Runoff depth & 0.70 & 0.90 & 0.66 & 1.00 & & & & \\
RC & 0.66 & 0.70 & 0.63 & 0.64 & 1.00 & & & \\
SSC & $0.21^{\text {ns }}$ & $0.08^{\text {ns }}$ & $0.02^{\text {ns }}$ & $0.22^{\text {ns }}$ & 0.34 & 1.00 & & \\
Discharge & 0.88 & 0.64 & 0.59 & 0.95 & 0.61 & $0.28^{\text {ns }}$ & 1.00 & \\
SY & 0.58 & 0.61 & 0.38 & 0.75 & 0.39 & $0.06^{\text {ns }}$ & 0.65 & 1.00 \\
\hline
\end{tabular}

lomax -max 10-minute rainfall intensity; RC -runoff coefficient; SY -sediment yield

All correlation coefficients are significant at $p<0.01$ except marked in " $n s$ " which are not significant at $\mathrm{P}<0.01$

The regression equations obtained from multiple regression models (Table 4.5) show that rain intensity was the most significant factor controlling the supply and transport of suspended sediment in all sub-watersheds. Rain intensity explained (a partial or shared contribution of) $20.9,21.7$ and $17.8 \%$ of variation in the sediment yield in Asanat, Debreyakob and Rim respectively. However, the unique contribution (when other variables are controlled) of rain intensity to sediment yield was relatively similar; $14.4 \%$ in Asanat, $13.2 \%$ in Debreyakob and $12.8 \%$ in Rim. This shows the importance of rain intensity as a major cause of suspended sediment load. 
Table 4.5 Multiple regression models (the strongest predictor, partial and unique contributions of sediment yield (\%) derived in each case after the regression analysis).

\begin{tabular}{lllll}
\hline & & \multicolumn{2}{l}{ Strongest } & \multicolumn{2}{l}{ Contribution (\%) } \\
Sub-watershed & Regression equation & predictor & Partial & Unique \\
\hline Asanat & $\mathrm{Y}=2.7 \mathrm{X}_{1}+37.5 \mathrm{X}_{2}+31.3 \mathrm{X}_{3}-14.6 \mathrm{X}_{4}+14.3 \mathrm{X}_{5}-194.3$ & $\mathrm{RI}$ & 20.9 & 14.4 \\
Debreyakob & $\mathrm{Y}=2.2 \mathrm{X}_{1}+35.3 \mathrm{X}_{2}+28.2 \mathrm{X}_{3}-12.2 \mathrm{X}_{4}+13.6 \mathrm{X}_{5}-192$ & $\mathrm{RI}$ & 21.7 & 13.2 \\
Rim & $\mathrm{Y}=2.9 \mathrm{X}_{1}+38.6 \mathrm{X}_{2}+30.2 \mathrm{X}_{3}-14.8 \mathrm{X}_{4}+15.3 \mathrm{X}_{5}-194.9$ & $\mathrm{RI}$ & 17.8 & 12.8 \\
\hline
\end{tabular}

$X_{1}-$ rainfall; $X_{2}$-discharge; $X_{3}$-rain intensity; $X_{4}-I_{10}$ max; $X_{5}$-runoff; $R I$ refers to rain intensity

Fig. 4.5 shows the predictive analysis of sediment yield and runoff flow depth. There was a dissimilarity in deviations of SSC and sediment discharge rate because the sediment discharge rate was greatly influenced by the peak runoff rate and other biophysical variables besides the high events of SSC (Figure 4.4).

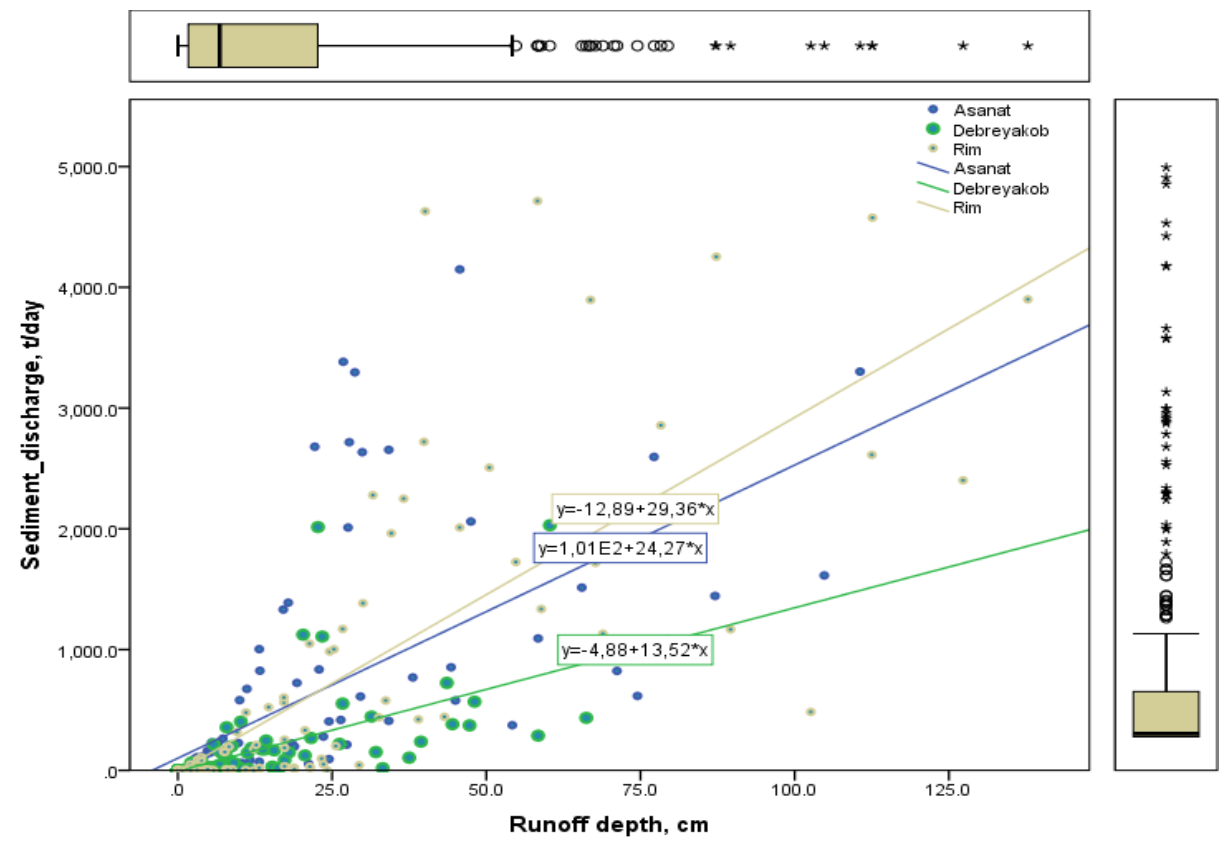

Figure 4.5 The relationship between runoff and sediment discharge for Asanat $\left(R^{2}=0.81^{* *}\right)$, Debreyakob $\left(R^{2}=0.67^{* *}\right)$ and $\operatorname{Rim}\left(R^{2}=0.85^{* *}\right)(2014-2015)$. The horizontal and vertical boxplots at the top and left side indicate the variation of runoff and sediment discharge values measured in all sub-catchments combined.

\subsubsection{Flow duration curves}

The FDCs show the daily discharge for all rain storms of the 2014-2015 period for the three sub-watersheds (Figure 4.6). The area under the flow duration curve gives the average daily 
flow and shows that the median daily flow is $50 \%$ value. The FDCs are irregular and steep. About 4248, 2129 and $11400 \mathrm{l} / \mathrm{s}$ direct discharge rates are exceeded $10 \%$ of the time in Asanat, Debreyakob and Rim respectively.

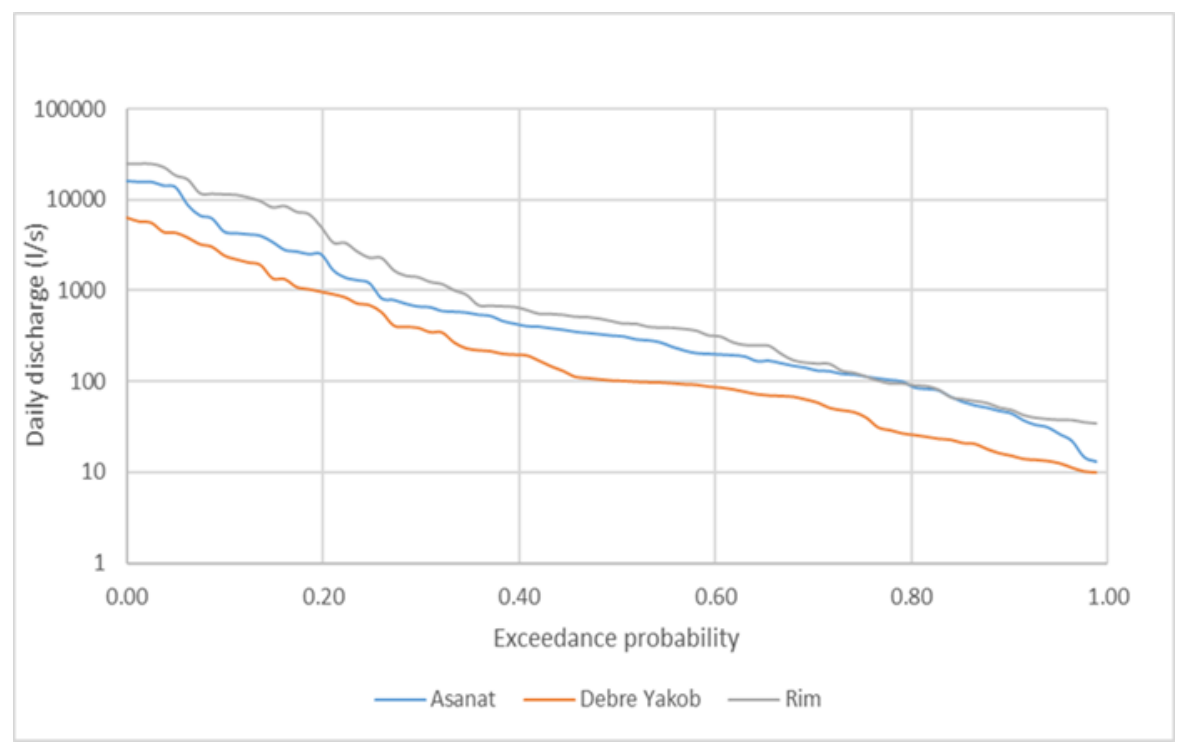

Figure 4.6 Flow duration curves (FDCs) for the three study sub-watersheds

\subsubsection{The contribution of largest events to total runoff and suspended sediment transport}

To study the importance of individual events, we assessed the contribution of the 12 largest daily runoff and sediment discharge events to the total runoff and sediment export for each of the three sub-watersheds. The results show that a large proportion of the total observed runoff and suspended sediment were produced by a small number of daily events (Tables 4.6-4.7). Runoff and suspended sediment caused by the 12 largest daily events represented more than 69, 77 and $74 \%$ of the total runoff, and 81,84 and $76 \%$ of the total sediment load in Asanat, Debreyakob and Rim sub-watersheds respectively in 2014. The first largest daily runoff event contributed 11.9 \% in Asanat, $12.7 \%$ in Debreyakob and $8.9 \%$ in Rim to the total runoff depth in 2015 , while the five largest daily events produce about half of the total runoff and sediment.

Rim sub-watershed accounts for the highest total values of both runoff and sediment transport across Koga catchment but the relative contributions of the daily largest events were lower than for Asanat and Debreyakob sub-watersheds, indicating that runoff and 
sediment are delivered more evenly in Rim catchment as compared to the other catchments. Although the sediment load is relatively lower in Debreyakob, generally, the highest percentage values of runoff and sediment transport were found in Debreyakob subwatershed for most of the largest daily events (Table 4.6-4.7), suggesting that sediment retention in Debreyakob is mainly effective for the smaller magnitude events.

Table 4.6 Relative contribution of runoff produced by n-largest daily runoff events, \% (2014-2015)

\begin{tabular}{|c|c|c|c|c|c|c|c|c|}
\hline \multirow{2}{*}{$\begin{array}{l}\text { Sub- } \\
\text { watershed }\end{array}$} & \multirow[t]{2}{*}{ Area, ha } & \multirow{2}{*}{$\begin{array}{l}\text { Total \# of daily events } \\
\text { July-Sep. } 2014\end{array}$} & \multicolumn{6}{|c|}{ Cumulative contribution (\%) of the $n$-largest daily runoff event } \\
\hline & & & 1 & 3 & 5 & 7 & 9 & 12 \\
\hline Asanat & 756 & 40 & 12.4 & 28.7 & 40.2 & 50.1 & 59.3 & 69.2 \\
\hline Debreyakob & 303 & 39 & 12.6 & 27.2 & 44.1 & 56.9 & 66.7 & 77.5 \\
\hline \multirow[t]{2}{*}{$\operatorname{Rim}$} & 1010 & 36 & 11.5 & 31.5 & 43.2 & 55.2 & 64.2 & 74.1 \\
\hline & & July-Sep.2015 & & & & & & \\
\hline Asanat & 756 & 49 & 11.9 & 30.4 & 46.1 & 55.2 & 60.7 & 68.8 \\
\hline Debreyakob & 303 & 47 & 12.7 & 31.0 & 44.2 & 56.4 & 61.9 & 71.6 \\
\hline Rim & 1010 & 47 & 8.9 & 24.8 & 36.8 & 46.8 & 54.5 & 64.0 \\
\hline
\end{tabular}

Table 4.7 Relative contribution of suspended sediment load produced by $n$-largest daily sediment load events, \% (2014-2015)

\begin{tabular}{|c|c|c|c|c|c|c|c|c|}
\hline \multirow{2}{*}{$\begin{array}{l}\text { Sub- } \\
\text { watershed }\end{array}$} & \multirow[t]{2}{*}{ Area, ha } & \multirow{2}{*}{$\begin{array}{l}\text { Total \# of daily events } \\
\text { July-Sep. } 2014\end{array}$} & \multicolumn{4}{|c|}{$\%$ n-largest daily sediment load event } & \multirow[b]{2}{*}{9} & \multirow[b]{2}{*}{12} \\
\hline & & & 1 & 3 & 5 & 7 & & \\
\hline Asanat & 756 & 40 & 12.0 & 35.51 & 52.07 & 64.16 & 72.79 & 81.25 \\
\hline Debreyakob & 303 & 39 & 14.1 & 37.54 & 57.44 & 70.62 & 79.43 & 84.37 \\
\hline \multirow[t]{2}{*}{ Rim } & 1010 & 36 & 13.2 & 37.03 & 55.53 & 69.25 & 71.08 & 76.22 \\
\hline & & July-Sep.2015 & & & & & & \\
\hline Asanat & 756 & 49 & 13.4 & 35.47 & 55.13 & 60.75 & 69.45 & 79.33 \\
\hline Debreyakob & 303 & 47 & 14.9 & 39.28 & 52.75 & 63.89 & 72.12 & 83.55 \\
\hline Rim & 1010 & 47 & 13.2 & 33.61 & 47.68 & 59.93 & 70.62 & 78.41 \\
\hline
\end{tabular}

Significant differences $(p<0.05)$ between the mean values were observed in Asanat and Rim for the 5-largest, 7-largest and 12-largest daily events in 2014 and 5-largest daily event in 2015. However, for Debreyakob significant differences $(p<0.05)$ were observed between almost all groups of largest contributions. The contribution of largest events to sediment load varied in relation to catchment size and rain season. The rates of sediment yield in Koga catchment are high and the time distribution of sediment load depends on few events due to the intrinsic nature of the climatic conditions (rain intensity).

\subsubsection{Hysteresis of hydrographs and sedigraphs}

The correlation between runoff and SSC for individual events was used as a framework to understand the linkage between peak runoff and SSC (orders of magnitude) or hysteresis (Hudson, 2003). The shape of the hydrographs and sedigraphs of single events of Asanat, Debreyakob and Rim showed distinct differences in the hydrological processes and 
sediment yield dynamics of streams. Because the study sub-watersheds are small ( $300-$ 1010 ha) with a short time of concentration, the hydrographs and sedigraphs are characterised by short lag times between peak runoff and sediment discharge and fast reduction in runoff. The lead and lag time between peak runoff discharge and SSC were used to describe hysteresis in Asanat, Debreyakob and Rim for selected individual events of different magnitudes in different parts of the rain season (Fig. 4.7). Complicated hysteresis, resulting from more than one time-peak or intermittent patterns of runoff and SSC, was observed for Debreyakob and Asanat sub-watersheds on July 15 and September 13, 2015 respectively. Linear hysteresis was found for all sub-watersheds on June 24, 2015 (Fig.4.7), positive hysteresis on July 15, 2015 in Asanat and Rim and negative hysteresis for Debreyakob on September 13, 2015. Overall, it can be deduced from Fig. 4.7 that the hysteresis graphs in the early rainy season were positive and linear, while later in the rainy season complicated and negative hysteresis occurred. This indicates the high sensitivity of the local sediment sources such as concentrated sediment inputs from rills and gullies and stream bank collapse at sub-watershed scale.

\subsection{Discussion}

\subsubsection{Correlation between rainfall, runoff and sediment yield}

The distinctive seasonal pattern of suspended sediment transport for the Koga stream subwatersheds suggests that sediment transport from hillslopes is more significant earlier in the rainy season. This is likely because of the highly erodible soils (due to break down of aggregate stability in field preparation) during the early rainy months, which could rapidly be transported into the channel due to the proximity of hillslopes and channels (Yeshaneh et al., 2014). Intensive rainfall after the long dry season in combination with low vegetation cover also contribute to high SSC at the start of the rainy season. The declining SSC curve at the end of the rainy season suggests that the supply of hillslope sediments has been exhausted, and that the erodibility of soil is greatly reduced due to vegetation cover. Only smaller amounts of suspended sediment are being supplied from the farmlands, due to a full vegetation (crop) cover in combination with the easily eroded particles having been removed already at the start of the rainy season. During this stage, most sediment comes from stream banks because of their steep bed slopes and saturation of fragile stream side slopes. Thus, exhaustion results not only in a reduction of sediment, but also in a change in the character of sediment transported by the river, as the relative amount of sand from bed material increases resulting in a change of erosion and sedimentation processes in stream profiles. 
Asanat
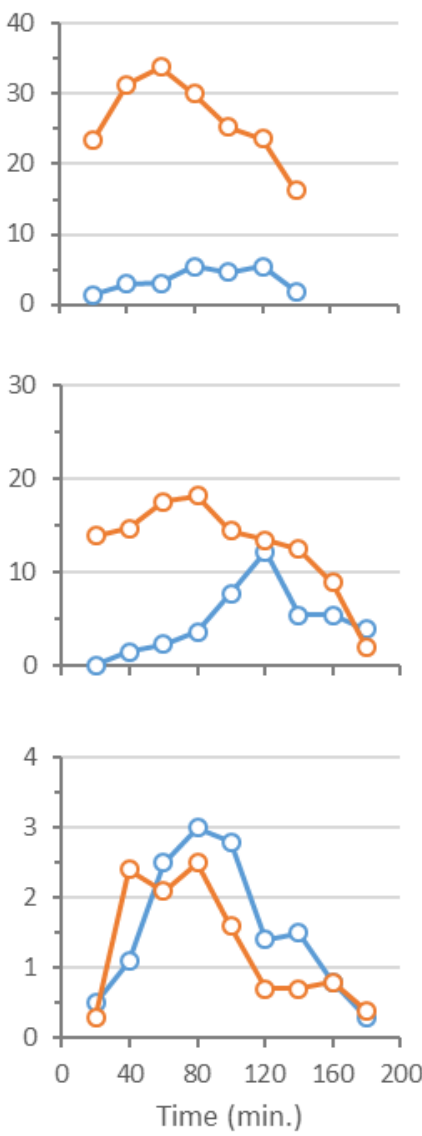

Debreyakob

June 24, 2015

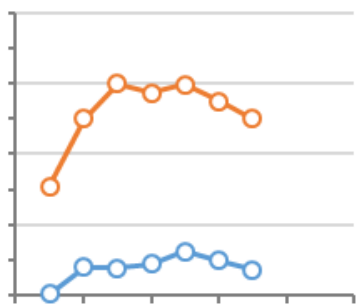

July 15,2015

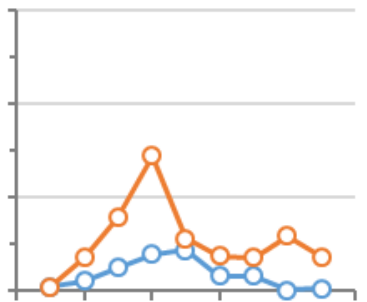

September 13, 2015

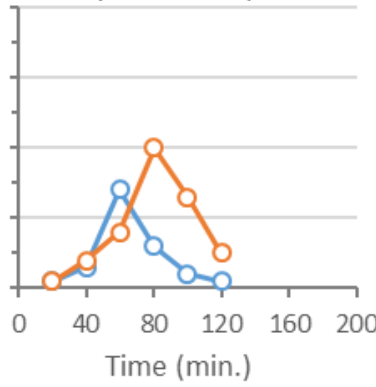

Runoff depth (cm)
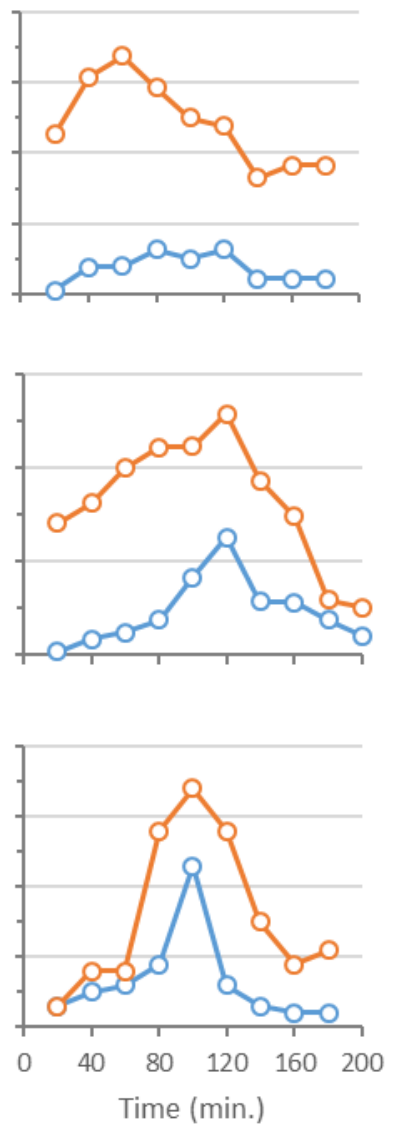

$\mathrm{SSC}(\mathrm{g} / \mathrm{l})$

Figure 4.7 Characteristics of hydrographs and sedigraphs for individual rain event in a) Asanat; b) Debreyakob and c) Rim (2015).

Late in the rainy season the river banks are saturated causing slipping and scouring from the bed of streams, which is dependent on the transport capacity of streams or shear stress, become an important source of sediment. This pattern could be common to all areas of Koga catchment where cultivated land is a major component of the drainage area. The significance runoff-SSC relations depends on the sensitivity of geomorphic systems and ecosystems (Wolman and Miller, 1960; Gallart et al., 2005; Zabaleta et al., 2007; LópezTarazón et al., 2009; Baptista et al., 2015; Wei et al., 2015). Later in the rainy season of hydrological year SSC declines because of rill formation and expansion also decline due to vegetation cover (Tebebu et al., 2010; Zegeye et al., 2010). The maximum daily suspended 
sediment concentration was slightly lower in Debreyakob compared to Asanat and Rim watersheds. This may be due to the SWC measures that have been installed at relative large scale in this sub-watershed (although SWC measures have been installed in the other two watersheds as well), being effective, in combination with more stable stream banks (lower stream bank erosion) (Jemberu et al., 2017).

Many other studies investigated the relation between rainfall, runoff and sediment yield. For example, in a study on response of runoff and sediment yield to changes in rainfall, Li and Gao (2015) found that runoff and sediment yield were strongly affected by the changes in rain intensity. Storms with increasing rain intensity yield highest quantities of total runoff and eroded sediments (Jungerius and Ten Harkel, 1994; Baartman et al., 2012). Another study by $\mathrm{Fu}$ et al. (2016) in Zhejiang province (China) indicated that rain intensity has stronger influence on sediment yield than slope length. According to Lana-Renault et al. (2007), the main factors that explain the variability of SSC during floods are the peak flow and rain intensity. Lubis et al. (2013) indicated that the fluctuation of river discharge and rain intensity have great effect on SSC in Pandang watershed in Indonesia.

A high degree of variability in SSC at similar runoff depth was observed, reflecting the differences in rainfall-runoff generation across study sub-watersheds. In this study, comparing the results for Asanat, Debreyakob and Rim, shown in Fig. 2a-c, 3 and Table 4.5, it was found that the distribution and degree of rainfall features, runoff and SSC were highly spatially and temporally variable between sub-watersheds. Moreover, the variation in annual rainfall determined the specific surface runoff and sediment yield across different months. Meanwhile, average rain intensity as a specific rainfall feature played a major role in runoff generation and soil loss across different spatial scales in Koga catchment. In line with this Wei et al. (2007) found a complex interaction between the spatial-temporal distributions of rainfall systems and watershed hydrological responses in the Loess Plateau of China. Vanmaercke et al. (2015) indicated that catchment runoff and sediment concentration depend on a wide range of variables and reflect the combined effect of all active and interacting runoff, erosion and sediment deposition processes. However, rain intensity had a more significant impact on runoff than on sediment yield (Vanmaercke et al., 2015; Zabaleta et al., 2007).

\subsubsection{Flow duration curves}

A sharp FDC end point, such as in Asanat, indicates high runoff generation from smaller rainfall events in short periods due to low catchment storage capacity as compared to Debre 
Yakob and Rim, probably due to steep slopes, shallow soils and poor conditions of the SWC measures in Asanat. Flat curves for lower runoff events in Rim and Debreyakob illustrate that the direct flows (stream discharge after rainfall) are sustained for longer periods due to relatively higher catchment storage capacity. Gentle slopes and deep soils contribute to relatively higher catchment storage capacity in Rim whereas efficient SWC measures in Debre Yakob might explain the lower response to smaller rainfall events. Thus, Asanat subwatershed is more likely dominated by direct flow while Debreyakob and Rim are characterised by higher base flow conditions. This is also evident from the intermittent nature of direct streamflow in Asanat which declines soon after the beginning of the dry season.

As the FDC of small catchment areas are very sensitive to local physiographic characteristics such as land use, geology, topography, investigation and analysis of FDC in such area is very valuable and needed (Banasik and Hejduk, 2013). Asanat sub-watershed with high gradient FDC at its end point end implies that storage capacity is regularly exceeded during periods of excess precipitation due to shallow soils and steep slope. Whereas catchment areas with low gradient and deep soil implies that the precipitation surplus is easily stored as a consequence of large storage capacity (Sugiyama et al., 2003). Thus, the lowest flows can be strongly affected by slope and soil depth as depicted by a sharp dip at the lower tail of the FDC (Vogel and Fennessey, 1994). According to Banasik and Hejduk (2013) the distribution of low flows is controlled chiefly by the geology and topography of the catchment area. Thus, the lower end of the FDC is a valuable means for studying the effect of geology and slope on runoff, erosion and sediment yield (Sauquet and Catalogne, 2011). Comparably, the steep FDC at the lower end of the FDC in Asanat indicated lower storage capacity and higher runoff response as compared to Debreyakob and Rim may be due to steep slopes and shallow soils. 


\subsubsection{Largest event contribution}

Although $\sim 50 \%$ of soil erosion occurs as a result of high-frequency, low-intensity rainfall events, large-magnitude, low-frequency events potentially contribute significantly to total erosion (Baartman et al., 2012). The variation in contribution of the largest events with catchment area is in line with previous results, e.g. those reported by Gonzalez-Hidalgo et al. (2010) in different catchments of the USA. An investigation by Griffiths et al. (2006) in Mojave desert, USA, indicated that flow variability and sediment production per unit area is larger in small catchments; this maximises the relative contribution of high magnitude events to the total sediment load. This indicates that events that generate a large discharge over a short duration play an important role in inducing severe soil erosion. This is in line with investigations in Spain by Kirkby et al. (2005) and in the Negev highlands by Yair and Raz-Yassif (2004) where few largest events formed the initial and essential driver of risks, tracks and degrees of soil erosion and surface hydrology. In line with this, in Debreyakob sub-water shed with lower catchment area, the contribution of largest daily runoff and sediment load events to total runoff and sediment rate were higher as compared to Asanat and Rim.

Sediment storage within catchments may increase with increase in catchment area (i.e. foot slopes deposits and terraces) that intensifies the reduction of sediment load with increasing catchment size (Williams, 1989; Griffiths et al., 2006; Parsons and Stone, 2006). The effect of the n-largest daily events decreases with basin area, and are not related to the absolute values of sediment export. Rim sub-watershed has a relatively larger area and showed a lower percentage contributions of $n$ largest events. The effect of the largest event on total sediment output emphasizes their importance and links to a common observation in tropical highlands, which is the lack of confidence in mean values that may be biased by the presence or absence of extreme events (Wolman and Miller, 1960; Beven et al., 1984; Williams, 1989; Lakew et al., 2014; Wei et al., 2015).

\subsection{4 hysteresis analysis}

It can be deduced from Fig. 4.7 that the hysteresis in the early rainy season were positive and linear, while later in the rainy season complicated and negative hysteresis occurred. This is due to higher lead time and lower lag time of SSC as compared to peak runoff (Hudson, 2003). Williams (1989) assumed that counter-clockwise hysteresis results from either: a difference between the flood wave velocity and the mean flow velocity that carries the suspended sediment, a high soil erodibility in combination with a prolonged erosion 
process during the flood, and a seasonal distribution of sediment production within the drainage basin. Anti-clockwise dominant hysteresis was reported by Yeshaneh et al. (2014) whereas mainly complicated hysteresis patterns are documented by Nyssen et al. (2008); Awulachew et al. (2010) in the Ethiopian highlands. Therefore, for catchment areas with high variability of hydrologic and meteorological parameters similar to Koga catchment, the use of hysteresis could not be appropriate for identifying soil erosion types, sediment transport processes and source areas on dynamic catchment characteristics.

During the middle and late rainy season, due to decline of rill formation and gully stabilization, contribution of nearby source areas is lower while the cumulative contribution of total contributing source areas come in later at event scale. Williams (1989) assumed that counter-clockwise hysteresis results from either: a difference between the flood wave velocity and the mean flow velocity that carries the suspended sediment, a high soil erodibility in combination with a prolonged erosion process during the flood, and a seasonal distribution of sediment production within the drainage basin.

\subsubsection{Further research}

The direct measurement of SSC and computing sediment load often uses only discrete suspended samples and continuous flow records. Besides, the sediment sampling does not take into account the turbidity and bed load transport. Therefore, the sediment load estimation using SSC and flow measurement usually underestimates sediment load (Nyssen et al., 2008; Williams, 1989). Therefore, sediment load dynamics can be accurately estimated using turbidity and sediment load modelling which incorporates the influence of small and peak runoff events (Guzman et al., 2013; Li and Gao, 2015). Further research should incorporate the relative contributions of effects of SWC measures at different spatial coverage for longer periods of time.

The runoff and sediment load dynamics were assessed using multiple regression models. However, these are lumped statistical models that cannot represent the explicit spatial scale and cannot be used for similar regions. However, the methods and procedures used in this study can be used to develop similar statistical models for similar regions to study runoff and sediment load dynamics at sub-watershed level. Moreover, estimating the contribution of individual runoff and sediment events to total sediment load, statistical tools (t-test, correlation and regression), the use of the features of flow duration curves, hydrographs and sedigraphs, are the important for assessment of spatial and temporal variability of runoff and sediment yield. 


\subsection{Conclusions}

Understanding of the patterns and variation of runoff and sedimentary processes and their control factors is essential for prediction of the hydrological response of small watersheds in sub-humid Ethiopian highlands. Very strong seasonal and event variation in rain intensity, runoff and sediment yield were found in all study sub-watersheds. Stepwise multiple regression analysis revealed that rain intensity was the strongest predictor of runoff and sediment discharge whereas large discharge events in the short time play an important role in inducing severe soil loss or sediment yield. Flow duration curves illustrate that discharge variability is high and storage capacity is low in Koga catchment specifically in Asanat. Areaspecific sediment yield was different for the study sub-watersheds. There was a striking difference between seasonal sediment and runoff dynamics, with suspended sediment concentration being very high at the start of the rainy season and gradually decreasing over time, while this did not follow the temporal dynamics of the runoff, which was low at the start of the rainy season and peaked halfway (end July - begin August). This is mostly due to the development of the vegetation cover and the higher susceptibility of the soils at the start of the rainy season because of sowing and field preparation (e.g. ploughing). The 5 largest events produced about $50 \%$ of total runoff and $>52 \%$ of the total sediment measured in the rainy season. Detailed runoff and SSC event analysis during different seasons showed three different types of hysteretic loops: linear and clockwise (mainly for early rain season), complex and negative for middle and late rainy season. This study confirms the complex and heterogeneous nature of sediment responses in Koga catchment. 


\section{Modelling the effect of soil and water conservation measures on soil erosion and sediment yield in the highlands of North- Western Ethiopia}

Soil and water conservation (SWC) measures have been implemented on a massive scale to prevent soil erosion in the Ethiopian highlands. However, very few methods exist to evaluate how implementation of such measures affects erosion and sedimentary processes. In this study, we simulated the effect of various SWC measures on soil erosion and sediment yield using the spatially distributed WATEM/SEDEM model. Field sampling and monitoring were performed to characterize erosion and sediment yields. GIS was used to calculate and analyze various model input parameters. WATEM/SEDEM was calibrated for three sub-watersheds in Koga catchment (Asanat, Debre Yakob and Rim). Five scenarios of SWC measures were evaluated: scenario I: a baseline condition (present-day situation) treated with bund structures; scenario II: bund structures and contour cultivation; Scenario III: a combination of bunds, contour cultivation and strip cropping; scenario IV: integrated use of bunds, contour cultivation, strip cropping and grass strips, and Scenario V: a scenario without SWC practices. The model simulation results showed that all SWC scenarios reduced soil erosion and sediment yield in all the sub-watersheds. Bund structures reduced soil erosion by more than 57, 65 and 53\% in Asanat, Debre Yakob and Rim sub-watersheds, respectively. The integrated use of bund structures, contour cultivation, strip cropping and grass strips (scenario IV) showed the largest effect on erosion and sediment yield. In scenario IV, compared to a scenario without SWC measures, sediment yield was reduced from 66.9 to $17.0 \mathrm{tha}^{-1} \mathrm{y}^{-1}$ in Asanat, 41.1 to $13.9 \mathrm{t} \mathrm{ha}^{-1} \mathrm{y}^{-1}$ in Debre Yakob and 59.0 to 12.5 tha $^{-1} y^{-1}$ in Rim sub watersheds. Bund structures and grass strips showed the largest contribution in controlling soil erosion and sediment yield in all study sub-watersheds. For the present-day situation, the measured and simulated erosion and sediment yield values were relatively lower for Debre Yakob which might be due to the lower transport capacity and sediment connectivity as a result of larger coverage of bunds and other conservation measures such as traditional ditches and diversion channels. This emphasizes the importance of integrated use of conservation strategies to reduce soil erosion and sediment delivery. This study illustrate that the measurement of sediment yield at the outlets of the catchment areas can be a poor indicator of upland soil erosion processes.

Based on:

Jemberu, W., Baartman, J., Fleskens, L., G.Selassie, Y., Ritsema, C.J. Modelling the effects of soil and water conservation measures on soil erosion and sediment yield in the highlands of North-Western Ethiopia. Hydrological Processes (to be submitted). 


\subsection{Introduction}

Despite many years of effort to reduce their effects, soil erosion and sedimentation are critical problems in the Ethiopian highlands (Nyssen et al., 2008; Setegn et al., 2009; Bayabil et al., 2010; Taye et al., 2013). Soil erosion causes not only on-site degradation of land resources but also off-site problems such as downstream sedimentation and deposition in fields, plains and water bodies (Zeleke and Hurni, 2001, Hurni et al., 2005, Yeshaneh et al., 2014). Loss of top soil and subsequent silting up of reservoirs degrades the environmental resources necessary for subsistence (Steenhuis et al., 1995; Hudson, 2003; Nyssen et al., 2009; Dagnew et al., 2015). This problem extends to downstream countries, Sudan and Egypt, because the Blue Nile drains the Ethiopian highlands and contributes sediment to downstream areas (Tessema, 2006; Nyssen et al., 2008; Bayabil et al., 2010; Setegn et al., 2010; Tilahun, 2012). To reverse land degradation, the government of Ethiopia launched a massive SWC program for the last three decades (Shiferaw and Holden, 1998; Herweg and Ludi, 1999; Mitiku et al., 2006). The interventions were focused on physical SWC strategies with emphasis on reducing accelerated erosion and downstream sedimentation (Desta, 2000; Zeleke and Hurni, 2001; Jemberu et al., 2017). However, sustainable land management (SLM) is not yet attained, with widespread failure of SWC measures (Herweg and Ludi, 1999; Gebrernichael et al., 2005; Tefera and Sterk, 2010).

Ex-ante determination of the effect of SWC strategies on soil erosion and sediment yield can support decision making about SLM (Nyssen et al., 2008; Setegn et al., 2010; Baptista et al., 2015). Some studies have indicated that the sediment load is reduced in the Ethiopian highlands by land use changes and widespread use of soil and water management strategies such as bund structures, check dams, flood-control ponds and water diversions (Gebrernichael et al., 2005; Gebreegziabher et al., 2009; Nyssen et al., 2010; Adimassu et al., 2014; Rust et al., 2014). However, few measurements are available to quantify the impacts of SWM strategies on soil erosion and sedimentary processes in the Ethiopian highlands, and modelling the linkage of on-site soil erosion rates within a catchment to the sediment yield at the outlet is often lacking due to lack of input data (Steenhuis et al., 1995; Nyssen et al., 2008; Adimassu et al., 2012; Haregeweyn et al., 2013; Grum et al., 2016).

Empirical lumped-approaches have been used to estimate sediment yield using the average basin characteristics such as area, drainage density, slope, land cover, soil type, etc. (Ritsema et al., 1996; Lenzi and Marchi, 2000; Nyssen et al., 2008; Setegn et al., 2010; Zhao et al., 2015). However, the validity of the equations resulting from such approaches is limited to the specific areas for which they have been established (Haregeweyn et al., 2008; Feng et al., 2010; Quiñonero-Rubio et al., 2016). Inherent to lumped approaches is that it is not possible to take into account the spatial structure of land use and topography within 
the catchment on erosion and sediment delivery (de Vente and Poesen, 2005; Haregeweyn et al., 2008; Tilahun et al., 2015). This inherently limits their applicability to practical problems such as the evaluation of different SWC measures on soil erosion and sediment delivery (Vandaele and Poesen, 1995; Van Rompaey et al., 2001; Zabaleta et al., 2007; Tamene et al., 2017). Likewise, the sediment yield measured at gauging stations of many river systems is only a fraction of the total sediment load delivered to reservoirs and dams in the downstream areas (Asselman, 1999; de Vente et al., 2006; Haregeweyn et al., 2008; Bayabil et al., 2010; Adimassu et al., 2014). These problems can be overcome by using a spatially distributed model, whereby the eroded sediment is explicitly routed over the landscape towards the river system, allowing the evaluation of the effect of SWC measures on erosion and sedimentation processes (Vandaele and Poesen, 1995; Romero-Díaz et al., 2007; Zabaleta et al., 2007; Wallinga et al., 2010; Wudneh et al., 2014; Zhao et al., 2015).

Spatially distributed models have been applied globally to support SWC decisions (BoixFayos et al., 2008; Betrie et al., 2011; Haregeweyn et al., 2013; Fleskens and Stringer, 2014; Lemann et al., 2016b). The spatially distributed Water and Tillage Erosion / Sediment Delivery Model (WATEM/SEDEM) provides estimates of long-term mean annual soil erosion rates and sediment yield (Van Rompaey et al., 2001; Van Oost et al., 2005; Van Rompaey et al., 2005; Verstraeten et al., 2007). Haregeweyn et al. (2013) used WATEM/SEDEM to assess sediment yield in Tigray region, Northern Ethiopia. Didoné et al. (2017) applied WATEM/SEDEM for evaluating the impact of SWC scenarios in southern Brazil. In SE Spain, WATEM/SEDEM was used to assess the impacts of check dams, land use change and forest restoration on sediment yield (Boix-Fayos et al., 2008; Quiñonero-Rubio et al., 2016).

Validation of the spatial pattern of erosion and sediment connectivity within the (treated) catchment is complicated and accurate prediction of sediment yield at outlets of subwatersheds does not mean that the spatial patterns of erosion and sediment yields are also accurately predicted (Bracken et al., 2015, Marchamalo et al., 2016; Takken et al., 1999). However, by simulating the spatial distribution of erosion, transport capacity, sediment routing and sediment deposition, the effects of SWC measures can be spatially evaluated (Feng et al., 2010; Quiñonero-Rubio et al., 2016). In modelling SWC measures, the routing algorithms can alter the transport capacity and sediment deposition patterns, while causing little change in predicted total erosion and sediment yield (Takken et al., 1999; Takken et al., 2005; Vigiak et al., 2006).

Based on previous experiences (Haregeweyn et al., 2013), the successful calibration of WATEM/SEDEM could be further used for evaluating of the effect of SWC measures on soil erosion and sediment delivery in the Ethiopian highlands. In this study, WATEM/SEDEM was applied to simulate the effect of alternative SWC scenarios at sub-watershed level to 
identify critical sediment source areas or erosion hotspots and to evaluate the effect of SWM strategies on soil erosion and sediment delivery. The objectives of the present study were: (1) to quantify the spatial distribution of soil erosion and sediment delivery at subwatershed scale; (2) to evaluate the effect of different SWC measures on soil erosion and sediment yield and (3) to determine the most effective set of SWC strategies using scenario analysis.

\subsection{Materials and methods}

\subsubsection{Study area}

Koga catchment is located south of Lake Tana, at the source of the Blue Nile, in the highlands of North-Western Ethiopia ( $37^{\circ} 02^{\prime \prime}-37^{0} 17^{\prime \prime}$ E longitude, $11^{0} 10^{\prime \prime}-11^{0} 25^{\prime \prime} \mathrm{N}$ latitude; Figure 5.1). The Koga catchment is a narrow and elongated catchment, which has a concentrated networks of water divides, with highly variable and rugged topography. The total area of the catchment is $230 \mathrm{~km}^{2}$ with elevations ranging from 1860 to $3128 \mathrm{~m}$ a.s.l. In this catchment, the annual rainfall pattern is unimodal and rainfall mostly occurs between June and September. The average annual temperature and rainfall are $18.4{ }^{\circ} \mathrm{C}$ and $1480 \mathrm{~mm}$, respectively. Approximately $86 \%$ of Koga catchment is cultivated land, while around $12 \%$ is forest and the remaining part fallow and grazing land. Koga catchment represents a typical Ethiopian sub-humid highland environment where SWC measures have been implemented on a massive scale to reduce the effect of soil erosion and sedimentation in downstream areas and reservoirs (Mekonnen et al., 2015). Three study sub-watersheds, Asanat, Debre Yakob and Rim, with drainage areas of 755, 303 and 1010 ha, were respectively selected at the upper, middle and lower reaches of Koga. Asanat is a hilly environment where more than $55 \%$ of the area has slopes of $15 \%-30 \%$ and $~ 11 \%$ of the area has slopes greater than $30 \%$. In Debre Yakob 32\% of the area has slopes of 15\%-30\% and about 33\% of the area has slopes of less than $10 \%$. Rim sub-watershed is relatively flat with $85 \%$ of the area having slopes of less than $10 \%$. Approximately, $72 \%$ of Asanat, $64 \%$ of Debre Yakob and $72 \%$ of Rim is cultivated land while around $12 \%, 18 \%$ and $55 \%$ is used for grazing in Asanat, Debre Yakob and Rim respectively. The study sub-watersheds drain to Koga river which in turn drains into Lake Tana. The soil types in Koga are classified as Leptosols, Luvisols, Nitosols, Vertisols and Fluvisols. At the lower elevations of the catchments, Luvisols are the dominant soil type; these areas are well-suited for agricultural production. Leptosols are the predominant soil type in the upper part of the catchments; these soils are less suitable for crop production. 


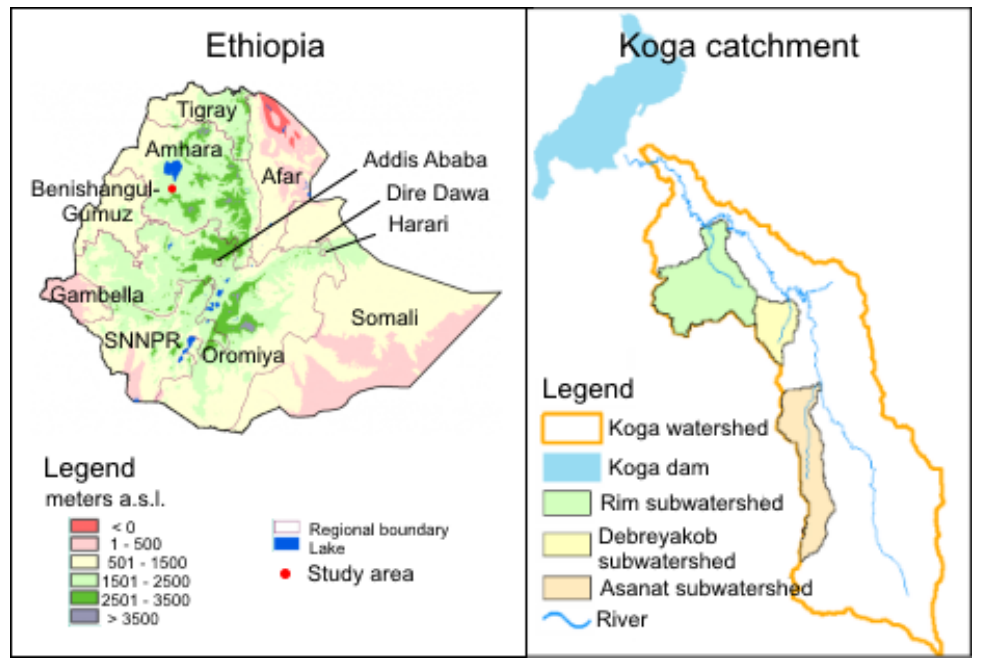

Figure 5.1 Location of Koga catchment in Ethiopia and study sub-watersheds within Koga catchment

\subsubsection{Field sampling and measurements}

Rainfall and stream discharge were automatically measured at the outlets of study subwatersheds at 10-minutes intervals using Hobo data logger rain gauges and pressure transducer divers, respectively for periods 2014-2015. Thus stream discharge was estimated from depth measurements using rating curves calculated from the monitoring diver stations (Jemberu et al. sub.). One-litre SSC samples were taken manually for all rainfall events during the rainy season of 2014 and 2015. Sampling during a rainfall event started when the discharge developed and when the water at each outlet looked brown. About 3-8 representative samples were taken for each rain event based on fluctuation of flow depth. Due to large discharge, it was often impossible to sample sediment from an entire water column. However, since the flow was very turbulent during those events, a good mixing of sediments was observed from the brown colour of storm water for the rising and receding limbs of the flood so we assumed samples were representative for the full water column. Each sample was filtered using Whatman filter paper with a pore opening of $2.5 \mu \mathrm{m}$, oven dried and weighted to allow determination of dry sediment mass. A total of 101 one-litre samples for Asanat, 98 for Debre Yakob and 105 for Rim were taken during the rainy seasons of 2014 and 2015. The sediment yield (SY), in tonnes per day, for the stream's cross-section was then obtained by multiplying the concentration, $C(g / l)$ by the discharge $Q\left(\mathrm{~m}^{3} / \mathrm{s}\right)$ (Asselman, 2000; Morehead et al., 2003; Moliere et al., 2004).

$\mathrm{SY}=\mathrm{C} * \mathrm{Q} * 86.4$

Where 86.4 is a factor to convert to ton/ha. 


\subsubsection{WATEM/SEDEM model description}

The WATEM/SEDEM model was developed to predict sediment yield for different catchment scales with limited data requirements (Van Oost et al., 2000; Van Rompaey et al., 2001, 2002). WATEM/SEDEM is a sediment delivery model that calculates how much sediment is transported to the river channel on an annual basis (Van Oost et al., 2000; Van Rompaey et al., 2001; Van Rompaey et al., 2005). It is a spatially distributed model; for each grid cell, mean annual soil erosion and mean annual transport capacity are calculated (Van Oost et al., 2000; Van Rompaey et al., 2001; Verstraeten et al., 2002). WATEM/SEDEM comprises of soil erosion and sediment transport capacity assessment, and sediment routing processes (Van Oost et al., 2000; Van Rompaey et al., 2001). The model enables exploring the spatial pattern of sediment sources, erosion hotspot areas and annual sediment delivery. The effect of various existing or new SWC measures can be evaluated by the way they impact on spatial patterns, rates and processes of soil erosion (Van Rompaey et al., 2002; Didoné et al., 2017).

The model calculations are based on a spatially distributed assessment of mean annual soil erosion using the Revised Universal Soil Loss Equation (RUSLE) and mean annual sediment transport capacity (TC) (Desmet and Govers, 1996; Verstraeten and Poesen, 2000, 2001; Van Rompaey et al., 2005; de Vente et al., 2008). An adapted version of the RUSLE (Renard, 1997) is used:

$S E=R * K * L S(i, j) * C * P$

Where:

$\mathrm{SE}=$ Mean annual soil loss $\left(\mathrm{kg} \mathrm{m}^{-2} \mathrm{y}^{-1}\right)$

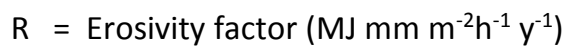

$\mathrm{K}=$ Erodibility factor $\left(\mathrm{kg} \mathrm{h} \mathrm{MJ}^{-1} \mathrm{~mm}^{-1}\right)$

LS $(i, j)=$ Two-dimensional slope gradient and slope length factor of $(i, j)$ coordinates

$\mathrm{C}=$ Crop management factor

$\mathrm{P}=$ Erosion control factor

The two dimensional slope length and steepness factor $L S(i, j)$ were calculated based on an algorithm proposed by Desmet and Govers (1996):

$$
\begin{aligned}
& L S(i, j)=\left[\left(A i, j+D^{2}\right)^{m+1}-A(i, j)^{m+1}\left(6.8 S g(i, j)^{0.8}\right)\right] / D^{m+2} X(i, j)^{m}(22.13)^{m} \\
& X(i, j)=\sin \alpha(i, j)+\cos \alpha(i, j)
\end{aligned}
$$


Where:

$A(i, j)$ is the runoff contributing area at the inlet of a grid cell $\left(m^{2}\right)$; $D$ is the length of the side of a grid cell $(m) ; S g(i, j)$ is the slope gradient of the grid cell $(i . j) ; \alpha(i, j)$ is the aspect of the grid cell $(i, j)$; and $m$ is the slope length exponent.

This two-dimensional approach of the RUSLE not only accounts for inter-rill and rill erosion but also for smaller ephemeral gullies as the effects of flow convergence are explicitly accounted for (Desmet and Govers, 1996).

\subsubsection{Transport capacity and sediment routing}

Transport capacity (TC) is the maximum potential sediment that can exit down slope of a grid cell per unit length $\left(\mathrm{kg} \mathrm{m}^{-1}\right)$. For each cell in arable and non-arable land use types, different TC values were considered and the original TC which considers the transport capacity as a function of potential rill and interrill erosion was used in this study (Van Oost et al., 2000; Van Rompaey et al., 2001; Van Rompaey et al., 2002).

$\mathrm{TC}=\mathrm{KTC} * \mathrm{R} * \mathrm{~K} *\left(\mathrm{LS}(\mathrm{i}, \mathrm{j})-4.1 \mathrm{~S}_{\mathrm{IR}}\right)$

Where:

$\mathrm{TC}=$ Transport capacity $\left(\mathrm{kg} \mathrm{m}^{-1} \mathrm{y}^{-1}\right)$

KTC $=$ Transport capacity coefficient $(\mathrm{m})$

$\mathrm{SIR}_{\mathrm{R}}=$ inter-rill slope gradient $\left(\mathrm{mm}^{-1}\right)$

KTC describes the proportionality between the potential for rill erosion and TC. It can be interpreted as the theoretical upslope distance that is needed to produce enough sediment to reach the TC at the grid cell, assuming a uniform slope and runoff discharge.

The inter rill slope gradient is calculated based on Govers and Poesen (1988) as follows.

$\mathrm{S}_{\mathrm{IR}}=6.86 \mathrm{~S}^{0.8}$

Where: $\mathrm{S}$ is slope gradient $\left(\mathrm{m} \mathrm{m}^{-1}\right)$

WATEM/SEDEM employs a routing algorithm to transfer the eroded sediment from the source to the river network using a multiple flow algorithm (Desmet and Govers, 1996; Van Rompaey et al., 2001; Haregeweyn et al., 2013). The original TC equation (Equation 5) allows the model to represent gully erosion through flow concentrations and preferential channel pathways connected with rivers (Van Rompaey et al., 2001; Verstraeten et al., 2007). The routing algorithms in treated catchment areas can alter the TC and sediment deposition patterns, while causing little change in predicted total erosion and sediment yield (Takken 
et al., 1999; Takken et al., 2005; Vigiak et al., 2006). Thus, following the flow path, the sediment is transferred downslope if the local transport capacity is higher than the incoming sediment volume. If the transport capacity is lower than the incoming sediment volume, sediment deposition occurs. The output of the model consists of a map indicating the amount of soil erosion or deposition at each pixel depending on transport capacity.

To investigate sediment connectivity, a sediment delivery ratio (SDR) approach that takes into account the spatial distribution of gross erosion and deposition processes was used, as suggested by Atkinson (1995), Baartman et al. (2013) and Ferro et al. (1998). Hence, attempts to model connectivity have been made by studying the SDR in order to accommodate gross erosion estimate of soil loss to values observed at a catchment outlets (Ferro and Porto, 2000; Van Rompaey et al., 2001) as follow:

$\mathrm{SDR}=\mathrm{SY} / \mathrm{E}$

Where,

SDR = the sediment delivery ratio

$\mathrm{SY}=$ sediment yield

$\mathrm{E}=$ gross erosion per unit area

\subsubsection{WATEM/SEDEM input data}

The rainfall erosivity factor $(R)$ was derived from the relationship between annual rainfall

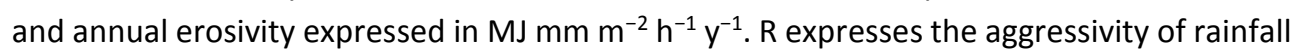
and kinetic energy (KE) is generally suggested to indicate the ability of a raindrop to detach soil particles from a soil mass (Renard, 1997; Nearing et al., 2005). R was calculated using the following formula proposed by Renard (1997) and Nearing et al. (2005):

$\mathrm{R}=\frac{\sum_{i=1}^{j}(E * I 30) i}{N}$

Where,

$\mathrm{E}=$ the total storm energy $(\mathrm{MJ})$

$I_{30}=$ the maximum 30 -minute intensity $\left(\mathrm{mm} \mathrm{h}^{-1}\right)$ of daily rainfall $\mathrm{i}$,

$\mathrm{j}=$ the number of rain events in an $\mathrm{N}$ year period

$\mathrm{N}=$ the number of observation years.

Total storm energy was determined using:

$E=1.213+0.89 \log I$ 
Where,

$E=$ is kinetic energy of each rainstorm $\mathrm{KJ} \mathrm{m}^{-2} \mathrm{~mm}^{-1}$

$\mathrm{I}=$ is average intensity of daily rainfall $\mathrm{i}$.

The erodibility ( $\mathrm{t} \mathrm{h} \mathrm{MJ} \mathrm{Mm}^{-1}$ ) of the soil was calculated from soil properties using the following equation proposed by Wischmeier and Smith (1978), Hudson (1993), Renard (1997):

$K=\left[\left(2.1 * 10^{-4} \mathrm{M}^{1.14}(12-\mathrm{OM})\right)+3.25(\mathrm{~S}-2)+2.5(\mathrm{P}-3)\right] / 7.59$

Where,

$M$ (the textural factor $)=(\%$ silt $+\%$ sand $) *(100-\%$ clay $) ;$

$\mathrm{OM}=\%$ organic matter

$\mathrm{S}$ and $\mathrm{P}$ are field-determined average values of aggregate structure and permeability classes described as follows:

$\mathrm{S}=$ Aggregate/structural class with values (1-4): 1 for very fine, 2 for fine, 3 for medium coarse, 4 for massive structure respectively, and

$\mathrm{P}=$ Permeable class with values (1-6)]: 1 for fast, 2 for fast to moderate, 3 for moderate, 4 for low to moderate, 5 for low, and 6 for very low permeability respectively.

The remaining RUSLE parameters, crop management $(C)$ factor and erosion control factor (P) factor, were consulted from the literature (Hurni, 1985; Renard, 1997). Annual values of the C-factor were determined based on the land use types defined by a previous study (Hurni, 1985), and spatially attributed based on the current land cover (Renald, 1997). The P-factor values were determined based on the types of SWC measures implemented in different areas (Table 5.1). The P-factor represents the ratio of soil loss with conservation measures to a reference plot without conservation measures: a value of one refers to a cultivated land without conservation practice.

Table 5.1 Crop management (C) factor and the physical conservation (P)factor for Ethiopian highlands

\begin{tabular}{llll}
\hline Land use & C factor & SWC measure & P factor \\
\hline Cultivated & 0.19 & Bunds & 0.42 \\
Degraded pasture & 0.05 & Grass strips & 0.70 \\
Dense grass & 0.01 & Contour cultivation & 0.91 \\
Forest & 0.008 & Strip cropping & 0.84 \\
Bushland & 0.04 & Fallow ploughed & 0.65 \\
miscellaneous land & 0.05 & No conservation & 1.00 \\
\hline
\end{tabular}

Source: Hurni (1985)

The P-factor considers the interaction of LS (i,j) attributes and vegetation cover (C-factor), as well as the direction of flow and TC, which depends on the type and effectiveness of 
physical conservation measures (Renard, 1997, Foster, 2002). Therefore, P-factor and Cfactor values were used in the WATEM/SEDEM model to verify the responses of different SWC scenarios to soil erosion and sediment yield in the study sub-watersheds. The P-factor values for the different supporting conservation practices were adoptable to local study sites environmental contexts (Wischmeier and Smith, 1978; Renard, 1997; Foster, 2002) and thus the compounding P-factor for different scenarios of SWC measures were calculated as follows:

$\mathrm{P}=\mathrm{P}_{\mathrm{B}} * \mathrm{P}_{\mathrm{CC}} * \mathrm{P}_{\mathrm{SC}} * \mathrm{P}_{\mathrm{GS}}$

Where $\mathrm{P}_{\mathrm{B}}, \mathrm{P}_{\mathrm{CC}}, \mathrm{P}_{\mathrm{SC}}$ and $\mathrm{P}_{\mathrm{GS}}$ are conservation practice sub-factors for bund structures, contour cultivation, strip cropping and grass strips respectively (Table 5.1). The Parcel trap efficiency in WATEM/SEDEM, Ptef, refers to the way each pixel's runoff contribution to the upstream contributing area is reduced. This means that for different land use types, less runoff is simulated, thereby decreasing downstream LS (i,j) values and erosion rate by Ptef (Van Oost et al., 2000; Van Rompaey et al., 2001). Ptef values of 10 for cultivated lands and 75 for pasture and forests were chosen based on the optimal or KTC(h) during model calibration. A DEM with $20 \mathrm{~m}$ resolution was derived from global SRTM topographic data by resampling $30 \mathrm{~m}$ resolution and the land use map was created from Landsat GLSTM_2000 image. Besides, a parcel map was created by the model by combining the DEM, stream, road, forest, arable land, pasture and catchment area delineations to account for the effect of landscape structure on soil erosion and sedimentation processes (Van Oost et al., 2000). A parcel map is a reclassified land use map that takes a distinction between, arable land, forest, pasture, roads, infrastructures, rivers and build-up areas. This makes it possible to incorporate the effect of field borders on runoff diversion, runoff interception, erosion and sediment deposition (Van Rompaey et al., 2001; Van Rompaey et al., 2007).

\subsubsection{SWC scenarios}

The SWC scenarios evaluated in this study were developed based on a biophysical inventory, farmers' perception (Jemberu et al., 2018) and the regional government's five year strategy program in the study sub-watersheds to select promising conservation strategies. Three conservation strategies, including physical (bund structures), agronomic (strip cropping and contour cultivation) and vegetative (grass strips) measures were created for the three sub-watersheds of Koga catchment to determine where each type of or combination of SWC measures can be implemented. Consequently, soil erosion, sediment deposition and sediment yields were simulated for five alternative scenarios of SWC measures described as follows. Scenario I: a baseline condition (present-day situation) 
including existing bund structures; Scenario II: existing bund structures and contour cultivation; Scenario III: combination of bunds, contour cultivation and strip cropping; Scenario IV: integrated use of bunds, contour cultivation, strip cropping and grass strips; and Scenario V: a scenario without SWC practices (Table 5.2).

Table 5.2 SWC scenarios simulated for Asanat, Debre Yakob and Rim sub-watersheds.

\begin{tabular}{llll}
\hline Scenario & Physical measure & Agronomic practices & Vegetative measure \\
\hline Scenario I & Bunds & - & - \\
Scenario II & Bunds & CC & - \\
Scenario III & Bunds & $\mathrm{CC}+\mathrm{SC}$ & - \\
Scenario IV & Bunds & $\mathrm{CC}+\mathrm{SC}$ & $\mathrm{GS}$ \\
Scenario V & No & - & - \\
\hline
\end{tabular}

NO: no SWC, CC: contour cultivation, SC: strip cropping, GS: grass strips

\subsubsection{Model calibration}

We calibrated and validated WATEM/SEDEM for this study based on sediment yields measured at the three study sub-watersheds of Koga catchment from 2014 to 2015 . The sediment yield data of 2014 was used for calibration and that of 2015 to validate the performance of the model. The model was calibrated based on area-specific and absolute sediment yield (by minimizing the difference between measured and simulated values) since the objective of the study was to assess the effect of SWC measures on soil loss and sedimentary processes for various SWC scenarios at sub-watershed level. The model was first calibrated for the baseline scenario (scenario I) by changing the maximum and minimum values of the KTC or KTC (h) and KTC (I). The model was sensitive to KTC (h) and less sensitive to $\mathrm{KTC}(\mathrm{I})$ whereas the model was insensitive to the threshold $\mathrm{KTC}(\mathrm{t})$ value. The $\mathrm{KTC}(\mathrm{t})$ was set at 0.1 for arable and 0.01 for non-arable land uses for all sub-watersheds. After calibration, the model was run for the four remaining SWC scenarios.

The Nash-Sutcliff efficiency (NSE) statistic was applied to evaluate the efficiency of the model. NSE is a normalized statistic determining the relative magnitude of residual variance (between predicted and observed values) compared with the measured data variance. NSE values between 0 and 1.0 demonstrate model efficiency; the closer the value of NSE approaches 1 , the more efficient is the model. A satisfactory model should have NSE $>0.50$ (Baartman et al., 2012). The accuracy of the model in predicting soil erosion for these scenarios was also assessed qualitatively by relating to previous studies on soil erosion (Jemberu et al., 2018) and available literature for similar areas (Herweg and Ludi, 1999; Bewket and Sterk, 2003; Mitiku et al., 2006; Nyssen et al., 2010). 


\subsection{Results and discussions}

\subsubsection{Model calibration and validation results}

In Rim sub-watershed, $\mathrm{KTC}(\mathrm{h})$ values of 350 and $\mathrm{KTC}(\mathrm{I}) 75$ delivered optimal model performance, whereas a KTC (h) value of 250 and $\mathrm{KTC}(\mathrm{I})$ value 25 were optimal in Asanat and Debre Yakob sub-watersheds. The observed and predicted sediment yields were 35.6 and $36.1 \mathrm{t} \mathrm{ha}^{-1} \mathrm{y}^{-1}$ for Asanat, 24.4 and $25.1 \mathrm{t} \mathrm{ha}^{-1} \mathrm{y}^{-1}$ for Debre Yakob and 31.7 and $32.5 \mathrm{t}$ ha${ }^{1} \mathrm{y}^{-1}$ for Rim respectively, with corresponding NSE values of 0.81 in Asanat, 0.56 in Debre Yakob and 0.72 in Rim at optimal values of KTC(h) (Figure 5.2). Generally the model overpredicted sediment yield in all sub-watersheds (Table 5.3). This may be partially attributed to considerable effects of SWC measures on soil erosion and transport capacity (Van Rompaey et al., 2005, Haregeweyn et al., 2013). The majority of cultivated lands of the study sub-watersheds are treated with bund structures. Although bunds had variable spacing, a routing algorithm was used for all bunds by creating a specific parcel map layer for all bunds. The model showed relatively higher performance in Asanat sub-watershed. This is likely due to a well-defined parcel map layer, and LS (i.j) and flow routing algorithm as a result of narrow and uniform spacing of bunds compared to Rim and Debreyakob. The parcel connectivity in each pixel, Ptef and P-factor, which together adjust the effect of bunds on erosion, accurately represent the situation on the ground in Asanat.

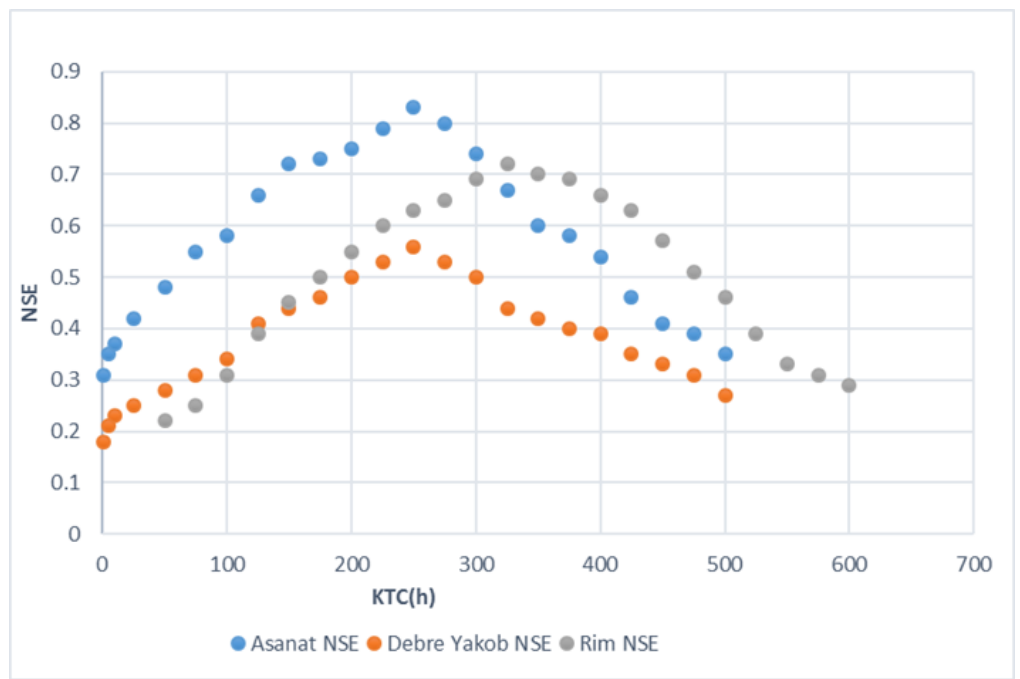

Figure 5.2 The KTC(h) calibration curves for Asanat, Debre Yakob and Rim sub-watersheds 
Table 5.3 Observed and predicted sediment yield $\left(\mathrm{t} \mathrm{ha}^{-1} \mathrm{y}^{-1}\right)$ for the study sub-watersheds

\begin{tabular}{llll}
\hline Sub-watershed & Observed SY & Predicted SY & NSE \\
\hline Asanat & 35.6 & 36.1 & 0.83 \\
Debre Yakob & 24.4 & 25.1 & 0.56 \\
Rim & 31.7 & 32.5 & 0.72 \\
\hline
\end{tabular}

SY: sediment yield, NSE: Nash-Sutcliff efficiency

\subsubsection{The effect of SWC measures on rate and patterns of soil erosion}

The net soil erosion maps as calculated by WATEM/SEDEM for the three study subwatersheds are given in Figures 5.3-5.5. The mean annual soil erosion rate calculated from the sum of mean annual sediment production and sediment deposition simulated by WATEM/SEDEM for the study watersheds are given in Table 5.4. The simulated soil erosion indicates high spatial variation in all study sub-watersheds.

Table 5.4 The results of total erosion, sediment deposition and yield ( $\left.t \mathrm{ha}^{-1} \mathrm{y}^{-1}\right)$ estimated by WATEM/SEDEM for the study sub-watersheds.

\begin{tabular}{lllll}
\hline Asanat & & & & \\
Scenario & SWC measures & Erosion & Deposition & Sediment yield \\
\hline I & B & 51.7 & 15.6 & 36.1 \\
II & B+CC & 47.9 & 14.5 & 33.4 \\
III & B+CC+SC & 45.6 & 13.8 & 31.8 \\
IV & B+CC+SC+GS & 35.6 & 18.6 & 17.0 \\
V & NO & 81.2 & 14.3 & 66.9 \\
\hline Debre Yakob & & & \\
Scenario & SWC measures & Erosion & Deposition & Sediment yield \\
\hline I & B & 40.5 & 15.4 & 25.1 \\
II & B+CC & 36.8 & 13.3 & 23.5 \\
III & B+CC+SC & 32.9 & 10.7 & 22.2 \\
IV & B+CC+SC+GS & 25.3 & 11.4 & 13.9 \\
V & NO & 66.8 & 25.7 & 41.1 \\
\hline Rim & & \multicolumn{5}{l}{} \\
Scenario & SWC measures & Erosion & Deposition & Sediment yield \\
\hline I & B & 44.9 & 12.4 & 32.5 \\
II & B+C & 39.0 & 11.7 & 27.3 \\
III & B+CC+SC & 34.3 & 12.6 & 21.7 \\
IV & B+CC+SC+GS & 24.5 & 12.0 & 12.5 \\
V & NO & 68.7 & 9.7 & 59.0 \\
\hline no SWC; B: bunds; CC: contour cultivation; SC: strip cropping; GS: grass strips
\end{tabular}

The results of the model with SWC scenarios show a progressive decrease in soil erosion, indicating a considerable effect of SWC measures. When comparing the present-day situation (scenario I) with a situation without SWC measures (scenario V), simulated soil erosion is more than $57 \%$ lower in Asanat, 65\% in Debre Yakob and 53\% in Rim subwatersheds. In scenario II (bunds and contour cultivation), erosion rates were further 
decreased by $8 \%$ in Asanat, $10 \%$ in Debre Yakob and $15 \%$ in Rim with respect to current conditions. In scenario III, $5 \%$ less erosion was observed in Asanat, $12 \%$ less in Debre Yakob and $14 \%$ less in Rim compared to scenario II. The largest reduction of soil erosion was simulated for scenario IV in all study sub-watersheds (Table 5.4). In scenario IV (combination of bunds, contour cultivation, strip cropping and grass strips), soil erosion was decreased by 128, 164 and 180\% in Asanat, Debre Yakob and Rim, respectively, when compared to scenario V (no SWC measures) and by 45,61 and $83 \%$ when compared to scenario I (present situation).
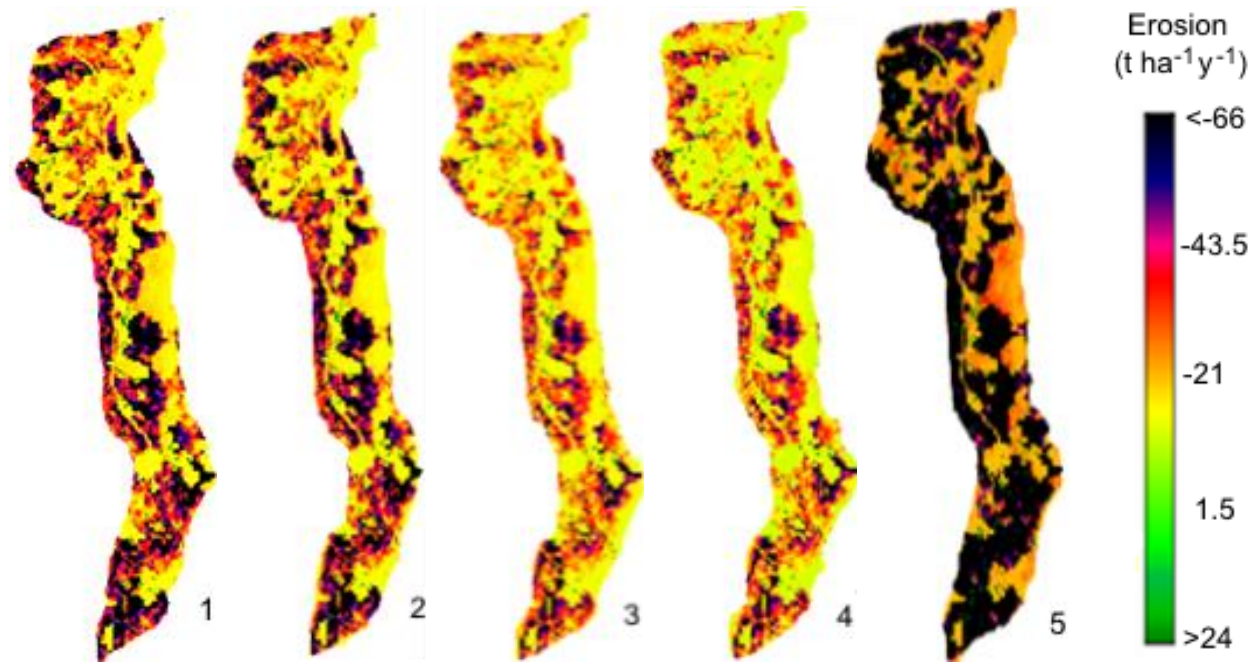

Figure 5.3 Spatial pattern of soil erosion within the Asanat sub-watershed, according to the scenarios (I-V) simulated with the WATEM/SEDEM. Negative values represent net erosion whereas positive values present deposition.

Soil erosion was reduced by a higher percentage in Debre Yakob than for Asanat and Rim when comparing the present day situation to a scenario where sub-catchments would be untreated (scenario V). This may be due to a larger coverage of bund structures and other conservation measures such as traditional ditches, diversions and check dams in Debreyakob. Relatively, contour cultivation, strip cropping and grass strips were more effective in reducing soil erosion in Rim compared to Debre Yakob and Asanat (Table 5.4). This is most likely due to the topographic characteristics in Rim. On steeper slopes, agronomic measures such as contour cultivation and strip cultivation are less effective in reducing soil erosion. Although soil erosion and/or sediment yield is reduced in the presentday situation (scenario I) as compared with a 'no SWC measures' situation (scenario V), in most parts of the cultivated lands of the study sub-watersheds still high rates of erosion were simulated. This emphasises the requirement to combine various conservation 
strategies to reduce soil erosion and sediment delivery in the study sub-watersheds. From the analysis of the present-day situation, the erosion map suggests that areas with greatest soil erosion are concentrated on locations with steep slopes and/or areas with poor bund structures (smaller dimensions and wider spacing). Lower erosion rates in intervention scenarios II-IV correspond to areas treated with effective bund structures, including upgrading of the stability of bund structures. Extremely high erosion rates ( $>66 \mathrm{t} \mathrm{ha}^{-1}$ ) were observed over large parts of cultivated lands in Asanat whereas higher deposition areas were concentrated in Debre Yakob and in the downstream part of Rim (Figure 5.3-5.5).
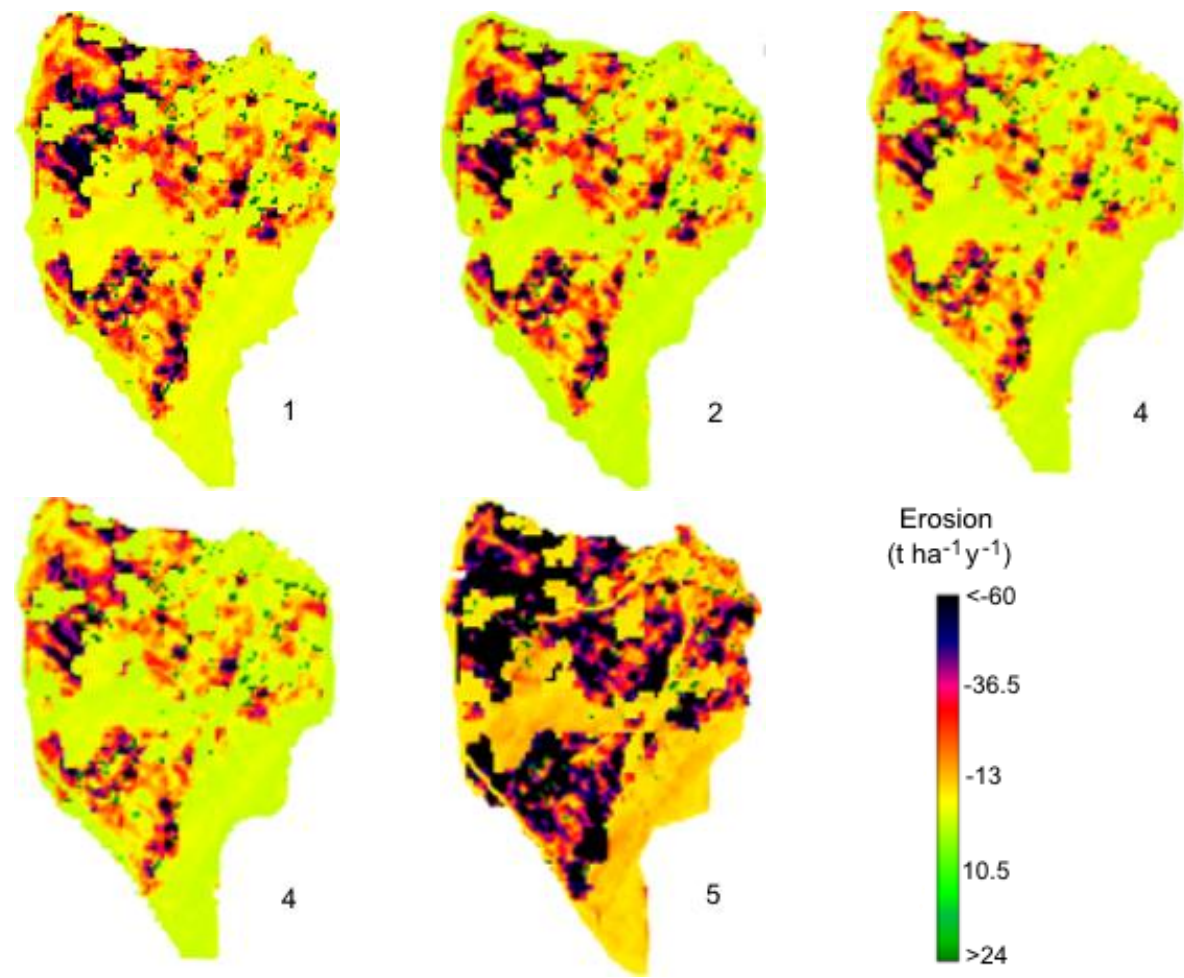

Figure 5.4 Spatial pattern of soil erosion within the Debre Yakob sub-watershed, according to the scenarios (I-V) simulated with the WATEM/SEDEM. Negative values represent net erosion whereas positive values present deposition.

Comparison of these model results with the range of soil erosion rates reported for cultivated lands treated with SWC measures shows generally good agreement. The model predicts reasonably acceptable ranges of soil erosion as compared to annual soil loss observed in treated farm plots in previous studies in similar areas in the Ethiopian highlands (Bewket and Sterk, 2003; Mitiku et al., 2006). Herweg and Ludi (1999) estimated an average soil loss reduction of $40 \%$ by graded soil bunds and $50 \%$ reduction with fanyajuu bunds in 
Anjeni, Ethiopian highlands. Another study in Tigray, Northern Ethiopia by Vancampenhout et al. (2006) found that stone bunds trapped $64 \%$ of soil otherwise lossed by soil erosion.
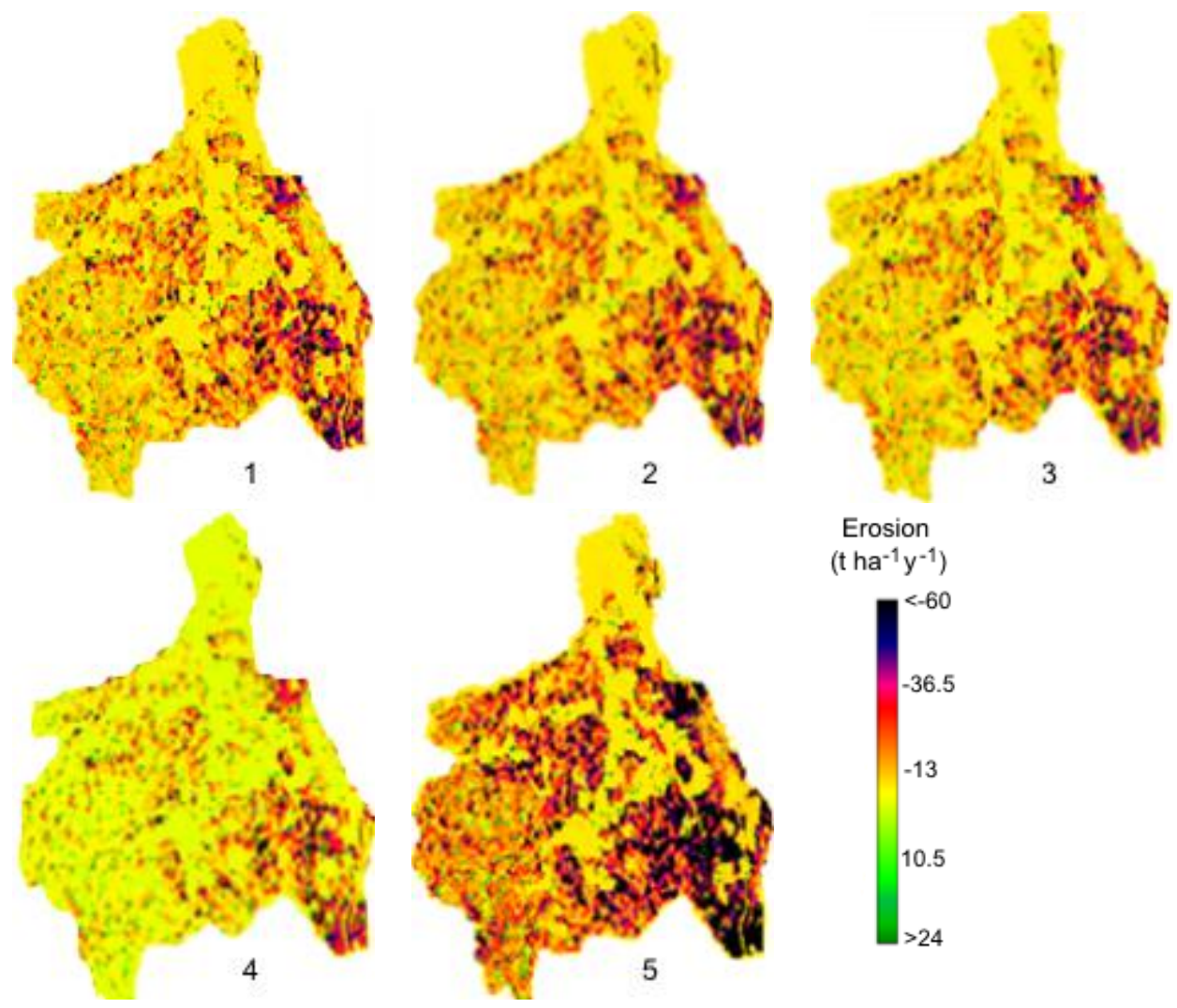

Figure 5.5 Spatial pattern of soil erosion within the Rim sub-watershed, according to the scenarios (I-V) simulated with the WATEM/SEDEM. Negative values represent net erosion whereas positive present deposition.

Simulation of the effect of physical SWC measures (bunds and diversion channels) on sediment yield with the Soil and Water Assessment Tool (SWAT) in the upper blue Nile basin by Lemann et al. (2016a) estimated an average sediment yield reduction of $54 \%$ while Dagnew et al. (2015) found a 57\% decrease in suspended sediment concentration (SSC) at Debremewi sub-watershed in NW Ethiopian highlands. A similar study in Kenya reported by Hessel and Tenge (2008) show that LISEM-simulated physical SWC scenarios decreased erosion by $60 \%$ in an agricultural catchment. Subhatu et al. (2017) estimated $32-37 \mathrm{t} \mathrm{ha}^{-1} \mathrm{y}^{-}$ ${ }^{1}$ soil loss using the USLE in treated catchment of Minichet, North Ethiopian highlands. 
The estimate made on impacts of SWC measures in this study also agrees well with another model-based soil erosion estimation for treated catchments by Hessel et al. (2003) where soil loss was decreased by $60 \%$ by simulating the impacts of SWC measures using LISEM (Limburg Soil Erosion Model). Nyssen et al. (2007) estimated a 0.32 conservation practice P-factor for bund structures in USLE and estimated soil loss rates of $58 \mathrm{t} \mathrm{ha}^{-1} \mathrm{y}^{-1}$ in the Tigray region of Northern Ethiopia. In a related study, Nyssen et al. (2006) investigated the effects of SWC measures using the WOFOST and LISEM models for Tigray and found a $68 \%$ reduction of soil erosion due to bund structures. In their assessment of landscape susceptibility to soil erosion using a GIS-based approach in North Ethiopia, Tamene et al. (2017) predicted a mean annual soil loss of $45 \mathrm{t} \mathrm{ha}^{-1} \mathrm{y}^{-1}$ using RUSLE for treated cultivated lands.

The large variation in predicted erosion rates across the study sub-watersheds reflects the high spatial variation of factors potentially influencing soil erosion. The effect of SWC measures on soil erosion was not uniform for the same land use types and slope classes. This emphasises that the effectiveness of SWC measures on controlling erosion depends on biophysical factors such as topography, land use and geology, etc. Furthermore, the spatial pattern and type of land use are relevant to erosion because changes in land use can alter the efficiency of SWC measures to control soil erosion within sub-watersheds (Desmet and Govers, 1995). Roads, field boundaries and other landscape structures also affect the efficiency of SWC measures to prevent soil erosion and sedimentation between various land units (Van Rompaey et al., 2001). This effect is well accounted in WATEM/SEDEM by incorporating a parcel map (Van Rompaey et al., 2001). The spatial variation of various conservation scenarios clearly indicates the importance of landscape modification by the use of physical SWC measures on soil erosion. The primary purpose of SWC measures is to divide the natural length of the hill slope into smaller sections so that runoff and soil erosion are reduced (Troeh et al., 1980) and this process is determined mainly by topographic characteristics and land use (Meshesha et al., 2012). Nyssen et al. (2007) and Meshesha et al. (2012) reported high variation in soil loss rates in plot experiments and catchment scale modelling, confirming the strong spatial variability and scale dependency of soil erosion processes due to various attributes of catchment areas.

Previous studies in the Ethiopian highlands suggest that bund structures reduce soil erosion; however, the effectiveness of these measures can be improved by integrated use of physical, agronomic and vegetative conservation strategies at sub-catchment level (Dubale, 2001; Betrie et al., 2011). Nyssen et al. (2007) indicated that the use of one or a combination of SWC measures depends on the objective and economic viability of conservation strategies. According to the plot experiments of Amare et al. (2014), the combined use of soil bund structures with Tephrosia plantation (a biological SWC measures) in the North- 
western Ethiopian highlands on average decreased soil loss by 71 to $26 \mathrm{t} \mathrm{ha}^{-1} \mathrm{y}^{-1}$. An additional benefit of the biological SWC measures reported by Amare et al. (2014) was that $2.8 \mathrm{t} \mathrm{ha}^{-1} \mathrm{y}^{-1}$ of dried forage was obtained from elephant grass grown on bund structures. Thus, the biomass obtained could compensate the land taken out of production by physical structures (8-10\%) and could alleviate the shortage of animal feed (Adimassu et al., 2012). In addition, the soil organic matter content is enhanced by integrated use of biological conservation strategies and bunds (Amare et al., 2014).

\subsubsection{Impacts of SWC measures on sediment connectivity and yield}

This study illustrates that sediment deposition and yield were highly variable within study sub-watersheds. This is most likely due to the effect of SWC measures as well as biophysical characteristics such as topography, land use and soil types (Mekonnen et al., 2015; Grum et al., 2017). However, previous studies indicated that specific sediment yield decreases with increase in catchment area (Descheemaeker et al., 2006; de Vente et al., 2007). According to Haregeweyn et al. (2008) and Grum et al. (2017), the lower rate of specific sediment yield in larger watersheds is due to increased sedimentation processes and sinks at obstructions in the lower reaches of larger watersheds. Even though the topography is less steep, the SDR was very high in Rim sub-watershed reaching up to 56\% (Table 5.5). This might be due to natural ditches, stream bank erosion and gullies which increase sediment connectivity. Rim sub-watershed is severely affected by landslides and gully erosion (Jemberu et al., 2018). In line with this, Verstraeten et al. (2002) reported that areas where surface runoff is concentrated in ditches and gullies facilitate sediment delivery and high TC and SDR. A large part of landscape becomes connected to the stream by continuous paths of concentrated overland flow and channel flow from gullies (Gallart et al., 1994).

This study demonstrates that the measurement of sediment yield at the outlet of catchment areas, taking into account the spatial distribution of total erosion and deposition processes, can be a good indicator of erosion taking place within the upland areas. However, in catchment areas with low TC and SDR, the measurement of sediment yield at the outlets of the catchment areas can be a poor indicator for erosion processes in the upland catchment areas. Overall connectivity within catchment areas varies with all sediment production, transfer and delivery processes that occur within it (Borselli et al., 2008). Therefore, catchment areas with high soil erosion are not necessary areas contributing most sediment to rivers (Stall, 1985; Steegen et al., 2000; Verstraeten et al., 2002). According to Cammeraat (2002), surface roughness, vegetation cover and rain intensity influence sediment production, transport from the upper part of the catchments and delivery to the river channels. The differences in sediment connectivity and yield between study sub-watersheds 
were apparently due to the effects of conservation measures and topographic characteristics. In addition the morphology and channel incision also controlled sediment connectivity and yield. The impact of a given type of impediment of sediment flow depends upon its size and position in the catchment area (Fryirs et al., 2007). Moreover, the sediment detachment, transfer and delivery to the river channels not only dependent on overall biophysical characteristics of catchment areas such as land cover, topography and geology, but also on the effects of watershed development activities (Grauso et al., 2018).

Table 5.5 Channel slope and length, and SDR for the study sub-watersheds

\begin{tabular}{llllll}
\hline $\begin{array}{l}\text { Sub-water } \\
\text { shed }\end{array}$ & SL $(\mathrm{km})$ & SS (\%) & $\begin{array}{l}\text { Gross erosion } \\
\text { (t/ha) }\end{array}$ & SY & SDR (\%) \\
\hline Asanat & 6.8 & 27 & 67.3 & 36.1 & 53 \\
Debre Yakob & 2.3 & 16 & 55.9 & 25.1 & 44 \\
Rim & 4.6 & 8 & 57.3 & 32.5 & 56 \\
\hline
\end{tabular}

SL: stream length, SS: mean stream bed slope, SY: sediment yield $\left(\mathrm{t} \mathrm{ha}^{-1} \mathrm{y}^{-1}\right)$, SDR: sediment delivery ratio

The large heterogeneities in TC and SDR in the study sub-watersheds may reflect topographic characteristics and the spatial pattern and effect of conservation measures implemented in the study sub-watersheds. In line with this, Einstein (1950) and Verstraeten et al. (2002) reported that sediment flows are highly variable with the topographic characteristics and land use types. Earlier work by Einstein (1950) and Stall (1985) showed that factors influencing soil loss and TC across catchment areas have implications for sediment connectivity and sediment yield. Marchamalo et al. (2016), in their study of sediment connectivity as a framework for understanding sediment transfer at multiple scales in SE Spain, emphasises that land use and SWC measures have a clear impact on sediment connectivity, by affecting the link between the sediment produced on the upper side of the catchment and transporting to streams. The Water Availability in Semi-Arid Environments with Sediment Dynamics Component (WASA-SED) model simulation by Medeiros et al. (2010) in Brazil showed that the spatial pattern of sediment connectivity within catchment changes as a function of landscape and land use. The high variation in sediment deposit and sediment yield could also be attributed to the effects of SWC measures, topography, land use and geology on transport in a variety of other studies (Stall, 1985; Verstraeten et al., 2002; de Vente et al., 2008; Baartman et al., 2013; Marchamalo et al., 2016). 


\subsection{Conclusions}

Runoff and suspended sediment concentration (SSC) were monitored at the outlets of three main sub-watersheds of Koga catchment, North-Western Ethiopian highlands during 20142015. The WATEM/SEDEM model was calibrated to quantify the effect of SWC measures on soil erosion and sediment yield. WATEM/SEDEM generally underestimated the effect of SWC measures in controlling soil erosion and sediment yield in all sub-watersheds. Soil erosion and sediment yield values were highly variable across study sub-watersheds. This is most likely due to the effect of SWC measures as well as biophysical characteristics such as topography, land use and soil types. The integrated use of bund structures, contour cultivation, strip cropping and grass strips had the highest impact on controlling soil erosion and sediment yield. Integration of bunds with one or more agronomic and vegetative measures shows a higher effect on soil erosion and sediment yield in the study subwatersheds. This emphasises that the use of bund structures alone is not sufficient as conservation strategy to control runoff and soil erosion in NW Ethiopian highlands. This study demonstrates that the harmful effects of soil erosion remain significant in Koga catchment and the Koga reservoir at the outlet of Koga river is highly affected by sedimentation. The calibration of WATEM/SEDEM at sub-watershed level has provided good model performance for simulated erosion and sediment yields. Therefore, WATEM/SEDEM adequately represents the underlying erosion and sedimentary processes and can be further used to evaluate the impacts of land use change and existing or new SWC scenarios. The model output results emphasises the importance of integrated use of conservation strategies to reduce soil erosion and sediment delivery. Using a spatially explicit modelling approach, as done in this study, increases insight in the spatially explicit effect of various measures on erosion rates, as opposed to measurement of sediment yield at the outlet of a catchment. 


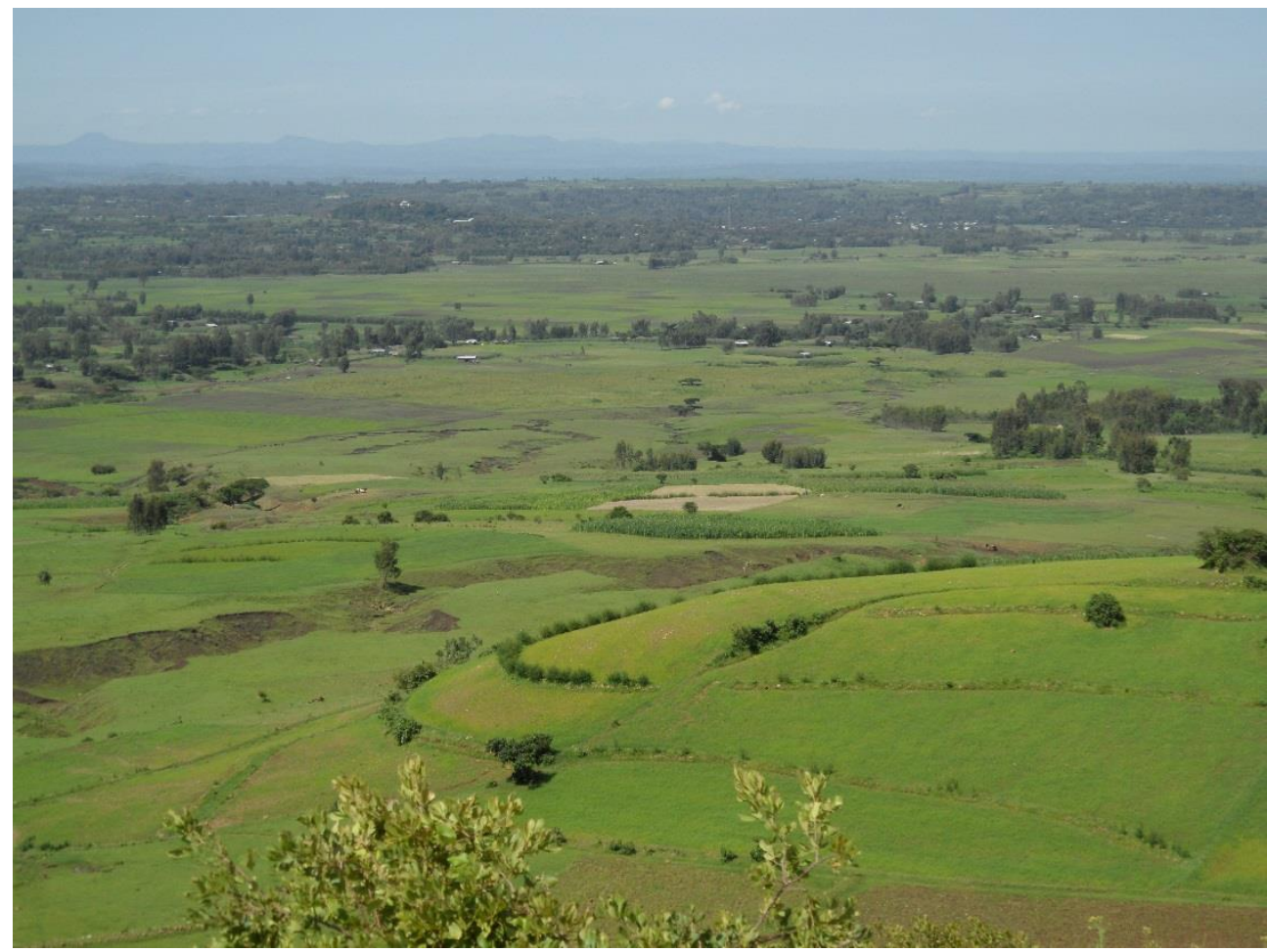


6 Synthesis 


\subsection{Assessing solutions to the land degradation challenge with stakeholders from field to catchment scale}

The Ethiopian highlands are severely affected by soil erosion-driven land degradation and this has constrained agricultural development and food security (Herweg and Ludi, 1999; Bewket, 2007; Hurni et al., 2010). Despite massive investment in SWC measures to decrease runoff and soil erosion, the damages by soil erosion, flooding and sedimentation are still severe environmental problems throughout the Ethiopian highlands, specifically in the fragile regions of the (sub)humid North-Western highlands of Ethiopia (Herweg and Ludi, 1999; Bewket, 2007). Prevention of erosion, flooding and sedimentation and improvement of agricultural production requires a thorough understanding of runoff, infiltration, erosion and sedimentary processes (Gebrernichael et al., 2005; Nyssen et al., 2010), and scientifically validated suitable SWC strategies need to be promoted to foster SLM systems in Ethiopia (Morgan, 1985; Desta, 2000; Adimassu et al., 2012).

Although it has been reported that bunds increase the physical fertility status of the soil by controlling runoff and soil loss (Gebrernichael et al., 2005; Geissen et al, 2006; Vancampenhout et al., 2006; Nyssen et al., 2007; Tadele et al., 2014), the performances of these measures on controlling the losses of soil and water are generally site-specific and highly variable (Anderson et al., 1990; Shiferew and Holden, 2001; Sonneveld and Keyzer, 2003; Roes et al., 2007). In addition most studies focus on the impacts of conservation strategies on soil characteristics without paying attention to the effects of specifications of SWC measures on soil hydrology and other physical soil properties at different slope categories. SWC measures have become an integral part of the local farming system and receive support from government within the social and economic environment (Hurni, 1988; Herweg and Ludi, 1999). As the owners and/or managers of the land, land users directly affect the success and/or failure of SWC measures. Therefore, a multidisciplinary and participatory approach to identify soil erosion and flooding risk areas and to quantify the impacts of SWC measures is required to be able to attain SLM (Ritsema et al., 1993; Tilahun, 2012; Ali et al., 2013; Baartman et al., 2012a; Wudneh et al., 2014).

Understanding runoff and sediment transport processes, catchment areas' hydrological responses, and geomorphology of streams is essential for effective soil and water management (Asselman, 1999; Nyssen et al., 2008; Bayabil et al., 2010; Guzman et al., 2013; Tilahun et al., 2015). Therefore, there is a need to assemble quantitative data on the extent, magnitude and actual rates of runoff, soil loss and sedimentation as well as their variations within the landscape (Nyssen et al., 2008; Bayabil et al., 2010; Nu-Fang et al., 2011; Baptista et al., 2015). 
This research therefore investigated the biophysical impacts of SWC strategies using stakeholder workshops, field sampling and measurements and spatially distributed modelling at sub-watershed level. The main focus of this study was to assess the effects of SWC strategies on soil erosion, soil physical properties, runoff, infiltration, and catchment level discharge and sedimentary processes and to select technically suitable conservation strategies using a multidisciplinary approach.

\subsection{Brief answer to the research questions}

In this section, the previous chapters are summarized and discussed in light of the four research questions in order to understand the effect of various SWC measures in reducing runoff, soil erosion and sedimentation. The synopsis diagram (Figure 6.1) demonstrates how farmers understand the processes of soil erosion and impacts of SWC measures, the effects of SWC measures on hydrological processes, soil erosion and sedimentation processes. First, the perceptions of farmers on soil erosion processes and impacts of SWC measures were evaluated at local level using participatory approaches. Participatory assessment of soil erosion and evaluation of the impacts of SWC measures using traditional knowledge resulted in acquiring lessons in soil erosion types and severity and in understanding the impacts of SWC measures on runoff, soil erosion, sedimentation and biomass production.

Participatory approaches to use traditional knowledge for the assessment of soil erosion severity and impacts of SWC measures is discussed in the following sections. The traditional knowledge can be used and could be improved for scientifically assessment of soil erosion and to evaluate the impacts of SWC measures (Figure 6.1). Participatory assessment of soil erosion and impacts of SWC measures was used to derive the importance of local knowledge in selecting suitable SWC measures for SLM. All existing local indigenous knowledge were identified and used for evaluating the impacts of SWC measures on runoff, soil erosion and sedimentation processes.

The impacts of dimensions of SWC measures on runoff, soil erosion and sedimentation were monitored at sub-watershed level in the highlands of North-Western Ethiopia. Field investigation and laboratory analysis showed that the dimensions of physical SWC measures such as bund structures influence the effects and suitability of SWC measures. The effects of SWC measures on runoff processes, soil erosion and sedimentation processes are discussed in detail in relation to research question IV. 


\section{Chapter 1:}

Introduction: background, research aim and questions, methodological approach and thesis outline

\section{Chapter 2:}

- Sheet erosion is widespread

- Soil erosion is reduced by SWC measures

- Graded stone-faced soil bunds are most suitable

- Level bunds are not appropriate
Chapter 3:

- dimensions of bunds vary widely

- Dimensions of bunds influence soil property and hydrology

- Bunds with larger dimensions show high soil water content
Chapter 4:

- High seasonal and event variability in RF, runoff and sediment yield

- Rain intensity is the strongest predictor of sediment discharge

- SSC is unrelated to the increasing runoff and rainfall

\section{Chapter 5:}

- WATEM/SEDEM model indicate SWC scenarios reduce soil erosion and sediment yield

- Bund structures reduce soil erosion by $53-65 \%$

- Integrated use biological, agronomic and physical SWC measures reduce soil erosion by $128-180 \%$

Chapter 6: Synthesis

General discussion of findings, scientific and societal contribution

Figure 6.1 Synopsis of the processes of the assessment of soil erosion and performances of SWC measures, and the effects of SWC measures on runoff, soil erosion and sedimentation.

I. What are the local people's perceptions about the severity of soil erosion and impacts of mitigation measures in the North-Western highlands of Ethiopia?

Local communities are well aware of the harmful effects of ongoing soil erosion and the impacts of mitigation measures on their farms (Chapter 2). They not only recognize the 
harmful effects of soil erosion but also the desired impacts of SWC measures in controlling erosion. Farmers believe that soil loss is highly influenced by slope steepness and erosivity of the rainfall, and is considered to be very variable between farm plots due to great differences in slope, land use, soils, crop management and SWC strategies. According to farmers, higher incidence and extent of stoniness, rock outcrops and root exposure was observed on steep slopes, whereas sheet wash marks such as runoff paths and smoothened surfaces were more evident on lower and medium slope classes. The large variation in estimated soil erosion rates (Figures 2.4 and 2.5) reflects high spatial variation of factors potentially influencing soil erosion. According to Nyssen et al. (2007) and Meshesha et al. (2012), variation in soil loss rates by rill and sheet erosion at plot and catchment scale confirm the strong spatial variability of soil erosion processes.

According to the local people, the desired impacts of SWC strategies were attained in general: runoff rates decreased, soil loss decreased and soil fertility and production increased. However, they also believed that SWC measures did not prevent erosion completely and the impacts of SWC practices were noted to be highly affected by the design quality and maintenance or management of the conservation strategies. Farmers had serious complaints about all types of bunds which were improperly large or undesirably level. Level bunds were not accepted in the study areas, due to waterlogging and overflow of runoff problems. The desired impacts and drawbacks of SWC measures as perceived by the farmers are confirmed by experimental research: Herweg and Ludi (1999); Gebiremikael et al. (2005) and Mitiku et al. (2006) found that in Ethiopian high rainfall areas, runoff reduction resulted in lower soil loss but at the same time, it caused water logging, which affected the production of certain crops. Herweg and Ludi (1999) and Gebiremikael et al. (2005) found that despite considerable soil loss reduction, erosion rates remain considerably high, even under SWC in Ethiopian highlands. According to Vancampenhout et al. (2006) SWC measures in the Ethiopian highlands lead to reduced soil and nutrient losses through erosion.

The fanyajuu technique was accepted only for management or maintenance of other types of bunds. Graded stone-faced soil bunds were mentioned as the preferred bund type because these bunds show higher desired impacts on controlling runoff and soil loss and were recommended by farmers to be adopted more widely in the subsistence farming system in the highlands of Amhara National Regional State. Agronomic SWC practices and soil or farm management activities were regarded as indispensable for SWC, and physical measures alone were perceived to not be sufficient for SWC. Biological SWC measures conserve soil and water effectively, but their establishment is rather difficult due to free grazing, lack of plant material (seeds and seedlings) and long dry periods in Koga catchment. Bewket and Sterk (2003), using a field survey methodology and Bayabil et al. (2010); 
Tesemma et al. (2010) and Seifu et al. (2013), using hydrological modelling, found that locations with combination of sound conservation practices in place show rather low soil loss despite high erosion potential due to e.g. steep terrain.

II. How do bund structure dimensions influence soil physical properties and hydrology in Koga catchment?

The implementation of bund structures modifies the terrain condition by changing the natural length and degree of the slope. Consequently, bund structures influence the soil physical properties and hydrology by changing the soil loss, transport and deposition processes. Accordingly, soil physical characteristics and hydrology were found to be significantly different across the slope of the terrain treated with bund structures (Table 3.2). The analysis of infiltration rate and total available water storage showed significantly higher values for treated farm lands than for untreated cultivated farm plots. Statistical analyses also revealed that soil moisture contents, infiltration rates, and available water capacity showed significant differences between the bunds on lower, middle and upper slope classes. Soils in all fields with bunds on gentle and moderately steep slopes have a significantly higher available water capacity than those on steep slopes. In line with this, other studies such as Nyssen et al. (2010) and Vancampenhout et al. (2006) showed that bund structures affect soil-water retention, soil depth, infiltration capacity and bulk density significantly.

The width and height of bunds affect soil depth and soil-water content. Soil sample analysis of samples taken between bunds older than 7 years across different slope categories showed that soils in fields with wider bunds had higher soil porosity, infiltration rate and available water storage compared to soils in fields with narrow bunds. Infiltration rate and available water storage increased with increasing height of the bund structures. The bulk density showed lower values for medium and higher heights of bunds. Statistical analyses revealed that soil depth was significantly different between all width classes and also compared to the control situation without bunds. Soil bulk density was highest in the control plots and significantly lower in fields with both small bund widths $(25-55 \mathrm{~cm})$ and larger bund widths $(>85 \mathrm{~cm})$. Erodibility was not very different between different bund width classes. Soil porosity was found to be significantly higher in fields with larger bund widths as compared to fields with narrow bunds width or without bunds (Table 3.3).

The impacts of bund height on infiltration rate and available water capacity decreased towards the upslope terrain positions in treated farmlands. Soil hydrology and physical soil properties were further influenced by the maintenance and integration strategies, soil management, and treatment activities which entailed that integration of different SWC 
strategies is the necessary and sufficient condition for SLM. The significant differences in soil-water storage and other soil physical properties in croplands treated with bunds, as found in this study, are beneficial for long-term sustainability of crop production. Previous studies, e.g. by Rasool et al. (2007) indicated that bund implementation resulted in particle size distribution, porosity, bulk density and land use (cover) changes across the slope of the terrain (different slope levels). According to Chen et al. (1997), soil erosion and deposition processes modify soil physical characteristics across a landscape. The difference in effectiveness of bunds to control runoff and soil loss and modification of the landscape is attributed to variations in bund dimensions; in turn, affecting soil physical properties and hydrology. Hamza and Anderson (2002) and Rasool et al. (2007) showed that changes in soil physical properties and slope hydrology also influences root penetration and nutrient uptake by plants and corresponding soil quality.

For stabilization of bunds, agronomic and/or biological management strategies have been used as an integral part of conservation-based interventions in Ethiopian highlands (Betru, 2002). In line with this different soil management strategies were found to be related to and affected by the design specifications of bund structures and influenced the physical qualities of soils. Therefore, the changes in bulk density and porosity for different widths of bunds may be attributed to the changes in the subsequent processes of erosion and deposition as well as to the management or treatment activities on the soils due to the implementation of bunds. These effects tend to vary with the dimensions of bunds which are also directly or indirectly related to their spacing.

III. How do treated sub-watershed areas respond to extreme events of rainfall and runoff, and what is the rate and pattern of runoff and sediment yield?

Analysis of daily runoff and sediment yield at the outlets of the three sub watersheds during the rainy seasons of 2014 and 2015 revealed that a large proportion of the total observed runoff and sediment load were produced by a small number of daily events (Tables 4.6 and 4.7). The 5 largest events produced more $50 \%$ of total runoff and $52 \%$ of the total sediment measured in the rainy season. The contribution of the largest events to runoff and sediment load varied in relation to catchment size and variation in rain intensity. The variation of contribution of largest events with catchment area is in line with previous results, e.g. those reported by Gonzalez-Hidalgo et al. (2010). An investigation by Griffiths et al. (2006) indicated that flow variability and sediment production per unit area is larger in small catchments, leading to a larger relative contribution of high magnitude events to the total sediment load. 
Comparing results of different sub-watersheds indicated that the distribution and degree of rainfall features, runoff and SSC were highly spatially and temporally variable between study sub-watersheds. Moreover, the variation in annual rainfall determined the specific surface runoff and sediment yield across different months. Meanwhile, average rain intensity as a specific rainfall feature played a major role in runoff generation and soil loss across different spatial and temporal scales in all three study sub-watersheds. In a study on response of runoff and sediment yield to changes in rainfall, Li and Gao (2015) found that runoff and sediment yield were strongly affected by changes in rain intensity. Storms with increasing rain intensity yielded highest quantities of total runoff and eroded sediments (Jungerius and Ten Harkel, 1994). Another study by Fu et al. (2016) indicated that rain intensity has a stronger influence on sediment yield than slope length. Rain events that generate a large discharge over a short duration play an important role in inducing severe soil erosion. This is in line with investigations in Spain by Kirkby et al. (2005) and in the Negev highlands by Yair and Raz-Yassif (2004) where natural rainfall features and their regimes, in particular rain intensity, formed the initial and essential driver of risks, tracks and degrees of soil erosion and surface hydrology.

Area-specific runoff and sediment yield was different for the study sub-watersheds. There was a striking difference between seasonal sediment and runoff dynamics, with suspended sediment concentration being very high at the start of the rainy season and gradually decreasing over time, while this did not follow the temporal dynamics of the runoff, which was low at the start of the rainy season and peaked halfway (end July - begin August). This is mostly due to the development of the vegetation cover and the higher susceptibility for erosion of the soils at the start of the rainy season because of sowing and field preparation (e.g. ploughing).

Detailed runoff and SSC event analysis during different seasons showed four different types of hysteretic loops: linear and clockwise (mainly for early rainy season), complex and negative for middle and late rainy season. This study confirms the complex and heterogeneous nature of sediment responses in Koga catchment. The high sediment concentrations reflect the abundant supply of sediments from the many freshly ploughed fields and they are variable because sediment concentration depends on erodibility of soil and erosivity of rainstorms (Steenhuis et al., 1995; Haregeweyn et al., 2008; Guzman et al., 2013; Taye et al., 2013; Tilahun et al., 2015; Grum et al., 2016). Therefore, the prevention of soil erosion depends upon selecting appropriate SWC measures which in turn requires a thorough understanding of soil runoff, soil erosion and sedimentation processes (Morgan, 2009). 
IV. What is the effect of various scenarios of SWC measures on soil erosion and sediment yield in the highlands of North-Western Ethiopia?

Application of the WATEM/SEDEM model at sub-watershed level in the Ethiopian highlands suggests that various SWC strategies may decrease soil erosion and sediment yield. The simulation results show that bund structures decrease soil erosion by 54 to $57 \%$ and sediment yield by 53 to $61 \%$ in Koga catchment. The scenario of integrated use of bund structures, contour cultivation, strip cropping and grass strips had the highest impact on controlling soil erosion and sediment yield. With this SWC scenario, soil erosion was reduced by up to 128 to $180 \%$ compared to untreated farm plots. Our results are consistent with findings of other studies in the Ethiopian highlands (Tilahun et al., 2013; Subhatu et al., 2017; Tamene et al., 2017).

The model predicts a reasonably acceptable range of annual soil erosion (20 - $120 \mathrm{t} \mathrm{ha}^{-1} \mathrm{y}$ $\left.{ }^{1}\right)$ in treated farm plots comparable with previous studies in similar areas of the Ethiopian highlands (Bewket and Sterk, 2003; Mitiku et al., 2006). The estimate made on impacts of SWC measures in this study also agrees well with other model-based soil erosion estimations for treated catchments by Hessel et al. (2003) who found a decrease in soil loss by $60 \%$ as a result of physical SWC measures. Nyssen et al. (2006) found a $68 \%$ soil erosion reduction with bund structures for the Tigray region of Northern Ethiopia using WOFOST and LISEM models. Tamene et al. (2017) predicted a mean annual soil loss of $45 \mathrm{t} \mathrm{ha}^{-1} \mathrm{y}^{-1}$ using RUSLE for treated cultivated lands. Herweg and Ludi (1999) estimated an average soil loss reduction of $40 \%$ by graded soil bunds and a $50 \%$ reduction with fanyajuu bunds in Anjeni catchment in the Ethiopian highlands. The overall sediment yield estimates in this study are in general agreement with sediment yield estimates made for treated cultivated lands in different regions of the country. For instance, the simulation of the effect of physical SWC measures (bunds and diversion channels) on sediment yield with SWAT (Soil and Water Assessment Tool) in the upper blue Nile basin by Lemann et al. (2016) estimated an average sediment yield reduction of $54 \%$ while Dagnew et al. (2015) found a $57 \%$ decrease in SSC in Debremewi sub-watershed. A similar study in Kenya reported by Hessel and Tenge (2008) show that LISEM simulated physical SWC scenarios decreased erosion by $60 \%$ in an agricultural catchment. Another study by Hessel and Tenge (2008) found a $60 \%$ decrease in sediment yield prediction with LISEM in the Loess plateau, China.

Integration of bunds with one or more agronomic and vegetative measures shows a higher reduction in soil loss and sediment yield in the study sub-watersheds. This emphasizes that the use of bund structures alone is not sufficient to control on-site and off-site impacts of soil erosion in the highlands of North-Western Ethiopia. Farmers also perceived that physical SWC practices reduced runoff and soil loss rates while soil water content, soil 
fertility and production increased. However, they also believed that physical SWC measures alone are not the sufficient strategies to prevent erosion completely. Similar to our results, other studies including Amare et al. (2014); Betrie et al. (2011); Nyssen et al. (2007) showed that the effectiveness of SWC measures can be improved by integrated use of physical, agronomic and vegetative conservation strategies at sub-catchment level.

\subsection{Implications}

\subsubsection{Scientific contribution}

The multidisciplinary approach combining the local communities' traditional knowledge and experiences, field sampling, and measurement and modelling were applied for quantifying the effects of SWC measures on soil erosion, soil properties, hydrology and sediment yield. This could contribute scientific evidence to inform effective management and sustainable use of soil and water resources. The results derived from this research add planning approaches and design specifications to the current innovative participatory conservation methods available for integrating physical, agronomic and vegetative strategies for SLM in the highlands of Ethiopia. As found in this research, farmers' traditional knowledge could complement the results from on-farm measurements and experiments in a wider context. The degree of public awareness of soil erosion and conservation, which is directly related to knowledge and perceptions of farmers (Herweg, 1998; Mimiko et al., 2006), is of critical importance in order to integrate local experiences with scientific evidences and to reverse the trend of increasing environmental damage and degradation (Belay, 1992; Yitaferu, 2007; Tefera and Sterk, 2010; Tamene et al., 2017). The participatory methodology contributed by this study, in which local communities exchange their views with experts not only in a discussion session, but through participatory field assessments of erosion severity and quality of SWC structures, offers a new way forward for integrated assessments. While such approaches may lead to obvious benefits in terms of more focused attention to sustainable land management, they also offer scientists with multi-disciplinary interests a new way of collecting data.

The results derived from the effects of the dimensions of bund structures on soil properties and hydrology contribute to the present knowledge on appropriate design specification required for suitable SWC measures for different biophysical conditions. In addition, our results regarding the effect of SWC measures at different sub-watershed areas with various topography, soil types and geology enable to select effective SWC measures for such different settings and to develop upscaling scenarios. Moreover, scenario analysis for selecting technically suitable SWC strategies can be used for ex-ante evaluation of different 
land use potentials, including existing and new SWC measures (Didoné et al., 2017). The results derived from this research contribute to the understanding of the response of treated sub-watershed areas to extreme events of rainfall and runoff and soil loss and sedimentary processes in different catchment areas. The upland soil erosion processes could be simulated by a spatially distributed model whereas for accurate calculation of sediment yield, fully validated numerical models specifically designed for simulating bed load transport dynamics should be used to simulate SSC at different spatial scales (Heimann et al., 2015).

The simulation of SWC measures with a spatially distributed model also contributes to the understanding of the effect of SWC measures on soil erosion and sedimentary processes. Although various efforts exist to model the impacts of SWC measures on soil erosion and sediment yield (Hengsdijk et al., 2005; Nyssen et al., 2010; Tilahun et al., 2013), evidences are needed on comparative analysis of soil loss, TC and sediment yield and the effects of SWC measures at different sub-watershed areas in the highlands of Ethiopia. Moreover, multidisciplinary approaches for evaluation of the effect of existing SWC measures and SWC scenarios are limited in Ethiopia. The results of this PhD study can be used for quantifying the effect of different SWC strategies and evaluating their performances under existing or future land use and SWC scenarios. The results of this research can be used in the assessments of SDR and connectivity with the catchment area which varies with soil loss, TC and sediment delivery processes. The measurement of SSC at the outlets of streams for estimating sediment yield cannot be a good indicator of upland soil erosion processes as the soil loss, transport and deposition processes are highly variable and a great deal of sediment is also transported in the form of bed load.

\subsubsection{Relevance to socioeconomic development}

Efficient soil and water management is a necessity not only for agricultural production but also for sustainable development in developing countries as it can have a huge impact on addressing the issues of poverty and food security (Holden and Shiferaw, 2004; Haileslassie et al., 2005). Therefore, it is essential to prevent soil erosion by implementing appropriate SWC strategies and approaches. For sustainability of livelihoods, technically suitable and economically profitable SWC strategies are indispensable. To maintain farm incomes and reduce externalities associated with soil erosion, considerable efforts have to be made towards identifying and promoting suitable SWC measures. However, the design of SWC measures, and dimensions in practice are not be optimal, leading to suboptimal SWC in Ethiopian highlands. As a result of this still high erosion rates do not help farmers to maximise productivity, but also leads to downstream impacts and associated costs. The 
results of the thesis can provide appropriate dimensions and approaches SWC measures for SLM. Productivity and SLM objectives are highly complementary, because conservation of soil, water and vegetation leads to a higher productivity of crops, livestock and balanced agroecosystem and thus improvement of livelihoods (Holden and Shiferaw, 2004). The complementarity between SWC and productivity explains the importance and popularity of scientifically tested and efficient SWC strategies for watershed development (Kerr et al., 2002).

A healthy soil system and availability of water are the determinant factors of crop yields in sub-Saharan Africa. Thus, increasing and sustaining agricultural production should aim not only at sustaining a higher level of production but also ensuring soil quality and availability of water over time. To maintain the key soil characteristics that affect sustainable agricultural production such as nutrient content, water holding capacity, organic matter content, soil reaction, top soil depth and soil biomass, suitable SWC strategies are needed (Nearing et al., 1999). The ultimate aim of SWC is to obtain a maximum sustainable level of production from a given area of land whilst maintaining soil loss below a certain erosion tolerance level (Morgan, 1985; Hurni, 1988; Herweg and Ludi, 1999). However, the sustainability of SWC measures is determined by various income-earning strategies themselves and in combination with biophysical and socio-economic conditions (BravoUreta et al., 2006).

Efficient SWC measures are considered as an investment for which significant benefits are expected later and for years to come. However, SWC measures can have an entirely different impact and consequently a different degree of adoption if they are transferred to other biophysical and/or socio-economic conditions. Economic profitability and technical suitability of SWC measures are complementary for SLM. Efficient SWC strategies controlling erosion and runoff, maintaining soil fertility and soil-water are a precondition for profitability and sustainability of SWC strategies.

\subsubsection{Extension and policy recommendation}

Similar to the results of this research, previous studies (Haregeweyn et al., 2013; Herweg and Ludi, 1999; Nyssen et al., 2007) discuss that the biophysical features such as land use, topography and geology are diverse and, as a consequence, rates and patterns of soil erosion and performances of SWC measures are highly variable in the Ethiopian highlands (Hengsdijk et al., 2005; Nyssen et al., 2007; Jemberu et al., 2018). However, the current SWC strategy in Ethiopia is a blue print (one-size fits all) approach that does not take into account the biophysical diversity of Ethiopia. The implementation of SWC is not integrated and 
follows administrative boundaries instead of hydrological units. Moreover, SWC planning approaches are not participatory at local level in the country (Hengsdijk et al., 2005; Jemberu et al., 2018). There have been situations where SWC achievements were good, with remarkable results, but measures have been removed regardless of the positive impact they had ( Bewket, 2007; Adimassu et al., 2012). Thus, empowering the community in a way that they assume the responsibilities of planning and set bylaws providing for proper implementation of the plans and the protection of assets created is of paramount importance (Shiferaw and Holden, 1998; Van Beek et al., 2017). Poor collaboration between stakeholders, lack of technical skills and poor planning of SWC, lack of awareness and participation of local people are the major causes for unsustainability of SWC measures in the Ethiopian highlands (Gebrernichael et al., 2005; Hurni et al., 2010; Adimassu et al., 2014; Jemberu et al., 2018).

The choice of appropriate SWC technologies should be based on local biophysical characteristics such as rainfall, geology, topography, land use, cultivation methods and other relevant features and the needs of farmers. In this way technical guides and manuals providing a range of options can be prepared at kebele level. For this the woreda level experts and development agents must be trained and empowered to design effective SWC measures considering these biophysical parameters. Specifically, technical manuals should be prepared for specific sub-watershed by consulting previous studies and using particular biophysical and socioeconomic data. The result of this study confirms that all physical SWC measures should be established with vegetative measures and all bund structures should be graded minimum 0.5 to $1.0 \%$ in the North-Western highlands of Ethiopia for SLM.

Promising conservation measures have to be identified by involving farmers in erosion assessment and implementation and evaluation of the impacts of SWC practices to increase the effectiveness of SWC practices and their adoption rate. A participatory approach has to be formulated which is an indispensable tool for sustainable land management. However, in the past genuine participation was lacking in Ethiopia. This is reflected in reluctance of farmers to maintain conservation measures. Previous studies (Bewket, 2007; Shiferaw and Holden, 1998) show that farmers are unwilling to take responsibilities for maintaining SWC measures unless they participated in planning and implementation of all SWC measures. Although, there is an attempt to make the local community aware of the problems of land degradation and motivate the participation in SWC activities, in Ethiopia yet more work needs to be done to empower the public and encourage them to establish local bylaws which guarantee SWC activities and achievements. Joint field assessments as piloted in this study may ensure that communities perspectives and technical knowledge of SWC experts are both taken into account in SWC activities. 
For SWC strategies to be recognized and effectively practiced, the awareness of the local community should be raised through participatory training and field visits so that they can consider and plan efficient SWC strategies. Ultimately through participation, they should assume the responsibility for maintaining and proper utilisation of the resource they developed ( Bewket, 2007; Adimassu et al., 2012). A written document on agreements made and means for implementing the activities and safeguarding maintenance should be worked out and agreed by the beneficiary target groups. Such formation of farmer groups in a watershed development team is moreover useful in making farmers work together to achieve better results and for the fact that SWC activities are labour intensive and require a team effort (Dubale, 2001; Amsalu and De Graaff, 2007).

If the local governments and community set active regulations and laws, which ensure and encourage the involvement of the public in conservation activities and protection of the assets created, there will certainly be a possibility to attain sustainable development in SWC. The planning and implementation of SWC measures should essentially follow the watershed principle. In this respect, the preparation of SWC measures should consider the natural hydrologic units for efficient, effective and sound conservation interventions. Moreover, implementation of SWC should be started at the upper side of catchments prior to other conservation activities downstream. Hence, supplementary structural measures such as water ways, cut-off drains and hillside protections are to be planned and implemented prior to bund structures and terraces. Waterways and diversion structures should be stabilised with vegetative measures or need to be paved with stone.

\subsection{Research challenges and directions for further research}

This thesis has contributed to a better understanding of runoff, soil erosion and sedimentation processes and the effect of various SWC strategies in the highlands of Ethiopia using a multidisciplinary approach. By considering farmers' perspectives and joint field assessments, the perceived quality of structures and their dimensions were taken into account when looking at the effectiveness and impact of SWC measures and this has not/rarely been done before (e.g. Nyssen et al., 2007; Tefera and Sterk, 2010; Tilahun et al., 2013; Adimassu et al., 2014). The following issues need to be further investigated to make the selected SWC techniques more efficient to reach SLM.

- Assess the effect of bund structures' dimensions and design on soil nutrient content and soil reaction (mineral content). Chapter 3 assessed the effect of the design of bund structures on selected soil physical properties and hydrology which are necessary and complementary with soil nutrient content and soil reactions. Thus, further research 
should focus on a wider range of physical and biochemical soil properties to consolidate the effect of SWC measures on general soil fertility status.

- Investigate the integrated impact of topographic characteristics, geology and land use change on runoff, soil erosion and sediment yield for treated sub-watersheds. Chapter 4 provides the response of treated sub-watershed areas to extreme events of rainfall and runoff and the patterns and rates of runoff and sediment yield for treated subwatersheds for minimal variation in topography and geology (relatively small study areas). Though integrating topography, geology and land use types is feasible to assess the variations and dynamics of runoff and sedimentation processes, the assessment of runoff and sediment yield dynamics using rainfall-runoff relationships and SSC at subcatchment level for minimal variation of topography and soil types (at smaller scale) could be an alternative option. Moreover, analysis of the shape and forms of hydrographs and sedigraphs can provide insight in the topographic, land cover and soil characteristics and their influence on runoff, soil loss and sedimentation processes (Dingman, 1994).

- Evaluate the economic suitability of various SWC measures. Though the effect of SWC measures on erosion, soil-water storage, soil fertility, runoff and biomass production was assessed based on local people's perception (chapter 2), in chapters 4 and 5 the evaluation of SWC measures is limited to their effect on runoff, infiltration, soil erosion and sediment yield. However, biophysical characteristics and technical suitability are preconditions for socio-economic suitability of SWC measures. Hence further research should integrate socio-economic models and farmers' perceptions for evaluation of the performances of SWC strategies for SLM.

- Further explore long-term sediment data under different land use scenarios with the WATEM/SEDEM model. We calibrated the WATEM/SEDEM for two years of sediment yield data at sub-watershed level. We used a conservation practice P-factor map to incorporate the variation in the type and quality of SWC measures. Although the Pfactor map provides the spatial attributes of the effects of SWC measures, to explore the effects of SWC measures exactly, accurate mapping of SWC measures is needed for further evaluation of the impacts of SWC measures under different land use scenarios.

- Investigate the impacts of SWC measures on runoff, soil erosion, sedimentation, soil moisture content, and soil fertility for longer time series encompassing a larger variability in dry and wet rainy seasons. 


\section{Literature cited}

Adimassu, Z., Kessler, A., Hengsdijk, H., 2012. Exploring determinants of farmers' investments in land management in the Central Rift Valley of Ethiopia. Applied Geography, 35, 191-198.

Adimassu, Z., Mekonnen, K., Yirga, C., Kessler, A., 2014. Effect of soil bunds on runoff, soil and nutrient losses, and crop yield in the central highlands of Ethiopia. Land Degradation \& Development, 25, 554-564.

ADSE, 2013. The land use dynamics in Amhara Region. First draft manual. Amhara Design and Supervision Enterprise. Bahir Dar, Ethiopia.

Alcorn, J.B., 1993. Indigenous peoples and conservation. Conservation Biology. 7, 424-426.

Ali, M., Seeger, M., Sterk, G., Moore, D., 2013. A unit stream power based sediment transport function for overland flow. Catena, 101, 197-204.

Amare, T., 2014. Combined effect of soil bund with biological soil and water conservation measures in the northwestern Ethiopian highlands. Ecohydrology \& Hydrobiology, 14, 192-199.

Amsalu, A., De Graaff, J., 2006. Determinates of adoption and continued use of stone terraces for soil and water conservation in Ethiopian high lands watersheds. Ecological Economics. 61, 294-302.

Amsalu, A., De Graaff, J., 2007. Determinants of adoption and continued use of stone terraces for soil and water conservation in an Ethiopian highland watershed. Ecological economics, 61, 294-302.

Amsalu, A., Stroosnijder, L., De Graaf, J., 2007. Long-term dynamics in land resource use and the deriving forces in the Beressa watershed, highlands of Ethiopia. Journal of Environmental Management 83, 448-549.

Anderson, S.H., Gantzer, C.J., Brown, J.R., 1990 Soil physical properties after 100 years of continuous cultivation. Journal of Soil and Water Conservation 45, 117-121.

Angima, S.D., Stott, D.E., O'Neill, M.K., OnG, C.K., Weesies, G.A., 2003. Soil erosion predicting using RUSLE for central Kenya highland conditions. Agriculture Ecosystem \& Environment 97, 259-308.

ANRS, 1999. Regional Conservation Strategy (RCS). Executive summary. Vol1. Bahir Dar, Ethiopia. pp. 75-110.

Arcía-Ruiz, J.M., 2010. The effects of land uses on soil erosion in Spain: a review. Catena 8(1), 1-11.

Arshad, M.A. and Martin, S., 2002. Identifying critical limits for soil quality indicators in agroecosystem. Agriculture, Ecosystems \& Environment 88, 153-160, DOI: 10.1016/So1678809(01)00252-3. 
Asefa, D., Oba, G., Weladji, R.B., Colman, J.E., 2003. An assessment of restoration of biodiversity in degraded high mountain grazing lands in northern Ethiopia. Land degradation \& development, 14, 25-38.

Asselman, N., 2000. Fitting and interpretation of sediment rating curves. Journal of Hydrology, 234, 228-248.

Asselman, N.E., 1999. Suspended sediment dynamics in a large drainage basin: the River Rhine. Hydrological processes, 13, 1437-1450.

Atkinson, E., 1995. Methods for assessing sediment delivery in river systems. Hydrological sciences journal, 40, 273-280.

Awulachew, S., 2010b. Improved water and land management in the Ethiopian highlands and its impact on downstream stakeholders dependent on the Blue Nile.

Ayele, G. K., Gessess, A. A., Addisie, M. B., Tilahun, S. A., Tebebu, T. Y., Tenessa, D. B., Langendoen J., Nicholson, C. F. \& Steenhuis, T. S. 2016. A Biophysical and Economic Assessment of a Community

Ayele, G. K., Gessess, A. A., Addisie, M. B., Tilahun, S. A., Tenessa, D. B., Langendoen J., Steenhuis, T. S. \& Nicholson, C. F. 2015. The economic cost of upland and gully erosion on subsistence agriculture for a watershed in the Ethiopian highlands. African Journal of Agricultural and Resource Economics 10, 265-278.

Baartman, J.E., Gorp, W., Temme, A.J., Schoorl, J.M., 2012a. Modelling sediment dynamics due to hillslope-river interactions: incorporating fluvial behaviour in landscape evolution model LAPSUS. Earth Surface Processes and Landforms, 37, 923-935.

Baartman, J.E., Jetten, V.G., Ritsema, C.J., Vente, J., 2012b. Exploring effects of rainfall intensity and duration on soil erosion at the catchment scale using openLISEM: Prado catchment, SE Spain. Hydrological processes, 26, 1034-1049.

Baartman, J.E., Masselink, R., Keesstra, S.D., Temme, A.J., 2013a. Linking landscape morphological complexity and sediment connectivity. Earth Surface Processes and Landforms, 38, 1457-1471.

Baartman, J.E., Temme, A.J., Veldkamp, T., Jetten, V.G., Schoorl, J.M., 2013b. Exploring the role of rainfall variability and extreme events in long-term landscape development. Catena, 109, 25-38.

Baartman, J.E.M., Van Lynden, G.W.J., Reed, M.S., Ritsema, C.J., Hessel, R., 2007. Desertification and land degradation: origins, processes and solutions a literature review. Desire Scientific Report No.4. ISRIC, The Netherlands.

Bakker, M., Govers, G., Van Doorn, A., Quetier, F., Chouvardas, D., Rounsevell, M., 2008. The response of soil erosion and sediment export to land use change in four areas of Europe: the importance of landscape pattern. Geomorphology 98, 213-226.

Banasik, K., Hejduk, L., 2013. Flow duration curves for two small catchments with various records in lowland part of Poland. Annu. Set Environ. Prot, 15, 287-300. 
Baptista, I. Irvine, B., Fleskens, L., Geissen, V., Ritsema, C.J., 2015a. Soil and water conservation strategies in Cape Verde (Cabo Verde in Portuguese) and their impacts on livelihoods: an overview from the Ribeira Seca Watershed. Land, 4, 22-44.

Baptista, I., Irvine, B., Fleskens, L., Geissen, V., Ritsema, C.J., 2016. Assessing the Biophysical Impact and Financial Viability of Soil Management Technologies Under Variable Climate in Cabo Verde Drylands: The PESERA-DESMICE Approach. Land Degradation \& Development, 27, 1679-1690.

Baptista, I., Ritsema, C.J., Geissen, V., 2015b. Effect of integrated water-nutrient management strategies on soil erosion mediated nutrient loss and crop productivity in Cabo Verde drylands. PloS one, 10, e0134244.

Baptista, I., Ritsema, C.J., Querido, A., Ferreira, A., Geissen, V., 2015. Improving rainwateruse in Cabo Verde drylands by reducing runoff and erosion. Geoderma, 237, 283-297.

Bayabil, H., Tilahun, S., Collick, A., Steenhuis, T., 2010. Are runoff processes ecologically or topographically driven in Ethiopian highlands? The case of Maybar. Ecohydrology. 3, 457-466.

Bekele, E.G., Knapp, H.V., 2010. Watershed modeling to assessing impacts of potential climate change on water supply availability. Water Resources Management, 24, 32993320.

Belay, T., 1992. Farmers' perceptions of erosion hazards and attitudes towards soil conservation in Gunono, Wolyita, southern Ethiopia. Ethiopian Journal of Development Research. 14, 31-58.

Berry, L., 2003. Land degradation in Ethiopia: Its extent and impact. Commissioned by the GM with WB support, 2-7.

Betrie, G.D., Mohamed, Y.A., van Griensven, A., Srinivasan, R., 2011. Sediment management modelling in the Blue Nile Basin using SWAT model. Hydrology and Earth System Sciences, 15, 807.

Betru, N., 2002. Soil conservation program in Amhara National Regional State. pp.109-128. Proceedings for conference on: Natural Resource Degradation \& Environmental Concerns in ANRS.

Beven, K., Kirkby, M., Schofield, N., Tagg, A., 1984. Testing a physically-based flood forecasting model (TOPMODEL) for three UK catchments. Journal of Hydrology, 69, 119-143.

Bewket, W. and Sterk, G., 2002. Farmers' participation in soil and water conservation activities in the Chemoga watershed Blue Nile Basin, Ethiopia. Land Degradation \& Development 13 (3), 192-200.

Bewket, W., 2002. Land cover dynamics since the 1950s in Chemoga watershed, Blue Nile basin, Ethiopia. Mountain Research and Development, 22, 263-269. 
Bewket, W., 2007. Soil and water conservation intervention with conventional technologies in northwestern highlands of Ethiopia: Acceptance and adoption by farmers. Land use policy, 24, 404-416.

Bewket, W., Sterk, G., 2003. Assessment of soil erosion in cultivated fields using a survey methodology for rills in the Chemoga watershed, Ethiopia. Agriculture, ecosystems \& environment, 97, 81-93.

Bewket, W., Stroosnijder, L., 2003. Effects of agro-ecological land use succession on soil properties in Chemoga watershed, Blue Nile basin, Ethiopia. Geoderma, 111, 85-98.

Bie, J.M., 2004. Assessment of soil erosion indicators for maize-based agro-ecosystems in Kenya. Catena. 59, 231-251.

Boix-Fayos, C., de Vente, J., Martínez-Mena, M., Barberá, G.G., Castillo, V., 2008. The impact of land use change and check-dams on catchment sediment yield. Hydrological Processes, 22, 4922-4935.

Bojko, O., Kabala, C., 2016. Transformation of physiochemical soil properties along a mountain slope due to land management and climate changes- a case study from the Karkonosze mountains, SW Poland. Catena 140, 43-54.

Borselli, L., Cassi, P., Torri, D., 2008. Prolegomena to sediment and flow connectivity in the landscape: a GIS and field numerical assessment. Catena, 75, 268-277.

Bracken, L.J., Croke, J., 2007. The concept of hydrological connectivity and its contribution to understanding runoff-dominated geomorphic systems. Hydrological processes, 21, 1749-1763.

Bracken, L.J., Turnbull, L., Wainwright, J., Bogaart, P., 2015. Sediment connectivity: a framework for understanding sediment transfer at multiple scales. Earth Surface Processes and Landforms, 40, 177-188.

Brady, N. and R., Weil, 2002. The Nature and Properties of Soils: 13th Edition. Prentice Hall. Upper Saddle River, New Jersey.

Brasington, J., Richards, K., 2000. Turbidity and suspended sediment dynamics in small catchments in the Nepal Middle Hills. Hydrological processes, 14, 2559-2574.

Bravo-Ureta, B.E., Solis, D., Cocchi, H., Quiroga, R.E., 2006. The impact of soil conservation and output diversification on farm income in Central American hillside farming. Agricultural Economics, 35, 267-276.

Brevik, E.C., 2010. Soil health and productivity. Soils, plant growth \& crop production. 1, 106-110.

Brevik, E.C., 2012. Soil health and productivity. CRC Press, Boca Raton, USA. pp.59-82.

Brunner, A.C., Park, S.J., Rvecker, G.P., Vlek, P.L.G., 2008. Erosion modelling approach to simulate the effect of land management options on soil loss by considering catenary soil development and farmers perception. Land Degradation \& Development. 19, 623 635. 
Brutsaert, W., Nieber, J.L., 1977. Regionalized drought flow hydrographs from a mature glaciated plateau. Water Resources Research, 13, 637-643.

Cammeraat, L., 2002. A review of two strongly contrasting geomorphological systems within the context of scale. Earth Surface Processes and Landforms, 27, 1201-1222.

Cao, S., Chen, L., Feng, Q., Liu, Z., 2007. Soft-riser bench terrace design for the hilly Loess Regions of Shaanxi Province, China. Landscape \& Urban Planning 80(1-2), 184-191.

Capler, C.A., Poudyal, N.C., Muller, L.I., Yoest, C., 2017. Assessing landowners' attitude toward wild hogs and support for control options. Journal of Environmental management. 201, 45-51.

Carey, S.K., Woo, M.-k., 2001. Slope runoff processes and flow generation in a subarctic, subalpine catchment. Journal of Hydrology, 253, 110-129.

Carvalho, T.M.M., Coelho, C.O.A., Ferreira, A.J.D., Charlton, C.A., 2002. Land degradation process in Portugal: farmers' perception of application of European agroforestry programmes. Land Degradation \& Development. 13, 177-188.

Cerdá, A., 1998. Relationship between climate and soil hydrological and erosional characteristics along climate gradients in Mediterranean limestone areas. Geomorphology 25 (1-2), 123-134.

Chambers, B.J., Garwood, T.W.D., 2000. Monitoring of water erosion on arable farms in England and Wales. Soil Use \& Management 16, 93-99.

Change, I.P.o.C., 2014. Climate Change 2014-Impacts, Adaptation and Vulnerability: Regional Aspects. Cambridge University Press.

Chen, Z.S., Hsieh, C.F., Jiang, F.Y., Sun, I.F., 1997. Relation of soil properties to topography and vegetation in tropical rainforest in Southern Taiwan. Plant Ecology 132(2), 229-241.

Daba, S., 2003. An investigation of the physical and socio-economic determinants of soil erosion in Hararge highlands, Eastern Ethiopia. Land Degradation \& Development. 14, 69-181.

Daba, S., Rieger, W., Strauss P., 2001. Assessment of gully erosion in Eastern Ethiopia using photogrammetric techniques. Catena. 50, 273-291.

Dagnew, D. C., Guzman, C. D., Zegeye, A. D., Tibebu, T. Y., Getaneh, M., Abate, S., Zemale, F. A., Ayana, E.K., Tilahun, S. A., \& Steenhuis, T. S., 2015. Impact of conservation practices on runoff and soil loss in the sub-humid Ethiopian Highlands: The Debre Mawi watershed. Journal of Hydrology and Hydromechanics. DOI: 10.1515/johh-2015-0021.

Dagnew, D.C., Guzman, C.D., Zegeye, A.D., Akal, A.T., Moges, M.A., Tebebu, T.Y., Mekuria, W., Ayana, E.K., Tilahun, S.A. and Steenhuis, T.S., 2016. Sediment Loss Patterns in the Sub-Humid Ethiopian Highlands. Land Degradation \& Development. DOI:10.1002/Idr.2643.

Danano, D. 2002. Analysis from organizational perspectives: The past, present and future of soil and water conservation efforts in Ethiopia. Ethiopian Soil Conservation Newsletter, MOA, August 2002, No. 8. 
De Vente, J., Poesen, J., 2013. Predicting soil erosion and sediment yield at regional scales: Where do we stand? Earth-Science Reviews, 127, 16-29.

De Vente, J., Poesen, J., 2005. Predicting soil erosion and sediment yield at the basin scale: scale issues and semi-quantitative models. Earth-Science Reviews, 71, 95-125.

De Vente, J., Poesen, J., Arabkhedri, M., Verstraeten, G., 2007. The sediment delivery problem revisited. Progress in Physical Geography, 31, 155-178.

de Vente, J., Poesen, J., Bazzoffi, P., Rompaey, A.V., Verstraeten, G., 2006. Predicting catchment sediment yield in Mediterranean environments: the importance of sediment sources and connectivity in Italian drainage basins. Earth Surface Processes and Landforms, 31, 1017-1034.

de Vente, J., Poesen, J., Verstraeten, G., Van Rompaey, A., Govers, G., 2008. Spatially distributed modelling of soil erosion and sediment yield at regional scales in Spain. Global and planetary change, 60, 393-415.

Descheemaeker K, Nyssen J, Rossi J, Poesen J, Haile M, Raes D, Muys B, Moeyersons J, Deckers S. 2006. Sediment deposition and pedogenesis in exclosures in the Tigray Highlands, Ethiopia. Geoderma, 132: 291-314.

Desmet, P., Govers, G., 1995. GIS-based simulation of erosion and deposition patterns in an agricultural landscape: a comparison of model results with soil map information. Catena, 25, 389-401.

Desmet, P., Govers, G., 1996. A GIS procedure for automatically calculating the USLE LS factor on topographically complex landscape units. Journal of soil and water conservation, 51, 427-433.

Desta, G., Hurni, H., 2011. Farmers' participatory soil erosion assessment and soil and water conservation improvement. Application of erosion indicators, CED-ESAPP, Switzerland, Bern.

Desta, L., 2000. Land degradation and strategies for sustainable development in the Ethiopian highlands: Amhara Region. ILRI (aka ILCA and ILRAD).

Didoné, E.J., Minella, J.P.G., Evrard, O., 2017. Measuring and modelling soil erosion and sediment yields in a large cultivated catchment under no-till of Southern Brazil. Soil and Tillage Research, 174, 24-33.

Dingman, S.L., 1994. Physical Hydrology Prentice Hall. Inc., New Jersey, 7458.

Dubale, P., 2001. Soil and water resources and degradation factors affecting productivity in Ethiopian highland agro-ecosystems. Northeast African Studies, 8, 27-51.

Easton, Z., 2010. A multi basin SWAT model analysis of runoff and sedimentation in the Blue Nile, Ethiopia. Hydrology and earth system sciences, 14, 1827-1841.

Einstein, H.A., 1950. The bed-load function for sediment transportation in open channel flows. US Department of Agriculture Washington DC.

Ekwue, E.I., 1992. Effect of organic and fertilizer treatments on soil physical properties and erodibility. Soil \& Tillage Research 22(3-4), 199-209. 
Eswaran, H., Lal, R., Reich, P., 2001. Land degradation: an overview. Responses to Land degradation, 20-35.

FAO, 1991. The den Bosch declaration and agenda for action on sustainable agriculture and rural development. Report of the conference. Rome, Italy.

FAO, 2014. Adapting to climate change through land and water management in East Africa. Results of pilot projects in Ethiopia, Kenya and Tanzania, FAO, Rome, Italy.

Feng, X., Wang, Y., Chen, L., Fu, B., Bai, G., 2010. Modeling soil erosion and its response to land-use change in hilly catchments of the Chinese Loess Plateau. Geomorphology, 118, 239-248.

Ferro, V., Di Stefano, C., Giordano, G., Rizzo, S., 1998. Sediment delivery processes and the spatial distribution of caesium-137 in a small Sicilian basin. Hydrological Processes, 12, 701-711.

Ferro, V., Porto, P., 2000. Sediment delivery distributed (SEDD) model. Journal of hydrologic engineering, 5, 411-422.

Flanagan, L.B., Johnson, B.G., 2005. Interacting effects of temperature, soil moisture and plant biomass production on ecosystem respiration in northern temperate grassland. Agricultural \& Forest Meteorology 130(3-4), 237-253.

Fleskens, L., Nainggolan, D., Stringer, L.C., 2014. An exploration of scenarios to support sustainable land management using integrated environmental socio-economic models. Environmental Management 54, 1005-1021.

Fleskens, L., Stringer, L.C., 2014. Land management and policy responses to mitigate desertification and land degradation. Land Degradation \& Development, 25, 1-4.

Foster, D.R., 2002. Conservation issues and approaches for dynamic cultural landscapes. Journal of Biogeography, 29, 1533-1535.

Fryirs, K.A., Brierley, G.J., Preston, N.J., Kasai, M., 2007. Buffers, barriers and blankets: the (dis) connectivity of catchment-scale sediment cascades. Catena, 70, 49-67.

Fu, X., Zhang, L., Wang, X., 2016. The effect of slope length on sediment yield by rainfall impact under different land use types. Water resources, 43, 478-485.

Gadgil, M., Berkes, F., Folke, C., 1993. Indigenous knowledge for biodiversity conservation. Ambio. 22, 151-156.

Gallart, F., Balasch, J.C., Regüés, D., Soler, M., Castelltort, X., 2005. Catchment dynamics in a Mediterranean mountain environment: the Vallcebre research basins (southeastern Pyrenees) II: temporal and spatial dynamics of erosion and stream sediment transport. Developments in Earth Surface Processes, 7, 17-29.

Gebrernichael, D., Nyssen, J., Poesen, J., Deckers, J., Govers, G., Moeyersons, J., 2009. Contour furrows for in situ soil and water conservation, Tigray, Northern Ethiopia. Soil and Tillage Research, 103, 257-264. 
Gebrernichael, D., Nyssen, J., Poesen, J., Deckers, J., Haile, M., Govers, G., Moeyersons, J., 2005. Effectiveness of stone bunds in controlling soil erosion on crop land in Tigray highlands, Northern Ethiopia. Soil Use \& Management 21(3), 287-297.

Geissen, V., Casasola, I. and Selpulveda, A., 2006. Effect of open ditch draining on sediment and soil properties in cultivated areas in Southeast Mexico. Geoderma 136(1-2), 401410.

Gessesse, G.D., 2014. Assessment of soil erosion in the Blue Nile Basin, Nile River Basin. Springer, pp. 193-218.

Girmay, G., Singh, B., Nyssen, J., Borrosen, T., 2009. Runoff and sediment-associated nutrient losses under different land uses in Tigray, Northern Ethiopia. Journal of Hydrology, 376, 70-80.

Gonzalez-Hidalgo, J., Batalla, R., Cerdà, A., De Luis, M., 2010. Contribution of the largest events to suspended sediment transport across the USA. Land Degradation \& Development, 21, 83-91.

Gore, J.A., Banning, J., 2017. Discharge measurements and streamflow analysis, Methods in Stream Ecology, Volume 1 (Third Edition). Elsevier, pp. 49-70.

Govers, G., Poesen, J., 1988. Assessment of the interrill and rill contributions to total soil loss from an upland field plot. Geomorphology, 1, 343-354.

Grauso, S., Pasanisi, F., Tebano, C., 2018. Assessment of a Simplified Connectivity Index and Specific Sediment Potential in River Basins by Means of Geomorphometric Tools. Geosciences, 8, 48.

Grepperud, S., 1996. Population pressure and land degradation: The case of Ethiopia. Journal of environmental economics and management, 30, 18-33.

Greenland, D.J., 1994. Soil Science and Land Management in Tropics. CBA International. Walling ford, UK.

Griffiths, P.G., Hereford, R., Webb, R.H., 2006. Sediment yield and runoff frequency of small drainage basins in the Mojave Desert, USA. Geomorphology, 74, 232-244.

Grum, B. Hessel, R., Kessler, A, Woldearegay, K, Yazew, E, Ritsema, C.J., Geissen, V., 2016. A decision support approach for the selection and implementation of water harvesting techniques in arid and semi-arid regions. Agricultural Water Management, 173, 35-47.

Grum, B. Woledearegay, K., Hessel, R., Baartman, J.E.M., Abdulkadir, M., Yazew, E., Kessler, A., Ritsema, C.J., Geissen, V., 2017. Assessing the effect of water harvesting techniques on event-based hydrological responses and sediment yield at a catchment scale in northern Ethiopia using the Limburg Soil Erosion Model (LISEM). Catena, 159, 20-34.

Guy, B.T., Sohrabi, T.M., Rudra, R.P., Dickinson, W.T., 2009. An empirical model development for the sediment transport capacity of shallow overland flow: model validation. Biosystems engineering, 103, 518-526. 
Guzman, C., Tilahun, S., Zegeye, A., Steenhuis, T., 2013. Suspended sediment concentrationdischarge relationships in the (sub-) humid Ethiopian highlands. Hydrology and Earth System Sciences, 17, 1067.

Haileslassie, A., Priess, J., Veldkamp, E., Teketay, D., Lesschen, J.P., 2005. Assessment of soil nutrient depletion and its spatial variability on smallholders' mixed farming systems in Ethiopia using partial versus full nutrient balances. Agriculture, ecosystems \& environment, 108, 1-16.

Hamza, M.A., Anderson W., 2002. Improving soil physical fertility and crop yield on clay soil in Western Australia. Australian Journal of Agricultural Research 53(5), 615-620.

Haregeweyn N, Poesen J, Nyssen J, Govers G, Verstraeten G, de Vente J, Deckers J, Moeyersons J, Haile M., 2008. Sediment yield variability in Northern Ethiopia: a quantitative analysis of its controlling factors. Catena, 75, 65-76.

Haregeweyn N, Poesen J, Verstraeten G, Govers G, Vente J, Nyssen J, Deckers J, Moeyersons J., 2013. Assessing the performance of a spatially distributed soil erosion and sediment delivery model (WATEM/SEDEM) in Northern Ethiopia. Land Degradation \& Development, 24, 188-204.

Haregeweyn, N., Poesen, J., Nyssen, J., Moeyersons, J., 2005. Specific sediment yield in Tigray- Northern Ethiopia: Assessment and semi-quantitative modelling. Geomorphology 69 (1), 315-331.

Heimann, F., 2015. Calculation of bedload transport in Swiss mountain rivers using the model sedFlow: proof of concept. Earth Surface Dynamics, 3, 35.

Hengsdijk, H., Meijerink, G., Mosugu, M., 2005. Modeling the effect of three soil and water conservation practices in Tigray, Ethiopia. Agriculture, ecosystems \& environment, 105, 29-40.

Herweg, K. and Ludi, E., 1999. The performance of selected soil and water conservation measures: case studies from Ethiopia and Eritrea. Centre for Development \& Environment, University of Bern, Switzerland.

Herweg, K., 1996. Field manual for assessment of current erosion damage. Soil Conservation Research Programme, Ethiopia and Centre for Development and Environment, University of Bern, Switzerland.

Herweg, K., Haile, M., Stillhardt, B., 2006. Sustainable land management: a new approach to soil and water conservation in Ethiopia. Swiss National Centre for Development \& Competence, North-South University of Bern, Switzerland.

Herweg, K., Ludi, E., 1999. The performance of selected soil and water conservation measures-case studies from Ethiopia and Eritrea. Catena, 36, 99-114.

Herweg, K., Steiner, K., Slaats, J., 1998. Sustainable Land Management. Guidelines for impact monitoring toolkit module, working documents for public discussion, Bern, Swizerland. 
Hessel, R., Messing, I., Liding, C., Ritsema, C.J., Stolte, J., 2003. Soil erosion simulations of land use scenarios for a small Loess Plateau catchment. Catena, 54, 289-302.

Hessel, R., Ritsema, C.J., Van de Elsen, H., 2008. DESIRE: Desertification mitigation and remediation of land: a global approach for local solution. ALTERRA-research institute for greener world, Land Degradation \& Development, Budapest, Hungary.

Hessel, R., Tenge, A., 2008. A pragmatic approach to modelling soil and water conservation measures with a catchment scale erosion model. Catena, 74, 119-126.

Holden, S., Shiferaw, B., 2004. Land degradation, drought and food security in a lessfavoured area in the Ethiopian highlands: a bio-economic model with market imperfections. Agricultural Economics, 30, 31-49.

Holman, I.P., Hollis, J.M., Bramley, M.E., Thompson, T.R.E., 2000. The contribution of soil structural degradation to catchment flooding: a preliminary investigation of the 2000 floods in England and Wales. Hydrology System Sciences 7(5), 754-765.

Hudson, N.W., 1993. Field measurement of soil erosion and runoff. Food and Agriculture Organization of the United Nations, Rome, Italy pp. 121-126.

Hudson, P.F., 2003. Event sequence and sediment exhaustion in the lower Panuco Basin, Mexico. Catena, 52, 57-76.

Hurni, H., 2010. Land degradation and sustainable land management in the highlands of Ethiopia. Addis Ababa, Ethiopia.

Hurni, H., 1985. Soil conservation manual for Ethiopia: a field manual for conservation implementation. Soil Conservation Research Project, Addis Ababa.

Hurni, H., 1988. Degradation and conservation of the resources in the Ethiopian highlands. Mountain research and development, 123-130.

Hurni, H., 1993. Land degradation, famine and land resources scenarios in Ethiopia. In Pimentel D (ed.): World soil erosion and conservation. Cambridge University Press. DOI: 10.1017/CBO9780511735394.004.

Hurni, H., 1993. World Soil Erosion and Conservation: Land degradation, famine, and land resource scenarios in Ethiopia.

Hurni, H., 1999. Sustainable management of natural resources in African and Asian mountains. Ambio, 382-389.

Hurni, H., Berhe, WA, Chadhokar, P., Daniel, D., Gete, Z., Grunder, M., Kassaye, G. 2016. Soil and water conservation in Ethiopia: guidelines for development agents. Second revised edition, Bern, Switzerland, Centre for Development and Environment (CDE), University of Bern.

Hurni, H., Tato, K., Zeleke, G., 2005. The implications of change in population, land use, and land management for surface runoff in Upper Blue Nile Basin area of Ethiopia. Mountain Research and Development. 25, 48-150. 
Hurni, H., Tato, K., Zeleke, G., 2005. The implications of changes in population, land use, and land management for surface runoff in the upper Nile basin area of Ethiopia. Mountain Research and Development, 25, 147-154.

Jabbar, M.A., Pender, J., Ehui, S.K., 2000. Policies for sustainable land management in the highlands of Ethiopia: Summary of papers and proceedings of a seminar held at ILRI, Addis Ababa, Ethiopia, 22-23 May 2000. Socio-economics and Policy Research Working Paper 30. ILRI (International Livestock Research Institute), Nairobi, Kenya.

Janssen, S., Van Ittersum, M.K., 2007. Assessing farm innovations and responses to policies: a review of bio-economic farm models. Agricultural systems, 94, 622-636.

Jemberu, W., Ayele, B., Tsegaye, L., 2014. Yield and water use efficiency of mulched dripirrigated onion in low land region of Amhara, north central Ethiopia. Universal Journal of Agricultural Research 2, 203-210. DOI: 10.13189/ujar.2014.020604.

Jemberu, W., Baartman, J., Fleskens, L., Gebreselassie, Y., Ritsema, C.J., 2017. Assessing the variation in bund structure dimensions and its impact on soil physical properties and hydrology in Koga catchment, Highlands of Ethiopia. Catena. 157, 195-204.

Jemberu, W., Baartman, J.E., Fleskens, L., Ritsema, C.J., 2018. Participatory assessment of soil erosion severity and performance of mitigation measures using stakeholder workshops in Koga catchment, Ethiopia. Journal of environmental management, 207, 230-242.

Jemberu, W., Baartman, J.E.M., Fleskens, L., Gebre-Selassie, Y., Ritsema, C.J., submitted. Magnitudes and dynamics of runoff and sediment yield: an in-depth analysis of hydrological responses of three treated sub-watersheds in the Ethiopian highlands. Hydrological processes.

Jungerius, P., Ten Harkel, M., 1994. The effect of rainfall intensity on surface runoff and sediment yield in the grey dunes along the Dutch coast under conditions of limited rainfall acceptance. Catena, 23, 269-279.

Kaihura, F.B.S., Kullaya, I.K., Kilasara, M., Lal, R., 1999. Soil quality effects of accelerated erosion and management systems in three eco-regions of Tanzania. Soils \& Tillage Research 53(1), 59-70.

Keesstra, S.D., Temme, A.J.A.M., Schoorl, J.M., Visser, S.M., 2014. Evaluating the hydrological component of new catchment-scale sediment delivery model LAPSUS-D. Geomorphology 212, 97-107.

Kerr, J.M., Pangare, G., Pangare, V., 2002. Watershed development projects in India: an evaluation. Intl Food Policy Res Inst.

Kirkby, M., Bracken, L., Shannon, J., 2005. The influence of rainfall distribution and morphological factors on runoff delivery from dryland catchments in SE Spain. Catena, 62, 136-156. 
Krois, J., Abendroth, S., Schulte, A., Schneider, M., 2013. Dry season runoff and natural water storage capacity in the high Andean catchment of the river Ronquillo in the Northern Sierra of Peru. Journal of Latin American Geography, 12, 59-89.

Kuo, W., 1999. Effect of grid size on runoff and soil moisture for a variable-source-area hydrology model. Water Resources Research, 35, 3419-3428.

Lana-Renault, N., Regus, D., Nadal-Romero, E., Garcia-Ruiz, J., 2007. Temporal variability in the relationships between precipitation, dischargef and suspended sediment concentration in a small Mediterranean mountain catchment. Hydrology Research, 38, 139-150.

Lefrançois, J., Grimaldi, C., Gascuel-Odoux, C., Gilliet, N., 2007. Suspended sediment and discharge relationships to identify bank degradation as a main sediment source on small agricultural catchments. Hydrological processes, 21, 2923-2933.

Lemann T, Zeleke G, Amsler C, Giovanoli L, Suter H, Roth V. 2016. Modelling the effect of soil and water conservation on discharge and sediment yield in the upper Blue Nile basin, Ethiopia.

Lemann, T., 2016b. Modelling the effect of soil and water conservation on discharge and sediment yield in the upper Blue Nile basin, Ethiopia.

Lenzi, M.A., Marchi, L., 2000. Suspended sediment load during floods in a small stream of the Dolomites (northeastern Italy). Catena, 39, 267-282.

Lesschen, J. P., Cammeraat, L. H., Nieman, T., 2008. Erosion and terrace failure due to agricultural land abandonment in a semi-arid environment. Earth Surface Processes \& Landforms 33, 1574-1584.

Li, T., Gao, Y., 2015. Runoff and Sediment Yield Variations in Response to Precipitation Changes: A Case Study of Xichuan Watershed in the Loess Plateau, China. Water, 7, 5638-5656.

López-Tarazón, J.A., Batalla, R., Vericat, D., Francke, T., 2009. Suspended sediment transport in a highly erodible catchment: the River Isábena (Southern Pyrenees). Geomorphology, 109, 210-221.

Lubis, K.S., Harahap, E.M., Rauf, A., Hasibuan, Z.A., 2013. Correlation of streamflow and sediment concentration at upstream and downstream Padang Watershed, Proceedings of The Annual International Conference, Syiah Kuala University-Life Sciences \& Engineering Chapter.

Ludi, E., 1997. Household and communal strategies: small-scale farming families and their options for self-improvement. A case study in Anjeni, Ethiopia. Soil Conservation Research Programme, Research Report 30. Addis Ababa and Bern.

Ludi, E., 2004. Economic analysis of soil conservation: case studies from the highlands of Amhara region, Ethiopia. Geographica Bernensia, African Studies Series A 18. Bern: Institute of Geography. 
Luettich, R.A., Harleman, D.R., Somlyody, L., 1990. Dynamic behavior of suspended sediment concentrations in a shallow lake perturbed by episodic wind events. Limnology and Oceanography, 35, 1050-1067.

Marchamalo, M., Hooke, J.M., Sandercock, P.J., 2016. Flow and Sediment Connectivity in Semi-arid Landscapes in SE Spain: Patterns and Controls. Land Degradation \& Development, 27, 1032-1044.

Masto, R.E., Sheike, S., Nehrk, G., Siliva, V.A., George, J., Ram, L.C., 2015. Assessment of environment soil quality around Sonepur Brazari mine of Raniganj coalfield, India. Soil Earth 6: 811-821. DOI:10.5194/sec-6-811.

Mati, B.M. Morgan, P., Gichuki, F., Quinton, J., Brewer, T., Linger, H., 2000. Assessment of erosion hazard with the USLE and GIS: A case study of the Upper Ewaso Ng'iro North basin of Kenya. International Journal of Applied Earth Observation and Geoinformation, 2, 78-86.

McHugh, O.V., Steenhuis, T.S., Abebe, B., Fernandes, E.C., 2007. Performance of in situ rainwater conservation tillage techniques on dry spell mitigation and erosion control in the drought-prone North Wello zone of the Ethiopian highlands. Soil and tillage research, 97, 19-36.

Medeiros, P.H., Güntner, A., Francke, T., Mamede, G.L., Carlos de Araújo, J., 2010. Modelling spatio-temporal patterns of sediment yield and connectivity in a semi-arid catchment with the WASA-SED model. Hydrological Sciences Journal-Journal des Sciences Hydrologiques, 55, 636-648.

Mekonnen, M., Keesstra, S., Baartman, J., Ritsema, C.J., Melesse, A., 2015. EValuating sediment storage dams: Structural off-site sediment trapping measures in northwest Ethiopia. Cuadernos de Investigación Geográfica, 41.

Mekuria, W., Vedcamp, E., Haile, M., Nyssen, J., Muys, B., Gebirehiwot, K., 2007. Effectiveness of exclosures to restore degraded soils as a result of overgrazing in Tigray, Ethiopia. Journal of arid environments, 69, 270-284.

Meshesha, D., Tsunekawa, A., Tsubu, M., Haregeweyn, N., 2012. Dynamics and hotspots of soil erosion and management Scenario of the Central Rift valley of Ethiopia. International Journal of Sediment Research. 27, 84-99.

Miao, C., Ni, J., Borthwick, A.G., 2010. Recent changes of water discharge and sediment load in the Yellow River basin, China. Progress in Physical Geography, 34, 541-561.

Mitiku, H., Herweg, K., Stillhardt, B., 2006. Sustainable land management: a new approach to soil and water conservation in Ethiopia. Centre for Development and Environment (CDE) and NCCR North-South, University of Bern, Switzerland. DOI: 10.7892/boris.19217.

Moges, A., Holden, N.M., 2007. Farmers perceptions of soil erosion and soil fertility loss in Southern Ethiopia. Land Degradation \& Development. 18, 534-554. 
Moliere, D., Evans, K., Saynor, M., Erskine, W., 2004. Estimation of suspended sediment loads in a seasonal stream in the wet-dry tropics, Northern Territory, Australia. Hydrological processes, 18, 531-544.

Molle, F., Wester, P., Hirsch, P., 2010. River basin closure: Processes, implications and responses. Agricultural Water Management, 97, 569-577.

Morehead, M.D., Syvitski, J.P., Hutton, E.W., Peckham, S.D., 2003. Modeling the temporal variability in the flux of sediment from ungauged river basins. Global and Planetary Change, 39, 95-110.

Morgan, R., 1985. Assessment of soil erosion risk in England and Wales. Soil use and Management, 1, 127-131.

Morgan, R.P.C., 2009. Soil erosion and conservation. John Wiley \& Sons.

Moutier, M., Shainberg, I., Levy, G.J., 2000. Hydraulic gradient and wetting rate effects on hydraulic conductivity of two calcium vertisols. Soil Science Society of America Journal 64 (4), 1211-1219.

Murthy, V.N.S., 2007. Text book of soil mechanics and foundation engineering. CBS Publishers \& Distributors, New Delhi, India.

Mwendera, E., Saleem, M.M., Dibabe, A., 1997. The effect of livestock grazing on surface runoff and soil erosion from sloping pasture lands in the Ethiopian highlands. Australian Journal of Experimental Agriculture, 37, 421-430.

Nabahungu, N.L., Visser, S.M., 2013. Farmers' knowledge and perception of agricultural watershed management in Rwanda. Land Degradation \& Development. 24, 363-374. DOI: 10.1002/1dr.1133

Nadal-Romero, E., Regüés, D., Latron, J., 2008. Relationships among rainfall, runoff, and suspended sediment in a small catchment with badlands. Catena, 74, 127-136.

Nadeu, E., Van Oost, K., Boix-Fayos, C., de Vente, J., 2014. Importance of land use patterns for erosion-induced carbon fluxes in a Mediterranean catchment. Agriculture, ecosystems \& environment, 189, 181-189.

Nearing, M., 2005. Modeling response of soil erosion and runoff to changes in precipitation and cover. Catena, 61, 131-154.

Nearing, M., Simanton, J., Norton, L., Bulygin, S., Stone, J., 1999. Soil erosion by surface water flow on a stony, semiarid hillslope. Earth Surface Processes and Landforms, 24, 677-686.

Nedasa, B., 2002. Soil conservation program in Amhara National Regional State: Natural resource degradation on environmental concerns in ANRS. Society of Soil Science. 6, 125-147.

Novara, A., Gristina, L., Saladino, S.S., Santoro, A., Cerdà, A., 2011. Soil erosion assessment on tillage and alternative soil management in a Sicilian vineyard. Soil and Tillage Research. 117, 140-147. DOI: 10.1016/j.still.2011.09.007. 
Nu-Fang, F., Zhi-Hua, S., Lu, L., Cheng, J., 2011. Rainfall, runoff, and suspended sediment delivery relationships in a small agricultural watershed of the Three Gorges area, China. Geomorphology, 135, 158-166.

Nyssen, J., Poesen, J., Moeyersons, J., Haile, M., Deckers, J., 2004. Human impact on the environment in the Ethiopian and Eritrean highlands - a state of the art. Earth-science reviews, 64, 273-320.

Nyssen J, Haregeweyn N, Descheemaeker K, Gebremichael D, Vancampenhout K, Poesen J, Haile M, Moeyersons J, Buytaert W, Naudts J. 2006. Comment on “Modelling the effect of soil and water conservation practices in Tigray, Ethiopia" [Agric. Ecosyst. Environ. 105 (2005) 29-40]. Agriculture, ecosystems \& environment, 114, 407-411.

Nyssen J, Poesen J, Gebremichael D, Vancampenhout K, D'aes M, Yihdego G, Govers G, Leirs H, Moeyersons J, Naudts J. 2007. Interdisciplinary on-site evaluation of stone bunds to control soil erosion on cropland in Northern Ethiopia. Soil and Tillage Research, 94, 151 163.

Nyssen J, Clymans W, Poesen J, Vandecasteele I, De Baets S, Haregeweyn N, Naudts J, Hadera A, Moeyersons J, Haile M., 2009. How soil conservation affects the catchment sediment budget-a comprehensive study in the north Ethiopian highlands. Earth Surface Processes and Landforms, 34, 1216-1233.

Nyssen J, Clymans W, Descheemaeker K, Poesen J, Vandecasteele I, Vanmaercke M, Zenebe A, Van Camp M, Haile M, Haregeweyn N. 2010. Impact of soil and water conservation measures on catchment hydrological response-a case in north Ethiopia. Hydrological processes, 24, 1880-1895.

Nyssen, J., Frankl, A., Zenebe, A., Poesen, J., Deckers, J., 2015. Environmental conservation for food production and sustainable livelihood in Tropical Africa. Land Degradation \& Development. 7, 629-631.

Nyssen, J., Poesen, J., Moeyersons, J., Haile, M., Deckers, J., 2008. Dynamics of soil erosion rates and controlling factors in the Northern Ethiopian Highlands-towards a sediment budget. Earth surface processes and landforms, 33, 695-711.

Ochoa, P.A, Fries, A., Mejìa, D., Burneo, J.I., Ruìz-Sinoga, J.D., Cerdà, A., 2006. Effects of climate, land cover and topography on soil erosion risk in semiarid basin of the Andes. Catena 140, 31-42.

Odendo, M., Obare, G., Salasya, B., 2010. Farmers perception and knowledge of soil fertility degradation in two contrasting sites in western Kenya. Land Degradation \& Development. 21, 557-564.

Okigbo, B.N., 1991. Development of sustainable agriculture systems in Africa. Ibada, Nigeria. Ólafsdóttir, R., Juluisson, A.D., 2000. Farmers' perception of land-cover changes in NE Iceland. Land Degradation \& Development. 11, 439-458. 
Olarieta, J.R, Rodriguez-Valle, F.L., Tello, E., 2008. Preserving and destroying soils, transforming landscapes: soils and land-use changes in the vallès country (Catalunya, Spain). Land Use Policy 25(4), 474-484.

Parsons, A., Stone, P., 2006. Effects of intra-storm variations in rainfall intensity on interrill runoff and erosion. Catena, 67, 68-78.

Piest, R.F., Wyatt, G.M., Bradford, J.M., 1975. Soil erosion and sediment transport from gullies. Journal of the Hydraulics Division, 101, 65-80.

Pío-León, J.F., Delgado-Vargas, F., Murillo-Amador, B., León-de-la-luz, J., Vega-Auiña, R., Nietro-Garibay, A., Córdoba-Maston, M., Ortega-Rubio, A., 2017. Environmental traditional knowledge in a natural protected area as a base for management and conservation policies. Journal of Environmental management. 201, 53-71.

Pulido, M., Schnabel, S., Contador, J.F.L., Lozano-Parra, J., González, F., 2016. The impact of heavy grazing on soil quality and pasture production in rangelands of SW Spain. Land Degradation \& Development. DOI: 10.1002/1dr.2501.

Quiñonero-Rubio, J.M., Nadeu, E., Boix-Fayos, C., Vente, J., 2016. Evaluation of the Effectiveness of Forest Restoration and Check-Dams to Reduce Catchment Sediment Yield. Land Degradation \& Development, 27, 1018-1031.

Rashidi, M., Hajiaghaei, A., Sadeghi, A., Mehrdada, N., Shayan, A., Jaberinasab, B., 2014. Prediction of soil infiltration rate based on particle size distribution, bulk density, organic matter and moisture content of soil. American-Eurasian Journal of Agricultural \& Environmental Science 14(5), 464-470.

Rasool, R., Kukal, S.S., Hira, G.S., 2007. Soil physical fertility and crop performance as affected by long-term application of FYM and inorganic fertilizer in maize-wheat system. Soil \& Tillage Research 101 (1-2), 31-36.

Renard, K.G., 1997. Predicting soil erosion by water: a guide to conservation planning with the revised universal soil loss equation (RUSLE).

Ritsema, C.J., Stolte, J., Oostindie, K., Elsen, E., 1996. Measuring and modelling of soil water dynamics and runoff generation in Agricultural loessial hill slope. Hydrological Processes 10: 1081-1089.

Ritsema, C.J., Kuipers, H., Kleiboer L. Van den Elsen E., Oostindie K., Wesseling J., Wolthuis J., Haringa P., 2009. A new wireless underground network system for continuous monitoring of soil water contents. Water Resource Research 45, W00D36, DOI: 10.1029/2008 WR007071, 2009.

Ritsema, C.J., Dekker, L., 2000. Preferential flow in water repellent sandy soils: principles and modeling implications. Journal of Hydrology, 231, 308-319.

Ritsema, C.J., Dekker, L., Oostindie, K., Tsegaye, T., 2008. Soil water repellence and critical soil water content. Soil Science step-by-step field analysis. DOI:10.2136/2008.soilsciencestepbystep.c8. 
Ritsema, C.J., Dekker, L.W., Hendrickx, J., Hamminga, W., 1993. Preferential flow mechanism in a water repellent sandy soil. Water Resources Research, 29, 2183-2193.

Ritsema, C.J., Stolte, J., Oostindie, K., van de Dijk, P., 1996. Measuring and modelling of soil water dynamics and runoff generation in Agricultural hill slope. Hydrological Processes 10(8), 1081-1089.

Ritsema, C.J., Stolte, J., van den Elsen, E.G.M., Liu, B., Fu, B., Liding, C., Jetten, V., Hessel, J., Ledin, S., Messing, I., Fagerstorm, M., 2002. Soil and water conservation planning on loess plateau in northern China. Soil and water conservation, regional policies and action. Tsinghua University Press, Beijing, China pp. 305-310.

Roes, D., Kafiriti, E., Wellens, J., Deckers, J., Maertens, A., Mugogo, S., Dondeyne, K., Descheemaeker K., 2007. Can soil bunds increase production of rain-fed lowland rice in southern Tanzania? Agricultural Water Management 89, 230-238.

Romero-Díaz, A., Alonso-Sarriá, F., Martínez-Lloris, M., 2007. Erosion rates obtained from check-dam sedimentation (SE Spain). A multi-method comparison. Catena, 71, 172-178.

Rovira, A., Batalla, R.J., 2006. Temporal distribution of suspended sediment transport in a Mediterranean basin: The Lower Tordera (NE SPAIN). Geomorphology, 79, 58-71.

Ruiz-Jaen, M.C., Mitchell Aide, T., 2005. Restoration success: how is it being measured? Restoration ecology, 13, 569-577.

Rust, W., Corstanje, R., Holman, I., Milne, A., 2014. Detecting land use and land management influences on catchment hydrology by modelling and wavelets. Journal of hydrology, 517, 378-389.

Sauquet, E., Catalogne, C., 2011. Comparison of catchment grouping methods for flow duration curve estimation at ungauged sites in France. Hydrology and Earth System Sciences, 15, 2421.

Scherr, S.J., 1999. Soil degradation: a threat to developing-country food security by 2020 ? Intl Food Policy Res Inst.

Schwartz, B., 2007. Field scale soil moisture measurements using TDR calibrated ERT data. Department of Geological Science, Virginia, Tech, Derring Hall, Blacksburg.

Schwilch, G., Bachmann, F., Valente, S., Coelho, C., Moreira, J., Laovina, A., Chacker, M., Aderghal, M., Santos, P., Reed, M., 2012. A structural multi-stakeholder learning process for sustainable land management. Journal of Environmental Management. 107, 52-60.

Searcy, J.K., 1959. Flow-duration curves. US Government Printing Office Washington.

Seeger, M. et al., 2004. Catchment soil moisture and rainfall characteristics as determinant factors for discharge/suspended sediment hysteretic loops in a small headwater catchment in the Spanish Pyrenees. Journal of Hydrology, 288, 299-311.

Segarra, E., Ervin, R.T., Dicks, M.R., Taylor, D.B., 1991. On-site and off-site impacts of soil erosion: their implications for soil conservation policy. Resources, conservation and recycling, 5, 1-19. 
Setegn, S.G., Dargahi, B., Srinivasan, R., Melesse, A.M., 2010. Modeling of Sediment Yield From Anjeni-Gauged Watershed, Ethiopia Using SWAT Model. JAWRA Journal of the American Water Resources Association, 46, 514-526.

Setegn, S.G., Srinivasan, R., Dargahi, B., Melesse, A.M., 2009. Spatial delineation of soil erosion vulnerability in the Lake Tana Basin, Ethiopia. Hydrological Processes, 23, 37383750.

Sharma, P., Bhushan, L., 2001. Physical characterization of soil amended with organic residues in rice-wheat cropping system using a single value soil physical index. Soil \& Tillage Research 60, 143-152.

Shiferaw, B., Holden, S., 1999. Soil erosion and smallholders' conservation decisions in the highlands of Ethiopia. World development, 27, 739-752.

Shiferaw, B., Holden, S.T., 1998. Resource degradation and adoption of land conservation technologies in the Ethiopian highlands: a case study in Andit Tid, North Shewa. Agricultural economics, 18, 233-247.

Shiferaw, B., Holden, S.T., 2001. Farm-level benefits to investments for mitigating land degradation; empirical evidence from Ethiopia. Environment \& Development Economics. 6, 338-355.

Sileman, A,B., Racklot, D., Evrad, O., Sanna, M., Lefevre, I., Bissonais, Y.L., 2015. Relative contributions of rill/interrill and gully/channel erosion to small reservoir siltation in Mediterranean environments. Land Degradation \& Development. DOI:10.1002/1dr.2387.

Sonneveld, B.G.S, Keyzer, M.A., 2003. Land under pressure: soil conservation concerns and opportunities for Ethiopia. Land Degradation \& Development 14(1), 5-23.

Steegen A, Govers G, Nachtergaele J, Takken I, Beuselinck L, Poesen J. 2000. Sediment export by water from an agricultural catchment in the Loam Belt of central Belgium. Geomorphology, 33: 25-36.

Steenhuis, T., Collic, A., Sileshi, B., Awulachew, A., Abdassalam, A., Eston, Z., 2008. Modelling Erosion and Sedimentation in upper Blue Nile (Ethiopia). Cornel University, Ithaca NY, USA.

Steenhuis, T., Tilahun, S., Elikamil, M., Atanaw , F., Worqlul, A., Walle, A., Ayana, E., Abiy, A., Alemu, M., Tessema, Z., Mohamad, Y., 2013. Simulating discharge and sediment concentrations in the increasingly degrading Blue Nile Basin. Cornel University, Ithaca NY USA.

Steenhuis, T.S., Collick, A., Easton, Z., Legesse, E., Bayabil, H., White, E., Awulachew, S., Adigo, E., Ahmed, A., 2009. Predicting discharge and sediment for the Abay (Blue Nile) with a simple model. Hydrological processes, 23, 3728-3737.

Steenhuis, T.S., Winchell, M., Rossing, J., Zollweg, J.A., Walter, M.F., 1995. SCS runoff equation revisited for variable-source runoff areas. Journal of Irrigation and Drainage Engineering, 121, 234-238. 
Stoof, C.R., Vervoort, R.W., Iwema, J., Elsen, E., Ferreira, A.J., Ritsema, C.J., 2011. Hydrological response of a small catchment burned by experimental fire. Hydro. Earth Syst. Sci. 6, 267-285.

Stoorvogel, J.J., Smaling, E.M.A., 1990. Assessment of soil nutrient depletion in Sub-Saharan Africa: 1983-2000. Vol. 2: Nutrient balances per crop and per land use systems. 09243062, ISRIC.

Stringer, L.C., Reed, M., 2007. Land degradation assessment in southern Africa: integrating local and scientific Knowledge bases. Land Degradation \& Development. 18, 99-115.

Stringer, L.C., Reed, M.S., Fleskens, L., Thomas, R.J., Le Q.B., Lala-Pritchard, T., 2017. A new dryland development paradigm grounded in empirical analysis of dryland systems science. Land Degradation \& Development. doi: 10.1002/Idr.2716.

Swift, M.J., Sanchez, P.A., 1984. Biological management of tropical soil fertility for sustained productivity. Nature and Resources. UNESCO, Paris.

Subhatu A, Lemann T, Hurni K, Portner B, Kassawmar T, Zeleke G, Hurni H. 2017. Deposition of eroded soil on terraced croplands in Minchet catchment, Ethiopian Highlands. International Soil and Water Conservation Research.

Sugiyama, H., Vudhivanich, V., Whitaker, A.C., Lorsirirat, K., 2003. Stochastic flow duration curves for evaluation of flow regimes in rivers. JAWRA Journal of the American Water Resources Association, 39, 47-58.

Symeonakis, E., Drake, N., 2004. Monitoring desertification and land degradation over subSaharan Africa. International Journal of Remote Sensing, 25, 573-592.

Taddese, G., 2001. Land degradation: a challenge to Ethiopia. Environmental management, $27,815-824$.

Tadele, A., Birru Y., Assefa Z., Gete z., 2014. Combined effects of soil bund with biological soil and water conservation measures in north western Ethiopian highlands. Ecohydrology \& Hydrobiology 14(3). DOI:10.1016/j.ecohdy.2014.07.002.

Takken, I. et al., 1999. Spatial evaluation of a physically-based distributed erosion model (LISEM). Catena, 37, 431-447.

Takken I, Govers G, Jetten V, Nachtergaele J, Steegen A, Poesen J. 2005. The influence of both process descriptions and runoff patterns on predictions from a spatially distributed soil erosion model. Earth Surface Processes and Landforms, 30: 213-229.

Tallaksen, L., 1995. A review of baseflow recession analysis. Journal of hydrology, 165, 349370.

Tamene, L., Adimassu, Z., Aynekulu, E., Yaekob, T., 2017. Estimating landscape susceptibility to soil erosion using a GIS-based approach in Northern Ethiopia. International Soil and Water Conservation Research.

Tamane, L., Adimassu, Z,. Ellison, J., Yaekob, T., Woldearegay, K., Mekonnen, K., Thorne, P, 2017. Mapping soil erosion hotspots and assessing the potential impacts of land management practices in the highlands of Ethiopia. Geomorphology, 292: 153-163. 
Taye, G., Poesen, J., Van Wesemaek, B., 2013. Effects of land use, slope gradient and soil and water conservation techniques on runoff and soil loss in semi-arid Ethiopian highlands. Journal of Physical Geography. 34, 236-259.

Taye, G., Poesen, J., Vanmaercke, M., van Wesemael, B., Martens, L., Teka, D., Nyssen, J., Deckers, J., Vanacker, V., Haregeweyn, N. and Hallet, V., 2015. Evolution of the effectiveness of stone bunds and trenches in reducing runoff and soil loss in the semiarid Ethiopian highlands. Zeitschrift für Geomorphologie 59(4), 477-493.

Tebebu, T. Y., Bayabil, H. K., Stoof, C. R., Giri, S. K., Gessess, A. A., Tilahun, S. A., and Steenhuis, T. S. (2016) Characterization of degraded soils in the humid Ethiopian highlands. Land Degrad. Develop. DOI: 10.1002/Idr.2687.

Tebebu, T. Y., Steenhuis, T. S., Dagnew, D. C., Guzman, C. D., Bayabil, H. K., Zegeye, A. D., Collick, A. S., Langan, S., Macalister, C., Langendoen, E. J., Tilahun, S. A. 2015. Improving Efficacy Of Landscape Interventions In The (Sub) Humid Ethiopian Highlands By Improved Understanding Of Runoff Processes. Frontiers In Earth Science 3, 49.

Tebebu, T., Abiy, A., Zegeye, A., Dahlke, Easton, Z., Tilahun, S., Collic, A., Kidanu, S., Moges, S., Dadgar, F., Steenhuis, T., 2010. Surface and sub-surface flow effect on permanent gully formation and upland erosion near Lake Tana in the northern highlands of Ethiopia. Hydrology \& Earth System Science 14, 2207-2217.

Tebebu, T.Y., 2009. Assessment of hydrological controls on gully formation near Lake Tana, northern highlands of Ethiopia, Citeseer.

Tefera, B., Sterk, G., 2010. Land management, erosion problems and soil and water conservation in Fincha'a watershed, western Ethiopia. Land Use Policy, 27, 1027-1037.

Tekle, K., Hedlund, L., 2000. Land cover changes between 1958 and 1986 in Kalu District, southern Wello, Ethiopia. Mountain research and development, 20, 42-51.

Teklewold, H., Kassie, M., Shiferaw, B., 2013. Adoption of multiple sustainable agricultural practices in rural Ethiopia. Journal of agricultural economics, 64, 597-623.

Tesemma, Z., Mohamed, Y., Steenhuis, T., 2010. Trends in rainfall and runoff in Blue Nile Basin. Hydrol. Process. 24, 3747-3757.

Tesfaye, G., Debebe, W., 2013. Farmers perceptions and participation on mechanical soil and water conservation techniques in Kembata Tembaro Zone: the case of kachabirra woreda, Ethiopia. Adv. Str. Geo. Engineering Journal. 2, 118-131.

Tessema, S.M., 2006. ASsessment of temporal hydrological variations due to land use changes using remote sensing/gis: a case study of lake tana basin. Ethiopia.

Tilahun S. A., C.D. Guzman, A. D. Zegeye, T. A. Engda, A.S. Collick, A. Rimmer and T.S. Steenhuis 2013. An efficient semi-distributed hillslope erosion model for the sub humid Ethiopian Highlands. Hydrology and Earth System Sciences 17, 1051-1063.

Tilahun, S. A., Ayana, E. K., Guzman, C. D., Dagnew, D. C., Zegeye, A. D., Tebebu, T. Y., Yitaferu, B. \& Steenhuis, T. S. 2016. Revisiting storm runoff processes in the upper Blue Nile basin: The Debre Mawi watershed. Catena 143, 47-56. 
Tilahun, S.A. et al., 2015. Distributed discharge and sediment concentration predictions in the sub-humid Ethiopian highlands: the Debre Mawi watershed. Hydrological Processes, 29, 1817-1828.

Tilahun, S.A., 2012. Observations and modeling of erosion from spatially and temporally distributed sources in the (semi) humid Ethiopian highlands, Citeseer.

Troeh, F.R., Hobbs, J.A., Donahue, R.L., 1980. Soil and Water Conservation for Productivity and Environmental Production. Soil and Water Conservation for Productivity and Environmental Production.

Uhlenbrook, S. et al., 2012. Impacts of conservation tillage on the hydrological and agronomic performance of Fanya juus in the upper Blue Nile (Abbay) river basin. Hydrology and Earth System Sciences, 16 (12), 2012.

Van Beek, C., Herold, N., Kessler, A., Vonk, R., 2017. The quest for improving soil fertility: why an integrated approach is needed. SAGE, 46: 289-294.

Van der Wateren-de Hoog, B., 1998. A regional model to assess the hydrological sensitivity of medium size catchments to climate variability. Hydrological processes, 12, 43-56.

Van Oost, K. et al., 2005. Spatially distributed data for erosion model calibration and validation: The Ganspoel and Kinderveld datasets. Catena, 61, 105-121.

Van Oost, K., Govers, G., Desmet, P., 2000. Evaluating the effects of changes in landscape structure on soil erosion by water and tillage. Landscape ecology, 15, 577-589.

Van Reeuwijk, L., 2002. Procedures for soil analysis. Sixth edition, Technical Paper 9, ISRIC, Wageningen, The Netherlands.

Van Rompaey, A., Bazzoffi, P., Jones, R.J., Montanarella, L., 2005. Modelling sediment yields in Italian catchments. Geomorphology, 65, 157-169.

Van Rompaey, A., Krasa, J., Dostal, T., 2007. Modelling the impact of land cover changes in the Czech Republic on sediment delivery. Land Use Policy, 24, 576-583.

Van Rompaey, A.J., Govers, G., Puttemans, C., 2002. Modelling land use changes and their impact on soil erosion and sediment supply to rivers. Earth surface processes and landforms, 27, 481-494.

Van Rompaey, A.J., Verstraeten, G., Van Oost, K., Govers, G., Poesen, J., 2001. Modelling mean annual sediment yield using a distributed approach. Earth Surface Processes and Landforms, 26, 1221-1236.

Vancampenhout, K., Nyssen, J., Gebremichael, D., Deckers J., Poesen, J., Haile, M., Moeyersons, J., 2006. Stone bunds for soil conservation in northern Ethiopian highlands: Impacts on soil fertility and crop yield. Soil \& Tillage Research 90(1-3), 1-14.

Vandaele, K., Poesen, J., 1995. Spatial and temporal patterns of soil erosion rates in an agricultural catchment, central Belgium. Catena, 25, 213-226.

Vanmaercke, M., Zenebe, A., Poesen, J, Nyssen, J., Verstraeten, G., Deckers, G., 2006. Magnitude and dynamics of runoff and sediment transport in the Geba River 
catchment, northern Ethiopia. Physical and Regional Geography Research Group, Catholic University of Leuven, Celestijnenlaan 200E Tower, 3.

Vanmaercke, M., Zenebe, A., Poesen, J, Nyssen, J., Verstraeten, G., Deckers, G., 2010. Sediment dynamics and the role of flash floods in sediment export from medium-sized catchments: a case study from the semi-arid tropical highlands in northern Ethiopia. Journal of Soils and Sediments, 10, 611-627.

Vanmaercke, M., Poesen, J., Govers, G., Verstraeten, G., 2015. Quantifying human impacts on catchment sediment yield: a continental approach. Global and Planetary Change, 130, 22-36.

Vente, J., Poesen, J., 2005. Predicting soil erosion and sediment yield at the base scale: Scale issues and semi-quantitative models. Earth-Science Reviews. 71, 95-125.

Verstraeten, G., Oost, K., Rompaey, A., Poesen, J., Govers, G., 2002. Evaluating an integrated approach to catchment management to reduce soil loss and sediment pollution through modelling. Soil Use and Management, 18, 386-394.

Verstraeten, G., Poesen, J., 2000. Estimating trap efficiency of small reservoirs and ponds: methods and implications for the assessment of sediment yield. Progress in Physical Geography, 24, 219-251.

Verstraeten, G., Poesen, J., 2001. Factors controlling sediment yield from small intensively cultivated catchments in a temperate humid climate. Geomorphology, 40, 123-144.

Verstraeten, G., Prosser, I.P., Fogarty, P., 2007. Predicting the spatial patterns of hillslope sediment delivery to river channels in the Murrumbidgee catchment, Australia. Journal of Hydrology, 334, 440-454.

Vigiak, O., Sterk, G., Romanowicz, R.J., Beven, K.J., 2006. A semi-empirical model to assess uncertainty of spatial patterns of erosion. Catena, 66, 198-210.

Vogel, R.M., Fennessey, N.M., 1994. Flow-duration curves. I: New interpretation and confidence intervals. Journal of Water Resources Planning and Management, 120, 485 504.

Volli, C., 2002. Policies for sustainable land management in highlands of Ethiopia: summary papers and proceedings of a seminar held at ILRI, Addis Ababa, Ethiopia. Socioeconomics and policy research working paper 30.

Walkley, A., Black, C.A., 1994. An examination of Degtjareff methods for determining soil organic matter and proposed modifications of the chromic acid titration method. Soil Science 37, 29-38.

Walle, S., Chantawarangul, K., Nontananandh, S., Jantawat, S., 2006. Effectiveness of grass strips as barrier against runoff and soil loss in Jijiga area. Northern part of Somalia region, Ethiopia. Kasetstart Journal 40, 549-555.

Walling, D.E., Webb, B., 1982. Sediment availability and the prediction of storm-period sediment yields. Recent developments in the explanation and prediction of erosion and sediment yield, 137, 327-337. 
Wallinga, J, Hobo, N, Cunningham, A, Versendal, A, Makaske,B, Middlekoop, H, 2010. Sedimentation rates on embanked floodplains determined through quartz optical dating. Quaternary Geochronology. 5(2-3):170-175.

Wang, H., Gao J., Li X., Wang, H.L., Zhang, Y., 2014. Effects of soil and water conservation measures on ground water levels and recharge. Water 6(12), 3783-3806, doi:10.3390/w6 6123783.

Wei, W., 2007. The effect of land uses and rainfall regimes on runoff and soil erosion in the semi-arid loess hilly area, China. Journal of hydrology, 335, 247-258.

Wei, W., Chen, L., Zhang, H., Chen, J., 2015. Effect of rainfall variation and landscape change on runoff and sediment yield from a loess hilly catchment in China. Environmental Earth Sciences, 73, 1005-1016.

Wei, Y.P., Chen, D., White, R.E., Willet, I.R., Edis, R., Langford, J., 2009. Farmers' perception of environmental degradation and their adoption of improved management practices in Alxa, China. Land Degradation \& Development. 20, 336-346.

Wesseling, J., Stoof, C., Ritsema, C.J., Oostindie, K., 2009. The effect of soil texture and organic amendment on the hydrological behaviour of coarse textured soils. Soil Use \& Management 25(3), 274-275, DOI: 10.1111/j.1475-2743.2009.00224.x.

Williams, G.P., 1989. Sediment concentration versus water discharge during single hydrologic events in rivers. Journal of Hydrology, 111, 89-106.

Wischmeier, W.H., Smith, D.D., 1978. Predicting rainfall erosion losses-a guide to conservation planning. Predicting rainfall erosion losses-a guide to conservation planning.

WoldeGabriel, G. et al., 2000. Volcanism, tectonism, sedimentation, and the paleoanthropological record in the Ethiopian Rift System. Special papers-geological society of america, 83-99.

Wolman, M.G., Miller, J.P., 1960. Magnitude and frequency of forces in geomorphic processes. The Journal of Geology, 68, 54-74.

Wu, T., Wu, G., Wang, D., Shi, Z., 2012. Soil-hydrological properties response to grazing exclusion in a steppe grass land of Loess plateau. Environment \& Earth Science 71, 745 752, DOI: 10.1007/s12665-013-2476-y.

Wudneh, A., 2012. Characteristics and onsite costs of the sediment lost by runoff from Dapo and Chekorsa Watersheds, Digga District, Ambo University.

Wudneh, A., Erkossa, T., Devi, P., 2014. Sediment and nutrient lost by runoff from two watersheds, Digga district in Blue Nile basin, Ethiopia. African Journal of Environmental Science and Technology, 8, 498-510.

Yair, A., Raz-Yassif, N., 2004. Hydrological processes in a small arid catchment: scale effects of rainfall and slope length. Geomorphology, 61, 155-169. 
Yazdanpanah, N., Mahmoodabdi, M., Cerdà, A., 2016. The impact of organic amendments on soil hydrology, structure and microbial respiration in semiarid lands. Geoderma 266: 58-65. DOI: 10.1016/j.geoderma.2015.11.032.

Yeshaneh, E., Eder, A., Blöschl, G., 2014. Temporal variation of suspended sediment transport in Koga catchment, North western Ethiopia and Environmental implications. Hydrological Processes 28, 5972-5984, DOI: 10.1002/hyd.10090.

Yeshaneh, E., Wagner, W., Exner-Kittridge, M., Legesse, D., Blöschl, G., 2013. Identifying land use/cover dynamics in the Koga Catchment, Ethiopia, from multi-scale data, and implications for environmental change. ISPRS International Journal of Geo-Information, 2, 302-323.

Yitaferu, B., 2007. Land degradation and options for sustainable land management in Lake Tana Basin, Amhara region, Ethiopia. Centre for Development and Environment (CDE), Geographisches Institute Universitat Bern, Bern.

Zabaleta, A., Martínez, M., Uriarte, J.A., Antigüedad, I., 2007. Factors controlling suspended sediment yield during runoff events in small headwater catchments of the Basque Country. Catena, 71, 179-190.

Zegeye, A., Steenhuis, T., Blake, R., Kidnau, S., Collick, A., Dadgari, F., 2010. Assessment of soil erosion processes and farmer perception of land conservation in Debre Mewi watershed near Lake Tana, Ethiopia. Eco. Wate. Eco. Soc. Ethiopia. 10, 297-306.

Zeleke, G., 2000. Landscape dynamics and soil erosion process modelling in north western Ethiopian highlands. African studies series A 16, Geographia Bernensia Berne, Switzerland.

Zeleke, G., Hurni, H., 2001. Implications of land use and land cover dynamics for mountain resource degradation in the Northwestern Ethiopian highlands. Mountain research and development, 21, 184-191.

Zenebe, A., Bezaye, G., Demeke, N., Mowo, J., Kidist, H., 2013. Farmers preference for soil and water conservation practices in central highlands of Ethiopia. African Crop Science Journal. 21, 781-790.

Zhang, Q., Fua, B., Chen, L., Zhada, W., Yang, Q., Liu, G., Gulinck, H., 2004. Dynamics and driving factors of agricultural landscape in the semiarid hilly area of the Loess Plateau, China. Agriculture, Economics \& Environment 1039(3), 535-543.

Zhao, G., 2015. Sediment yield estimation in a small watershed on the northern Loess Plateau, China. Geomorphology, 241, 343-352.

Zhou, P., Luukkan, O., Tokola, T., Nieminen, J., 2008. Effect of vegetation cover on soil erosion in mountainous watershed. Catena. 75, 319-325.

Zinabu, G.M., Kebede-Westhead, E. Desta, Z., 2002. Long-term changes in the chemical features of waters of seven Ethiopian rift-valley lakes. Hydrobiologia 477, 81-91 


\section{English summary}

Prolonged soil drying and severe moisture stress during the dry season, and soil saturation, erosion, flooding and sedimentation during the short rainy season are critical problems in the North-Western Ethiopian highlands. Despite massive investment in SWC strategies to reduce these problems, soil erosion, moisture stress, flooding and sedimentation are still severe problems throughout Ethiopia and specifically in fragile regions of humid/sub-humid highlands of North-Western Ethiopia. The success to prevent erosion, moisture stress, flooding and sedimentation and effective management and utilisation of water and soil resources have been very limited (Bewket, 2007; Nyssen et al., 2007; Adimassu et al., 2012; Jemberu et al., 2017). The prevention of soil and water loss, flooding and sedimentation requires a thorough understanding of hydrological and sedimentary processes and selecting suitable SWC strategies to increase land productivity for effective management and utilisation of soil and water resources. However, very few studies are available about the impacts of SWC measures on hydrological processes and sediment yield in Ethiopia (Herweg and Ludi, 1999; Dagnew et al., 2015; Jemberu et al., 2017). Further, in order to foster SLM systems in Ethiopia, scientifically validated appropriate SWC strategies are needed.

After the general introduction (chapter 1), chapter 2 describes participatory assessment of soil erosion severity and performances of mitigation measures with local community. This research aimed to assess soil erosion and performance of different SWC measures from the farmers' perspective by documenting their perceptions and experiences in Koga catchment, highlands of Ethiopia. To this aim, workshops were organised in three sub-catchments differing in slopes and SWC measures. Workshops included group discussions and field monitoring of sheet erosion indicators, and rills and systematically describing the status of soil erosion, soil fertility and yield to assess the performance of SWC measures. Results show that farmers are aware of not only the harmful effects of ongoing soil erosion but also the impacts of mitigation measures on their farms. Sheet erosion was found to be the most widespread form of erosion while rill damage was critical on plots cultivated to cereals on steep slopes.

Farmers perceived that the desired impacts of SWC practices were attained in general: runoff and soil loss rates decreased, while soil fertility and production increased. However, they also believed that SWC measures did not prevent soil erosion completely. Comparatively, graded stone-faced soil bunds revealed maximum desired impacts and were 
most appreciated by farmers whereas all level bunds caused water logging. Most traditional ditches were highly graded and begun incising and affected production of cereals.

Chapter 3 deals with the effect of bund structures dimensions on soil selected properties and hydrology. Field investigations and laboratory analysis were carried at three subwatersheds of Koga catchment in the highlands of NW Ethiopia to evaluate the variation in bund structure design and its impact on soil-water retention, bulk density, porosity and soil depth. Results show that the dimensions and stability of bund structures, and consequently, the impacts of bunds varied widely. The widths and heights of bunds, and slope gradients were significantly correlated with infiltration rate and available soil-water content. Water holding capacity was $24 \%$ higher compared to that on untreated farms. Bunds with larger dimensions of top width $(>85 \mathrm{~cm}$ ) and height $(>75 \mathrm{~cm}$ ) showed 17 and $18 \%$ higher water holding capacity compared to fields with bunds having lower dimensions. In addition, results exhibited that the porosity and soil depth were significantly affected by the dimensions of bund structures and increased with increasing widths and heights of bunds. A $14 \%$ increase in porosity; a $41 \%$ increase in infiltration rate; and a $18 \%$ decrease in bulk density was found in soils of treated farms compared to those of untreated farm plots. Differences in particle size distribution and soil erodibility among widths of the bunds were low.

Chapter 4 discuss the quantitative relationships for rainfall features, runoff characteristics and sediment yield patterns for treated sub-watersheds areas in Koga catchment, highlands of North-Western Ethiopia. Multiple regression models were formulated to predict sediment discharge using daily: rainfall, 10-minute maximum rain intensity, rain intensity, SSC and runoff discharge. FDC, hydrographs, sedigraphs and statistical analysis were analysed to assess the hydrological and sedimentary processes and the response of treated sub-watersheds to extreme events of rainfall and runoff. Results show that very strong seasonal and event variability in rain intensity, runoff and sediment yield was observed in all study sites. The rain intensity was the strongest predictor of sediment discharge. This implies that the hydrological response of the study sub-watersheds mainly depended on rain intensity, as they have minimal variation in slope, topography and soils. Area-specific sediment yield was different for the study sub-watersheds and did not show scale dependence. There was a striking difference between seasonal sediment and runoff dynamics, with suspended sediment concentration being very high at the start of the rainy season and gradually decreasing over time, while this did not follow the temporal dynamics of the runoff, which was low at the start of the rainy season and peaked halfway in the rainy season. FDC illustrates that discharge variability is high and storage capacity very low in Koga catchment specifically in Asanat. 
The importance of individual events was very high and more than $50 \%$ of runoff and $52 \%$ of total annual sediment load was produced by the five largest events. This dominance of the largest events in terms of runoff and suspended sediment transport clearly emphasises the high temporal variability of runoff and sediment production. Runoff and SSC event analysis during different seasons showed three different types of hysteretic loops: clockwise and linear (mainly for early rain season), complex and negative for middle and late rainy season. This indicates the complex and heterogeneous nature of runoff and sediment yield response of study sub-watersheds.

Chapter 5 considers the spatially distributed WATEM/SEDEM modelling approach to quantify the effects of SWC strategies on soil erosion and sedimentary processes. WATEM/SEDEM was calibrated for three sub-watersheds in Koga catchment (Asanat, Debre Yakob and Rim). Five scenarios of SWC measures were evaluated: scenario I: a baseline condition (present-day situation) treated with bund structures; scenario II: bund structures and contour cultivation; Scenario III: combination of bunds, contour cultivation and strip cropping; scenario IV: integrated use of bunds, contour cultivation, strip cropping and grass strips, and Scenario V: a scenario without SWC practices. The model simulation results showed that all SWC scenarios reduced soil erosion and sediment yield in all the subwatersheds. Bund structures reduced soil erosion by more than 57, 65 and 53\% in Asanat, Debre Yakob and Rim sub-watersheds, respectively.

The integrated use of bund structures, contour cultivation, strip cropping and grass strips (scenario IV) showed the largest effect on erosion and sediment yield. In scenario IV, compared to a scenario without SWC measures, sediment yield was reduced from 66.9 to $17.0 \mathrm{t} \mathrm{ha}^{-1} \mathrm{y}^{-1}$ in Asanat, 41.1 to $13.9 \mathrm{t} \mathrm{ha}^{-1} \mathrm{y}^{-1}$ in Debre Yakob and 59.0 to $12.5 \mathrm{t} \mathrm{ha}^{-1} \mathrm{y}^{-1}$ in Rim sub watersheds. Bund structures and grass strips showed the largest contribution in controlling soil erosion and sediment yield in all study sub-watersheds. For the present-day situation, the measured and simulated erosion and sediment yield values were relatively lower for Debre Yakob which might be due to the lower transport capacity and sediment connectivity, as a result of larger coverage of bunds and other conservation measures such as traditional ditches and diversion channels. This emphasises the importance of integrated use of conservation strategies to reduce soil erosion and sediment delivery. This study illustrates that the measurement of sediment yield at the outlets of the catchment areas can be poor indicator of upland soil erosion processes.

The calibration of WATEM/SEDEM at sub-watershed level has provided good model performance for simulated erosion and sediment yields. Despite the semi-quantitative nature of the methodology, using farmers' perceptions and experiences to document land degradation and the impacts of SWC measures is crucial as they are the daily users of the 
land and therefore directly affecting the success or failure of SWC measures. Field measurements and analysis of the local biophysical settings at catchment level are essential to enhance on- and off-site impacts of SWC measures. Therefore, WATEM/SEDEM representing the underlying soil erosion and sedimentary processes, documenting the local community perceptions and experiences, field measurements and analysis are crucial to evaluate the effect of SWC measures on hydrological processes and sediment yield on existing land use and SWC measures or new land use and SWC scenarios. 


\section{Acknowledgements}

I would like to take the pleasure the completion of my thesis as an opportunity to take those who made significant contribution to the successful completion of the PhD journey. I would have not been possible to complete this work without a large number of people whom I owe immense gratitude and appreciation. Foremost, my deepest respect and special thanks go to my promotor Prof. Coen Ritsema, Soil Physics and Land Management Group leader, for accepting me as a PhD student, encouragement and helping with excellent advice. Dear Coen, I am grateful to the freedom you gave me to explain my views all the time and your incisive suggestions and comments that helped me to grow as a researcher.

Second my special thanks and appreciation go to my co-promotors Dr Jantiene Baartman and Dr Luuk Fleskens, for all of their guidance and support throughout my PhD research. I immensely thank you for the day-to-day guidance, follow-ups, constructive criticisms, comments and suggestions. I would like to express my local supervisor Dr Yihenew G. selassie for his persistent support during the field research work and writing of the thesis. At all the stages in the course, I benefited from your advice and astute criticisms.

I am grateful to CASCAPE (Capacity Building for Scaling up of evidence-based best practices in Agricultural Production in Ethiopia) project for granting me the PhD fellowship. I am very grateful to all staff of Koga Irrigation and Watershed Development project in Merawi especially, Ato Belay Zeleke was very collaborative and provided a transmission to work with the local community. I am very grateful to Amhara National Regional State Bureau of Agriculture and Mecha district office of Agricuture in Merawi for providing secondary data. I would like to thank Bahir Dar University, College of Agriculture and Environmental Science, for granting me study leave and providing me field materials and equipment. I thank all my colleagues in department of Natural resources management for their friendly support and encouragement during my PhD study.

My heartfelt gratitude goes to Marnella van der Tol for her all-time indispensable support in administrative arrangements. I am greatly indebted to Klaas Oostindie for his assistance in outlining and editing my thesis book. I am thankful to the staff and students of Soil Physics and Land Management Group of Wageningen University. I am indebted to thank many friends in Wageningen University, particularly Ammar, Berhane, Celia, Isaurinda, Mohamed, Asmare, Karrar, Selam, Meskerem, Carlos, Tesfaye, Nickolas, Samuel T., Rens, Xiaomei, Samuel H., Lingtong, and many others for their friendship and support during my stay in Wageningen. 


\section{About the author}

Walle Jemberu Lakew was born in 1975 and grew up in Mertule Mariam, Ethiopia. He received his BSC degree in Agricultural Engineering from Alemaya (now Haremaya) University of Agriculture in 1998. He then studied Economics at Bahir dar University and obtained BA degree in Economics in 2007. He received his MSc degree in Tropical Land Resources Management in 2009 from Mekelle University.

Right after graduating in 1998, he was employed in North Gondar Zone of Amhara National Regional State and served as soil and water conservation expert from 1998-2002. He was employed by Federal Democratic Republic of Ethiopia ministry of Agriculture (FDRE MoA) as senior instructor based at Woreta Agricultural Vocational Education and Training (ATVET) Centre in 2002. He has taught courses such as Soil and water conservation, Water harvesting technologies and Irrigation. Walle has served as a department head of Natural Resources Management from 2002-2006.

In 2007 he was employed in Bahir Dar University, College of Agriculture and Environmental Science, Department of Natural Resources Management. He has been teaching courses like Soil and Water Conservation, Soil physics, Renewable Energy sources and Management, Land evaluation and land use planning, Natural Resources Management and Soil and Water Management. In October 25 2013, he admitted to the PhD program of Soil Physics and Land Management Group of Wageningen University and Research. His PhD study was funded by ALTERA as part of Capacity building for Scaling up of evidence-based best practices in Agricultural Production in Ethiopia (CASCAPE) project.

He conducted an interdisciplinary research in the field of soil and water management and sustainable land management. He followed several courses and participated in local and international conferences. This dissertation presents the results of his PhD study which also contains published and peer-reviewed articles in scientific journals.

\section{Publications}

\section{Peer reviewed papers}

Jemberu, W., Baartman, J., Fleskens, L., Ritsema, C. 2017. Participatory assessment of soil erosion severity and performance of mitigation measures using stakeholder workshops in Koga catchment, Ethiopia. Journal of Environmental Management. 207: 230-242. 
Jemberu, W., Baartman, J., Fleskens, L., G. Selassie, Y., Ritsema, C. 2017. Assessing the variation in bund structure dimensions and its impact on soil physical properties and hydrology in Koga catchment, Highlands of Ethiopia. Catena 157 : 195-204.

Jemberu, W., Baartman, J., Fleskens, L., G. Selassie, Y., Ritsema, C. Magnitudes and dynamics of runoff and sediment yield: an in-depth analysis of hydrological responses of three sub-watersheds in the Ethiopian highlands. Hydrological processes. Under peer review.

Jemberu, W., Baartman, J., Fleskens, L., G. Selassie, Y., Ritsema, C. Modelling the effect of soil and water conservation measures on soil erosion and sediment yield in the highlands of North-Western Ethiopian highlands. Hydrological processes Submitted.

Proceedings, Reports and Mater thesis

Jemberu, W., Almaw, A., 2011. Soil and water management: Agricultural extension midcareer program. Ministry of Agriculture Addis Ababa.

Jemberu, W., Ayele, B., Tsegaye, L., 2014. Yield and water use efficiency of mulched dripirrigated onions in low land Amhara Regions, Northern Ethiopia. Journal of Agricultural research. 6, 203-210. DOI: 10.13189/UJAR.2014.020604

Ayele, B., Desta, G., Wondafrash, A., Engidayehu, G., Siraw, G., Kasa, L., Legesse, M., Jemberu, W., Kidanu, S., Zegeye, Y., Nigussie, Z. 2012. Assessment of the natural resource management works through public mobilisation in Amhara National Regional State Ethiopia. GIZ sustainable land management program, Bureau of Agriculture, ANRS, Bahir Dar. 


\section{PE\&RC Training and Education Statement}

With the training and education activities listed below the PhD candidate has complied with the requirements set by the C.T. de Wit Graduate School for Production Ecology and Resource Conservation (PE\&RC) which comprises of a minimum total of 32 ECTS (= 22 weeks of activities)

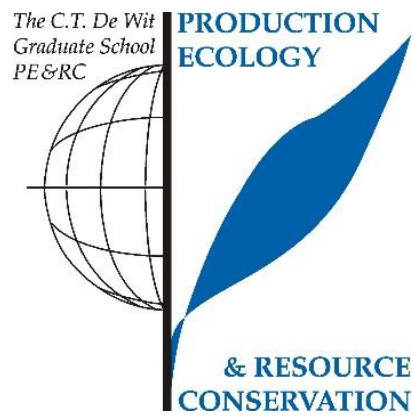

\section{Review of literature (4.5 ECTS)}

Soil erosion and conservation: treats and options in the upper Blue Nile Basin, Bahir Dar institute of technology, Bahir Dar University, Ethiopia

\section{Writing of project proposal (4.5 ECTS)}

- Upscaling best soil and water conservation measures for sustainable land management in the highlands of Ethiopia

\section{Post-graduate courses (3.9 ECTS)}

- Introduction to R for statistical analysis; PE\&RC (2016)

- Rural livelihoods (2014)

- Participatory Rural Appraisal (PRA) (2012)

\section{Laboratory training and working visits (4.5 ECTS)}

SWC measures - exchange of ideas and achievements; FDRE MoA (2013)

- $\quad$ Training of trainers (TOT) Land Resources Management; Ministry of Agriculture and Government of the People's Republic of China (2012)

\section{Invited review of (unpublished) journal manuscript (2 ECTS)}

- Catena: assessing the impact of soil and water conservation structures on runoff and erosion processes through measurements and modelling in the Northern Ethiopian Highlands (2018)

- Sustainable water resources management: development of soil moisture model for agricultural water management under soil moisture stress conditions in Sikkim, India (2017)

\section{Deficiency, refresh, brush-up courses (15 ECTS)}

- Basic statistics; PE\&RC (2016)

- $\quad$ Erosion processes and modelling; WUR (2014)

- Inventory techniques in geosciences; WUR (2013)

- Land degradation and development; WUR (2013)

Competence strengthening / skills courses (1.5 ECTS)

- Project and time Management; WGS (2016) 
- $\quad$ PE\&RC Weekend (2016)

- PE\&RC Day (2014)

Discussion groups / local seminars / other scientific meetings (7.8 ECTS)

International workshop on climate change; FDRE MoA, Addis Ababa (2015)

- $\quad$ Project conference with Ethiopian delegates; WUR (2014)

- National conference in land use change and land degradation; Bahir Dar (2013)

- International workshop: sustainable land management in Ethiopian highlands; Bahir Dar (2013)

Local Level Participatory Planning Approaches (LLPPA) (2012)

International symposia, workshops and conferences (3 ECTS)

- European Geosciences Union Annual Assembly (2016)

- $\quad$ CASCAPE symposium; Dire Dawa (2015) 